\title{
THE EFFECT OF TALK IN ARGUMENT TEXT CONSTRUCTION
}

\author{
by \\ Margaret Franken
}

A thesis submitted to Victoria University of Wellington

in fulfilment of the requirements

for the degree of Doctor of Philosophy

in Applied Linguistics

Victoria University of Wellington 


\begin{abstract}
Research on second language teaching and learning has to date focused primarily on the major skills of reading, writing, listening, and speaking but has treated them as relatively separate areas of investigation. By contrast this research investigates the role of one skill, speaking, in the performance of another, writing. The study investigates the effect of an instructional sequence that aimed to prepare upper high school students (Form 6/Grade 12) to write better argument essays. The sequence was experienced by the students in two ways. One way was for students to engage in talk with a peer before and during writing. The other way was for students to work in a solitary way. Qualitative data analysis compared the writing scores gained by students on two sets of variables: one to indicate the quality of text in general terms (Hamp-Lyons, 1986) and the other to indicate quality of text in terms of specific features of argument: claims, elaboration of claims, grounds and elaboration of grounds (Toulmin, 1958; Toulmin, Rieke and Janki, 1984).
\end{abstract}

The results of the qualitative analysis indicate that opportunity to work with a peer before and during writing had a limited and specific effect on the texts that students wrote. Positive effects for opportunity to talk were seen in the quantity of grounds-related material, but only when students wrote texts that appeared to require more content and domain-specific knowledge (Alexander, Schallert and Hare, 1991). It appeared that talk could operate to help students access relevant prior knowledge (Alexander, Schallert and Hare, 1991) to support the claims made in their argument texts. Working in a solitary way resulted in significantly better mean scores for linguistic accuracy and complexity. This finding is not 
consistent with claims made in the output hypothesis (Swain, 1985; Swain, 1995; Swain and Lapkin, 1995). One explanation is that students working together may not have been 'pushed' to consider aspects of language form in attempts to communicate meaning. Another is that this did occur but consideration of form did not transfer to subsequent writing. Another variable that appeared to influence writing quality was the level of resourcing provided for the writing task. Access to textual resources (input in the form of cohesive and linear text) appeared significantly to affect all three of the general measures of text quality, suggesting that textual input is a valuable linguistic and rhetorical resource for writers. When students' texts were analysed specifically for frequency of features of argument, different effects were found for levels of resourcing. Claims and elaboration of claims were most affected by the semi-resourced form of input represented by fact sheets (lists of propositions). Students appeared to make use of input in the form of fact sheets for meeting claim-like requirements in their texts. This might have been because the fact sheets represented information in a way that required the least amount of transformation to be accessible and useful.

Analysis of transcript data was carried out on three selected pairs of students to explore the nature of the talk which produced significant and positive results. The type of talk associated with the pair that showed the greatest scores was qualitatively different in terms of the amount and topic of substantive talk and the frequency of responses to initiations. The talk also operated to push each participant, particularly the weaker of the two, to respond, explain and elaborate. The fact that the weaker student in the most productive pair made use of what he articulated 
suggested that, for him, the talk appeared to set the discourse parameters of the writing task.

In addition, the results of the study pointed to the fact that speaking with a partner, particularly a more expert partner, before and during writing can bring positive effects particularly for drawing on relevant prior knowledge, thereby enhancing content and domain-specific knowledge. A proficient and interactionally expert partner can promote discussion of relevant prior knowledge useful for supporting claims made in argument texts. The analysis of transcript data indicates that few students show interactional proficiency and that this may prove a worthwhile focus for pedagogy.

The present study supports the line of research in collaborative learning (Cohen, 1994) as it has explored the conditions under which positive effects on writing are likely to occur. Research may profitably continue to explore the features of successful interaction and the conditions that successful interaction creates, particularly as it enables better writing. Not only are conditions worthy of further research, so too are effects, as they are likely to operate on different aspects of writing and in different genres. Constraints operating particularly in the area of argument need to continue to be explored empirically.

The present study has concluded with the belief that there is still much to know in the relationship between speaking and writing. For this reason, teachers may do well to pay careful consideration to the way in which pair and group tasks are managed in the classroom. This entails the 
provision of guidance and support for the participants so that purposeful interaction occurs. 


\section{ACKNOWLEDGEMENTS}

The writing of the thesis has spanned three different cities, three different jobs and the early years of my second child's life. There are many people to thank.

First of all the greatest thanks to the students who volunteered and participated in the study and to Jenny Bedford, Head of the ESL Department at Lynfield College, who worked with me on the study and who showed great professionalism, enthusiasm and willingness to give anything a go.

Thanks to colleagues and friends at the English Language Institute, Victoria University, at the Auckland College of Education, and at Massey University's Department of Linguistics and Second Language Teaching. These include my supervisor, Jim Dickie, Paul Nation, and Hilary Smith. Thanks to Jim for his inspiration, guidance and many hours of thought. Thanks to Paul and Hilary for acting as readers. I would also like to thank Jane Dudley, who handled the many faxes and e-mail messages of correspondence. At Massey, special thanks to Associate Professor Steve Haslett for statistical advice and to Associate Professor Noel Watts for supporting me by providing the conditions to help me write up the study.

Last of all thanks to my family, my partner Peter Cleave for his long term support and willingness to read the thesis at various times, to Leo, my son for his patience and to Esmé, my daughter who has known her mother with thesis for her first four years. For childcare, I have Peter to thank and the many friends who at critical times offered to entertain my children. 


\section{TABLE OF CONTENTS}

\section{ABSTRACT}

TABLE OF CONTENTS

LIST OF TABLES

LIST OF FIGURES

xiv

\section{INTRODUCTION}

\section{VIEWS ON LITERACY}

1.1 Introduction

1.2 Oracy and literacy

1.3 What literacy entails

1.3.1 Literacy as functions

1.3.2 Literacy as knowledge and use of language conventions

1.3.3 Literacy as knowledge and use of discourse conventions

1.3.4 Literacy as patterns of social practice

1.3.5 Literacy as a way of thinking

\section{WRITING PROFICIENCY AND EXPERTISE}

\subsection{Introduction}

2.2 Factors accounting for writing proficiency

2.2.1 Affective factors

2.2.2 Language factors

2.2.3 Schema knowledge

2.2.4 Cognitive factors

2.3 An integrated view of expertise

2.3.1 The expertise of subjects in the research study 
2.5.2 Ways of preparing students for writing

$\begin{array}{ll}\text { 2.5.3 Documenting the discourse of the writing classroom } & 47 \\ & 48\end{array}$

2.6 Researching intervention $\quad 49$

$\begin{array}{ll}2.6 .1 \text { Free writing } & 49 \\ & 50\end{array}$

$\begin{array}{ll}\text { 2.6.2 Memory search and free association techniques } & 50 \\ 2.6 .3 & 51\end{array}$

$\begin{array}{ll}2.6 .3 \text { Heuristics } & 51 \\ 2.6 .4\end{array}$

$\begin{array}{ll}2.6 .4 \text { Inquiry } & 52 \\ 2.6 .5 \text { Peer discussion } & 53\end{array}$

$\begin{array}{ll}2.6 .5 \text { Peer discussion } & 53 \\ \end{array}$

$\begin{array}{ll}2.7 \text { Conclusion } & 57\end{array}$

\section{THE ROLE OF TALK}

ERROR! BOOKMARK NOT DEFINED.

\subsection{Introduction}

3.2 Cognitive benefits

3.2.1 Talk as the enactment of complementary roles

3.2.2 Talk as a scaffold

3.2.3 Talk as a catalyst to change thinking 61

$\begin{array}{ll}\text { 3.2.4 Talk as exploratory discourse } & 61\end{array}$

3.2.5 Talk as a means of promoting literate thinking 62

3.2.6 Talk as a way of modeling processes

$\begin{array}{ll}\text { 3.2.7 Talk as relationship with audience } & 65 \\ & 66\end{array}$

$\begin{array}{ll}\text { 3.3 Language-related benefits } & 68\end{array}$

$\begin{array}{ll}\text { 3.3.1 The role of talk in literacy development } & 68 \\ & 69\end{array}$

$\begin{array}{ll}\text { 3.3.2 The role of talk in second language acquisition } & 69 \\ 3.3 .1 & 70\end{array}$

$\begin{array}{ll}\text { 3.3.2.1 Effects of talk on aspects of second language proficiency } & 73\end{array}$

$\begin{array}{ll}3.4 \text { Social and affective benefits } & 76\end{array}$

$\begin{array}{ll}3.5 \text { Summary } & 76\end{array}$

3.6 Exploring the nature of talk $\quad 77$

$\begin{array}{ll}\text { 3.6.1 Behaviours during interaction } & 77 \\ 3.6 .2 \text { Task variables } & 77\end{array}$

$\begin{array}{ll}\text { 3.6.2 Task variables } & 79 \\ \text { 3.6.3 Gender and } & 79\end{array}$

$\begin{array}{ll}\text { 3.6.3 Gender and race variables } & 81\end{array}$

$\begin{array}{ll}\text { 3.6.4 Level of proficiency of participants } & 82 \\ \text { 3.6.5 Limitations of talk } & 84\end{array}$

$\begin{array}{ll}3.7 \text { Studying the effect of talk on writing } & 87\end{array}$

$\begin{array}{ll}3.8 \text { Conclusion } & 87\end{array}$

4. FEATURES OF THE INSTRUCTIONAL SEQUENCE $\quad 89$

4.1 Introduction

4.2 The choice of the argument genre $\quad 90$

\begin{tabular}{ll} 
4.2.1 Explanations of difficulty & 90 \\
\hline
\end{tabular}

$\begin{array}{ll}4.2 .2 \text { Responses to reported difficulty } & 91 \\ \end{array}$

4.3 Descriptions of the argument genre $\quad 96$

$\begin{array}{lr}\text { 4.3.1 Toulmin's analysis } & 96\end{array}$ 
4.4 Types of argument texts

4.5 Summary

4.6 Stages of the instructional sequence

4.7 Conclusion

\section{METHODOLOGY}

5.1 Introduction

5.2 Target Group

\subsection{Participants}

5.3.1 The students

5.3.2 The teachers

5.4 Allocation to group

5.5 Forming pairs

5.6 Programme duration

5.7 Research design

5.7.1 Independent variables

5.7.2 Dependent variables

5.7.3 Covariate measures

$\begin{array}{ll}5.8 \text { Collection and analysis of data } & 123\end{array}$

5.8.1 Statistical methods 123

$\begin{array}{ll}\text { 5.8.2 Text analysis } & 123 \\ \text { 5.8.2. Measuring beter texts in general terms } & 124\end{array}$

5.8.2.1 Measuring better texts in general terms $\quad 125$

5.8.2.2 Measuring better argument $\quad 125$

5.8.2.3 Applications of Toulmin et al's analysis for measurement purposes $\quad 126$

5.8.3 Procedures adopted for the study $\quad 129$

$\begin{array}{ll}\text { 5.8.3.1 Specifying the constituents and their relations } & 129\end{array}$

$\begin{array}{ll}\text { 5.8.3.2 Specifying the unit of analysis } & 129 \\ & 132\end{array}$

$\begin{array}{ll}\text { 5.8.4 Summary of the text analysis procedure } & 132 \\ 5.83\end{array}$

$\begin{array}{ll}5.8 .5 \text { Inter-rater reliability } & 133 \\ & 133\end{array}$

$\begin{array}{ll}5.9 \text { Conclusion } & 136\end{array}$

\section{RESULTS}

\subsection{Introduction}

6.2 General quality of texts

6.2.1 Communicative quality $\quad 138$

6.2.2 Text organisation

6.2.3 Linguistic accuracy and complexity 
6.4 Quality of argument

6.4.1 Claims

6.4.2 Elaboration of claims

6.4.3 Grounds

6.4.4 Elaboration of grounds

6.5 Ratio scores

6.5.1 Claims/elaboration of claims

6.5.2 Grounds/elaboration of grounds

6.5.3 Claims/grounds

6.6 Summary

\section{DISCUSSION OF QUANTITATIVE RESULTS}

\subsection{Introduction}

7.2 Explaining the specific effects of talk

7.2.1 Talk and content knowledge

7.2.2 Talk and grounds-related material

7.2.3 Talk and textual resourcing

7.3 Explaining effects of solitary activity

7.3.1 Interference and transfer

7.3.2 Attentional resources

7.4 Explaining the limited effects of talk

7.5 Explaining the effects of resourcing

7.5.1 The effects of non-textual resourcing

7.5.2 The effects of textual resourcing

7.6 Additional factors

7.7 Conclusion

\section{ANALYSING INTERACTION}

\subsection{Introduction}

8.2 Method

8.2.1 Selection of pairs for analysis

8.2.2 Transcription

8.2.3 Framework for analysis

8.2.4 Procedure for analysis

8.3 The interaction of three case study pairs

8.3.1.2 The nature of the substantive and procedural talk

8.3.2.2 The nature of the substantive and procedural talk 
8.3.3.2 The nature of the substantive and procedural talk

8.4 Discussion of observations

\begin{tabular}{ll} 
8.4.1 Affective factors & 206 \\
\hline
\end{tabular}

\begin{tabular}{ll} 
8.4.2 Engagement in knowledge sharing & 207 \\
\hline
\end{tabular}

\begin{tabular}{ll} 
8.4.3 Gender & 208 \\
\hline .4 .4 Proficien
\end{tabular}

\begin{tabular}{ll} 
8.4.4 Proficiency and expertise of participants & 209 \\
\hline
\end{tabular}

\begin{tabular}{ll} 
8.4.5 Clarifying the status of the variable, talk & 209 \\
\hline
\end{tabular}

$\begin{array}{ll}8.5 \text { Conclusion } & 211\end{array}$

9. CONCLUSION 213

$\begin{array}{ll}9.1 \text { Introduction } & 213\end{array}$

$\begin{array}{ll}9.2 \text { Pedagogical issues } & 214\end{array}$

$\begin{array}{ll}9.3 \text { Theoretical issues } & 218\end{array}$

$\begin{array}{ll}\text { 9.4 Methodological issues } & 219\end{array}$

$\begin{array}{ll}9.5 \text { Summary } & 222\end{array}$

$\begin{array}{ll}\text { BIBLIOGRAPHY } & 224\end{array}$

\section{APPENDICES}

APPENDIX 1 SAMPLE INSTRUCTIONAL MATERIALS AND RESOURCE MATERIALS

APPENDIX 2 INFORMATION ON SUBJECTS 267

APPENDIX 3 MATERIALS FOR SCORING TEXTS 271

APPENDIX 4 TEXT RELATIONS (ADAPTED FROM

O'BRIEN, 1995) USED TO GUIDE TEXT ANALYSIS

APPENDIX 5 SAMPLE TEXT, TEXT ANALYSIS AND SCORE SHEET

APPENDIX 6 MATERIALS FOR STATISTICAL ANALYSIS 284

APPENDIX 7 FULL TRANSCRIPTS OF STUDENT INTERACTION

APPENDIX 8 CATEGORISED TRANSCRIPTS

APPENDIX 9 MELOTH AND DEERING'S (1994) ORIGINAL CODING SCHEME FOR TASK TALK 


\section{LIST OF TABLES}

Table 1 Inter-rater reliability statistics for the assessment of general text quality and argument text structure

Table 2 Descriptive statistics for general analytical measures: means, standard deviations, and standard errors of measurement under the various conditions

Table 3 ANOVA on communicative quality scores for level of resourcing

Table 4 Descriptive statistics for communicative quality scores: means, standard deviations, and standard errors of measurement for level of resourcing

Table 5 ANOVA on text organisation scores for level of resourcing

Table 6 Descriptive statistics for text organisation scores: means, standard deviations, and standard errors of measurement for level of resourcing

Table 7 ANOVA on linguistic accuracy and complexity scores for level of resourcing and level of talk

Table 8 Descriptive statistics associated with level of talk and linguistic accuracy and complexity: means, standard deviations, and standard errors of measurement

Table 9 Descriptive statistics associated with level of resourcing and linguistic accuracy and complexity: means, standard deviations, and standard errors of measurement

Table 10 Descriptive statistics for argument measures: means, standard deviations, and standard errors of measurement

Table 11 ANOVA of frequency of claims for level of talk and level of resourcing

Table 12 Descriptive statistics for frequency of claims: means, standard deviations, and standard errors of measurement for level of talk

Table 13 Descriptive statistics for frequency of claims: means, standard deviations, and standard errors of measurement for level of resourcing 
Table 14 ANOVA of frequency of elaboration of claims for level of resourcing

Table 15 Descriptive statistics for frequency of elaboration of claims: means, standard deviations, and standard errors of measurement for level of resourcing

Table 16 ANOVA of frequency of grounds scores for level of talk $\times$ group interaction; level of resourcing $\times$ level of talk $\times$ group interaction

Table 17 Descriptive statistics for frequency of grounds: means, standard deviations, and standard errors of measurement for level of resourcing, level of talk and group

Table 18 ANOVA of frequency of elaboration of grounds for level of resourcing; level of resourcing $\times$ level of talk $\times$ group interaction

Table 19 Descriptive statistics for frequency of elaboration of grounds: means, standard deviations, and standard errors of measurement for level of resourcing, level of talk and group

Table 20 ANOVA of ratio scores for grounds/elaboration of grounds for level of resourcing

Table 21 Descriptive statistics for ratio scores for grounds/elaboration of grounds: means, standard deviations and standard errors of measurement for level of resourcing

Table 22 ANOVA of ratio scores for claims/grounds for level of resourcing; level of resourcing $\times$ level of talk $\times$ group interaction

Table 23 Descriptive statistics for ratio scores for claims/grounds: means, standard deviations, and standard errors of measurement for level of resourcing, level of talk, and group

Table 24 Frequency of types and categories of talk in the interaction between Stan and Alan

Table 25 Frequency of types and categories of talk in the interaction between Will and Fred 
xiii

Table 26 Frequency of types and categories of talk in the interaction between Anne and Carl 


\section{LIST OF FIGURES}

Figure 1 Toulmin et al's (1979) analysis of argument

Figure 2 Hyland's (1990) description of the argumentative essay

Figure 3 The stages of the instructional sequence

Figure 4 Instructional plan

Figure 5 Factors in the experimental plan

Figure 6 Mean scores for sum of general analytical measures across levels of resourcing

Figure 7 Mean scores for communicative quality, organisation and ideas, and linguistic accuracy across levels of talk

Figure 8 Mean scores for linguistic accuracy and fluency for three levels of resourcing

Figure 9 Mean frequency of grounds for topics across levels of resourcing

Figure 10 Mean frequency of elaboration of grounds for topics across levels of resourcing

Figure 11 Mean ratios of claims to grounds for topics across levels of resourcing

Figure 12 Coding scheme for peer talk (adapted from Meloth and Deering, 


\section{INTRODUCTION}

An important function of education is to develop in students the ability to think independently and display a reflective attitude towards knowledge and experience. These goals are embodied in six of the eight essential skills listed in The New Zealand Curriculum Framework (Ministry of Education, 1993). The relevant essential skills are communication skills, information skills, problem-solving skills, self-management skills, social and cooperative skills, and work and study skills. Such goals are promoted in the senior high school curriculum through student interaction and practising argumentation dialogue. This is on the assumption that these activities have been positively linked with logic and reasoning, critical thinking skills, and appreciation of others' points of view. Effective articulation of argument demands that claims have clarity and that grounds that support those claims are relevant, appropriate, and sufficient in number. The construction of an effective argument in this way, presupposes critical thinking skills, the ability to define a problem, the ability to form relevant hypotheses, the ability to make justified inferences and the ability to evaluate the validity of reasoning. Reflective thinking implies an ability to evaluate the reasonableness of one's own and other peoples' thoughts and also the ability to change opinion on the basis of new information gained from others (Marttunen, 1994). When one considers what argument is said to practise and facilitate, the focus on argument text construction in the present study is justifiably relevant.

Although speaking is listed alongside the other skills of listening, reading, writing and viewing in the New Zealand English curriculum document, 
English in the New Zealand Curriculum (Ministry of Education, 1994a), writing is still one of the most prominent means of assessing learning and the acquisition of skills and knowledge. Given this fact, there is a need for research that links skills in the curriculum and for research that investigates ways of improving student performance in the speaking and writing of argument.

The first chapter explores literacy and examines different views of what literacy means in the academic context of the school. Literacy, and more specifically writing proficiency, are critical requirements in the school system and subsequent academic contexts. An examination of literacy is central to the present study as it examines the primacy of writing and proposes that if speaking is given prominence in writing instruction, it will positively affect the nature of the writing produced. The present study therefore views writing and speaking not as autonomous modes but rather as complementary modes.

Examining what accounts for and contributes to expert writing involves focusing on a specific aspect of literacy. It involves surveying the factors that are said to influence performance, models of novice and expert writing, and ways in which intervention in writing has been approached. The factors include affect, schema knowledge, general language proficiency, and vocabulary knowledge. In looking at models of writing proficiency, Chapter 2 first presents general cognitive process models. These models focus on how writers do more or less of the behaviours identified as being associated with the process. More recently writing research has come to consider concerns that go beyond this, as for 
instance, in the view that writing in an academic context interacts with discourse and text structure knowledge. Having explored writing proficiency and expertise, we need to review ways in which teachers have approached the task of developing proficiency and expertise. Survey findings suggest that writing is not taught well. It is therefore important to review the range of pedagogies advocated by research to help students with their writing.

The third chapter discusses the many claims made for the general benefits of speaking. These include cognitive benefits, language-related benefits, and social and affective benefits. The language-related benefits are examined in most detail. Studies of particular interest are those which test the effects of interaction and talk on aspects on second language proficiency as those are of most relevance to the present study. The second part of the chapter is devoted to exploring the nature of talk, and what conditions or factors are known to have some influence on how talk is carried out, and what effects it can bring.

Talk in the present study was one of the two conditions under which a sequence of instruction was carried out on a series of occasions. The features of the sequence of instruction are described in Chapter 4. As the study acknowledges the importance of text structure or discourse knowledge, and the importance of contextualising attention to grammatical features, the sequence of instruction places considerable emphasis on analysis of the argument genre. A number of models of argument are presented in this chapter as they informed the design of the dependent variables. The stages in the entire sequence of instruction that 
students experienced are set out and the rationale for each of the stages is presented.

Chapter five presents the methods for investigating the claim that speaking has a positive effect on the writing of argument texts. It provides details about the subjects, and the research design including variables and measures used. Both general measures and measures related specifically to the structure of argument texts were used in the present study. As the latter were specifically designed by the researcher in an attempt to capture the hypothesised effects of talk on argument texts, the procedure by which they were designed and quantified is described in detail.

Quantitative data analysis was carried out to investigate the effect of speaking on the writing of argument texts in the study. The results of the quantitative data analysis and the interpretation of the results are presented respectively in Chapters 6 and 7. The results of the quantitative data analysis pointed to specific effects of talk, and effects of other variables not originally predicted to be important.

The specific effects of talk were restricted to one group on one occasion. This finding guided the selection of three case study pairs whose transcripts of interaction were analysed using a modified form of Meloth and Deering's (1994) task talk analysis. A description and analysis of the nature of the interaction between the three pairs is presented in Chapter 8. The differences in quantity and particularly quality of talk between the three pairs supplements the quantitative findings and interpretations of those findings. 
The conclusion, Chapter 9, briefly summarises the findings of both the quantitative and qualitative data analysis and discusses the implications for theory and practice. It also points the way to further research. 


\section{VIEWS ON LITERACY}

\subsection{Introduction}

The study seeks to contribute to an aspect of literacy development, the writing of argument texts (Toulmin, 1958; Toulmin, Rieke and Janki, 1984). It seeks to do so by giving students in the study experience of a sequence of instruction which aims to develop knowledge and use of appropriate conventions for the argument genre. It aims to encourage critical skills which students apply to the texts of others as well as their own texts, and it aims to help them write in a way that is creative and critical and reflective. In order to begin this study, a review of literacy is necessary in order to situate each of these planned outcomes. To this end, the review considers different perspectives on literacy, including literacy as knowledge of language and discourse conventions, literacy as a social practice, and literacy as a way of thinking.

The study also most importantly sets out to test whether or not talk facilitates these aims to a greater extent than solitary activity. The study hypothesises that providing opportunities for speaking before and during writing will have a positive effect on the way in which argument texts are constructed by high school writers. Claiming positive effects of talk for writing assumes to some extent that talk is closely aligned to writing. This assumption rests on the logic that if speaking and writing are aligned and not autonomous modes (Street, 1984, 1993), aspects of content knowledge and linguistic knowledge are accessible and able to be utilised for subsequent writing. 
The assumption that talk and writing are not autonomous is supported in this chapter in a number of ways: by examining the features of spoken and written language, by looking at functional roles that speaking and writing are said to play, and by looking at views on literacy that go beyond the mechanics of speaking and writing to include ways of knowing and ways of thinking.

\subsection{Oracy and literacy}

The first and most generally understood meaning of literacy refers to reading, writing, and numeracy. Reading and writing are seen to be major components of a languages curriculum (see for example English in the New Zealand Curriculum, 1994). In this document, reading and writing are listed alongside speaking, listening and viewing. However, in terms of their relative importance, reading and writing receive more attention than speaking, listening, and viewing. Writing in particular is seen to be the mark of literate behaviour and is the benchmark for assessing students in an academic domain. In addition, writing and reading are extensively monitored by both national and international education authorities and research bodies (see for instance Elley, 1991, 1992, 1994).

Although listening is the major way in which information is transmitted in school and speaking is believed to be a way of clarifying ideas, both listening and speaking are not the focus of assessment and neither is their development consistently monitored throughout the school system. As Halliday (1989:97) notes, "In a literate culture, we tend not to take the spoken language seriously". 
A value laden distinction between what some authors name literacy skills (relating only to reading and writing) and oral discourse persists and underlies any discussion of academic proficiency. What is the foundation of this distinction and what are views that question the validity of the distinction?

The role of literacy in culture has been a central issue in anthropology. For example, some anthropologists have seen it necessary to describe the features of cultures which have oracy and those which have written literacy (Goody, 1968, 1986, 1987; Olson, 1977; Ong, 1982; Wells, 1987). In so doing, they have not only stressed the differences between oral and literate cultures, but also the differences between the modes of speaking and writing. They maintain that writing is distinctive because it is, "an autonomous mode of communication" (Goody, 1968:40). From this perspective, the written mode becomes an object of study. What is focused on is what writing can do that speaking cannot. Of most significance is the belief that writing allows for a level of cognitive operation that is not possible with speaking. Writing allows for a degree of abstract thought, when what is written about is not in the there and now'; instead it is decontextualised. Observations such as these have arisen from studies of non-literate cultures. (See for instance Greenfield's study of the Wolof in Africa, reported in Street, 1984). Observations such as these can also be seen to underpin the work of Bernstein (1971). Given these claims, one can understand the value accorded to writing in an academic context.

This study does not view speaking and writing as autonomous modes as it claims that speaking can in fact positively effect writing. Students can, 
in speaking, cover topics that are abstract and decontextualised. It is hypothesised that if students do this, the way in which the abstract and decontextualised information in their writing is conveyed will be qualitatively better.

In contexts other than the academic, writing is not necessarily accorded the same value and in fact the value placed on literacy in academic contexts is questioned. Heath, (1982) states:

Understanding and responding to the myriad of applications, reporting forms, and accounting procedures which daily effect the lives of nearly every family... bears little resemblance to the decoding of extended prose passages or production of expository writing, the two literacy events most associated with school success. (p. 115)

Some language educators question whether written language will continue to enjoy the same supremacy. Lakoff (1982) for instance suggests that communication is increasingly becoming more orally based. Heath supports this claim about the predominance of the spoken mode in contexts other than the academic. The written mode is seldom referred to but exists primarily for reference. Many literacy events may be more focused on responding orally to written sources. "There are more literacy events which call for appropriate knowledge of forms and uses of speech events than there are actual occasions for extended reading or writing" (Heath, 1982:4). Killingsworth (1993) also acknowledges that literacy is no longer the preserve of reading and writing. Literacy is becoming more oral and in fact, the term 'secondary literacy' has been coined to refer to oral literacy events. 
We also need to acknowledge the fact that spoken language does not apply only to conversation or interaction. We now have a new form of spoken language; the language of the media in which written scripts are spoken aloud. Ong (1982) refers to this as 'secondary orality'.

It is evident then that notions of literacy are changing and that new perspectives are emerging which challenge the primacy and autonomy of written language. The work discussed above indicates that we cannot continue to see literacy in a dichotomous way, a way which views the modes as being mutually exclusive. Rather, literacy must be seen as a complex pattern of use in which both speaking and writing with their receptive counterparts are seen to be equally valid, serving sometimes similar, but sometimes different purposes. To claim that speaking has benefits for writing is in fact to go further. It is to claim that their respective functions and forms can in fact overlap. In the following sections, views from linguists, applied linguists, and educators support this claim.

\subsection{What literacy entails}

As most linguists and applied linguists have focused on documenting the differences between the modes of speaking and writing, this section will begin by presenting the different ways of analysing spoken and written language. The models discussed below all share the view that written and spoken language are not strictly autonomous. They share Halliday's (1989) view that,

Although we use the term 'written language', this does not mean that there is one invariant type of English that is associated with 
all forms of written discourse. There is a whole cluster of different varieties - a scatter of types of variation - that share the written medium. But we can refer to certain features of the language as being characteristic of written registers; and if we talk about somebody using the 'written mode', this is an informal way of suggesting that the language used is that of a text that would typically be found in writing. In the same way we refer to spoken language, again without implying that all forms of speech are alike. But there are features characteristic of spoken registers just as there are of written; and in similar fashion we can talk about the 'spoken mode' (p. 46).

The analyses focus on different levels of analysis. Some take a functional approach (Michaels and Collins, 1984; Dyson, 1992) documenting the purposes that spoken language and written language respectively serve. Others analyse features at the level of lexis, syntax, or discourse (Givon, 1979; Biber, 1988; Halliday, 1989).

\subsubsection{Literacy as functions}

The significance of written language is partly tied to its functional value. Halliday (1989:32) in documenting the features of spoken and written language says, "It is true that written language is very different from spoken language. It has different functions, different contexts, and consequently it 'means' in very different ways". The features of 'literate' discourse in functional terms are described below.

A number of writers (for example Michaels and Collins, 1984; Dyson, 1992) share the view that literate language carries out the functions of 
labelling objects, asking substantive questions, using previous statements as the basis for present statements, putting forth hypothetical statements, requesting clarification or elaboration, linking ideas explicitly and talking about form and style (a metalinguistic function). It is interesting to note that these are precisely the types of functions that many writers claim talk can achieve and which are to be discussed in Chapter 3. They are also some of the functions that are hypothesised to bring about change in the argument texts that the students will write in the present study. Michaels and Collins do acknowledge that although written language typically fulfills the functions listed above, the functions could also be carried out through talk in certain circumstances. In fact, the functions listed above were initially observed by them to occur in oral sharing time in school classrooms. On the basis of this observation, they conclude that sharing time is an oral preparation time for literacy.

In this study, not only are effects of talk on subsequent written texts quantified, but the talk that accompanies and precedes the writing is analysed. It is anticipated that, like the observations of Michaels and Collins, different interaction patterns and different types of talk will occur with different students. We may assume that the students' talk will show variation in terms of this aspect of literacy. Some of the talk will manifest features of 'literate discourse' while that of others may not. The former is expected to be that which is associated with positive effects on written texts.

Michaels and Collins (1984) provide a functional analysis without description of form. Descriptions of the form of literate language are essential as they can be seen to be the conventions we value in an 
academic context. Some descriptions of form, which incidentally do not exclude functional considerations, are discussed below.

\subsubsection{Literacy as knowledge and use of language conventions}

Halliday (1989) documents a comprehensive list of features of spoken and written language. Halliday accounts for prosodic, lexical and syntactic differences in the two modes of language use. Written language is characterised as being lexically dense. This refers to the ratio of lexical items to grammatical items. Spoken language on the other hand is seen as being lexically sparse, having a lower ratio of lexical items to grammatical items. Spoken language also exhibits lexical items that are more frequent than those in written language. Halliday claims that the lexical density of written language is likely to be of the order of twice as high as that for speech (Halliday, 1989:80).

Features of intonation, rhythm and 'intricacy' also mark spoken language. Halliday (1989) explains 'intricacy' in the following way. Sequences of conversational discourse are:

intricate constructions of clauses, varying not only in the kind of interdependency... but also in the logical semantic relationships involved. These include not only three basic types of expansion adding a new point, restating or exemplifying the previous one, or adding a qualification - but also the relationship of projection, whereby the speaker brings in what somebody else says or thinks and incorporates it grammatically into his own discourse. (p. 86)

The notion of intricacy provides Halliday with the grounds to claim that written language is not more complex or more organised than spoken 
language. "The spoken language is every bit as highly organised as the written, and is capable of just as great a degree of complexity. Only it is complex in a different way" (Halliday, 1989:87).

An additional but central aspect of Halliday's (1989) account of spoken and written language is that each constrains and determines the representation of experience. Spoken language is dynamic and represents processes. Written language does not focus on processes. It represents things and products, many of which are abstract. It is static and synoptic. "Put from a learner's point of view: reading/writing and listening/speaking are different ways of learning because they are different ways of knowing" (Halliday, 1989:97).

Again Halliday stresses the complementary aspects of the two modes. Halliday claims that both ways of knowing are essential (1989:98). Tied to the notion of complementarity is the notion that the two modes are not mutually exclusive or are not autonomous. Rather they need to be seen on a cline. Halliday states that, "the 'written' and 'spoken' do not form a simple dichotomy; there are all sorts of writing and all sorts of speech, many of which display the features of the other medium" (1989:32). In much the same way as we have functional varieties within the modes of speaking or writing, so the modes themselves meet particular sometimes overlapping and sometimes different functional requirements.

Givon (1979) does not begin from the distinction between spoken language and written language. Rather, he posits two modes, the pragmatic mode and the syntactic mode. The formal features which distinguish the modes include the following. The pragmatic mode has a 
topic-comment structure and loose coordination while the syntactic mode has a subject-predicate structure and tight subordination. In the pragmatic mode, the number of verbs is roughly equal to the number of nouns while nouns are more numerous in the syntactic mode. The verbs are also more semantically complex and the grammatical morphology is much more elaborate.

Givon does not specifically state that the pragmatic and syntactic modes are aligned respectively with speaking and writing but rather, they characterise two modes of communication which are manifest in the following contrasts: pidgin versus creole, child versus adult language and informal versus formal language. It is the latter contrast that is of most relevance to the issue of literacy. Givon (1979:230) states: "The extreme instance of the formal-planned pole is educated, book-written language". Heath (1982) also equates writing with the most formal pole, as she says of the syntactic mode, "The epitome of this type of language is said to be the formal expository essay" (p. 92).

Another but much more comprehensive study, investigating linguistic differences between spoken and written language, is that of Biber (1988). The significance of his work is that, in contrast to previous studies, it is quantitative, it is supported by statistical analysis, it is 'macroscopic', in that it investigates many linguistic features, and it is multidimensional. Using the LUND corpus of spoken English and the LOB corpus of written English, Biber analysed the frequency and covariation of a set of thirty one major linguistic features including for instance, tense and aspect markers, passives, nominals, and coordination. In all, a total of twenty three genres were subjected to analysis. The linguistic features in the 
genres were clustered by means of factor analysis (see Biber, 1988: 79-97). The results of the factor analysis produced a set of six dimensions of variation including interactive versus informational production, narrative versus non-narrative concerns, explicit versus situation-dependent reference, and abstract versus non-abstract information. Biber's subsequent work (1989) used these dimensions as the basis for specifying different text types with the view to producing a typology of English texts. What is of major interest in this typology, is the fact that the genres associated with categories of text types are not exclusively either spoken or written. A text type can be represented by both spoken or written genres. Take for instance the text type, 'involved persuasion'. This can be represented by the spoken genres, spontaneous speeches, and interviews, or by the written genres, professional letters and popular lore. As Biber (1988) concludes:

One of the central findings of the present study is that there is no linguistic or situational characterization of speech and writing that is true of all spoken and written genres. On the one hand, some spoken and written genres are very similar to one another.... On the other hand, some spoken genres are quite different from one another... as are some written genres.... The relations among these genres are systematic but must be specified in multidimensional space. (p. 36-37)

In the present study, Biber's distinction between the term genre and text type is acknowledged on the understanding that certain linguistic features are likely to be associated with particular genres. This is significant in this study as one of the outcomes for students is to develop knowledge and use of appropriate conventions for the argument genre. The conventions in 
this case are both language and discourse conventions as described in the following section. The language conventions however are contextualised within the argument genre.

\subsubsection{Literacy as knowledge and use of discourse conventions}

The descriptions given by Givon and Halliday deal with features of prosody, sentence structure, lexical choice and text cohesion. Identifiable features of form can be seen to operate not only at this level but also at the level of the entire text. As Heath (1982:92) states, "Formal schooling at all levels is said to prescribe certain features of sentence structure and lexical choice, text cohesion, and topic organisation for formal language". Several approaches to language analysis that study conventional units at the discourse or text level exist. The next section deals with these models, which generally could be classified as text type models. The models operate from the premise that literacy equates with knowledge and a command over a wide variety of types of texts and that such a command allows students membership in a conventionalised discourse community.

Several models present knowledge of text conventions as a set of generalisable patterns of discourse. One such model is that of Mohan (1986). He proposes a model called "the knowledge framework". Mohan's knowledge framework includes the following kinds of patterns: description, sequence, choice, classification, principles and evaluation. In some models, the types of texts are seen to be particular to certain topics and certain subject areas. The topic type hypothesis described by Johns and Davies (1983) is an example of this type of model. Johns and Davies propose a set of twelve different types of texts or 'topic types' including amongst others: physical structure, characteristics, instruction, process, 
and theory. Unlike the examples of models that provide sets of text types, Hoey (1983) details one type of text, the problem solution text type.

What all these models of texts share is the claim that the types of texts are identified by the elements or components that they contain. Therefore, for instance, if a text contains reference to parts of a thing, attributes, location and functions of those parts, in the Johns and Davies model this text is deemed to be a physical structure text. Therefore the starting point of the analysis is semantic units. How those semantic units or elements are ordered also features in the analysis. In addition to the above, these models of texts share a subsequent and secondary level of analysis which is linguistic so that the elements themselves are typically associated with certain linguistic structures (Biber, 1988).

Developing knowledge and use of appropriate conventions for the argument genre incorporates semantic, rhetorical and linguistic knowledge. The students in this study are provided with opportunities to develop and use this knowledge in speaking and in subsequent writing. The study assesses whether those features are present in the students' texts and whether or not that knowledge is reflected in the substantive and metalinguistic talk engaged in by students. More elusive and difficult to specify as a learning outcome for the students in this study, is the appreciation of the social context and purposes which are associated with the writing of argument texts.

The models of texts described in the section below are situated in a social context and individual texts are specified by means of their purpose. 
These models then can be seen as part of a view that sees literacy as social practice.

\subsubsection{Literacy as patterns of social practice}

The notion that speakers and in particular writers learn to achieve different purposes in conventionalised and socially sanctioned ways lies at the heart of what it means to view literacy as social practice. An approach to language description that begins from this basis is the genre approach. As Eggins (1994:9) states: "The concept of genre is used to describe the impact of the context of culture on language, by exploring the staged, step-by-step structure cultures institutionalize as ways of achieving goals". Texts, then, which share a particular and clearly identifiable purpose and audience and as a result have a conventionalised pattern are called genres.

Genre theory and analysis is possibly most commonly associated with the work of systemic functional linguists such as Halliday (1985), Martin (1989, 1992), Christie (1989), and Kress (1989, 1993). This largely Australian theoretical approach has been adopted in practical ways and incorporated in the national school curriculum (Macken, 1989, 1990) and at tertiary level (Joyce, 1992) in Australia. Other models for genre analysis exist but not all are theoretically informed (Swales, 1990, for instance) and thus tend to be eclectic in their approach.

Davies (1989:132) identifies a genre-based syllabus as one "which is founded on the identification and analysis of specific genres that students are required to read and write in their subject based studies". Different types of genres that have been identified by different theorists include: 
recounts, instructions, narratives, information reports, explanations, arguments (Martin, 1989; Christie 1989; Derewianka, 1990); research articles, abstracts, theses and dissertations, books and monographs, presentations, and grant proposals, (Swales, 1990). The different approaches to genre and genre analysis share the focus on determining the prototypical elements of different genres and the patterns in which these elements occur. They may however represent the elements and the patterns of elements in different ways. Hasan (1989) focuses on identifying obligatory and optional elements in a text and accounting for the way they are sequenced. Others, such as Martin (1989) for instance, make no attempt to distinguish between obligatory and optional elements. Swales (1990) presents the elements of a genre as a series of stages or moves. Paltridge (1995) includes a more detailed discussion of the variation in approaches to genre analysis.

In terms of analyses of conventions, the genre-based models and those described above in section 1.3.3, which could be labelled text types, share common ground. The primary orientation and starting point however differ. While text type analysis begins with identifying the elements or constituents, genre analysis begins with the purpose and audience. It should be noted that the use of the term, genre, in this study does not include only texts that share a purpose and audience, but also that share constituent types and certain linguistic features.

Genre based approaches primarily see writing as "a social act that can take place only within and for a specific context and audience" (Johns, 1990:27). Genre based approaches have been labeled by some as formalist approaches (Mahala, 1991), others as social constructionist 
(Berlin, 1987; Johns, 1990). The view that, "Knowledge, language and the nature of discourse are determined for the writer by the discourse community" (Johns, 1990:28), has important ideological implications for researchers, theorists and practitioners of writing.

Mahala (1991:775) states that "disciplines usually appear as discrete discourse communities, bound by agreement about appropriate objects and methods of study; teachers appear as their spokespersons, students as aliens seeking membership by adopting the ways of the community". What then is our approach to pedagogy? A strong position (for example Bizzell, 1987) advocates that the discourse community itself must change and accommodate erstwhile 'outsiders'. A weak position recommends that teachers and researchers strive to understand the requirements of the discourse community and present that understanding to students. There are interesting examples of research exploring the requirements of the discourse community, as for example when Johns (1993) investigated the nature of the texts that engineering students were required to write on graduation and in employment. The weak position is that which is adopted in this study.

In the discussion above literacy is perceived as the individual's knowledge of and control over a relatively prescribed set of language and text conventions. Formalist or social constructivist approaches to language analysis have their limitations as they appear to prescribe a set of conventions with the implication being that students who have control of these conventions will be literate. 
In discussing writing across the curriculum programmes in American universities, Mahala (1991) expresses a concern related to the assumption of homogeneity of language in subject areas. He states,

A view of the academy that would allow the student to see the writer's 'objectivity', or the natural science model of the social sciences as issues inside the dialectic of knowledge-making, is suppressed in the interests of offering a clear snapshot of stable, supposedly agreed-upon, conventions for writers. (p. 780)

Literacy develops in and is influenced by varying social and cultural contexts. As McKay (1993:68) states, "reading and writing are not private affairs involving a set of discrete skills but rather social acts that one engages in within a community". These communities are seen as different. Literacy thus must be studied in its varying social contexts. What distinguishes such approaches from those discussed above is that they recognise multiple views of literacy and as such address Mahala's concern with a potentially reductionist approach to literacy that "suppresses dialogue about boundaries in the interests of schematising knowledge" (1991:782).

What has become of interest to anthropologists such as Street (1984, 1993) is what different literacy practices enable people to do in a social context and how conceptions of literacy practices vary in terms of the power accorded to the users. Literacy practices are linked to power structures. For this reason, Street $(1984,1993)$ calls the approaches that have this perspective, ideological approaches. From such a perspective the modes themselves are not the focus but their significance for different people is. 
As mentioned above, this study does not set out to incorporate explicitly this view of literacy in its learning outcomes. Rather, Mahala's concern about representing conventions as prescribed and inflexible is addressed in the instructional sequence (see Chapter 4).

In the field of education, the ideological trend can be traced back to the seminal work of Britton, Burgess, Martin, McLeod and Rosen (1975). Britton et al claimed that language use could be categorised in terms of three language functions: the expressive, the transactional and the poetic. They saw the expressive function as one common to all communicative situations and therefore one that all students had experience of. Students used the expressive function to present their own interpretation of the world as they saw it. Britton et al's claim was that most of the language of the school, particularly in writing, involved the use of the transactional function and that to succeed, students needed to have a good command of that function. They asserted that schools needed to look at the language the students came to the school with and needed to use as the base on which other language experiences could be built. Their motivation was the great numbers of working class students alienated from the school system because of different language experiences.

Mahala (1991) says of the work of Britton and his colleagues:

The early LAC movement to include more expressive language in the curriculum was, in many ways, not only a critique of educational method, but also struck at the root of what it meant to be a member of a 'literate community'. Such a community had to be defined, for curricular purposes, not in terms of institutionally prescribed outcomes, not as an initiation into some 
closed community of 'educated' people, but in terms of the multiple literacies and voices... that actually existed in particular classrooms. (p. 776)

The work of Britton and colleagues is of significance to this study because of the theory that speaking has a role in bridging between learner's prior knowledge and the academic tasks of the school. This is a view consistent with this study. It is hypothesised that speaking will bring benefits in terms of tapping prior knowledge (Alexander, Schallert and Hare, 1991; Smagorinsky and Smith, 1992). The work of Britton et al is discussed in more detail in Chapter 3, as they claim a particular significance for speaking in developing literacy.

More recent work has documented particular literacy practices of individuals and groups in the context of the school. Dyson's (1992) ethnographic study for instance shows how a specific genre, story telling can have multiple interpretations for a child. The purposes of a genre can be more complex than the genrists suggest. Jameel, the child studied by Dyson, saw story telling as a way to perform but could also communicate his story using more 'literate' conventions. In other words, Jameel had a range of literacy competencies which was reflected in the range of genres he had control over. Dyson says "Children's repertoire of genres become the resources they draw upon in school literacy tasks" (1992:6). Variation exists in different children's repertoires. Some children's ways may conflict with the school's ways. Dyson maintains that teachers should be explicit about their demands and expectations and allow children to experience the teacher's role and thus appreciate and experience the power relationships that underlie all literacy events. This she terms is a 
dialogic perspective on literacy. Students working together in interaction is of course another dialogic perspective.

A dialogic view of literacy can be extended to include the way in which texts are read. Critics of formalist approaches with respect to reading state that students need to be able to interpret text beyond the structural and the literal. The "reality and truth" (Johns, 1990:31) of a text not only resides in the reader's mind but has also been constructed in that of the writer. In other words to be literate in reading means to be able to interpret the intentions of the writer. Interpretation of text is a way of thinking about text. The following discussion elaborates this view of literacy.

\subsubsection{Literacy as a way of thinking}

For both in reading and writing, levels of performance which are essentially described in terms of higher or lower order ways of thinking, have been proposed. Meek (1991:10) for instance claims that,

there are two models of literacy on offer in our schools: a utilitarian one aimed at giving people the ability to write little more than their name and address and to fill in forms, and a supercharged model which allows its possessors to choose and control all that they read and write. This powerful literacy includes the ability, the habit even, of being critical, that is, of making judgments, especially about the writing of others.

Bereiter and Scardamalia (1982) and Wells (1987) propose similar models with more distinctions. The model that Wells proposes has four stages: the performative, functional, informational and epistemic. At the 
performative level, one knows and uses the correct conventions regarding language forms; at the functional level, one recognises that form is tied to social function and one can use written language appropriately in a variety of contexts; at the informational level, one recognises that written language is organised in particular ways in particular disciplines; lastly at the epistemic level a reader and a writer are involved in "creativity, exploration and critical evaluation" (Wells, 1987:110).

A later model of writing performance put forward by Scardamalia and Bereiter (1987) makes a distinction between knowledge telling and knowledge transforming. The latter is essentially a creative enterprise, a way of operating cognitively which allows the writer to create new insights while writing so as to transform thoughts rather than merely articulate knowledge already acquired. Further models accounting for the way expert writers write are examined in the following chapter.

In reading, there exist a number of models that attempt to capture different levels of cognitive operation. For instance, Herber's Instructional Framework (1970), considers three levels of operation for reading a text. The first level is the literal, reading on the lines to see what is actually said. The second level is reading between the lines to make inferences about what the author might mean. The third level, applied comprehension, involves reading beyond the lines to make associations with other knowledge, to solve problems, and to modify existing perceptions.

Morris and Stewart-Dore (1984) developed a model for teachers to implement in their classrooms based on Herber's Instructional Framework. 
Other similar pedagogical applications that have as their basis different levels of cognitive operation include reciprocal reading. Approaches that encourage students "to see the epistemological issues such as the objectivity of the academic writer" (Mahala, 1991:781), can be seen in a critical literacy framework.

Models that view literacy as performance on a scale calibrated by different levels of thinking are essentially claiming that, although there is a basic almost literal level of performance, there is also an extended state of literacy that is qualitatively superior like 'high culture'. Thus, the ultimate outcome of literacy instruction is to have all students 'reading beyond the lines' and writing to 'transform' ideas. We may question whether or not this is really a realistic goal for literacy instruction particularly and as goal for all (see Resnick, 1987, for a discussion of this from a historical perspective). The learning outcomes for the students in this study include having a critical approach to the reading of their own texts and those of others, and a creative and reflective approach to the writing of their own texts. It remains to be seen whether opportunity to speak with a partner will bring these aims within the reach of many of the students.

This line of reasoning also leads back to a consideration of the distinction between spoken language and written language because what is claimed by such writers generally is that written language alone allows for one to operate at a superior level of cognitive operation. As Wells (1987:113) states, "transforming thoughts and knowledge... are most effectively extended and developed through engaging in these more reflective modes of language use". However Wells (1987) unlike others, does concede that this level of thinking is potentially possible in spoken language. He states: 
Once developed in writing these same skills then become more readily available in oral discourse: one becomes able to speak a written language.... In the fullest sense, therefore, to become literate is to become able to exploit the full symbolic potential of language for thinking in either the written or spoken mode. (p. 113-114)

The above view is built into the present study, and for this reason, Chapter 3 more fully explores claims made about what can be achieved through speaking.

\subsection{Summary}

This chapter has discussed views of literacy. The discussion has made it clear that literacy is not about a clear cut distinction between speaking and writing and neither is literacy a unitary notion. Rather, we do better to talk about multiple literacies as practised in differing social contexts. Meek (1991:8) makes the significance of this view clear for educators when she says:

Literacy is part of our class system.... Those who have visible privileges and powerful authority over others - doctors, lawyers, bankers, scholars, scientists, entrepreneurs and priests - have in many cases if not in all, profited from the shaping of their careers by the specialised literacies that are associated with them in school and university.

It is clear that the different functions, forms, ways of thinking, social contexts, purposes and perceived significance of literacy practices all need to be accommodated within a theory guiding literacy instruction. 
This study focuses on an aspect of literacy development, the writing of argument texts. The discussion above has considered this aspect of literacy particularly with respect to developing knowledge and use of appropriate conventions for the argument genre. The study also aims to encourage critical skills which students apply to the texts of others as well as their own texts, and it aims to help them write in a way that is creative and critical and reflective. These aims reflect, to some extent, the view that literacy can be seen as social practice and a way of thinking. How these aims are accommodated in the sequence of instruction, is covered in Chapter 4 . How these aims may be able to be better facilitated through talk is described in Chapter 3. The following chapter, Chapter 2 considers what factors affect writing performance and surveys how writing has been taught. This is to provide a context for the particular intervention, talk, being trialled in this study, and also to guide the sequence of instruction. 


\section{WRITING PROFICIENCY AND EXPERTISE}

\subsection{Introduction}

The previous chapter has discussed the notion of literacy and as such has included consideration of reading, writing and speaking. This chapter focuses specifically on writing and therefore offers a more detailed examination of what accounts for and contributes towards writing proficiency and how expertise can be conceptualised. Among the factors considered in this chapter are affective, linguistic and cognitive ones. The significance of surveying such factors is that some or all may prove important in explaining results gained from the planned intervention. An examination of notions of proficiency and expertise is also carried out. Several models are presented including Carter's (1990) theory of expertise, as it represents a view of writing proficiency that integrates social aspects, cognitive aspects and knowledge of the ways in which texts are structured. In so doing, it acknowledges social views of literacy discussed in the previous chapter. An examination of notions of proficiency and expertise is crucial to pedagogy in general and to the study in particular, as the outcome of such a discussion influences the goals we set for writing, the way we teach writing, and in this research, it specifically guides the planned intervention. The second part of the chapter presents survey research investigating the ways in which writing is taught and the ways in which students are prepared for writing, and reviews what we know about the effects of certain prewriting interventions. 


\subsection{Factors accounting for writing proficiency}

Essentially writing is a considered a social, cultural, affective, cognitive and linguistic enterprise and as such all these dimensions need to be borne in mind when looking at what accounts for proficiency. Many of the social and cultural aspects have been discussed previously in Chapter 1 when considering what literacy entails.

\subsubsection{Affective factors}

Affective factors refer to a complex set of psychological states that can have significant effects on academic learning. Measures of academic affect include assessments of self-concept, self-efficacy, perceived usefulness, intrinsic motivation, extrinsic motivation, locus of control, attributions and expectations of success and failure, and anxiety. Recent research (eg Eccles, Wigfield, Harold and Blumenfeld, 1993; Marsh and Yeung, 1996) has shown that the many aspects of academic affect can be specific to particular school subjects.

Affect has been widely investigated as a factor in second language acquisition. Reviews of such research (see for example MacIntyre and Gardner, 1991) conclude that the relationship between affect and achievement is not a simple linear one. Ellis (1994:483), in discussing MacIntyre and Gardner's model interpreting research findings, states that the relationship between variables such as anxiety and learning may be "moderated by the learner's stage of development and by situationspecific learning experiences". As yet little research has been done in the second language area clarifying the particular conditions and situations in 
which variables such as anxiety have a direct relationship on achievement.

Researchers in first language development have some insights to offer on the issue of situation-specific learning experiences. Larson (1985) claims that affective factors are particularly significant in the context of the high school. Larson (1985) in explaining why this is particularly so at the high school level, claims that adolescents have heightened emotions. Affect is also significant in determining how well students perform specifically in writing (Cleary, 1991). In addition to heightened emotions, Cleary (1991:105) also suggests that "developmental explanations for decreased motivation for writing" may exist. It is clear from observation that a great number of secondary school students, many of whom previously enjoyed writing, experience what Daly (1985) has defined as 'writing apprehension'. Cleary's research has clarified what the bases for writing apprehension may be. These are fourfold: frustration and overburdened conscious attention to text, life situation factors, threat in the writing environment and extrinsic motivation outweighing intrinsic motivation. In most cases there is a complex interaction among these factors as has been previously mentioned in the opening discussion of academic affect.

It is also possible that the factors in writing apprehension have their roots in previous school experiences. For example in discussing a student who developed negative affect towards literacy events, Cleary (1991:503) states "It is possible that threat to a positive view of self took place in early years when the student's mode of expression, verbal or written, was not congruent with the school's accepted mode". In light of the previous discussion of literacy, we may assume this to be particularly so for 
students who are speakers of other languages and who have become literate in the contexts of other societies and cultures.

Measures of academic affect or more specifically writing apprehension are not within the scope of this study. However in the analysis of interaction of three case study pairs (Chapter 8), affect is acknowledged through the categories of positive and negative appraisal (Meloth and Deering, 1994) which can be assigned to their instances of talk.

\subsubsection{Language factors}

In explaining differences in writing achievement, most teachers of second language writers would assert that general language proficiency including knowledge of structures and vocabulary is the most significant factor. Research and theory does not support this belief. Krashen (1984) identified not just general language proficiency or 'knowledge of the code' as a factor accounting for writing proficiency; he also identified the efficiency of the writer's process. Cumming (1989) also makes a distinction between second language proficiency and writing expertise. He maintains that each have separate effects. Second language proficiency may well affect the texts produced but it does not change the way the composing is carried out. He states:

As people gain proficiency in their second language, they become better able to perform in writing in their second language, producing better texts, attending more fully to aspects of their writing. Unlike writing expertise, however, attaining greater second language proficiency does not appear to entail qualitative changes in the thinking processes or decision making behaviours used for composing. Indeed the processes of composing in a second 
language did not appear, in this study, to be visibly affected by second language proficiency. (p. 121)

We know little about how specific aspects of language knowledge correlate with or cause improvements in writing in a second language. However in first language theory, Corson (1988) claims that vocabulary knowledge, particularly control of the formal Graeco-Latin vocabulary, is an important factor in the ability to write well in content areas. Stahl, Chou Hare, Sinatra and Gregory (1991) investigated the role of vocabulary knowledge. According to Stahl et al (1991), a high level of vocabulary knowledge is a significant predictor of the ability to reconstruct a text in written form.

The issue of second language proficiency effects on second language writing proves to be a complex one. Clearly more research on individuals, tracing the correlations between different aspects of proficiency both on the composing behaviours and on the texts produced could profitably be carried out. This study however focuses on the effects of an intervention. The effects of the intervention are assessed through group data which merges proficiency differences amongst the subjects in the study. However, the subjects to be studied in the transcript analysis have different levels of second language proficiency and demonstrate different ways of using talk to help their partner to construct text.

\subsubsection{Schema knowledge}

In this discussion, it is useful to refer to an important distinction made by Kintsch and van Dijk (1978). Kintsch and van Dijk distinguish between two types of schema knowledge: content schema and formal schema. 
Content schemata refer to knowledge of concepts whereas formal schemata refer to knowledge of the way in which types of texts are typically structured. Alexander, Schallert and Hare (1991) prefer the term 'text structure knowledge'. Text structure knowledge includes the knowledge of discourse conventions as discussed in section 1.3.3. Here we look at the role of text structure knowledge or content and formal schema and the role that they play in influencing writing proficiency.

The role of both these types of knowledge has been extensively researched with reference to reading proficiency both in a first (Meyer, 1975) and second language (Carrell, 1983, 1984). Generally the findings from such research support the claim that instruction in reading that focuses on the macrostructure level of the text will result in better recall of the content in the text.

The way in which schema knowledge affects writing has been investigated to a lesser extent. In the second language area, Franken's (1988) research showed that instruction in a text structure and its constituents (incorporating both content and formal schemata) for beginning learners at the first stage of high school (Form 3) had a significant effect on the quality of written texts the students produced.

In the area of first language research, Langer's (1984) work demonstrated that prior knowledge or more specifically what they brought to the task in terms of content and domain-specific knowledge positively affected the quality of texts produced. Content knowledge is said by Alexander et al (1991: 332) to include "formal and informal knowledge of some aspect of one's physical, social or mental world", while domain-specific knowledge 
is "a realm of knowledge that broadly encompasses a field of study or thought".

Stahl, Chou Hare, Sinatra and Gregory (1991) investigated the role of prior knowledge also in terms of content and domain-specific knowledge in the recall and rewriting of text. The students (10th graders) were more likely to produce gist statements of the text if they had a high level of prior knowledge. The reason for annotating the term, 'prior knowledge' is that it has recently been redefined by Schallert in Alexander et al (1991:319) as "everything a person knows including tacit and explicit knowledge of procedures and typical ways of expressing information". The ways in which prior knowledge was conceptualised and tested in the studies mentioned above are not as encompassing as Schallert's definition.

In some models of writing (eg Bereiter et al, 1988; Cumming, 1989) the sophistication of discourse knowledge predicts the levels of expertise in writing. Cumming's (1989) expert writers appear to write "implicitly or explicitly in reference to well formed scripts, rhetorical plans or goal directed planning" (1989:112).

\subsubsection{Cognitive factors}

Cognitivist views of writing, which see writing as a problem solving activity have been a significant influence on $L_{2}$ writing theory and pedagogy (Johns, 1990). In research terms, a cognitivist perspective has guided attempts to describe writers at work and to account for 
differences in writing proficiency. What then is the nature of the knowledge, procedures and strategies more proficient writers use?

Early cognitive models in English as a first language, (Flower and Hayes, 1980a, 1980b, 1981); and in English as a second language, (Zamel, 1983; Raimes, 1985; Arndt, 1987) proposed a generalised way of carrying out the writing process, and more proficient writers merely differed in terms of the quality and automaticity of their processes. As mentioned above, Krashen (1984) also proposed that the way learners carried out the process was a significant factor. In line with his theory on learning and acquisition, he proposed that it was this aspect that teachers could directly influence through instruction.

Recent work (Wallace, Hayes, Hatch, Miller, Moser and Silk, 1996) has specified procedural knowledge or knowledge of how to carry out the process in more detail. Wallace et al specify basic writing skills and task schema. The former term, basic writing skills, refers to abilities such as detecting problems in the text, while the latter refers to a writer's conception of what writing or parts of the writing process entail.

Scardamalia and Bereiter's (1985, 1987) cognitive model proposes knowledge telling and knowledge transforming as two dimensions along which writers differ. Experts are said to consider the act of writing as involving two problem spaces, one is to do with beliefs and ideas about the topic, while the other has to do with how the composition will be written. These are respectively named the substantive problem space and the rhetorical problem space. Experts are said to be able to negotiate both problem spaces. As Scardamalia and Bereiter (1985) explain, 
A dialectal process arises... when there is interaction between the two problem spaces. This occurs when rhetorical problems are solved through means that involve changes in substance and where substantive changes - that is, alterations in belief or knowledge are perceived as creating significant problems in the rhetorical space. (p. 311)

An example of the way in which this may operate is when for instance a writer feels she/he needs to elaborate and give more explanation and this in turn prompts the writer to find more substantive material.

Novice writers operate in a distinctly different way. The writer constructs a mental representation of the writing to be done, and topic and genre identifiers are searched for. Those topic and genre identifiers trigger off a memory search through a process of spreading activation, among concepts and through recalling information on how to fulfil genre requirements. New text then itself acts as topic and genre identifiers. In this way associated and relevant concepts are generated for use and the writing to some extent fulfils genre requirements.

The most comprehensive L2 research investigating the role of particular cognitive strategies has been that of Cumming (1989). Cumming (1989:84) states, "Differences in performance appear to arise - while writing in a second language - from the knowledge, procedures and strategies writers use to produce their writing". He characterises writing proficiency as involving three major factors: the extensive use of heuristic search strategies for evaluating and resolving problems, attention to complex aspects of writing while making decisions, and the production of effective 
content and discourse in compositions. Cumming's (1989) model of proficiency also includes a metacognitive element. He found that proficient L2 writers had control strategies they could apply to their writing. They had a guiding mental model of how to proceed in their writing.

What each of these models reinforce is the notion that writing is a complex cognitive activity, with writers performing aspects of that process at different developmental levels. Both first and second language learners are constrained in part by linguistic knowledge. Early models of the writing process (eg Flower and Hayes, 1980b) acknowledged another constraint, that of working memory resources, when they represented the writing process as one of 'juggling constraints'. Working memory resources has recently resurfaced as a factor in explaining different levels of performance in the work of Wallace et al (1996).

In summary, what needs to be acknowledged in attempting to define expertise is the interplay of many factors: affect, basic language proficiency or linguistic knowledge, content and discourse knowledge, procedural knowledge including task schema, and cognitive processing constraints.

\subsection{An integrated view of expertise}

As stated in the opening section of this chapter, any model of writing expertise needs to be socially and culturally situated. Writing is a social practice and the texts that writers produce to some extent represent the conventions of the social contexts and culture in which they acquire 
literacy. Carter's theory (1990) outlined below provides a valuable model for considering development and expertise in these terms. Carter considers expertise not only from a cognitive viewpoint but also from a social viewpoint, his work represents an answer to an issue that has been preoccupying many theorists, researchers and practitioners at the present time (see Kroll, 1990, for a selection of articles).

Carter's (1990) framework draws on the distinction between general knowledge and local or task-specific knowledge (Perkins and Salomon, 1989; (Alexander et al, 1991; Smagorinsky and Smith, 1992). General knowledge relates to general strategies for carrying out tasks or solving problems. Local knowledge relates to knowledge that is specifically needed to carry out a task or solve a problem. Smagorinsky and Smith (1992), in documenting the types of knowledge involved in writing, use a similar classification. They classify knowledge of cognitive strategies, or general procedural knowledge in their terms, as a part of general knowledge. To this category they add general knowledge of text structure. The other two categories are task-specific knowledge and communityspecific knowledge.

In terms of writing, general strategies reflect the position of the cognitivists such as Flower and Hayes mentioned above who stress the universality of processes in producing text. Knowledge and use of processes must be combined with local knowledge. This is knowledge of particular and appropriate discourse forms needed in different contexts. Carter's (1990) viewpoint of expertise therefore encompasses both the local and the general and, in fact, sees them as end points on a continuum. He states, 
As people gain greater experience in a particular domain, their performance in that domain relies on knowledge that becomes more and more local, less and less general...Between the extremes of global general knowledge of the rank novice and the fluent use of local knowledge by the expert, there is a range of knowledge that becomes increasingly local, of strategies that become increasingly domain-specific (p. 273).

Carter claims that mastery in one domain has little significant effect on performance in another domain. Experts rely on general strategies when domain-specific knowledge fails them. General strategies allow novices to gain more and more specific knowledge of a domain. Glaser's statement that:

Experts are experts because they possess highly organised schemata developed over a long time, that are related to a specific field. Novices are novices because they do not possess such sophisticated schemata, because of the inadequacies of their knowledge bases.... (Glaser in Carter, 1990:272)

indicates how such a view of expertise allows one to consider the social aspects of writing together with a cognitive view that encompasses considerations of skills and strategy use together with knowledge of how texts are constructed.

The important line of research by Alexander and Judy (1988), Perkins and Salomon (1989) and Chan, Burtis, Scardamalia and Bereiter (1992) provides a missing element in the work of Carter and one is, no doubt, of significance to the writing performance of the students in this study. It is the element of content knowledge. The writers above explore the 
relationship between strategy use (incorporating procedural knowledge) and knowledge of the subject area (content and domain-specific knowledge). There is an interrelationship between strategy use and content and domain-specific knowledge. Strategy use appears most effective when one operates from a firm knowledge base.

\subsubsection{The expertise of subjects in the research study}

In this study, the students' level of expertise needed to be addressed. The study explores the role of content and domain-specific knowledge through different topics in the instructional sequence (see also Chapter 4). The intervention programme required that students write in three main domains: a general knowledge domain for which they required little domain-specific knowledge, a general science domain for which they required some domain-specific knowledge, and a specific history/economics domain that required more domain-specific knowledge. In the latter two domains content knowledge was provided for the students in form of resource materials. The students were expected to have different levels of content or domain-specific knowledge. Whether this became a factor affecting their writing performance as inferred from measures of text quality, remained to be seen.

The present research study worked with Form 6 (Grade 12) students in the production of one type of genre, argument texts. The English curriculum, English in the New Zealand Curriculum (Ministry of Education, 1994) recognises degrees of expertise in terms of procedural knowledge and articulates these in its statement of learning outcomes. What is 
expected, with respect to argument texts at approximately a Form 6 level is that students should be able to:

- express and argue a point of view persuasively, structuring material confidently (level 6)

- debate a proposition or point of view, structuring well researched material effectively (level 7)

- debate in depth a proposition or point of view, structuring well researched material effectively (level 8).

It is expected that students at a Form 6 level will not be novices when writing argument essays, however neither will they be experts. Because of the level of expertise that we can assume senior high school students to have, the proposed intervention exercised both general writing process strategies as well as task-specific knowledge of the argument genre.

\subsection{Summary}

The first section of this chapter has looked at writing proficiency and expertise. An examination of proficiency and expertise is crucial as the outcome of such a discussion determines decisions about pedagogy: the selection of appropriate performance goals from the curriculum statement. It determines the way in which instruction or intervention is carried out and it also guides the alternative pathways or opportunities one provides for students to achieve performance goals (see Franken and Watson, 1996 for a discussion of this notion). In this study, talk is proposed as an alternative pathway to achieving a text which is well structured, which demonstrates knowledge and the use of appropriate conventions for the 
argument genre, and which demonstrates a critical and reflective approach in debating a point of view.

\subsection{Teaching writing}

Given the importance we attach to writing, the question arises, how do we teach it? Do any of the methods we employ make use of the knowledge we have about what influences writing proficiency? This section reviews surveys investigating writing in content areas in high schools, including the preliminary survey carried out for the thesis.

\subsubsection{Types of writing experiences}

In Britain the Bullock Report, commissioned in 1972, presented findings from a committee of inquiry into language in British schools. Its principal recommendation was that each school should have an organised policy for language across the curriculum. What followed were a number of studies investigating the role of writing in content areas. One such study was conducted by Martin, D'Arcy, Newton and Parker (1976) who found that the writing opportunities that students had were limited in terms of their purpose and restricted in terms of their audience.

In America, Applebee's (1984) study represents a significant and large scale study of writing in content areas. It involved both survey and case study data and resulted in similar findings to British studies. Applebee found that the majority of teachers expressed the belief that writing had an important role to play in content area learning. However the belief was not translated into practice. Here also the writing that high school students did was primarily for the teacher as examiner. All subject areas 
emphasised writing at the word or sentence level. Most writing tasks involved mechanical filling in of information. Even when writing tasks required long responses, typically the tasks were tests of content knowledge.

Philips (1985) carried out a small case study of the types of writing experiences that New Zealand secondary students in four classrooms had over the period of a month. The results were again similar. There was a paucity of authentic contexts in which writing was being practised. Most writing tasks were very brief (two or three sentences long). The writing done in English was often longer and therefore was the exception. In all subjects, writing was used chiefly as a method of recording information and as an indication of the level of understanding of particular topics. Philips (1985:180) sums up by saying, "Most of the writing carried out was of a routine mechanical nature requiring minimal input from the students themselves".

The preliminary survey carried out for this study found several positive results. When writing was carried out, a considerable amount of class time was spent on actual writing. The writing tasks covered a range and although short answer writing was common, particularly in Science, more extended texts were often required of students. These tended to fall into two categories: the essay (including information reports, argument texts, creative texts), and the research report. The preliminary survey involved observations of classes in three schools; in three subject areas: English, Science and History; and at three levels: form three, form five and form seven. In total ninety classes were observed. 
From the overview above, it can be seen that concerns regarding language through the curriculum are shared by educationalists working in different countries and that observations of practice are remarkably similar and not greatly positive. If we consider the writing experiences of high school students in content areas, we see that the writing experiences that students have are of a very mechanical nature, the students often have little opportunity to actively construct their own topics, and they have little choice in what must be represented in writing and how it must be represented as the form and content are often predetermined by the teacher. Writing often has the function of being a content check for the teacher: do the students understand the facts?

If we take the following models of writing: expressivist as proposed by Elbow, 1973 and Graves, 1983; cognitivist (Flower and Hayes, 1981); or interactive (Nystrand, 1986; Hinds, 1987; Eisterhold, 1990) as outlined by Berlin (1987) and Johns (1990), there is in each of these models a notion of the writer making choices. What guides and determines these choices is what is different in different models. In the writing experiences of high school students there may be little in the way of making choices. Very often the teacher merely presents what students have to write and how they have to write it. In the subject areas of English and History, there is currently a move towards teaching students research skills in which they themselves discover information relevant to a self-selected topic. The objectives for such projects are positive. However, the methodology to create a situation of inquiry is lacking. It may be that such research projects do little better than disguise transmission modes of teaching and learning. 


\subsubsection{Ways of preparing students for writing}

The surveys above are concerned mainly with documenting the types of writing that students carry out in schools. That is one level of analysis. In addition, we need to look in detail at the ways in which students are prepared for writing tasks. Less research exists exploring the quality of prewriting experiences. However Applebee's (1984) case study data from his survey does provide the observation that little was being done to prepare students for writing in content areas. "Prewriting activities were minimal, usually no more than an explanation of the 'topic' and instructions as to the length and form" (Applebee, 1984:3).

He also had this to say about the nature of assistance during the writing and the type of feedback given to students: "Help during the writing task was rarely provided; and reactions to completed work focused on 'accuracy' and 'correctness' rather than the development of ideas" (Applebee, 1984:3).

The findings of the preliminary survey support those of Applebee regarding prewriting but not regarding the reactions to work. Contrary to what one might expect by observing teacher behaviour, students did not generally perceive that the teacher valued mechanical and unoriginal writing. The students questioned in the preliminary survey ranked their own viewpoint, and their own ideas highly from the list of text features that they felt their teacher valued. 


\subsubsection{Documenting the discourse of the writing classroom}

Another relatively new area of research is the investigation of what happens in the writing classroom from a discourse analysis point of view. Cumming (1992), shunning more traditional units of classroom interaction analysis (eg Sinclair and Coulthard, 1975) on the grounds that they are inappropriate for the writing classroom which operates more like a 'workshop' than a content-focused class, adopted the unit, instructional routine. He defined instructional routines as "behavioural units which serve to structure and focus pedagogical activities through sequences of verbal exchanges between teachers and students" (Cumming, 1992:19). From case studies of three teachers, Cumming identified six instructional routines for organising teacher-student interaction. One of these in particular, collectively constructing interpretations, was focused on prompting students to interact with the teacher in a whole class context. Cumming said of this interactive activity, its aim was "to model individual students' thinking Socratically to demonstrate relevant thinking, rhetorical, or linguistic processes for the whole class" (1992:25).

Weissberg (1994) focusing on the type of moves teachers used in five ESL (English as a second language) composition classrooms, found that moves related to rehearsing text orally before or at the point of writing, and moves related to developing or rehearsing possible ideas for a topic were infrequent compared to moves that related to explaining rules or conventions, moves that related to explaining features of model texts, or moves that related to reading sections of text aloud. Not surprisingly, Weissberg also found that teacher talk dominated class time. 
A focus on the verbal behaviour of teachers needs be complemented by a study of the nature of student talk where cooperative activities are being encouraged at various points in the writing process. This is a contribution that can be made by this study in its investigation of the nature of talk that results in positive effects on argument text construction. Many of the observations made about facilitative talk in Chapter 8 can, no doubt, be generalised to the writing of other texts, writing in other classrooms, and also perhaps to teacher-student discourse in writing classrooms.

\subsection{Researching intervention}

The above section has surveyed existential studies (ie studies of what students and teachers typically do). This section on writing intervention looks at research investigating the effects of altering the conditions under which writing is done and the effects of altering writing behaviour. Naturally, as writing is one of the two aspects of what is conventionally thought of as literacy, research into effective intervention in writing has been widespread. The composing process paradigm provided researchers with clear areas for investigation as, for example, the effects of altering planning behaviour, and revision behaviour. In terms of teacher intervention, possibly the most noticeable area of interest has been in the area of providing feedback (see for example Fitzgerald, 1987, for a comprehensive review). In terms of a general approach to intervention research, Hillocks' (1984) review is still to date one of the few and certainly the most comprehensive. Some of the findings from Hillocks (1984) are included in the discussion below. 
The following section describes research primarily in prewriting intervention. A survey of research that focuses more on exploring the effects of different forms of prewriting assistance than on approaches to writing in general is of use, not because of what it offers in terms of techniques, but rather what light it sheds on the different conditions that are facilitated and the different effects that options bring about.

In the following section, prewriting intervention is surveyed under the following headings: free writing, memory search and free association techniques, heuristics, inquiry, and peer discussions. Many of these approaches and tasks fall into the classification of invention. This is largely because the help given is in the generation or invention of ideas. Invention is not new. It was employed by Aristotle and the classical rhetoricians as "a means of putting the speaker in contact with knowledge and relationships that already existed" (Young and Becker in Spack, 1984: 652). With the recent and still current composing-as-process paradigm, interest in invention has been revived (see for instance Spack, 1984; Hillocks, 1986; Liebman-Kleine, 1987).

\subsubsection{Free writing}

Free writing can be considered an approach to writing development that capitalises on the unique intentions and purposes of the individual or it can be considered as a prewriting activity which prepares students for the production of the response to the criterion task. As an approach, it is characterised by the selection of topics by students, frequent writing by students, and the absence of grading or assessment of papers. Papers are however often aimed at communicating with a specific audience, either the teacher or peers. Hillocks (1986) reported that few experimental 
studies using free writing as a focus of instruction had achieved significant gains in the quality of writing produced. More recently, advocates of the free writing approach claim that as well as resulting in better products, it enhances fluency, that is, practice improves the efficiency of the process. This claim remains as yet untested.

As a prewriting technique, free writing functions as a memory search. In using free writing, students are encouraged to generate text without worrying about errors. Liebman-Kleine (1987) provides the label, openended exploratory writing. Looping is a type of free writing activity advocated by Spack (1984). In looping, students write non-stop for a short period of time; they then stop, read, reflect and sum up in a single sentence. This procedure is repeated. Spack's (1984) dialogue writing, where students carry on a conversation with themselves in writing about a particular topic, also falls into the free writing category but interestingly seeks to develop a dialogic approach to writing.

Free writing is directed towards content and linguistic concerns. A benefit for L2 students in particular is that it allows them to generate text while generating ideas. The text generated is done so without fear of errors. However, Liebman-Kleine (1987) cautions that L2 writers may not have the linguistic fluency to produce text in this way.

\subsubsection{Memory search and free association techniques}

Hillocks (1986) discusses another category of prewriting intervention involving memory search and free association techniques which are in principle similar to free writing techniques. Brainstorming activities are representative of this approach to prewriting. Results from the small 
number of studies done have been generally positive in that the writing produced after the use of these techniques is seen to be better in terms of content.

Hierarchical treeing is a category label devised by Liebman-Kleine (1987) to cover techniques which involve the visual organising and generating of data but which may well fit into the category of memory search activities proposed by Hillocks. For example, graphic outlines can help to organise ideas while brainstorming diagrams can help to explore ideas. LiebmanKleine (1987:107) states, "The goal of these trees is to encourage analytical, hierarchical thinking."

Liebman-Kleine reports that in the L2 classes she surveyed, these appeared to be the most successful and most enjoyed by students. This may be because treeing is visual and analytical rather than linguistic. The technique also provides a sense of structure and control. In contrast to the practice of presenting students with models or plans of ideas which are prescriptive, the visual plan is generated by the students themselves. In addition to these advantages, the students can see that there can be a direct relationship between what is produced in their visual plans and what goes into the construction of their final texts.

\subsubsection{Heuristics}

"A heuristic may be defined as a systematic guide for investigating a phenomenon" (Hillocks, 1986:178). The guide may be as simple as a set of questions e.g. reporter's questions or may involve a more complex set of questions or procedures. An example of the latter is Young, Becker and Pike's (1970) system using tagmemics. Tagmemics involves knowing how 
an object or concept is different from others, how it is similar, and how it fits into a larger system. Possibly a more accessible technique than that of classical invention or tagmemics is cubing (Spack, 1984). In cubing, students consider a topic from six points of view: they describe it, compare it, associate it, analyse it, apply it, and argue for and against it.

Liebman-Kleine suggests that these techniques are not successful with L2 writers for three reasons: L2 writers lack the linguistic fluency needed to express different views on a topic; the techniques themselves demand attention because of their complexity thereby causing interference; and L2 writers tend to see heuristic devices as inflexible rules not as prompts which need to be responded to flexibly.

Hillocks (1986) reports mixed results on the effect of heuristics on the quality of texts produced by students. Scales, a type of heuristic device which sets out the criteria for the successful completion of the task, however have generally been found to be successful. Franken's (1988) research showed that ESL students working with self-questioning checklists based on content requirements made significant improvements in the quantity and quality of what they wrote in Science. Self-generated scales are used as part of the sequence of instruction in this study. The rationale for this, with respect to the goals of the programme, is discussed in Chapter 4.

\subsubsection{Inquiry}

The most successful type of approach in helping students to write effectively is inquiry maintains Hillocks (1986). In the inquiry mode, the students' prewriting experiences begin with the analysis of a set of 
prescribed data. There may be, in the processing of that data, the use of strategies similar to those used in heuristics. The difference however is that a step-by-step approach is used. The strategies are discrete and are not necessarily a part of a complete set of questions or prompts. In addition, the strategies that students learn in order to work with data are related to the requirements of the discourse. In the review conducted by Hillocks (1986), inquiry treatments when contrasted with some other treatment always showed significant positive results.

The interventions discussed above primarily fall into the category of invention when we consider a functional rather than descriptive categorisation. A comprehensive classification system for prewriting activities that is based on the cognitive function is provided by Adegbija (1991). The four categories of Adegbija's scheme are types of cognitive strategies and are as follows: global strategies, content-related activities, order-related activities and language-related activities. Global strategies are those which "serve the function of orienting their (the students') minds towards the assigned topic" (Adegbija, 1991:229). They are called global because they involve wide search strategies that relate to the broad area of content not just the specific topic. The second category, content-related strategies are those which students engage in when coming to terms with the content required for the assigned topic. Content-related strategies may include brainstorming, noting down key points, gathering information from sources whether they be people or written texts. The category of order-related activities is that in which students sequence and group ideas in preparation for their writing. The last category relates to activities designed to improve the quality of the language used in the eventual text. The activity may include, for example, the analysis of the 
writing assignment in terms of its genre. Once the genre has been determined, the learners may then go on to specifying the nature of the language features that their text may be expected to exhibit.

The prewriting interventions discussed above, as invention, primarily invoke global and content-related strategies. To a lesser extent they invoke order-related strategies and language generation strategies. A simple but comprehensive functional description such as that of Adegbija provides a worthwhile context in which to begin to evaluate the contribution talk can have for writing.

\subsubsection{Peer discussion}

Peer discussion is a wide term that can be used to cover a multitude of arrangements with a multitude of purposes. First, it may be seen as the opportunity to talk freely about the assigned writing topic, or second, it can be used as the mode in which any invention activities may be carried out. Hillocks illustrates the first and general role of peer discussion when he states that the function of peer discussion is "to encourage students to recall what they know about a topic before writing about it" (1986:174).

For L2 writers, general peer discussion as preparation for writing may bring additional advantages. Long (1989:9) for instance claims that in a group context students "can attempt coherent sequences of conversational turns, not just isolated sentences." Clearly there may be great rehearsal advantages for writers both in terms of ideas and language forms. 
Several studies in the Hillocks (1986) review have examined the effect of general peer group discussion on the quality of writing produced. Hillocks concludes that the results from L1 studies are inconclusive. This is no surprise as the studies mentioned by Hillocks simply took the activity of peer discussion at face value and failed to look at the conditions underlying the discussion that would have had a part to play in generating the positive or negative results.

Another piece of recent research illustrates this problem. Sweigert (1991) empirically tested the direct effects of speaking on the quality of writing produced. He found group discussion to positively affect the ideas and organisation of the writing that followed. However, the research provides no insights into the nature of the conditions that underlie a task such as group discussion. Is group discussion effective because of the numbers of participants involved, the nature of the talk it facilitates, the nature of the cognitive activity it encourages, or the affective climate it promotes?

Peer discussion can also be conceived of as a mode in which other techniques are performed. Franken's (1991) paper is an example of this, where results of a study are reported in which students used collaborative mapping as a way of assembling and organising facts before writing. The study concluded that the technique in itself would not result in writing that was better organised, unless some provision for helping students to better organise their essays was built into the mapping activity.

The discussion above points to the fact that talk is seen to perform the raft of functions identified by Adegbija. Rubin, Goodrum and Hall (1990:72) present another perspective, a procedural one, on how speaking 
can be used to prepare students to write. They outline three ways in which speaking can be used in writing classes: it can accompany writing "as in pre-writing discussion or peer writing conferences"; it can be used to reflect part of the process, for example the reading aloud of written text for checking; and the third way aims to increase the writer's flexibility and expression by allowing writers to explore the role of the reader as well as the writer. This is also presumably achieved by the reading aloud of text.

\subsection{Conclusion}

As yet in second language writing research we know little about the effect

of prewriting activities in general. Bereiter and Scardamalia (1985) have made the point that prewriting exercises such as those surveyed above are exercises that essentially promote thought about substantive issues for writing. However, having considered models of writing proficiency and expertise we can ask the question, as Scardamalia and Bereiter (1985) have done, "Do the mental processes involved in prewriting exercises correspond to those of expert writers?"

Spack (1984:663) says that "we should test the hypothesis that ESL students' writing performance will improve if they are taught invention skills". A certain procedure may actually place constraints on some writers' natural and unique thinking and writing processes. Some students may find that a particular exercise runs counter to the way in which they perceive what writing is. For example, there may also be developmental constraints in the effective use of invention eg as might occur with students who had insufficient target language vocabulary. In the case of prewriting tasks that involve speaking, there is the assumption that 
speaking will help students in preparing for writing. It is this assumption that the next chapter will discuss. 


\section{THE ROLE OF TALK}

\subsection{Introduction}

Stables (1995:62) states "a host of writers and thinkers from psychologists to literary critics have convincingly explained how meaning itself is constructed through linguistic interaction". This chapter discusses some of the most significant theoretical and pedagogical explanations offered in support of linguistic interaction (or talk) and includes discussion of the benefits of talk for writing. It comments on research that seeks to provide support for the theoretical and pedagogical claims relating to the benefits of talk and explores the specific conditions under which talk is said to bring benefits for learning and writing.

At this point, it seems necessary to clarify what is meant by talk and what the term talk covers. The term has been used above interchangeably with interaction and more specifically linguistic interaction. Talk is the means by which interaction is carried out as students work on a task that has been clearly assigned to them, usually by the teacher. Talk as a condition in the research for this study will be further specified in the following chapter which includes a discussion of the independent variables.

\subsection{Cognitive benefits}

Cazden (1988) proposes a set of four cognitive functions of talk including: talk as the enactment of complementary roles; talk as a catalyst 
to change thinking; talk as exploratory discourse and talk as relationship with audience. These provide a useful starting point for the discussion of the benefits of talk and are used as the framework for this section. However additional functions have been identified and are included below.

\subsubsection{Talk as the enactment of complementary roles}

Cazden (1988) states that in the context of interaction, peers assume complementary roles. This is best explained with reference to Forman's description of how two successful 'collaborators' worked on a set of complex chemistry tasks. She says:

In their early collaborative problem-solving sessions, George and Bruce worked in parallel and each used an empirical strategy.... After about a month of working together, they devised a social procedure for generating combinations empirically by assuming complementary problem-solving roles: one selected chemicals and the other checked their uniqueness. (Forman, in Cazden, 1988:130)

The roles adopted by the two continued to be refined and adapted as their respective knowledge grew and the tasks changed. The adoption of complementary roles helped to get the tasks done at the time and helped when students were later required to complete similar tasks independently. Forman makes the comment that the peers could perform the tasks together before they could perform them alone.

Although the roles adopted by the students were complementary, they were different. One can assume that scaffolding had a part to play in the 
acquisition of knowledge of at least one of the peers. The way talk can act as a scaffold is developed below.

\subsubsection{Talk as a scaffold}

The term, scaffolding, describes the role of an expert in assisting a learner to solve problems in the zone of proximal development described by Vygotsky (Gredler, 1997). "Scaffolding is the process of controlling the task elements that are initially beyond the learner's capacity" (Gredler, 1997:365). In relation to talk, it is the expert's talk that provides the means by which task elements are brought within the learner's capacity. However, talking on the part of the learner also brings benefits, as through the act of talking, verbal thought is supported by words. The act of verbalising in turn acts as a support or scaffold for thought. Fletcher (1985) found that students involved in a computer problem solving game did as well when they verbalised their thoughts aloud to themselves as when they talked in a group to others. A useful term that captures the fact that the talk of the individual, not necessarily of, and to, the other can bring benefits, is best described as cognitive facilitation (Fletcher, 1985).

\subsubsection{Talk as a catalyst to change thinking}

The theory that talk is a catalyst to change thinking was an important notion in the work of Piaget (1950). "To Piaget, social interaction is important because of the cognitive conflict it stimulates; talk is a catalyst for internal change without directly influencing the nature of the developing ideas" (Cazden, 1985:13). 
Talk operates in this way when there is a confrontation with alternative ideas and when participants in the interaction seek to arrive at a mutually agreed on position. This results in a change of thinking and in new thinking as participants have taken new learning from their partner (Scardamalia and Bereiter, 1985; Cazden, 1988). This process has been referred to as dialectic (Scardamalia and Bereiter, 1985).

Social constructivist theory maintains that talk or interaction changes and develops thinking but goes further than this. For example, Vygotsky, a key social constructivist, claims that not only does social interaction lead to the development of a child's cognitive abilities such as memory and problem solving but that speech, the means by which interaction is carried out, itself is taken over by the child and internalised.

\subsubsection{Talk as exploratory discourse}

The work of Britton (1970), Britton, Burgess, Martin, McLeod and Rosen (1975) and Barnes (1976) can be seen as the initial impetus and as the reference point for the conception of talk as a way of exploring and clarifying thought. Britton (1970) maintains that exploratory talk is experienced through the expressive function. Exploratory talk is speaking "without the answers fully intact" (Barnes, 1976). Therefore speaking is the medium through which students have the opportunity not merely to reproduce information but to use language to try out ideas and hypotheses tentatively and to represent their own interpretation of the world.

Britton contrasts the expressive function with two other functions used in the school curriculum, the transactional and the poetic. Britton maintains 
that the expressive function of language "should be regarded as a matrix from which the other two categories develop" (Britton in Pradl, 1982: 124). Mohan (1986) has likewise selected the expressive function as critical to learning and writing. He claims that the use of the expressive function may be the primary means of learning in the high school. "If teachers can provide more opportunities for exploratory talk and writing students would have a chance to think through material and make it their own" (Mohan, 1986:13). Exploratory talk used to carry out the expressive function is seen then as a way of students 'owning' new learning.

Speaking can also be seen as a way of carrying out the more specific function of hypothesising. Corson (1988) claims that speaking encourages a "hypothetical mode of learning", essential in problem-solving. Opportunities to talk facilitate this as external speech or dialogue becomes internal speech or thought which can then operate to solve problems.

An important concomitant of a hypothetical mode of learning is a mental set or attitude toward learning. Rosen and Rosen (in Corson, 1988:24) suggest, "Those talking are encouraged to set up hypotheses in their telling to verbalise doubt and not find the state of doubt intolerable". This statement contains the important element of attitude or mental set to learning and as such seems similar to Bereiter's (1990) notion of intentional learning. What makes for successful learning of new information is the perception of difficulty entailed in the new learning. Speaking is the medium through which perception of difficulty is verbalised. 
An effect of talk related to its potential for expressing hypotheses is the recognition of gaps in one's knowledge when one verbalises one's thought (Webb, 1989). In this way talk appears to be the means by which one can monitor the consistency of one's discourse.

\subsubsection{Talk as a means of promoting literate thinking}

A number of writers maintain that talk can activate qualitatively better thinking. The concepts associated with the notion 'better thinking' vary to some degree. A significant number of educational psychologists investigating the best conditions for group work (Swing and Peterson, 1982; Webb, 1989; Cohen, 1994; Webb, Troper and Fall, 1995), have settled on the term 'higher order thinking' although it remains undefined by them. In terms of explaining what the term entails, we can refer to some of the effects listed by Webb et al. (1995). These include recognising and resolving inconsistencies, developing new perspectives, constructing more elaborate conceptualisations, strengthening connections between new information and previous learning, and utilising problem-solving strategies. The term is not unrelated to the notion of knowledge transformation, the ability to produce text in an essentially evaluative and critical way.

Wells (1989) uses the term literate thinking. He claims that 'literate thinking' can be activated through speaking. The types of behaviours associated with literate thinking include the ability "to attend to the actual propositions that are asserted, to evaluate their coherence and consistency and to examine the evidence adduced to support them and their plausibility in the light of experience" (Wells, 1989:254). Literate 
thinking implies that one also has the ability to talk about text through metalanguage.

Literate thinking is also similar to Scardamalia and Bereiter's (1987) term, knowledge transforming which they have restricted to refer only to expert writing behaviour. Bereiter (1990) disagrees with Wells's claim that speaking can achieve literate thinking. He argues that transformation of knowledge that occurs as a part of the critical examination of text is only possible through writing, not through speaking. Speaking can activate knowledge telling however. As discussed in section 2.2.4, knowledge telling is a developmentally less sophisticated mode of operating which merely requires the activation of discourse knowledge.

The claim that talk and interaction are able to activate 'better thinking' is an important one that needs to be viewed in the context of discussions about the differences between speaking and writing. If one accepts the claim, one essentially challenges the distinction between what writing can achieve and what speaking cannot (Bereiter, 1990). The present study predicts that there will, in fact, be cognitive benefits for the students engaged in interaction with a peer, although these benefits are addressed indirectly through measures of writing quality that focus on content and the structure of the argument texts written by the students.

\subsubsection{Talk as a way of modeling processes}

It can be inferred from the two functions of interaction discussed previously, namely the ability of talk to provide a context for the adoption of complementary roles and its potential to activate better thinking, that talk does have the potential for providing participants with 
a model of thinking and language processes. There has been significant research in the types of thinking that result from interaction. Researchers are now intent on exploring the conditions under which talk models higher order thinking (Swing and Peterson, 1982; Webb, 1989; Webb et al, 1995) and the conditions under which low achieving students adopt thinking processes of more able peers.

Cumming (1992) showed that writing teachers in his case studies frequently prompted student talk with the aim being "to model individual student's thinking Socratically to demonstrate relevant thinking, rhetorical, or linguistic processes for the whole class" (1992:25). If teachers' talk with students can achieve this modelling, so too can talk between students. Linguistic processes in particular are referred to again in section 3.3.1.

The fact that declarative knowledge as well as procedural knowledge can be modelled in interaction with peers is also addressed in the section below in relation to language development. The present study investigates whether or not declarative and procedural knowledge are modelled through the study of transcript data.

\subsubsection{Talk as relationship with audience}

The claim that talk serves to help students be sensitive to the requirements of an audience is possibly the most significantly argued claim with respect to benefits for writing. However little empirical evidence for the claim exists. Audience awareness has been identified as a particularly significant in the way expert writers differ from novices by a number of writing researchers (see for instance Flower, 1984; Zamel, 1983; 
Kirsch and Roen, 1990; Nystrand, 1990), and, as mentioned previously, one of the contexts for experiencing that difficulty is the writing of argument texts.

Barnes (1976) links audience requirements also to exploratory talk by making the distinction between exploratory talk and final draft talk. $\mathrm{He}$ states:

The distinction between exploratory and final draft is essentially a distinction between different ways in which speech can function in the rehearsing of knowledge. In exploratory talk and writing, the learner himself takes responsibility for the adequacy of his thinking; final-draft talk and writing looks towards external criteria and distant, unknown audiences. Both uses of language have their place in education. (Barnes, 1976: 113-114)

Conversation involves two roles that as a speaker, and that as a listener. The participants in interaction adopt these roles interchangeably. Some theorists (Flower, 1984; Nystrand, 1990) propose that expert writers are in fact able to adopt dual roles, the role of a writer much the same as a speaker in conversation; and the role of reader, similar to a listener in conversation. Mangelsdorf (1989) says:

Achieving appropriate language use involves audience awareness, or moving from writer-based prose (in which writers are mainly addressing themselves) to reader-based prose (in which writers have altered their text to adapt to the needs and expectations of readers). Reader-based prose 'creates a shared language and shared context between writer and reader' while writer-based 
prose often simply reveals the process of the writer's thinking. (p. 137)

Some have extended the notion of a writer's dual role to claim that expert writers in fact carry out a type of internal dialogue. From this viewpoint then, interaction can be seen to model those dialectic processes important for expert writing performance. Scardamalia and Bereiter (1985:309) say however that there is little evidence to show that expert writers do in fact carry out an internal dialogue. Although interaction may then make writers more audience aware and hence improve writing, it does not appear that internal dialogue is needed for expert performance.

As will become evident when discussing the difficulties involved in writing argument texts in Chapter 4 , the function of talk as relationship with audience is one of the major rationales for choosing talk as an intervention for the writing of argument texts.

\subsection{Language-related benefits}

There is little doubt that in general terms, early speaking proficiency provides the foundation for literacy development and academic proficiency. This section begins with a discussion of the role of speaking in literacy development. However more central to the study are the claims made regarding the effects of speaking on second language acquisition. Both general claims and claims made for specific effects are then examined. 


\subsubsection{The role of talk in literacy development}

Significant variations in the type of language interactions that children experience as preschoolers have been well documented and need brief discussion only. Heath's (1983) work is possibly the best known. Heath spent almost ten years studying two working class communities in southeastern United States with the fictitious names, Trackton and Roadville. In Roadville, a white community, parents and caregivers encouraged babies and children into active participation in conversation. They expanded children's utterances and often adopted a teaching type role by focusing on the children speaking correctly and appropriately. In contrast, in Trackton, a black community, babies and young children are not viewed as potential conversational participants.

The work of Wells $(1981,1987)$ in England parallels that of Heath (1983) to some extent. This was also a long term study, conducted over a period of ten years. Wells investigated the consequences that different patterns of interaction were likely to have for children's prospects for success at school. Wells found that differences were closely related to the ease with which children expanded their language to include the use of reading and writing.

Variations in interactional patterns in general and those associated with print lead to different types of speaking proficiency. Speaking proficiency of a particular kind does appear to correlate positively with ability in reading. Different students may have experienced different styles of interaction and ones that are perhaps dysfunctional with the school (Heath, 1983; Wells, 1987; Corson, 1988). In the early years of school, speaking proficiency is the significant skill. Speaking has primacy over 
other skills and contributes to their development. Corson (1988:29) states, "For much of children's first school experience, oral language is the curriculum." The young child learns to talk by talking, as well as learn by talking.

One of the interesting roles that oral language has at this level is to allow young children to verbalise thought. Corson gives the example of children talking books aloud. When doing this, they are learning to 'think' in talk and thus are learning to link thinking with talking (Corson, 1988:56).

\subsubsection{The role of talk in second language acquisition}

In examining the role of talk in second language acquisition, there appear to be several important points of reference, one being the research on the benefits of group work (see for instance Long and Porter, 1985) another being the skill building hypothesis and the last being the output hypothesis (Swain, 1985; Swain, 1995; Swain and Lapkin, 1995).

The research on group work has pointed to the fact that the most salient and positive aspect of peer interaction for NESB (non-English speaking background) learners, is the quantity of input they receive and the increased opportunities they have for language practice. Long and Porter (1985) include the following three in their set of five pedagogical arguments in favour of group work. They claim it increases language practice opportunities, it improves the quality of students' talk, and it helps to individualise instruction. The claims made by Long and Porter relate to the function of group work, the effect of group work, and the pedagogical rationale for talk. This section aims to focus on the functions 
of group work and talk while its proposed effects on aspects of language proficiency are discussed in the following section.

The second point of reference, the skill building hypothesis, relates to the role of talk in providing language practice. According to Krashen (1989), the skill building hypothesis states that rules are first learned consciously and then gradually automatised through practice.

The third point of reference, the output hypothesis, stresses the notion that students must have opportunities to use and practise the language. The quantity of input is not as critical as the quality of output. Swain's claim is essentially that production will aid acquisition only when the learner is pushed. When learners experience communicative failure, they are pushed into making their output more precise and coherent. They move from top-down semantic processing to bottom-up syntactic processing. They are pushed through the clarification requests, and the confirmation checks made by their conversational partner.

Recent developments in the of the output hypothesis (Swain and Lapkin, 1995) have proposed four more specific functions of output in second language acquisition, some of which are not new. Its first function is to enhance fluency through practice. The second is that it allows for hypothesis testing. The third function is to make learners aware of gaps in their knowledge and as a result to trigger the generation of linguistic knowledge that is new or consolidates what the learner already knows. The last function is that it encourages metalinguistic use. 
It appears that writers share views on several of these functions. Many share the view that language practice is an important function of talk. McGroarty (1989:131) for instance states that speaking "provides frequent opportunity for second language practice and negotiation of meaning...". The claim that output enhances fluency through practice is related to Krashen's skill building hypothesis above. It has been investigated empirically and is discussed below in the section on effects.

Many also share the view that talking with a partner also provides a context for hypothesis testing at all linguistic levels as well as at a conceptual level (Corson, 1988). Therefore through interaction with others second language learners in particular can try out hypotheses about the phonemic, grammatical and discourse level of language (Mangelsdorf, 1989). Mangelsdorf states:

When language learners test hypothesises, they adjust their language and ideas according to feedback from their respondentscorrection or affirmation for example. The back-and-forth nature of this kind of language use is similar to a dialogue in which communicators engage in social as well as cognitive interaction. (p. 140)

De Bot (1996) explains how learners come to see gaps in their knowledge and act on those gaps. He says:

To produce, they need to be more active: they need to create communicative intentions and express them in linguistic forms; in so doing they discover what they actually can and cannot do. Noticing a problem is not solving it, but the awareness of a 
problem may lead to more attention to relevant information in the input, given incentives to solve the problem. (p. 551)

The metalinguistic function of talk can be achieved when students talk about language-related problems or language-related observations. De Bot (1996:554) states that when students are put in a communicative situation in which language-related problems are discussed, "through discussion, the students become more aware of the problem and try to solve it together".

The four major claims for the effects of talk on second language acquisition reflect to some extent those made about learning in general: talk operates as exploratory discourse, as a catalyst to change thinking, and as a means of promoting literate thinking (including a metalinguistic function). However what differs is the consideration of the role of talk in providing language practice. The next section considers what evidence exists for the beneficial effects of talk in second language acquisition and where those effects might lie.

\subsubsection{Effects of talk on aspects of second language proficiency}

Immediate effects of repeated opportunities to speak have been investigated by Nation (1989a) and Arevart and Nation (1991). In Arevart and Nation's study, positive effects were seen in grammatical accuracy and complexity when students took part in a speaking technique which required students to repeat the same talk to a partner three times under an increasingly restricted time constraint. This focuses on the role of talk in providing language practice, as the opportunity to articulate in the presence of a peer was important. The response of that peer was not. 
Other language benefits have been hypothesised in specific aspects of language. Corson (1990), for instance claims that talk has a positive effect on vocabulary, particularly Graeco-Latin vocabulary as it provides a context for production. With respect to text organisation, talk may encourage participants to make relationships between ideas explicit, and, because audience requirements are prompted, it is seen to affect writing in the area of communicative effectiveness (Mangelsdorf, 1989:137). The specific effects relate to the ability of talk to facilitate hypothesis testing, to make learners aware of gaps in their knowledge, and consequently to trigger new linguistic knowledge.

The effects of interaction can be examined also on a larger scale by the examination of communicative approaches to language teaching. However, communicative language teaching methods which promote tasks that result in natural interaction, may develop greater fluency and discourse skills but not necessarily more accurate proficiency (Ellis, 1994).

The work mentioned above does not stress the role of a partner's response in interaction, as it primarily stresses the view of talk as practice. The role of the partner's response however has been the focus of study in collaborative learning (see Webb, 1991), and the focus of study by Pica (1988) and Pica, Holliday, Lewis and Morgenthaler (1989) in second language acquisition. Pica (1988) and Pica et al, 1989) have found that learners' output is indeed more grammatical when others (in this case native speakers) request confirmation and particularly clarification. De Bot (1996) interprets Pica's research by saying:

The modifications in the output may have resulted from an allocation of attentional resources that allowed the speaker to 
concentrate on a specific (sometimes form-related) aspects of the language. (p. 533)

In terms of proposing that talk will have an effect on writing, we need to consider research investigating the long term retention of learning from interaction. Nobuyoshi and Ellis (1993) investigated this using two different conditions. The experimental subjects experienced a clarification request every time they produced an utterance containing a past tense error while the control group only received a clarification request when there was a genuine communication breakdown. The latter condition is much more like what participants experience in genuine interaction. After a week, students were again observed in an interactive task. Some, but not all of the learners in the experimental condition, experiencing focused meaning negotiation, maintained the improvements made in the initial session. The control group made no improvements on the first occasion and retained no knowledge.

Ellis summarises the state of this research. He states, "So far there is little hard evidence to support the output hypothesis, although there is sufficient to suggest that it is worth pursuing" (1994:284).

Including a view that talk can provide valuable language practice, adds a dimension to the nature of talk and the conditions under which it is claimed to be effective. The present study takes the view that it is the nature of the responses more than the mere articulation of ideas that may result in both cognitive and language-related benefits. It specifically investigates the nature of the responses made by interactional partners through the transcript data. 


\subsection{Social and affective benefits}

Generally social and affective changes are seen to be an outcome of group work and interaction (Cazden, 1988; Cohen, 1994). Cohen analyses outcomes in terms of 'productivity'. She says "For those researchers concerned with equity, productivity is defined as the occurrence of equalstatus interaction". She adds that productivity may also be defined in terms of desirable prosocial behaviours such as being cooperative or being friendly towards students of a different ethnic or racial group. Related to this type of outcome is a concern for the use of cooperative learning in a multiethnic setting. In this case productivity is defined as positive intergroup relations. (p. 3)

The present study attempts to monitor evidence of these outcomes in the transcript data by firstly analysing the degree to which the interaction of the pairs reflects equal-status interaction, and secondly by identifying aspects of talk that are deemed to fulfil a social and affective function. More general claims related to attitudinal shifts in, for instance, motivation (Long and Porter, 1985; Cazden, 1988) are beyond the scope of this study.

\subsection{Summary}

Cohen (1994) in her opening statement of her review of cooperative learning states:

Cooperative learning has gained increasing acceptance in classrooms... as a strategy for producing learning gains, the development of higher order thinking, prosocial behaviour, 
interracial acceptance, and as a way to manage heterogeneity in classrooms with a wide range of achievement in basic skills. (p. 1)

The sections above have surveyed both the theoretical and empirical bases for aspects of this claim. We know what talk should theoretically achieve. We now need to explore what talk should be like. In attempting to probe the underlying conditions that talk is said to provide when it occurs before writing, it is necessary to seek ways to explain the different aspects of talk. And before ending this section, it is also important to consider some possible limitations of talk and interaction.

\subsection{Exploring the nature of talk}

Little can be explained by thinking of talk as a unitary concept. This is evident from the fact that studies exploring such interventions as group work, opportunities for interaction, and collaborative learning (see for example Cohen, 1994) have found great variability in findings. Some writers have provided interesting and valuable analyses of talk and criteria for effective talk. These are discussed below

\subsubsection{Behaviours during interaction}

Barnes $(1976: 98,99)$ proposes that if talk is to bring advantages, students must "themselves rehearse aloud the demands of the task which they are facing"; they must "put into words what they are doing with the data, and with what purpose"; and finally they must "do so repeatedly in response to questions from someone else". In a sense the three criteria, and in particular the first two that Barnes offers are metacognitive ones. Barnes appears to be claiming that awareness of the procedural aspects of the 
task at hand and the articulation of that awareness is what is important. Interestingly, Barnes does not acknowledge the dialogic nature of talk, the potential for learning declarative knowledge from a partner. Bruffee (1984) and Wells (1989) on the other hand focus on precisely that aspect of talk. They both, in different ways aim to clarify the conditions under which talk can facilitate better thinking and writing.

Bruffee (1984) sets out a distinction between normal and abnormal discourse. Peers working together when beliefs are shared characterise normal discourse while peers working together when their beliefs are different characterise abnormal discourse. Bruffee claims that normal discourse is adequate for clarifying thought but abnormal discourse is necessary for generating new knowledge.

Wells (1989) states that truly critical thinking can be achieved through talk, but talk of a special nature. Wells calls this collaborative talk. He discusses what might be the characteristics of collaborative talk that promotes "the sort of reflective and systematic thinking which is one of the hallmarks of literate behaviour (Wells, 1989:260). The term literate behaviour refers to "all those uses of language in which its symbolic potential is deliberately exploited as a tool for thinking" (Wells, 1989:253).

For talk to promote critical thinking, Wells specifies that the participants must:

- know each other's understanding and intentions

- take the appropriate steps to ensure that mutual understanding is maintained 
- offer opinions and alternative suggestions each from his/her own perspective

- justify and support opinions and suggestions by relevant arguments.

It seems clear that there are particular strategies that facilitate learning by a partner. For instance Webb (1991) makes the point that it is not enough merely for a participant to respond to a peer and in fact receiving responses is not always helpful. The responses that a peer receives need to be matched to the request or the need of the other participant.

For other researchers, particularly language researchers, uptake is the critical outcome of interaction. Slimani (1989) found that neither learner participation or opportunities to negotiate meaning led to uptake. What was critical was when other students topicalised items. Therefore what the listener hears as significant, as indicated by the partner, may prove to be important.

\subsubsection{Task variables}

A number of writers have clearly distinguished tasks that require communication from those which do not (Long, 1989; Nation, 1989b; Cohen, 1994). Tasks which require communication have been referred to in a variety of ways including communicative tasks, two-way tasks, group tasks. Cohen (1994) provides a useful definition:

A group task is a task that requires resources (information, knowledge, heuristic problem solving strategies, materials and skills) that no single individual possesses so that no single individual is likely to solve the problem or accomplish the task objectives without at least some form of input from others. (p. 8) 
Long claims that two-way tasks produce more negotiation work and more useful negotiation work than one-way tasks (1989:13); and that closed tasks produce more negotiation work and more useful negotiation work than open tasks (1989:16). An open task is one in which participants know there is not one single solution whereas a closed task requires participants to reach one single correct solution. Similar to the open task classification is the description of a task as an ill-structured problem. Cohen (1994) claims that interaction is critical to the solving of an illstructured problem. However this is in the context of a group (two-way) task. She explains:

Given a problem with no one right answer and a learning task that will require all students to exchange resources, achievement gains will depend on the frequency of task-related interaction. (p. 8)

The desired outcome of interaction in Long's (1989) view is negotiation of meaning, a crucial factor in second language acquisition. Conversational negotiation of meaning can aid language acquisition as long as the focus of the message is on content. Gaies (1983) however makes the case that students can in fact experience negotiation of meaning in teacherdominated second language classrooms.

Another issue is the matching of task type with desired outcome. Cohen (1994) makes this clear. She states:

For more routine learning, it is necessary for students to help each other to understand what the teacher or the textbook is saying, and it is helpful for them to offer each other substantive and procedural information. For conceptual learning, effective 
interaction should be more of a mutual exchange process in which ideas, hypotheses, strategies, and speculations are shared. (p. 4)

In the present study, it remains to be seen, given the parameters of the sequence of instruction, what type of talk produces benefits.

\subsubsection{Gender and race variables}

Different cultural groups bring with them different conventions for writing and for specific genres, as discussed in the view of literacy as social practice. They also bring with them knowledge and use of different interactional patterns and different expectations regarding the role of interaction. Likewise gender variables are predicted to play a role in the way interaction is managed and talk is used.

The literature on the effect of these two variables in general terms is significant. Cultural variables are often discussed with reference to a particular ethnic group (see for instance Sullivan, 1996) on Vietnamese students). Increasingly, research is being carried out on patterns of interaction in the context of tasks associated with writing (see for instance Johnson, 1992). One of the most comprehensive accounts of the interaction between these two variables in a New Zealand context, is found in Jones (1991).

Ethnicity and gender are considered in this study as potential covariate measures. However what is potentially more informative is to consider possible gender effects in particular when analysing transcript data generated from the pair interaction. 


\subsubsection{Level of proficiency of participants}

The basis on which groups or pairs of students are formed in the classroom for interactive tasks has a significant effect on the what participants are likely to gain from the interaction. Piaget and Vygotsky are possibly two of the most significant educationalists who in proposing theories advocating the use of talk, have also specified the configuration of participants in that talk.

Vygotsky's zone of proximal development is achieved by means of talk with an expert. He assumes that expert to be an adult but does concede that this can be a more expert child. As he states below, the zone of proximal development is,

the distance between the actual developmental level as determined by independent problem solving and the level of potential development as determined through problem solving under adult guidance or in collaboration with more capable peers. (1978: 86)

Therefore Vygotsky's notion of effective talk implies unequal status between participants, one is a novice, the other an expert. In contrast, Piaget's (1950) notion of effective talk is talk among peers who are equal participants in the interaction. The specification of theoretically most beneficial participants can be evaluated by considering research in the area.

In language proficiency terms, Ellis (1994:600) summarises second language research in the area by saying "Not surprisingly, intermediate learners got more input and better quality input from advanced learners than from other intermediate learners. Conversely, advanced learners get 
more opportunity to practise when they are communicating with intermediate learners". This suggests that mixed proficiency pairings may result in better interaction. Similar findings have come from education research. Webb (1991) for instance reports that those students who do the explaining, and who give detailed elaborate explanations in tasks are the ones who benefit. High achievers tend to give more explanations and thus they tend to be the ones to benefit. In the general run of the classroom too, the students with greater language proficiency (Ellis, 1994) and high achieving students (Webb, 1991) are more likely to seek out opportunities for interaction.

Wong-Fillmore's (1982) work supports the above in a negative way. She found that open classes that required more independent work were not good language learning environments when there were large numbers of L2 students. Students with less language proficiency were better to rely on the teacher than on peers. And so, for these students teacher-directed classes provided better language learning opportunities.

Some writers question whether or not one really needs to participate in an interactive task to benefit. Some research suggests that being a passive participant may bring benefits also. Newton (1993) for instance has found that less active participants in an interactive language activity still acquired new vocabulary. Kamler (1980) suggests that just the presence of an audience will bring benefits.

This section has explored the conditions under which talk is said to bring benefits and has looked at the variables underlying effective talk. The discussion suggests that there may be some limitations to talk. Talk will 
not be effective or collaborative (Wells, 1989), unless both participants work to understand each other's viewpoints, respond substantively and appropriately to each other's talk and perhaps also signify to the other what is of importance. Talk will be more effective if students are engaged in tasks which promote negotiation of meaning. This is particularly so in the context of an ill-structured problem as writing is. Talk may also be less beneficial for less proficient students and for female students. Another significant limitation that has already been alluded to is the fact that talk may facilitate some genres but not others, particularly the

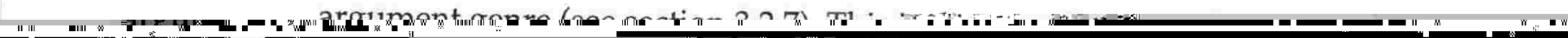

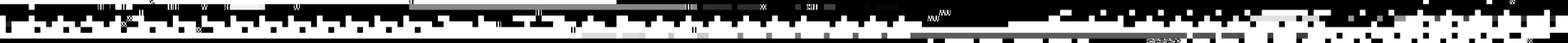
, - -

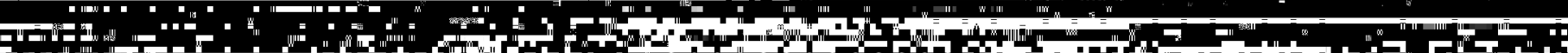
21.

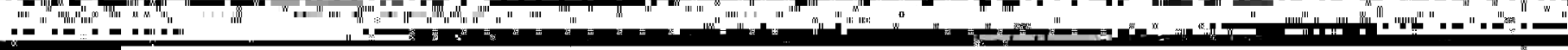

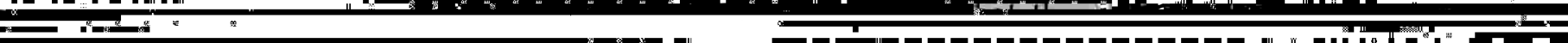
GF." Pre 2

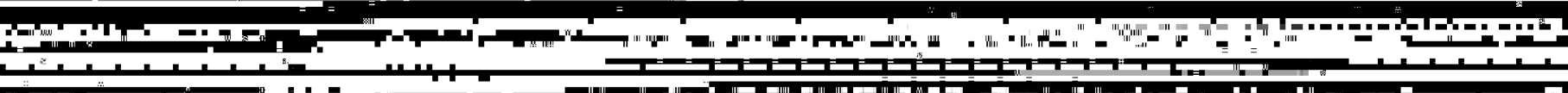

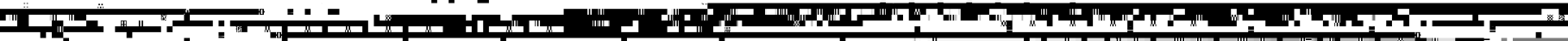

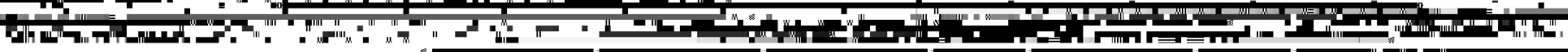

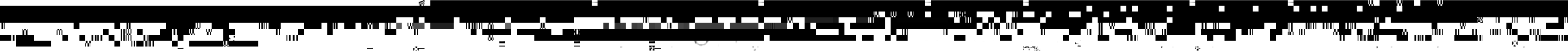

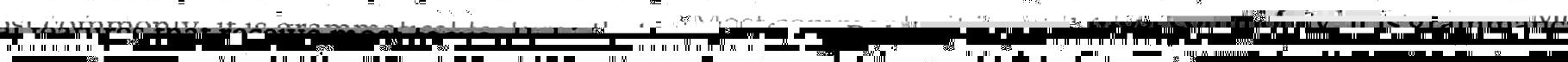

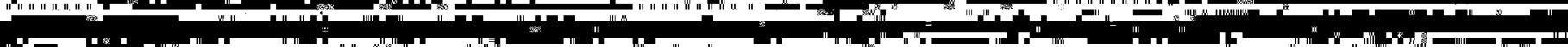

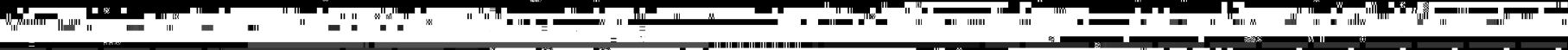
II 
adjusting to modes of expression common to other cultures, for example the kinds of analytical thought processes found in literate cultures.

What is of interest in the present study is the notion of interference or constraints on performance (to represent a more contemporary nomenclature) as this applies within a language and as it applies to the relationship between speaking and writing. Rubin et al. (1990) make the point about developing writers that "a residue of oral communication strategies can interfere with effective writing" (p. 63). Mangelsdorf (1989) states that inexperienced writers can overestimate the reader's ability to understand their ideas and that they will often transfer conventions of speech to their writing where it may be inappropriate.

Some writers have made the distinction between the discourse requirements in the spoken mode and discourse requirements in the written mode (Rumelhart, 1980; Bereiter and Scardamalia, 1982). Bereiter and Scardamalia claim that discourse schemata are open in the context of speaking (the talk is open to modification by the conversational partner) whereas writing invites little participation from an audience as it is generally a solitary activity. Particular discourse types namely information reports and arguments are more open than those such as narratives which are determined by the writer's own agenda. Bereiter and Scardamalia claim that children enter school with a relatively good control of the schemata that underlie oral communication. The transition between the oral and written is least difficult when the discourse requirements of the written mode is closed such as in the case of narrative. Oral narratives are less open than any other oral form and 
therefore the most accessible kind of writing for inexperienced writers. Discourse types like argumentation pose the greatest problem.

Knudsen (1989) reports that children will most readily transfer oral discourse schemata when the requirements of the writing task are closed. The greatest difficulty for writers occurs when the discourse requirements for writing are open. In the context of both the oral and written discourse schemata being open, the requirements are not the same (although they appear so). They cannot be transferred and need to be relearned.

The relative success of particular techniques in improving writing may be due to the fact that they close the discourse requirements of the writing task to some extent. Knudsen, (1989) for example, when re-evaluating the techniques which Hillocks (1984) identified as being effective, offered an analysis of closed discourse requirements to explain why the use of models was successful. Clearly the area of discourse modification from speech to writing is important but so too are the areas of modification of language forms and the use of composing strategies (Cumming, 1989). The methods combined with speaking to do this, include studying model texts and setting criteria, and using cue cards as outlined in the following chapter.

It may be that the speaking tasks that precede writing need to be closely aligned with the demands of the writing task. Therefore we may need to consider talk not as a separate variable but in its interaction with tasks in the instructional sequence 


\subsection{Studying the effect of talk on writing}

Little empirical research investigating the effects of speaking on writing exists to date. Sweigert's (1991) study is in fact one of the first to directly measure the effect of speaking on the quality of the writing produced by students. Sweigert's study concluded that students who participated in small group discussion (contrasted with class discussion or listening to a lecture) produced better opinion essays in terms of ideas and organisation, were better able to remain on task and were generally more positive about the prewriting activity. Sweigert's study did not examine the conditions and the nature of the talk that could explain these findings.

Investigating a correlational or causative relationship between speaking and writing is potentially problematic. There is the question of what constitutes talk and what constitutes worthwhile talk. Stables (1995:66) discusses the notion that what passes for group work in most classrooms clearly is not. Students may sit in a group but not be engaging in any useful collaborative work. They may be in a friendship group and their interest may be largely "social and ephemeral" (Stables 1995:66).

\subsection{Conclusion}

Many writers (Britton et al., 1975; Barnes, 1976; Applebee, 1984; Corson, 1988) have concluded that there are not sufficient oral language opportunities in school classrooms and that the opportunities that do exist for language practice neither enhance learning nor the production of text. These observations, together with the literature relating to the teaching of language across the curriculum, to pedagogies for writing (in particular those relating to prewriting activities), and to the factors 
accounting for writing expertise, suggest that students would benefit from a more frequent use of tasks to prepare them for writing in content areas, and the utilisation of peers as support for content learning and writing.

The specific hypotheses that guide the research study are that firstly opportunities to engage in talk of a particular kind will result in better texts which meet the requirements of the task in terms of content and genre, and secondly better processes which demonstrate awareness and use of appropriate strategies relating to content and genre. The talk of "a particular kind" is not true group work talk as defined by Cohen (1994:3), as students can and do participate in the instructional sequence on their own. However the talk is combined with a focus on language forms, discourse forms, and strategy modelling as described in the following chapter outlining the features of the instructional sequence. 


\section{FEATURES OF THE INSTRUCTIONAL SEQUENCE}

\subsection{Introduction}

The study is situated in the context of a classroom programme in the subject of English at the sixth form level (grade 12) of a local New Zealand high school. The programme was for NESB students who needed English for study purposes and for the purposes of passing an entry test for university study (IELTS). As such it was not the same as a regular mainstream sixth form English class although the students were expected to cover the sixth form English curriculum programme the following year. The programme that constituted the experimental study needed to reflect the aims and goals of the teacher with respect to these students. It also needed to reflect principles of language across the curriculum, it needed to tie in with the type of assessment tasks they would be faced with in IELTS, and it needed to have a basis in the English curriculum document, English in the New Zealand Curriculum (1994).

In addition to the requirements above, it needed to fulfil the specific aims as part of the study. Also set out in Chapter 1, these were:

- to develop knowledge and use of appropriate conventions for the argument genre

- to encourage the development and use of critical skills which students apply to the texts of others as well as their own texts

- to encourage writing that is creative, critical, and reflective

- to use speaking in a way that facilitates the development and use of the above. 
This chapter will describe the features of the sequence of instruction that formed the basis of the programme for the study. It will begin with the choice of genre that students were required to write, which was argument. It will go on to present the stages in the sequence of instruction and discuss what was hoped to be achieved at each stage.

\subsection{The choice of the argument genre}

Argument has been the subject of much study, in terms of analysis, in terms of development, and in terms of pedagogical intervention. There are two major reasons why argument was the genre chosen for investigation in the study. The first of these is the fact that argument is viewed as a critical genre in the school curriculum (see English in the New Zealand Curriculum, 1994). McCann (1989) sums up its importance in the statement below.

Argument is a complex activity which often incorporates many of the other writing tasks stressed in a composition course. Its position as a culminating activity for courses of study indicates how highly regarded argument is. In a very narrow sense, argument is an important tool for students who face the task of writing dozens of lengthy papers before finishing their college careers. In a broader sense, argument is an essential instrument for a free society that deliberates about social, political, and ethical issues. (p. 62)

The second factor the choice of argument for the study relates to the difficulty that the students have in gaining control over the genre. Many studies investigating students' ability to write argument texts have 
illustrated difficulties across a range of age levels (McCann, 1989, Knudsen, 1992a, 1992b). McCann (1989) reports NAEP (National Assessment of Educational Progress) results from the USA in the decade 1970-1980, which reveal that "students have much more difficulty with persuasive writing tasks, which involve argument, than with narrative, descriptive, or expository tasks" (McCann, 1989:62). No more than 20\% of students were rated as competent or better in the ten year survey across three age levels, 9, 13 and 17 year olds (McCann, 1989). Argument is also a genre that is included in the IEA (International Association for the Evaluation of Educational Achievement) surveys of writing ability conducted in fourteen countries. The Elley Report (Elley, 1991) points to particular difficulties experienced by high school students in New Zealand schools as compared with performance by peers in other countries.

\subsubsection{Explanations of difficulty}

Explanations relating to the fact that children appear to have control over other genres earlier than they do argument, are primarily social, sociocognitive or linguistic. It is claimed that unlike argument, other genres particularly narratives and recounts are often practised and listened to in the course of daily communication. McCann (1989:63) hypothesises "Perhaps the features of formal argument cannot be learned as readily from daily oral interchanges". Bereiter and Scardamalia (1982) have a similar view when they argue that children have not developed the appropriate discourse schemata for writing argument texts.

A further issue with respect to discourse schemata is the hypothesised difference between the structure of schemata for speaking and writing in 
relation to the degree of 'openness' or 'closedness' (Rumelhart, 1980). In the case of argument, oral discourse is open to some extent as there are new inputs from a conversational partner. However, argues Knudsen (1989), in written argumentation, the discourse schemata are closed. Therefore, learners find it difficult to move from oral argument to written argument (see also section 3.6.5).

Scardamalia and Bereiter (1987) express this problem in terms of the cognitive demands of speaking as opposed to writing. They state:

The large problem faced by beginning writers is that of converting a language production system developed for conversation, a system independent at every level on inputs from the social environment, to a system capable of functioning autonomously. (p.150)

This could also be considered a socio-cognitive explanation, as it accounts for the social context and role of participants. Another sociocognitive argument is one that claims that students are not developmentally ready to deal with the genre because of the fact that it requires a stronger focus on audience than is required when writing other genres (Berkenkotter, 1981). As Hays, Durham, Brandt and Raitz (1990) state,

In argumentation, a writer's readers embody to varying degrees viewpoints different from those of the writer and thus challenge her to support her view to someone else and, at more mature levels of thinking, modify it in the process of this 'dialogue'. (p.249) 
Writers who are able to do this, operate in a way that is described as dialogic, which in summary refers to the ability of a writer "to interact with and negotiate among varying perspectives" (Hays et al, 1990:250; Dyson, 1992). It is precisely this demand that suggests that working with a partner in a particular way may result in the production of a better argument text, the major contention examined in the present study.

Hays et al (1990) argue that a writer's ability to do this is determined by social and cultural experience and socio-cognitive development. They report on a study looking at the interaction between assessed sociocognitive level in students' texts, overall text quality, as well as measures of audience sensitive features. Higher levels of socio-cognitive development were statistically related to both of these variables suggesting that socio-cognitive development needs to be a factor explaining the difficulty of writing argument texts.

Martin (1989) describes the process of learning to write argument texts as one in which learners must increasingly gain control of a linguistic process, the expression of grammatical metaphor. Martin (1989:32) says "Children need to learn to produce grammatical metaphors if they are to write convincing Expositions". By grammatical metaphor, what is meant is that the form of the utterance is not a direct expression of its meaning. So for instance instead of using a verb to express feeling such as 'I am concerned', the writer uses a noun, 'I would like to express my concern'. One of the major processes in grammatical metaphor, as can be seen from the example above is nominalisation. While writing makes great use of grammatical metaphor, speaking uses more direct terms. Grammatical metaphor is then a feature of written rather than spoken argument. 
Like several other writers (for example Heath, 1982), Martin places argument at the far end of a theorised continuum, represented by speaking at one end and writing at the other. The continuum is defined by aspects of linguistic form. This position is reminiscent of an autonomous model of literacy. If it is true that writing has exclusive forms that are not shared by speaking, it seems less likely that speaking is a potential linguistic support for writing.

It must be acknowledged from the surveys and studies mentioned above that there are difficulties and complexities associated with learning to write argument texts. The arguments in the research focus on the fact that there is a significant difference between spoken language and written argument. This distance requires learners to modify existing schemata and add new ones, to learn new linguistic forms of expression, to take on a hypothetical audience and to negotiate between the viewpoints which that hypothetical audience may hold. Despite the fact that this requires a level of socio-cognitive maturity, this study maintains that the presence of a peer who adopts the role of an audience and a collaborator will make the task of writing argument texts easier.

\subsubsection{Responses to reported difficulty}

The results of surveying writing performance are often used to benchmark developmental competence. In other words, results of surveys serve to demonstrate what students cannot do - that students cannot, for instance, write a coherent argument at 11 years of age. This leads to the issue of appropriate curriculum planning raised by McCann (1989:71). Should curriculum planning be constrained by developmental interpretations from surveys focusing on difficulties with the genre? We 
do need to remember that writing tasks carried out by students for surveys are often set out of meaningful contexts, and performance is therefore affected. It may be that control over the argument genre is particularly dependent on intervention not developmental constraints, a point of view developed in the present study.

Intervention for the writing of argument texts has recently been the subject of a number of published studies: McCann (1989), Knudsen (1989, 1992a, 1992b), Carrell and Connor (1990), Johns (1993) and an edited volume of papers (Costello and Mitchell, 1995). Knudsen (1989) makes an interesting comment about the state of knowledge of effective intervention:

Although effective instructional strategies have been identified with respect to narrative writing (Scardamalia and Bereiter, 1986), research efforts have not been as successful in determining the effectiveness of instructional strategies in teaching knowledge of other discourse modes, specifically argumentative-persuasive writing and informational-expository writing. (p.92)

Knudsen's (1989) study is of the greatest relevance to the present study as it has explored the very options considered for this study. Guided by the outcomes of Hillocks's (1984) study, Knudsen (1989) contrasted four possible intervention options including the presentation of text models, scales (sets of criteria for a writing outcome), a combination of the above, and free writing. She found that the first option, working with text models before writing, was most effective in producing better argument texts as measured holistically. Both text models and scales (found to be effective 
in the meta-analysis used by Hillocks, 1984) were used in the sequence of instruction for this study.

In summary, any intervention needs to consider the difficulties and complexities associated with the writing of argument texts. Possibly the most significant explanation of difficulty is that of audience requirements for argument, the fact that writers must take on and represent various viewpoints. As Knudsen (1992b:168) points out, "One reason why children have difficulty with argumentation is their lack of awareness of how to generate an argument text without input from a conversational partner... the conversational partner is absent in written composition". This study is interested in establishing what happens when a conversational partner is present.

\subsection{Descriptions of the argument genre}

The section above has explored the difficulties and complexities associated with the argument genre. Part of understanding the difficulties and complexities involves knowing what it is we are dealing with. Part of planning an intervention and testing its effects is knowing how we can formally recognise a 'good' argument text, and knowing how we can plan dependent variables that relate to a formal description. To this end, the following section examines models that attempt to describe the genre.

\subsubsection{Toulmin's analysis}

Toulmin's (1958) and Toulmin, Rieke and Janki's (1984) analyses of argumentation has served as the basis for many subsequent studies, and serves as the basis for this study too. The following discussion aims to 
clarify the structure of argumentation as described by Toulmin et al and as modified by others. It also briefly mentions other descriptions of argumentation.

Toulmin (1958) and Toulmin et al's (1984) description of argument (see Figure 1) consists primarily of the identification of parts or constituents. Figure one lists the five constituents, the type of question each constituent responds to and where possible gives an indication of examples and possible realisations. 
Figure 1 Toulmin et al's (1979) analysis of argument

\begin{tabular}{|l|l|l|}
\hline Constituents & Question & Examples and realisations \\
\hline Claim & What is your position? & $\begin{array}{l}\text { Statement of belief, opinion or } \\
\text { position }\end{array}$ \\
\hline Data or Grounds & $\begin{array}{l}\text { What information are } \\
\text { you going on? }\end{array}$ & $\begin{array}{l}\text { Experimental observations, common } \\
\text { knowledge, statistical data, } \\
\text { personal testimony, previously } \\
\text { established claims }\end{array}$ \\
\hline Warrants & $\begin{array}{l}\text { How do you justify the } \\
\text { move from these } \\
\text { grounds to that claim? }\end{array}$ & $\begin{array}{l}\text { The relationship may not be } \\
\text { explicitly marked, or may be eg } \\
\text { If D, then C. } \\
\text { Data such as D entitle one to draw } \\
\text { conclusions, or make claims, such as } \\
\text { C. } \\
\text { Given data D, one may take it that } \\
\text { C. }\end{array}$ \\
\hline $\begin{array}{l}\text { Modal qualifiers } \\
\text { and rebuttals }\end{array}$ & $\begin{array}{l}\text { How certain are you? } \\
\text { What might the } \\
\text { counterarguments be? }\end{array}$ & $\begin{array}{l}\text { Expressions of degrees of certainty eg } \\
\text { Without a doubt } \\
\text { Acknowlegements of other arguments } \\
\text { eg } \\
\text { Others may disagree ... } \\
\text { Although there is some truth in the } \\
\text { statement, ... }\end{array}$ \\
\hline Backing & $\begin{array}{l}\text { You presume the above } \\
\text { but why do you? }\end{array}$ & $\begin{array}{l}\text { eg Scientific evidence supports the } \\
\text { claim that ... }\end{array}$ \\
\hline
\end{tabular}

The five constituents identified by Toulmin are claims, data or grounds warrants, modal qualifiers or rebuttals, and backing. A claim is the expression of the opinion of the writer and defines the starting point for the argument. The data or grounds are the facts we appeal to as foundation for the claim. For data to operate successfully the condition of relevance must be met. Warrants act as "bridges, and authorise the sort of step to which our particular argument commits us" (Toulmin, 1958:98). Toulmin states (1958:100) "...the warrant is, in a sense, incidental and explanatory, its task being simply to register explicitly the legitimacy of the step involved...". Toulmin (1958) himself acknowledges a problem 
with distinguishing warrants from data. The problem of specifying warrants appears to arise because Toulmin is a logician. Logicians are interested in specifying the relationship between propositions in an explicit way. As researchers in writing and discourse analysis (Halliday and Hasan, 1976; Coe, 1988) have stated, relationships between propositions do not always need to be explicitly signalled in writing and instantiated by means of a sentence or phrase. Sometimes the mere juxtaposition of propositions and the coherence achieved through lexical items for instance is sufficient for there to be a perceived relationship. Qualifiers indicate the extent to which we can make the connection between data and claim given the warrant. The rebuttal indicates circumstances in which the authority of the warrant would have to be set aside. Backing refers to the general body of information that is presupposed by the warrant appealed to in the argument.

In the system of analysis chosen for the study, it was decided to focus on claims and grounds or data as the most important and easily identifiable constituents. Warrants and modal qualifiers were incorporated with the claims or grounds with which they were associated. Rebuttals were considered as counter-claims or counter-grounds and therefore were classified as claims and grounds. Although it was considered as a viable semantic unit, the constituent, backing, never appeared in students' texts.

Toulmin et al's (1984) description acknowledges the hierarchical nature of text as they state that claims can operate at different levels of the texts, as for instance when subclaims are tied to the main claim. Two of the dependent variables for the study were in fact the elaboration of claims and the elaboration of grounds, both of which attempt to quantify the 
notion of elaboration implicit in a hierarchy. This is another reason why Toulmin et al's description was chosen to guide the analysis of texts in this study.

As stated above Toulmin and his colleagues are logicians. Toulmin himself however identifies himself as a logician interested in 'working logic' rather than 'idealised logic'. He states, "Unfortunately an idealised logic, such as the mathematical model leads us to, cannot keep in serious contact with its practical application" (Toulmin, 1958:147). Toulmin's model itself requires modification for those interested in using it as an analytical tool, rather than merely as a way to specify standards on a scale as in the case of McCann (1989), Knudsen, (1992a, 1992b). Section 5.8.2.3. describes other applications of Toulmin and Toulmin et al's description.

\subsubsection{Other descriptions of argument text structure}

In the discussion of genre based approaches in section 1.3.4, the Australian view stemming from Hallidayan functional systemic linguistics was given prominence. This section, in describing how argument texts are structured also draws on this source.

Hyland's (1990) description will be detailed as it is representative of other functional systemic descriptions, for example Derewianka (1990). Hyland (1990) describes what he calls the argumentative essay as a threestage structure composed of a series of moves, some of which are optional. The model is outlined below. Optional elements are marked by parentheses. 
Figure 2 Hyland's (1990) description of the argumentative essay

\begin{tabular}{|c|c|c|}
\hline Stage & \multicolumn{2}{|c|}{ Move and explanation } \\
\hline Thesis & $\begin{array}{l}\text { (Gambit) } \\
\text { (Information) } \\
\text { Proposition } \\
\text { (Evaluation) } \\
\text { (Marker) }\end{array}$ & $\begin{array}{l}\text { controversial or dramatic statement } \\
\text { background material } \\
\text { states writer's position and delimits topic } \\
\text { brief support of proposition } \\
\text { introduces and/or identifies a list }\end{array}$ \\
\hline Argument & $\begin{array}{l}\text { Marker } \\
\text { (Restatement) } \\
\text { Claim }\end{array}$ & $\begin{array}{l}\text { signals the claim and relates it to the text } \\
\text { rephrasing or repetition of the proposition } \\
\text { reason for acceptance of the proposition eg } \\
\text { (a) strength of perceived shared assumptions } \\
\text { (b) generalisation based on data or evidence } \\
\text { (c) force of conviction } \\
\text { grounds that underpin the claim eg } \\
\text { (a) assumptions used to make the claim } \\
\text { (b) data or references }\end{array}$ \\
\hline Conclusion & $\begin{array}{l}\text { (Marker) } \\
\text { Consolidation } \\
\text { (Affirmation) } \\
\text { (Close) } \\
\end{array}$ & $\begin{array}{l}\text { signals conclusion boundary } \\
\text { relates argument to proposition } \\
\text { restates proposition } \\
\text { widens context or perspective of proposition }\end{array}$ \\
\hline
\end{tabular}

The table above from Hyland (1990) shows that five constituents are obligatory for an argument text: the proposition, the marker, the claim, support for that claim, and consolidation. The following equivalents exist between the above analysis and the analysis of Toulmin et al: the proposition is equivalent to the claim; the claim is equivalent to warrants; support is equivalent to grounds, and consolidation is equivalent to the claim. On this basis, it could be argued that Hyland is merely providing a further classification for propositions operating as claims. Arguably, it is 
only the proposition or claim and the support of that claim that is obligatory.

An aspect that works against the adoption of Hyland's model is that it appears too rigid and formalistic. In a study such as this, students write ill-formed texts and rarely is there a three part structure with thesis, argument and conclusion overlying the constituents. In fact even some well-formed texts do not conform to this pattern.

Interesting and important to mention is the work of Johns (1993). The paper presents an investigation of the structure and associated language conventions of argument texts in the specialised context of engineering. Johns interviewed successful grant writers in the field in order to analyse both the processes employed and their beliefs about the form of successful grant applications. Using Toulmin's (1958) categories of constituents, claims and data, she documented how these categories or constituents were understood to be formulated by the expert writers. Claims, for instance, were written in exact scientific terms. As an example she cites, "We propose to use this new [sic] developed $\mathrm{H}_{2} \mathrm{O}$ detection method to measure the rate constant for the $\mathrm{H}_{2} \mathrm{O}+\mathrm{O}_{3}$ reaction" (1993:82). As a consequence of the domain, most of the data appeared as mathematical formulas, supported by tables, figures and illustrations (1993:83).

Conventions of argument texts in the specialised context of engineering differ from those appropriate for senior level high school writing in more general areas across the curriculum. Nonetheless the process of 
questioning experts is interesting and valuable as a way of establishing conventions for a particular genre.

\subsection{Types of argument texts}

Martin (1989) makes a functional distinction in what we have to date been calling argument. He suggests that there are two categories of argument or in his terms 'exposition'. There is hortatory exposition and analytical exposition. Hortatory exposition has as its function to 'persuade to' while analytical exposition 'persuades that'. Analytical exposition is more typical of lectures, essays, and examination answers and is predominantly carried out in written mode. It is also the type of argument that features in this study. Hortatory exposition, by contrast, is more commonly found in letters to the editor, sermons, and political speeches and can be both spoken or written but tends to have the features of spoken language, such as less lexical density (Martin, 1989:27-29).

\subsection{Summary}

The planning of the intervention and the sequence of instruction, was done with primary reference to the work of Toulmin (1958) and Toulmin et al (1984). This work provides a model of argument that is dynamic, hierarchical and based on semantic elements or constituents. In terms of formally recognising a 'good' argument text and thus being able to test the effects of the intervention, Toulmin and Toulmin et al's model guided the design of the dependent variables. The process of designing the dependent variables is discussed in detail in Chapter 5. This chapter continues with a description of the instructional sequence. 


\subsection{Stages of the instructional sequence}

The instructional sequence is set out below in Figure 3 below. The task requirements explain what students were expected to do at each stage. For further illustration, sample instructional materials are given in Appendix 1. Note that tasks one and two changed order after week two of the programme when reading resources were introduced.

Before presenting the sequence of instruction below, it is necessary to clarify some points relating to the implementation of the programme and the way in which students were prepared for the tasks. Before the programme began, two sessions of writing were carried out by the students. Although the primary purpose of this was to generate potential covariate data, it was also an opportunity to present students with the type of tasks, topics, and acitivities they would be expected to engage in. The activities not included at these times, (analysing a sample text to establish criteria for the genre, checking one's own writing against the criteria, and using cues cards) were modelled at the beginning of the programme to all students together. In addition to this preparation, the beginning of each topic was proceeded by a very general discussion of points that the researcher had noticed while reviewing the students' progress. This variously covered aspects of language or text organisation. 
Figure 3 The stages of the instructional sequence

\begin{tabular}{|l|l|}
\hline Stages & Task requirements \\
\hline $\begin{array}{l}1 \text { Articulating knowledge } \\
\text { and claiming a thesis }\end{array}$ & $\begin{array}{l}\text { The first task required students to think about and } \\
\text { note down what they already knew about the } \\
\text { assigned topic. If working with a peer they were } \\
\text { required to share their thinking with that peer. }\end{array}$ \\
\hline $\begin{array}{l}2 \text { Analysing a sample text } \\
\text { to establish criteria for } \\
\text { the genre }\end{array}$ & $\begin{array}{l}\text { Students were required to read an argument text and } \\
\text { identify the features of the text that made it a good } \\
\text { example of the genre. The features they identified } \\
\text { were listed on the right of the text and later served } \\
\text { as criteria for their own writing. If working with a } \\
\text { peer, they generated the list together or shared the } \\
\text { lists they had compiled. }\end{array}$ \\
\hline $\begin{array}{l}3 \text { Information } \\
\text { gathering/organising }\end{array}$ & $\begin{array}{l}\text { Students were required to generate ideas for the } \\
\text { topic and map this information. If working with a } \\
\text { partner, they mapped together or shared their } \\
\text { maps. }\end{array}$ \\
\hline $\begin{array}{l}4 \text { Composing } \\
\text { argument }\end{array}$ & $\begin{array}{l}\text { While composing students had to make regular } \\
\text { reference to a cue card. If working with a partner, } \\
\text { the partner selected and read a cue after reading the } \\
\text { other's text. }\end{array}$ \\
\hline $\begin{array}{l}5 \text { Checking against the } \\
\text { criteria for the genre }\end{array}$ & $\begin{array}{l}\text { Students checked their own writing against the } \\
\text { criteria they had identified in task two. If working } \\
\text { with a partner, the partner was shown the criteria. }\end{array}$ \\
\hline $\begin{array}{l}\text { Students had time to revise their texts. Both groups } \\
\text { did this in a solitary manner. }\end{array}$ \\
\hline $\begin{array}{l}\text { Students presented their argument without reference } \\
\text { to their written texts. If working with a partner, the } \\
\text { partner listened to their argument. If working alone, } \\
\text { the teacher was the audience for this stage. }\end{array}$ \\
\hline
\end{tabular}

The sequence of tasks reflects the aims stated in the introduction of this chapter, which were to develop knowledge and use of appropriate conventions for the argument genre, to encourage the development and use of critical skills which students apply to the texts of others as well as their own texts and to encourage writing that is creative, critical and 
reflective. The aims in fact describe a level of expertise (Carter, 1990) which, in order to be attained, requires different types of procedural knowledge, background knowledge, domain-specific knowledge, linguistic knowledge and metalinguistic knowledge (as defined by Alexander, Schallert and Hare, 1991).

The stages of the instructional sequence allow for the development and use of general procedural knowledge by covering aspects of a generalisable writing procedure, namely by establishing opportunities for telling or writing down what the students already know about a topic (task one), and for brainstorming and organising ideas which may encourage the integration of background and new knowledge gained from a partner and/or through reading the resource material (task three). The organisation of ideas is facilitated by means of mapping, seen to be useful in producing well organised essays (Robinson and Kiewra, 1995). There is also opportunity for the students to review their texts and to make changes.

The sequence of instruction also encourages the development of procedural knowledge that is specific to the writing of argument texts. By studying model texts and generalising their observations to formulate criteria, students can gain knowledge of how to write an effective argument. The act of formulating criteria, either on one's own or with a partner requires metalinguistic knowledge and reinforces metacognitive learning (Smagorinsky and Smith, 1992; Rubin et al, 1990). Tasks two and five in fact combine two of the intervention options studied by Hillocks (1984) and Knudsen (1989) and are aimed to produce a strong positive effect. 
The use of the cue card used while composing (task four), is likewise seen to develop specific procedural knowledge. It models a type of generating activity and when responded to, actually generates domain-specific knowledge. The cue card, derived from Scardamalia and Bereiter (1985), is claimed by them to be a way of facilitating reflective thought for writing.

It can be seen that the sequence of instruction includes a focus on content or domain-specific knowledge and on procedural knowledge both specific and general. The fact that these two concerns are combined and integrated in the sequence recognises the work of researchers such as Alexander and Judy (1988) and Perkins and Salomon (1989) whose belief it is that strategic knowledge (an 'effortful' type of procedural knowledge) is important in utilising domain-specific knowledge in learning.

\subsection{Conclusion}

The sequence of instruction follows through the types of tasks that aim to develop general process skills, eg brainstorming, organising ideas, writing and reviewing. As such it can be said to have a cognitivist viewpoint (Johns, 1990). However its concerns are also focused on the use and development of appropriate conventions of the argument genre. Students set criteria for good argument texts, they use those criteria as checklists for their own writing and they use argument-specific cue cards to assist their writing. The programme therefore also reflects a social constructivist viewpoint. 
Lastly and most importantly, the belief that interaction will bring positive benefits situates the study in an interactive approach. An interactive approach is one which views the writer as a person involved in a dialogue with an audience, which may be the writer him/herself or another. "In this approach, text is what an individual creates through a dialogue with another conversant; thus both the writer and the reader take responsibility for a coherent text" (Johns, 1990:27). The following chapter sets out how the belief in an interactive approach was examined empirically. 


\section{METHODOLOGY}

\subsection{Introduction}

The study investigated whether the opportunity to talk with a peer before and during writing positively affected written texts that students produced. This treatment contrasted with a solitary approach to the prewriting and writing phases of the instructional sequence. The specific research questions are as follows:

1. Does an instructional cycle that provides opportunities for talk of a particular kind lead to a better text than an instructional cycle that contains little or no opportunities for talk?

2. What type of effect do opportunities for talk have on the quality of argument texts produced?

3. What is the nature of the talk that best facilitates the production of argument texts?

\subsection{Target Group}

Careful consideration was given to choosing the target group for the research. Reference was made to English in the New Zealand Curriculum (Ministry of Education, 1994) where, by approximately Form Six, students are expected to be able to "debate a proposition or point of view, structuring well researched material effectively, in appropriate styles for different audiences, in a range of authentic contexts" (1994:35). It could reasonably be expected that students working at this level have basic control over the argument genre and that it would be appropriate to focus on refinement and elaboration of argument. Thus Form Six was 
chosen as the target curriculum level because goals relating to refinement and particularly elaboration were integral to the proposed instructional programme and to the hypotheses being tested by the research design. Another factor that supported this decision was that sixth formers and their teachers have some flexibility in the curriculum. They are between major examinations and hence were expected to be more receptive to a module of work that may deviate from conventional writing modules.

\subsection{Participants}

The selection of a school, a teacher, and a class was approached by asking for volunteers from a group of high school teachers all of whom were participating in a language across the curriculum teacher development programme in the Auckland region. Volunteers were asked to have access to, or be teaching an intact class of students who were first language speakers of languages other than English.

Details of the proposed research design were explained to prospective volunteers. This included the fact that the programme would involve approximately three to four hours of class time per week for eight weeks and that the teacher would be expected to work on the programme with the researcher.

A school, a teacher, and a class for whom these conditions were not too difficult to meet, was found. The class teacher indicated willingness and enthusiasm to participate in the study. Likewise all the students indicated willingness to participate. Student and parent or caregiver consent was obtained before the study commenced. Additionally, a 
number of other steps were taken to ensure that the research was conducted in an ethical manner. The school was informed about and asked to comment on the research design, the school was given a copy of a published paper (Franken, 1994) which set out the instructional procedure, and student participants and the teacher were assured of confidentiality. Ethical considerations were monitored with reference to a list of ethical rules for school-based research from Hitchcock and Hughes (1995: 51-52).

\subsubsection{The students}

The twenty students who acted as subjects for the study came from a mixed sex Form 6 class at an Auckland high school. As such they were an intact group for data gathering purposes.

The majority of students were from Asia: Taiwan, Hong Kong, Malaysia and Korea. The remaining subjects were from India, Mexico, Macedonia and Fiji.

The teacher had collected a significant amount of information on the students which supplemented that collected by the researcher in the two initial pretest sessions. Relevant background information on the subjects is summarised in Appendix 2.1. This includes information on age, ethnicity, and years studying English.

As the students had particular needs related to second language learning, they were considered to be an ESL class. As such, the students had the mainstream English programme modified in order prepare them for the IELTS (International Language Testing Service) test, the results of which 
could be used to support an application to enter a New Zealand university either at the end of the current year or at the end of the following year. The IELTS test is one of two tests used by New Zealand universities to screen admissions of overseas students on language proficiency grounds. Most of the students therefore saw themselves in need of English instruction in preparation for the IELTS test and to help them in other areas of the curriculum.

The regular programme operated on a modular basis covering different kinds of academic skills: listening, reading, speaking, and writing. The present study fitted into the programme as the academic writing module for semester one.

\subsubsection{The teachers}

The teaching on the programme was carried out by the class teacher and the researcher. The class teacher was experienced and had had both TESOL (teaching English to speakers of other languages) and LAC (language across the curriculum) training. She had volunteered to participate in the programme and hence was assumed to be sympathetic and supportive of the programme.

As mentioned above, the school, including the class teacher, was aware of the aims of the research and the instructional programme. Prior to the commencement of the programme, the researcher met with the teacher to brief her on the instructional procedure in detail. Later, after the pretest sessions, the teacher was also consulted about the ranking of the students and the subsequent allocation to groups. Throughout the programme, the teacher and the researcher met on a weekly basis to discuss general 
progress in the programme, the upcoming topic, and arrangements for dealing with problems such as student absences. Catch-up sessions for the occasional absentee were administered by the researcher. Thus no gaps in the data occurred as a result of absenteeism.

\subsection{Allocation to group}

The study required there to be two parallel groups, group 1 and group 2 . In order to do this, two pretests were administered. The pretest data are included in Appendix 2.2. together with other baseline language proficiency information.

The class was ranked in terms of the quality of the argument texts that they wrote in the pretest sessions. The texts were rated according to Toulmin's analytical categories for argument texts (as modified by McCann, 1989) and a holistic measure of quality of argument text based on the model proposed by Knudsen (1992a, 1992b) (see Appendix 3.2). The shortcomings of these methods of analysing argument texts for use as dependent variables are discussed later in section 5.8.2.3. However, they did serve the purpose of ranking students on argument text writing.

The scores on both types of measures for the texts written in the two pretest sessions were summed, converted to $\mathrm{z}$ scores, and ranked. From the rank ordered list, pairs with closely aligned scores were formed and then randomly assigned to one of two groups. Means were calculated for the summed scores of each group. Group 1 scores showed a mean of 35.8 whereas group 2 had a mean of 36.5 (see Appendix 2.2). Language proficiency data that was both relatively recent and gathered at the same 
time for all students was used to confirm the essential parity of the two groups.

\subsection{Forming pairs}

On alternative weeks, groups 1 and 2 worked with a partner from within their groups. The principle guiding the pairing of students needed to be considered carefully. Were the students to form their own pairs or were the researcher and class teacher to do this?

Stables (1995:66) points out the dangers of students working perpetually in friendship groups. They are potentially disruptive, and students' concerns may be focused on the social rather than the academic. Such groups also do not represent the reality of collaboration in out-of-school contexts where people may have to work with those they would not necessarily choose to work with. "Education must be about learning to work with others, including those we do not choose" (Stables, 1995:66). Although the concerns that Stables raises are valid, it is also the case that students may feel more motivated and are more inclined to talk with selfchosen partners.

To address both sides of the issue, a compromise position was adopted. Initially students were free to choose a friend to work with and therefore the first pairs were self-chosen friendship dyads. However, on occasions after the first, when students worked collaboratively, they were asked to choose a partner who differed from the one chosen on the first occasion. 


\subsection{Programme duration}

The study lasted six weeks and took place over two months, March and April of 1995. The pretest and posttest sessions added another two weeks to the overall duration. The instructional cycle (ie the sequence of activities used to complete one topic) involved a total of three periods per week amounting to two and a half hours. The first session was a double period during which students generally completed all prewriting activities. The third period was used for students to write their texts.

\subsection{Research design}

The research adopted primarily a quantitative approach with qualitative data being used to supplement and complement quantitative findings. Clearly research questions 1 and 2 (see section 5.1) require the analysis of group data while question 3 requires the inspection of cases. The need to integrate both qualitative and quantitative data sources is a well recognised principle of balanced research (for example, see Snyder, 1995).

The following section primarily covers aspects of the quantitative design. The section describes each of the factors and the levels associated with each factor in detail. The procedure for analysing the transcript data is described in the chapter that follows the presentation and discussion of quantitative results.

\subsubsection{Independent variables}

The main independent variable was originally conceived of as talk versus no talk. However, the researcher soon recognised that subjects showed 
great variability in the nature and quantity of talk. Some subjects spoke little to each other; some a lot. Some subjects' talk was on task while that of others was not. Therefore, in order to acknowledge this variability, the intervention treatment was renamed opportunity for talk and contrasted with the condition of little or no opportunity for talk. Each of the groups experienced both the treatment and comparison condition in the programme, but they did this on alternative occasions. This was a way of addressing potential confounding of treatment with time on the programme. The extent to which little or no talk actually occurred in the comparison condition was monitored by the teacher recording all interaction initiatives from students.

In addition to the variable related to talk, a second variable related to the design features of the writing task was built into the experiment. The task factor should be viewed as a combination of level of resourcing, domain specificity related to the topic, and experience with the genre. The three levels of the task factor were: no resourcing on the first two occasions when students were writing on general topics (non-resourced writing/general writing); resourcing by means of a fact sheet on the third and fourth occasions when students were writing on topics that required more domain-specific knowledge (semi-resourced writing/semi-domain-specific writing); and resourcing by means of a written text on the last two occasions for domain-specific topics (resourced writing/domain-specific writing). The exact wording of the topics is given in Figure 4. It should be borne in mind that the effect of the task variable on the quality of argument texts produced by the students at any point of time was a function of the cumulative experience that students had of the genre to that time. 
As mentioned previously, the two groups experienced both the treatment and the control conditions but at different times. It is important then to acknowledge that there is an additional factor in the design arising from the need to counterbalance the groups with the two instructional conditions. Although some investigators have called a factor such as this a 'sequence' or 'position' factor, it is more appropriate in the present design to follow the nomenclature of Reese (1997:146) and conceptualise it as a 'group' factor.

In writing experiments, it has been usual to control for the time spent under the treatment variations that impact directly on writing, as well as for the time taken to do the writing itself (see for example, Sweigert, 1991). In school situations, a given time period is usually set aside for an entire sequence of instruction or activities. The sequence (and sometimes parts thereof) is usually constrained by the timetable. In the present study, stages one to three of the instructional sequence (see Figure 3) took place in a double 50 minute period, while stages four to seven involved one 50 minute period two days later. This is as far as the researcher felt able to constrain the amount of time spent on specific parts of the sequence. In a sense, this decision acknowledges the fact that writing and preparing for writing is a complex dynamic activity. The time spent on each part of the sequence can be regarded as being in free variation, but subject to opportunity costs (ie if more time is spent on talk, there may be less time available for writing and vice versa). Experimentally, one is adding an opportunity condition (ie talking with a partner) and then testing the sensitivity of the instructional sequence as a whole to accomodate the added element. Is performance enhanced by the inclusion of that added element or opportunity? 


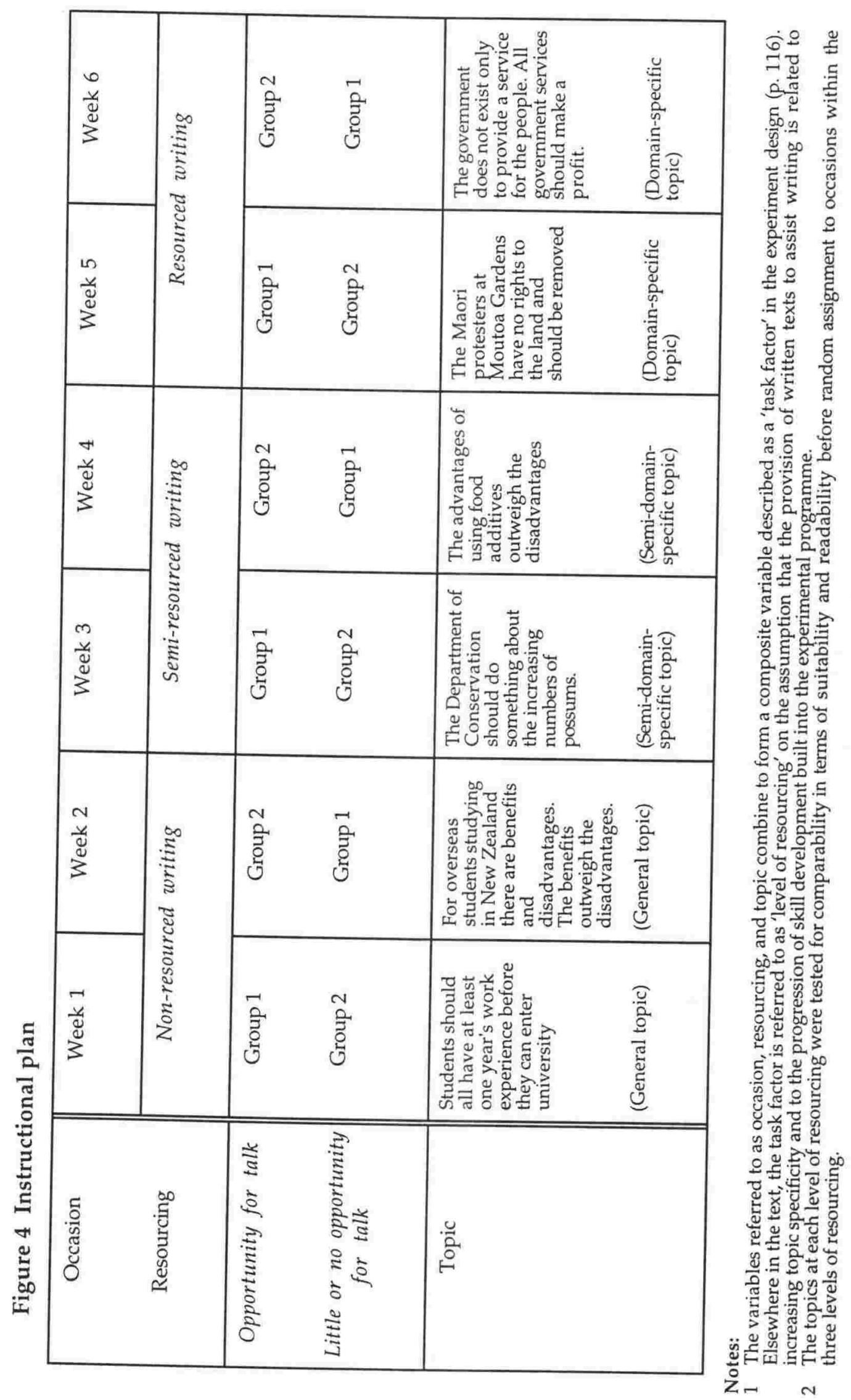




\subsubsection{Dependent variables}

The benefits of speaking prior to writing an argument text were examined in two ways: through using three general analytical measures of writing quality adapted from Hamp-Lyons (1986) (see Appendix 3.1), and four measures related to argument structure. This resulted in a set of seven dependent variables.

The three general analytical measures were communicative quality, text organisation, and linguistic accuracy/complexity. These three measures were aimed at answering the first research question, namely, does an activity cycle that provides opportunities for talk of a particular kind lead to a better text that an activity cycle that contains little or no opportunities for talk?

The measures related to argument structure were the constituents: claims, elaboration of claims, grounds, and elaboration of grounds. The second research question, investigating the type of effect opportunities for talk had on the quality of argument produced, was addressed by these measures.

It is important that 'better text' is conceptualised not as a unitary notion, but rather as a composite phenomenon (Hamp-Lyons and Henning, 1991). The separation of aspects of texts in the way detailed above enables the researcher to trace specific effects.

In addition to the seven variables described above, ratio scores based on the measures related to argument structure, were computed in three ways: the ratio of claims to elaboration of claims; the ratio of grounds to 
elaboration of grounds; and the ratio of claims to grounds. Frequency of argument constituents may be one of the significant indicators of a 'good' argument, particularly when one considers frequency of grounds for instance. However, in evaluating a 'good' argument text, one also needs to consider the relative frequency of elaboration of grounds constituents in their own right. It is not enough that an argument merely lays out the nucleus of the argument, it also needs to be elaborated in order to convince an audience of the strength of the argument. Ratio scores were perceived as a way of evaluating the degree of elaboration in the argument texts the students in the study wrote.

The dependent variables are listed in Figure 5, below. A more detailed discussion of how these measures were arrived at is given in section 5.8.3, where text analysis procedures are described.

\subsubsection{Covariate measures}

A number of covariate measures were collected to provide additional control within the design, should this have been required. The measures included pretest scores as well as various measurement options by which the individuality of students could be captured. The covariates are described in more detail below.

The pretest required students to write two types of texts, a response to both a non-resourced and resourced writing task. These two levels represent two of the three levels of resourcing discussed above in terms of independent variables. 
A number of student variables were considered for possible inclusion in the statistical analysis should the need arise. These included the degree to which each individual availed her/himself of the opportunity for talk in the treatment condition, as well as ethnicity and gender. As the former variable was predicted to be the most useful to estimate the quantity of talk associated with each of the pairs, a sample of tapes was selected and students were ranked in terms of the number of on-task utterances generated by them in the pairs. Figure 5 summarises the experimental plan for the study together with the levels associated with each factor. 
Figure 5 Factors in the experimental plan

\begin{tabular}{|c|c|}
\hline Factor (and status) & Levels \\
\hline $\begin{array}{l}\text { Y Objectives/outcomes factor } \\
\text { (Dependent variable) }\end{array}$ & $\begin{array}{l}y_{1} \text { Communicative quality } \\
y_{2} \text { Organisation and ideas } \\
y_{3} \text { Linguistic accuracy and complexity } \\
y_{4} \text { Frequency of claims } \\
y_{5} \text { Frequency of elaboration of claims } \\
y_{6} \text { Frequency of grounds } \\
y_{7} \text { Frequency of elaboration of grounds } \\
y_{8} \text { Ratio of claims to elaboration of claims } \\
y_{9} \text { Ratio of grounds to elaboration of grounds } \\
y_{10} \text { Ratio of claims to grounds }\end{array}$ \\
\hline $\begin{array}{l}\text { A Treatment factor } \\
\text { (Independent variable) }\end{array}$ & $\begin{array}{l}a_{1} \text { Opportunities for talk } \\
a_{2} \text { Little or no opportunities for talk }\end{array}$ \\
\hline $\begin{array}{l}\text { B Task factor } \\
\text { (Independent variable) }\end{array}$ & $\begin{array}{l}b_{1} \text { Non-resourced/general } \\
b_{2} \text { Semi-resourced/semi-domain-specific } \\
b_{3} \text { Resourced/domain-specific }\end{array}$ \\
\hline $\begin{array}{l}\text { G Group } \\
\text { (Counterbalancing variable) }\end{array}$ & $\begin{array}{l}g_{1} \text { Group one } \\
g_{2} \text { Group two }\end{array}$ \\
\hline P Subject factor & $\mathrm{p}_{1}, \mathrm{p}_{2} \ldots \ldots \ldots \ldots \ldots \ldots \ldots \mathrm{p}_{20}$ \\
\hline $\begin{array}{l}\text { X Entry performance } \\
\text { (Covariate measure) }\end{array}$ & $\begin{array}{l}x_{1} \text { Pretest (non-resourced) } \\
x_{2} \text { Pretest (resourced) }\end{array}$ \\
\hline $\begin{array}{l}\mathrm{Z} \text { Individual difference factor } \\
\text { (Covariate measure) }\end{array}$ & $\begin{array}{l}z_{1} \text { Talkativeness } \\
z_{2} \text { Ethnicity } \\
z_{3} \text { Gender }\end{array}$ \\
\hline
\end{tabular}




\subsection{Collection and analysis of data}

All written material from all parts of the instructional cycle was collected from both groups on all occasions. Analysis of students' texts generated the data for statistical analysis. The statistical methods are discussed below. Following this, is a detailed description of the way in which the text analysis procedures were arrived at and how they were used.

Audio-taped data was collected on all pairs working in the treatment condition. This provided case study data for exploring the third research question, namely, what is the nature of the talk that best facilitates the production of argument texts? The choice of case study students and occasions was determined by the results of statistical analysis. These results indicated where significant effects for talk lay. The section following the text analysis procedures explains how the audio-taped data was analysed.

\subsubsection{Statistical methods}

The aim of the experiment was to examine the changes in students' writing performance as they worked through the programme experiencing both treatment and comparison conditions, and experiencing three different levels of resourcing for the writing task.

For each of the dependent variables, the design for the experiment was a balanced doubly repeated measures design (namely factors A and B in Figure 5 above) with group as a main effect. Repeated observations constitute a repeated measures design. As Littell, Freund and Spector (1991:265) state, “What distinguishes repeated measures data from any 
other multivariate data is not so much the existence of the repeated measurements but the desire to examine changes in the measurements taken...".

Since there were no missing values, repeated measures analysis of variance was carried out in multivariate mode. The statistical program generated data from several multivariate tests: Wilks' Lambda, HotellingLawley Trace, and Pillai's Trace. As the tests all generated the same results, one test, Wilks' Lambda is represented in the ANOVA tables. This test allows the effect of the repeated measures, their interaction, and the interaction of repeated measures with a main effect or effects to be tested using an F test. In this case the main effect, as stated above, was group.

\subsubsection{Text analysis}

The main aim of the text analysis was to account for features of text that may have been influenced by peer talk before and during writing. A number of aspects of text were of potential interest with respect to this: linguistic features of text including the type and accuracy of the grammatical constructions, rhetorical features of the texts including cohesive and coherence markers, text structure and content features relating to the way in which the argument was built up by constituents, the way in which those constituents were organised, and the quality of those constituents.

A selection of ways of measuring and analysing texts was made with reference to the first two research questions: 
1. Does an activity cycle that provides opportunities for talk of a particular kind lead to a better text than an activity cycle that contains little or no opportunities for talk?

2. What type of effect do opportunities for talk have on the quality of argument produced?

This section discusses in detail the decisions that were made regarding the type of data analysis that would serve to answer the first two research questions.

\subsubsection{Measuring better texts in general terms}

As mentioned in section 5.4, a modified form of the Hamp-Lyons formative feedback profile was used as a way of assessing the quality of students' texts in a very general way (see factors $y_{1}, y_{2}$ and $y_{3}$ in Figure 5). The analysis generated scores in three areas: organisation, content and grammatical accuracy. The three scores were referred to as general analytical measures and all three operated on a fourteen point scale. The modified formative feedback profile is given in Appendix 3.1.

\subsubsection{Measuring better argument}

As outlined in the literature review, competence at working with specific types of texts is an issue in accounting for expertise. There is then a developmental rationale for looking at the quality of the argument in the texts that students wrote. There is also a pedagogical rationale as suggested by the genre approach outlined in Chapters 1 and 4 . Hence the need for the second research question investigating the type of effect that opportunity for talk has on the quality of argument produced, and the 
need to find a way of capturing quality of argument in a detailed way (see factors $y_{4}-y_{10}$ in Figure 5). The section below details how these seven dependent measures were arrived at.

The search for appropriate argument text analyses was not a straightforward task. Toulmin (1958) and other philosophers (Toulmin, Rieke, and Janki, 1984) provide an analysis of argumentation, both written and oral that has formed the basis of subsequent work by language educators such as McCann (1989); Knudsen (1989, 1992a, 1992b); Johns (1993). Toulmin et al's analysis has been described in detail in Chapter 4.

\subsubsection{Applications of Toulmin et al's analysis for measurement} purposes

McCann (1989) used a scale for assessing the quality of argument texts based on Toulmin's (1958) original analysis of argumentation. Five constituents of an argument identified by Toulmin (1958) and Toulmin et al (1984) were used: claims, grounds, warrants, qualifications and rebuttals. Qualifications and rebuttals were renamed opposition and responses to opposition respectively. McCann added another constituent, proposition, which refers to "a specific kind of claim which stipulates a policy or procedure to be followed to alleviate a problem" (McCann, 1989:67). The constituent, backing, was not used. The scale devised by McCann, placed claims, data and warrants on a 7 point scale, while proposition, opposition and response to opposition were placed on a 4 point scale (see Appendix 3.3). 
There were two investigative aspects to McCann's (1989) study. The first related to the students' ability to recognise features of argument in written texts, and the second to their ability to construct argument texts. For the first part, McCann constructed argument texts which displayed different patterns of realisation of constituents. Poor argument texts for instance consisted only of a small number of claims plus grounds. The students were assessed to see whether they could adequately judge the quality of argument texts. In the second part of the study, McCann used the scale discussed above to examine the quality of argument texts produced by the students on one occasion, in response to the same prompt.

Knudsen (1992a, 1992b) used the same scale to compare grade level written performance in a more thorough way. The texts of 4 th, 6th, 10 th and 12th graders written in response to three prompts were analysed using McCann's scale. Knudsen also added a 6 point holistic scoring scale which describes fairly general features of text, a few of which were particular to argumentation (Knudsen, 1992a:177). A high score of six for instance would be gained by papers that could be described in the following way:

Papers that address the topic, state and elaborate arguments, and exhibit logical thought. These papers are outstanding.

Responses are well organised and fluent. The word choice is effective. The organisation is excellent. Punctuation is very good. Either mechanical errors do not interfere with reading the paper or there are few mechanical errors.

Responses may develop an argument to support the point of view and may list, develop, or elaborate multiple points of view. 
In Knudsen (1992a, 1992b), the results of the Toulmin scoring were regressed on the holistic scores to determine which of Toulmin's characteristics affected the raters' holistic scores. The general findings of this research and that of McCann have been mentioned in section 4.2 which discusses the difficulty of argument and possibilities for intervention.

The scale used by McCann and Knudsen sets out the elements of argument texts as a full set of requirements but, unlike customary procedures in text analysis, does not signal that some elements are optional and some obligatory, for example, propositions, statements of opposition and response to opposition may not need to be present in all well formed argument texts. The picture presented is that there is only one way to an argument text through the presence of all the elements. However as Toulmin states, "In a well conducted argument, we do not just have to produce enough 'reasons': we have to produce those reasons at the right time if they are to do the job they are required to do" (1958:13). Toulmin's statement captures the importance of accounting for the way in which constituents in argument texts interact with each other to achieve coherence.

A number of less genre-specific but rhetorically focused schemes for analysis were considered to account for the way in which coherence was achieved in the texts. Schneider and Connor (1990), for instance, propose topical structure analysis which claims to be sensitive to cohesion chains by identifying noun phrases that form the theme of any sentence or T-unit. This form of analysis was rejected as not being sensitive to the particular 
features of argumentation such as elaboration of reasons (grounds or data). The following section describes the procedures finally adopted.

\subsubsection{Procedures adopted for the study}

\subsubsection{Specifying the constituents and their relations}

In the previous section describing the nature of argument, a number of models were considered. The models had in common the fact that they specified the constituents or parts of an argument. This level of analysis has been referred to as the macrostructure of the text (van Dijk, 1980 Paltridge, 1995) or its schematic structure (Martin, 1989). Van Dijk (1980:v) describes the macrostructure as "the higher level semantic and conceptual structures...". Little issue has been taken with the descriptions of the higher level semantic structures of argument, particularly that of Toulmin and Toulmin et al. However in the discussion above concerning applications of Toulmin's scheme to analyse text quality, reservations were raised about the ability of previous methods to capture the interaction of argument constituents. The notion of mapping students' texts in a two dimensional way to capture the interaction and elaboration of constituents was adopted in general as a procedure for analysis. Toulmin himself does provide a mapping procedure but this proved to be too finely grained for applying to written texts produced by students in the present study.

A procedure was devised by the researcher with reference to the work of Meyer (1975) and Mann and Thompson (1988, 1992). Mann and Thompson's (1988) Rhetorical Structure Theory provided a descriptive framework for text that was seen to be sensitive to elaboration, as it 
identified hierarchic structure in text (Mann and Thompson, 1988:243). In addition to this, Mann and Thompson (1988:243) claim that, "It describes the relations between text parts in functional terms.... It provides comprehensive analyses rather than selective commentary. It is insensitive to text size." It has also been successfully applied in an analytical (Fox, 1987) and diagnostic way (O'Brien, 1995). It has been used specifically to examine the way in which narratives are structured by Japanese and Spanish learners of English (Kumpf in Mann and Thompson, 1988), while O'Brien's investigation focused on the coursework essay written by tertiary students.

Rhetorical structure analysis allows a rater to examine the text on many levels including the entire text. Essentially it is the chunking of text into units (varying in size depending on the rater's purpose) in terms of their binding relationship. O'Brien and others before her (Mann and Thompson, 1988, who initiated the procedure), proposed that in all such chunked elements there exists a nucleus and a satellite or satellites. The nucleus is the essential element which, when removed, renders the text ill formed, uncohesive and difficult to understand. The satellite on the other hand, as the name suggests, is more peripheral. This feature of the procedure provided a useful way of capturing the development or elaboration of the major constituents in the argument texts that students wrote. As mentioned above, the constituents of argument were identified in the students' texts. A subsequent step identified the satellite statements that were associated with the major constituents of the genre, namely claims and grounds. 
Rhetorical Structure Theory has previously only been applied to the qualitative analysis of student texts (see O'Brien, 1995). However, the identification of the number of relations between nuclei satellite statements offered a powerful and new way of analysing argument texts as it seemed to focus on aspects of text that could potentially be sensitive to talk, namely the linking of propositions, particularly grounds to claims, and to the elaboration of those grounds. Mann and Thompson's graphic representation of analysis involves a detailed mapping procedure that was simplified for the purposes of this study (see Appendix 5).

The notion of nucleus and satellite was also adopted at the whole text level where background material was introduced as a means of contextualising the subsequent argument (the nucleus). Hyland's (1990) analysis also makes the distinction between background material and the core features of the argument. In addition, his analysis adds an additional constituent, the conclusion. Both the introduction and the conclusion were treated as satellite items.

Rhetorical Structure Theory also describes a list of possible relations proposed to exist between the nucleus and satellite including elaboration, sequence, background, evaluation. The relations between nuclei and satellites and satellites themselves were coded using Mann and Thompson's list of relations. The relations used in the text analyses for the study are defined in Appendix 4. Although each of the satellite units was identified in terms of its relation to a nucleus, the classification itself did not form part of the analysis of results. Rather, it provides the basis for further analysis at a later point in time. 
The notion of semantic relations put forward by Mann and Thompson is to be distinguished from the functional systemic notion of logico-semantic relations (in the work of Halliday, 1985; Martin, 1992). The latter are linguistic and clause based, while the former are proposition based. The latter may overlook relations between clauses if they are not explicitly signalled, by means of conjunctions for instance. Mann and Thompson (1988:250) state that, "Recognition of the relation always rests on functional and semantic judgments alone ... We have found no reliable, unambiguous signals for any of the relations". Another way of classifying semantic relations has been proposed by Crombie (1985). However Crombie's relational perspective still relies on linguistic identification.

\subsubsection{Specifying the unit of analysis}

Many studies of text analysis begin from the position of separating the text into linguistic units of analysis. Mann and Thompson (1988: 248) state that, "Unit size is arbitrary, but the division of the text into units should based on some theory-neutral classification... the units should have independent functional integrity". Mann and Thompson's unit of analysis is essentially a clause unit, "except that clausal subjects and complements and restrictive relative clauses are considered as parts of their host clause units rather than as separate units" (1988:248). O'Brien (1995) adapts her choice of unit according to different purposes, so for shorter texts such as examination questions she uses a slightly modified clause unit. For longer texts such as course work essays, she uses the sentence.

This study began by attempting to identify semantic constituents of the argument texts. Toulmin (1958) states, 
When one gets down to the individual level of sentences, a finer structure can be recognised, and this is the structure with which logicians have mainly concerned themselves. (p. 94)

Essentially this structure is semantic. A linguistic analysis in the form of T-units, clause units or sentence units for instance would override important semantic distinctions. However an inventory of possible linguistic representations of the different types of constituents was kept.

\subsubsection{Summary of the text analysis procedure}

The students' texts were first sectioned into three parts, the thesis, the argument, and the conclusion, the constituents were identified and labelled according to Toulmin's categorisation (ie claims, grounds, warrants, etc); the relationship between constituents was then identified with reference to Mann and Thompson's (1988) procedure for identifying rhetorical structure. The result of the mapping was entered on a score sheet. (See Appendix 5 for a sample analysis recorded on a score sheet.) The score sheet quantified the features identified by the mapping procedure. The score sheet is preceded by a sample text as an instantiation of the text analysis procedures used to generate the data for the study.

\subsubsection{Inter-rater reliability}

The reliability of the ratings given for text quality measures and argument text measures was estimated by calculating the percent of exact or near exact agreements achieved by two raters (one of which included the researcher), for a sample of fifteen percent of the texts. That is, the 
number of cases where both raters agreed within one scale point were counted, divided by the total number of texts in the sample, and then multiplied by 100 .

Table 1 summarises the percent of agreement achieved by the raters for each aspect of general text quality and each aspect of argument text structure (excluding ratio scores). The values in the table are based on texts produced on occasions one, three and five for a random sample of nine students. 
Table 1 Inter-rater reliability statistics for the assessment of general text quality and argument text structure

\begin{tabular}{|lc|}
\hline \multicolumn{1}{|c|}{ Text measures } & Inter-rater agreement (\%) \\
\hline Communicative quality & 94 \\
Organisation and ideas & 83 \\
Linguistic accuracy and complexity & 94 \\
Frequency of claims & 89 \\
Frequency of elaboration of claims & 89 \\
Frequency of grounds & 78 \\
Frequency of elaboration of grounds & 83 \\
\hline
\end{tabular}

There was relatively high agreement between the two raters for features of communicative quality, and linguistic accuracy and complexity. The least agreement in coding occurred when texts written under the resourced condition were segmented into grounds.

The literature on inter-rater reliability (see for example Abedi, 1996; Burry-Stock, Shaw, Laurie and Chissom, 1996) has indicated that the statistic 'percent of agreement' may underestimate the actual agreement between raters because random variations in the scoring of texts are not accounted for by this technique. In fact, when a rater agreement index (RAI) was calculated for the three dimensions of general text quality, taking into account the number of points on the rating scale, an RAI of 0.96 was obtained. 


\subsection{Conclusion}

The methodology for the study needed to measure up to criteria for ecological validity. The researcher needed to provide an instructional programme which met the needs of the students, and which involved the teacher but was not overly intrusive or time consuming. The instructional programme needed to link in with the national curriculum statement, English in the New Zealand Curriculum and needed to be developmentally appropriate for the second language students. The way the data was analysed needed to reflect what teachers valued in argument texts. Furthermore, in the context of these requirements, the instructional programme and more specifically the research design, needed to be balanced and capable of evaluating statistically significant effects associated with the independent variables. This chapter has outlined how most of this was achieved. The next chapter examines the results that were obtained from analysing group data obtained at various points in the study. 


\section{RESULTS}

\subsection{Introduction}

The benefits of speaking prior to and while writing an argument text as expressed in the first two research questions,

1. Does an instructional cycle that provides opportunities for talk of a particular kind lead to a better text than an instructional cycle that contains little or no opportunities for talk?

2. What type of effect do opportunities for talk have on the quality of argument texts produced?

were examined through three sets of measures. One set was comprised of three general analytical scores: communicative quality, organisation and ideas, and linguistic complexity and accuracy. A second set of measures was related to argument structure. These were four frequency measures involving claims, elaboration of claims, grounds, and elaboration of grounds. The last set was a set of three ratio scores, grounds to claims, claims to elaboration of claims, and grounds to elaboration of grounds. The raw data of scores gained for each of these measures is given in Appendix 6.1.

The two research questions specifically test the independent variables, opportunity to talk versus little or no opportunities to talk. The data tables and discussion of results represent these variables as with talk and without talk. The two variables represent contrasting positions on the level of talk factor. 
Also in focus in the results, is a second set of independent variables, labelled at this stage: non-resourced writing, semi-resourced writing, and resourced writing. These refer respectively to working without any input texts or resources before writing, working with lists of facts (fact sheets) or notes, and working with entire texts for input. The data tables and discussion refer to these options as particular instances of the level of resourcing factor (however as the discussion in section 5.7.1, makes clear, this factor represents some difference also in the degree of domain specificity and experience with the genre).

The GLM (General Linear Measures) procedure used to statistically analyse the data generated in association with the independent variables is given in Appendix 6.2.

Transcript data which addresses the remaining research question investigating the nature of the talk that best facilitates the production of argument texts, are presented in Chapter 8.

\subsection{General quality of texts}

The notion of 'better texts', as in the first research question, was specifically operationalised as a score on a 14 point scale for each of the three general measures: communicative quality, text organisation, and linguistic accuracy/complexity. The mean scores for each of the three measures summing across all levels of resourcing were computed for the two different conditions, with talk and without talk. These mean scores are plotted in Figure 6. 
Figure 6 Mean scores for sum of general analytical measures across levels of resourcing

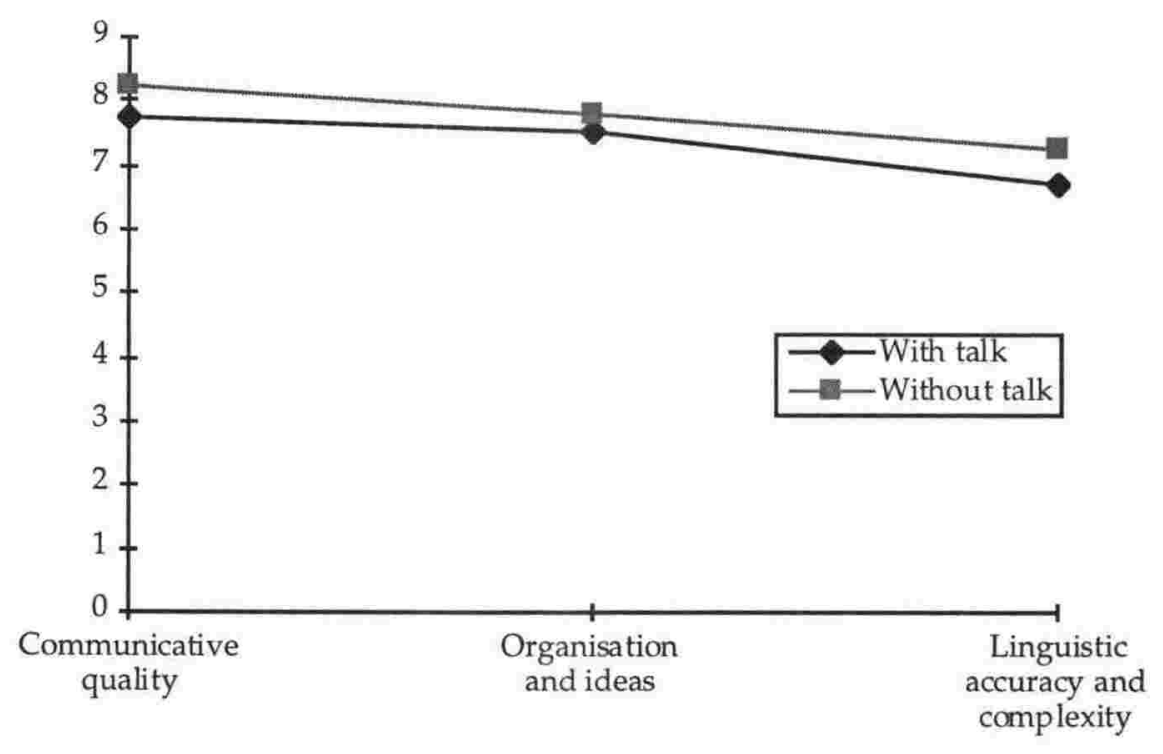

Visually, the plots in Figure 6 indicate that there was likely to be no significant difference between the scores gained on the with talk condition and the without talk condition on all three general measures of text quality: communicative quality, organisation and ideas, and linguistic accuracy and complexity when scores across levels of resourcing were summed.

The level of resourcing for the writing task did however appear to influence the general trend in the quality measures used in the study. It can be seen in Figure 7 below that when the scores were summed across levels of talk, there appeared to be a significant affect from textual resources as represented by the resourced condition. Figure 7 indicates that students wrote better texts in all three measures of general text quality in this condition. 
Figure 7 Mean scores for communicative quality, organisation and ideas, and linguistic accuracy across levels of talk

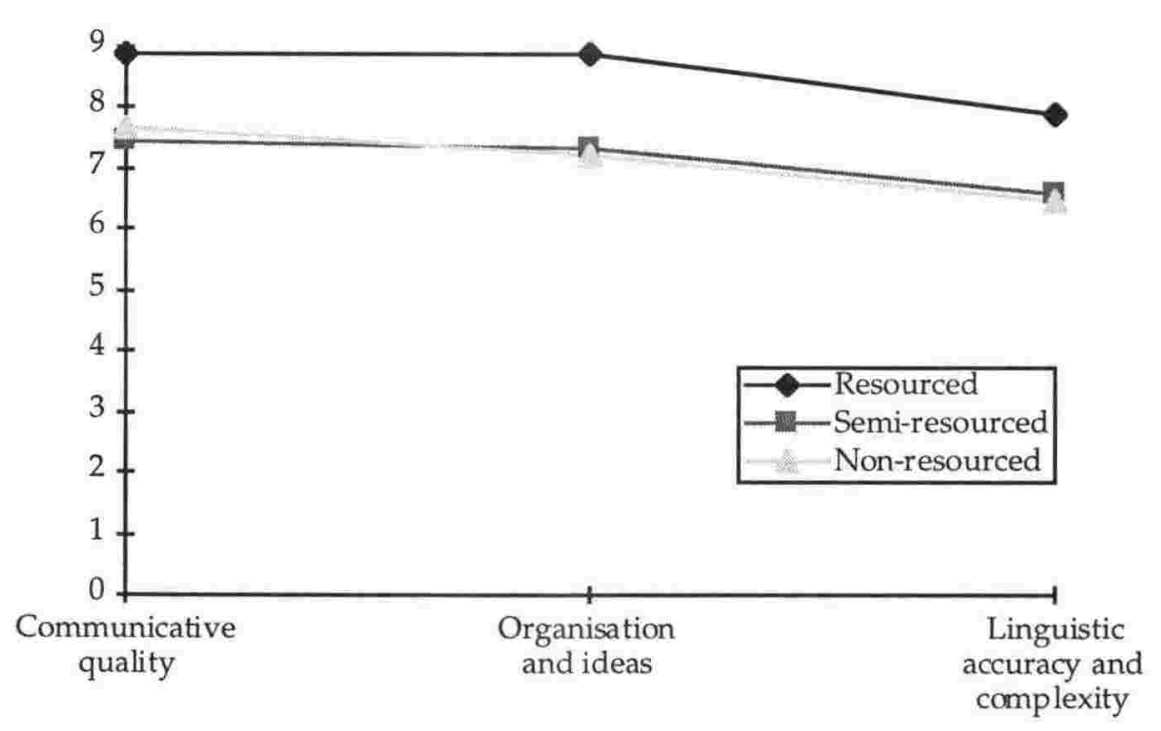

Table 2 provides the descriptive statistics for the three general analytical measures within the three types of resourcing and the two working conditions, talk and without talk. The standard deviations (SDs) indicate there was some variation on all the scales within the various experimental conditions, with no scale having a large number of extreme ratings. The standard errors of measurement (SEs) allow the likely stability of the group means to be evaluated with respect to chance factors influencing the measurement process.

The standard errors in Table 2 confirm that no significant difference between the with talk condition and without talk condition, across levels of resourcing, existed in the data. The standard errors in Table 2 associated with level of resourcing, however, indicate that resourced writing appeared to have a significant beneficial effect on the general quality of texts students wrote. 


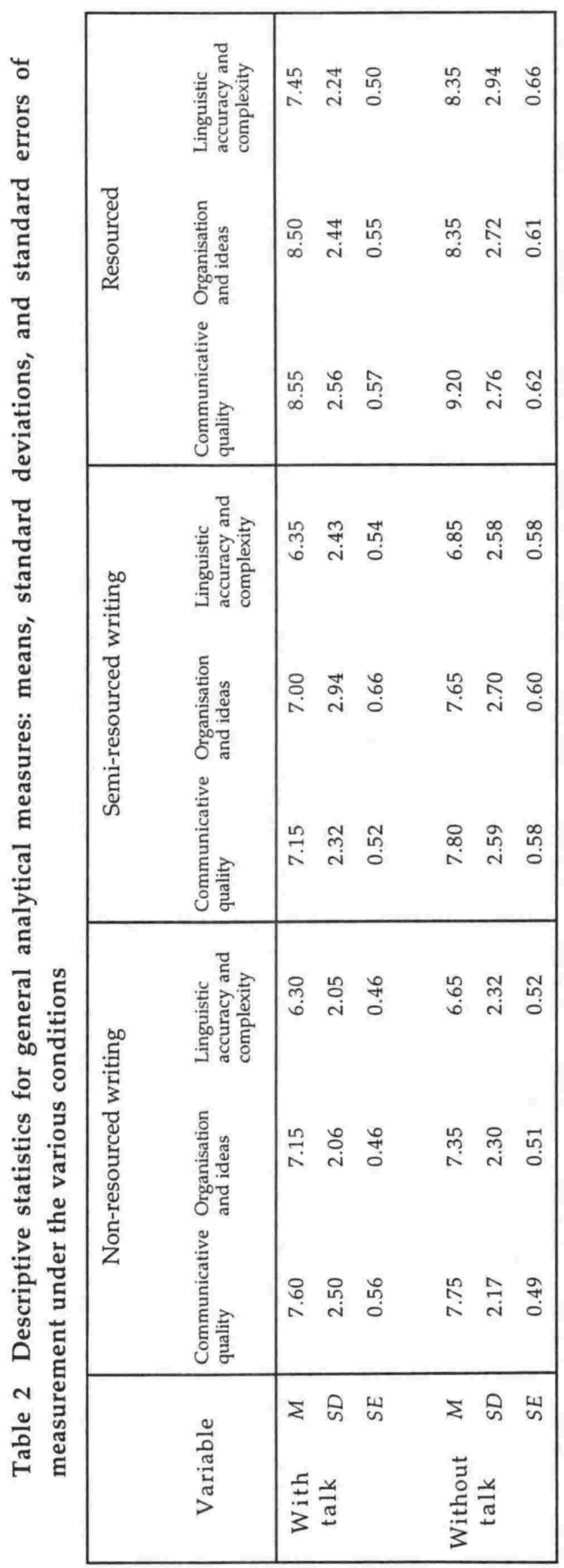


Initial examination of the data, and the results of the multivariate and univariate analyses signaled that comparisons across the levels of resourcing, in particular, were likely to provide results of interest with respect to the three general analytical measures.

Separate multivariate analyses, with the level of talk and the level of resourcing for the writing task as independent variables, were performed on each of the three general measures of text quality to investigate whether the general observed patterns in the data were statistically significant. It was also necessary to determine whether effects of talk could be located when the dependent measures were considered separately.

\subsubsection{Communicative quality}

When communicative quality was used as the dependent variable, significance at $p<0.0001$ was obtained for a level of resourcing effect. No significant effect was found for level of talk. A univariate analysis of variance with repeated measures (ANOVA) was conducted for this test, as described in Table 3. Table 3 reports the results from Wilks' Lambda since the repeated measures analysis of variance was carried out using the multivariate mode for repeated measures when calculating the test statistics.

Table 3 ANOVA on communicative quality scores for level of resourcing

\begin{tabular}{|c|c|c|c|c|}
\hline Source & $F$ & Num df & Den $d f$ & $p$ \\
\hline $\begin{array}{c}\text { Level of } \\
\text { resourcing }\end{array}$ & 22.93 & 2 & 15 & $<0.0001$ \\
\hline
\end{tabular}


A visual analysis of the means was carried out to locate the source of the significant effect for level of resourcing. Table 4 shows the means, standard deviations, and standard errors of measurement associated with the three different levels of resourcing, and communicative quality. The mean for communicative quality scores for the resourced condition was the highest at 8.88 , while the mean score for the non-resourced writing condition and that for the semi-resourced writing condition were 7.68 and 7.48 respectively. From an inspection of the standard deviations, the variability of the communicative quality scores increased very slightly as the students were exposed to textual resources of increasing complexity.

Table 4 Descriptive statistics for communicative quality scores: means, standard deviations, and standard errors of measurement for level of resourcing

\begin{tabular}{|c|c|c|c|}
\hline Statistic & $\begin{array}{c}\text { Non-resourced } \\
\text { writing }\end{array}$ & $\begin{array}{c}\text { Semi-resourced } \\
\text { writing }\end{array}$ & $\begin{array}{c}\text { Resourced } \\
\text { writing }\end{array}$ \\
\hline$M$ & 7.68 & 7.48 & 8.88 \\
$S D$ & 2.31 & 2.45 & 2.65 \\
$S E$ & 0.37 & 0.39 & 0.42 \\
\hline
\end{tabular}

The results in this section indicate that the provision of input texts as in the resourced writing condition affected the communicative quality of the students' texts in a positive way. The scores on the first of the general measures of text quality appeared therefore to be due to the textual nature of the resourcing associated with the writing task. Providing students with fact sheets did not have a comparable effect. A higher group score on communicative quality could not be statistically attributed to the level of talk factor. 


\subsubsection{Text organisation}

A similar level of resourcing effect was found when the students' texts were scored for quality of text organisation and ideas. Multivariate significance $(p=0.0082)$ was obtained. The univariate ANOVA results for the tests are reported in Table 5.

Table 5 ANOVA on text organisation scores for level of resourcing

\begin{tabular}{|c|c|c|c|c|}
\hline Source & $F$ & Num df & Den df & $p$ \\
\hline $\begin{array}{c}\text { Level of } \\
\text { resourcing }\end{array}$ & 7.04 & 2 & 15 & 0.0029 \\
\hline
\end{tabular}

The descriptive statistics for the level of resourcing effect on text organisation are given in Table 6. This data also suggests that the condition with the greatest level of resourcing resulted in the most positive effect on ideas and text organisation. This provides evidence of the contribution of textual support for writing. On the occasion when students were exposed to textual input, the quality of the ideas in the text and the organisation of the text appeared to be enhanced. Like the communicative quality scores, there was no significant difference between the text organisation scores gained while working in the semi-resourced condition and the non-resourced condition. 
Table 6 Descriptive statistics for text organisation scores: means, standard deviations, and standard errors of measurement for level of resourcing

\begin{tabular}{|c|c|c|c|}
\hline Statistic & $\begin{array}{c}\text { Non-resourced } \\
\text { writing }\end{array}$ & $\begin{array}{c}\text { Semi-resourced } \\
\text { writing }\end{array}$ & $\begin{array}{c}\text { Resourced } \\
\text { writing }\end{array}$ \\
\hline$M$ & 7.25 & 7.33 & 8.43 \\
$S D$ & 2.16 & 2.80 & 2.55 \\
$S E$ & 0.34 & 0.44 & 0.40 \\
\hline
\end{tabular}

The opportunity to speak with a partner did not have a statistically significant effect on the quality of ideas and organisation.

\subsubsection{Linguistic accuracy and complexity}

When the students' texts were scored for linguistic complexity, multivariate significance was obtained for the level of talk $(p=0.0076)$ and for the level of resourcing $(p<0.0001)$ and on Wilks' Lambda. The results of the univariate analysis are reported in Table 7.

Table 7 ANOVA on linguistic accuracy and complexity scores for level of resourcing and level of talk

\begin{tabular}{|c|c|c|c|c|}
\hline & $F$ & Num df & Den df & $p$ \\
\hline $\begin{array}{c}\text { Level of } \\
\text { talk }\end{array}$ & 9.32 & 1 & 16 & 0.0076 \\
$\begin{array}{c}\text { Level of } \\
\text { resourcing }\end{array}$ & 22.12 & 2 & 15 & $<0.0001$ \\
\hline
\end{tabular}

The means, standard deviations, and standard errors of measurement are reported in Tables 7 and 8 below. 
Table 8 Descriptive statistics associated with level of talk and linguistic accuracy and complexity: means, standard deviations, and standard errors of measurement

\begin{tabular}{|c|c|c|}
\hline Statistic & Talk & Without talk \\
\hline$M$ & 6.70 & 7.28 \\
$S D$ & 2.27 & 2.69 \\
$S E$ & 0.29 & 0.35 \\
\hline
\end{tabular}

Table 8 indicates that the without talk condition resulted in higher mean scores for linguistic accuracy and complexity. Note that the standard deviations and standard errors, unlike the $\mathrm{F}$ test for level of talk in Table 7, do not adjust for the level of resourcing. The standard deviations and standard errors in Table 8 are thus overestimates in the sense of being measures of variation due to talk/without talk for a given level of resourcing. Likewise the standard deviations and standard errors below in Table 9 are not adjusted for level of talk and thus may be larger than predicted from the ANOVA table, Table 7.

Table 9 Descriptive statistics associated with level of resourcing and linguistic accuracy and complexity: means, standard deviations, and standard errors of measurement

\begin{tabular}{|c|c|c|c|}
\hline Statistic & $\begin{array}{c}\text { Non-resourced } \\
\text { writing }\end{array}$ & $\begin{array}{c}\text { Semi-resourced } \\
\text { writing }\end{array}$ & $\begin{array}{c}\text { Resourced } \\
\text { writing }\end{array}$ \\
\hline$M$ & 6.48 & 6.60 & 7.90 \\
$S D$ & 2.17 & 2.49 & 2.62 \\
$S E$ & 0.34 & 0.39 & 0.41 \\
\hline
\end{tabular}

Figure 8 below represents the descriptive data relating to the level of talk and the level of resourcing with respect to linguistic accuracy and 
complexity. It visually represents the relative effects of both factors, the level of talk and the level of resourcing. Figure 8 indicates that when provided with textual resourcing prior to and during writing, students' scores for grammatical accuracy and complexity increased. The differences between the scores produced in the non-resourced, semiresourced and resourced conditions increase as the programme progresses.

Figure 8 Mean scores for linguistic accuracy and fluency for three levels of resourcing

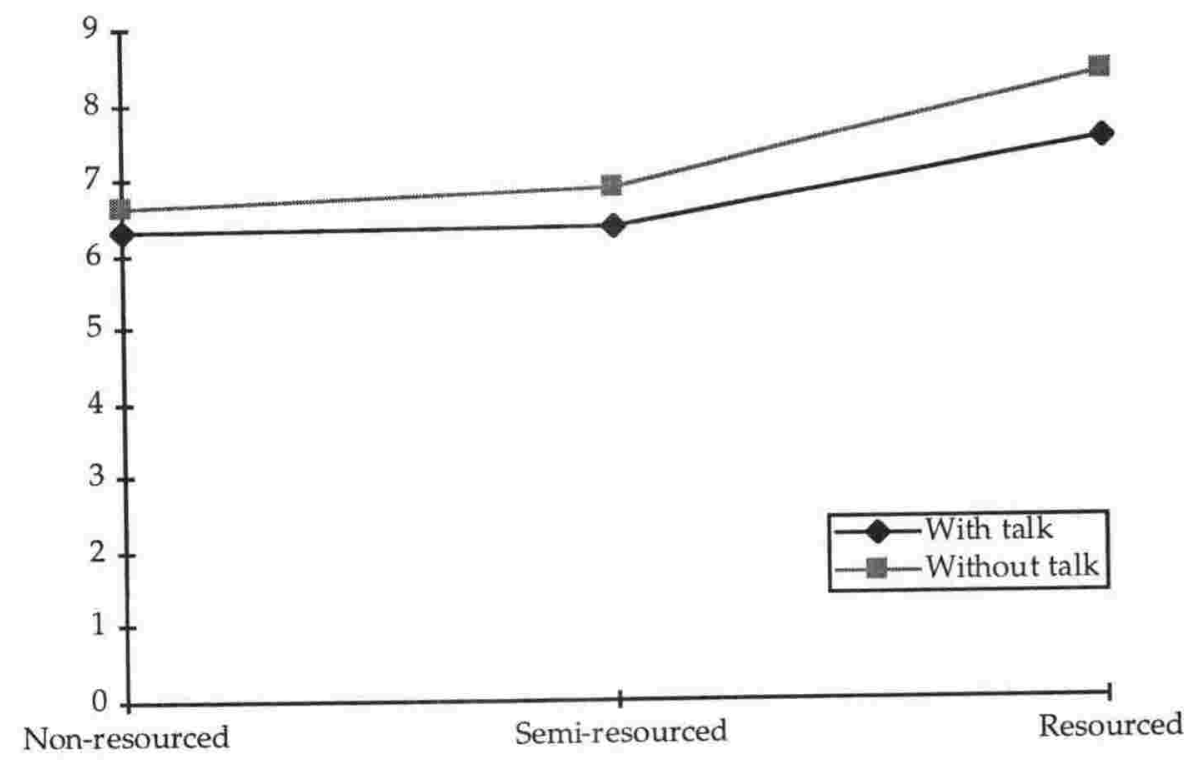

As the resourced condition occurred at the end of the programme, the improvements in the grammatical accuracy and complexity scores may not only be related to textual resourcing but may also be a function of time in the programme. In Figure 8, we also see that students working in the without talk condition during the time of the study produced texts with higher accuracy and complexity scores than when they worked together. Therefore, opportunity to talk with a peer before and during 
writing did not appear to contribute to the linguistic resources accessible to the students. However, textual input did appear to influence the linguistic accuracy and complexity of the language used by students in their texts.

\subsection{Summary}

The descriptive data indicates that in general students wrote somewhat better texts on all three general analytical measures when preparing for and carrying out writing alone. However statistical analysis did not bear out this general observation. The opportunity to talk with a partner or to work in a solitary way before or during writing produced no statistically significant differences in the measures of general text quality: communicative quality and organisation and ideas. The only statistically significant effect lay in the linguistic accuracy and complexity of students' texts. Students' texts were more accurate and more complex when they worked alone.

The descriptive data also indicated that students wrote better texts on all three measures of general text quality when working with textually resourced input. This observation was borne out by statistical analysis.

\subsection{Quality of argument}

The notion of 'quality of argument' was operationalised as a frequency score for each of the four constituents of argument: claims, elaboration of claims, grounds, and elaboration of grounds. Unlike measures on a scale (the measures for general text quality), frequency scores are not limited 
within a range. The detailed descriptive statistics for the argument measures are given below in Table 10. 


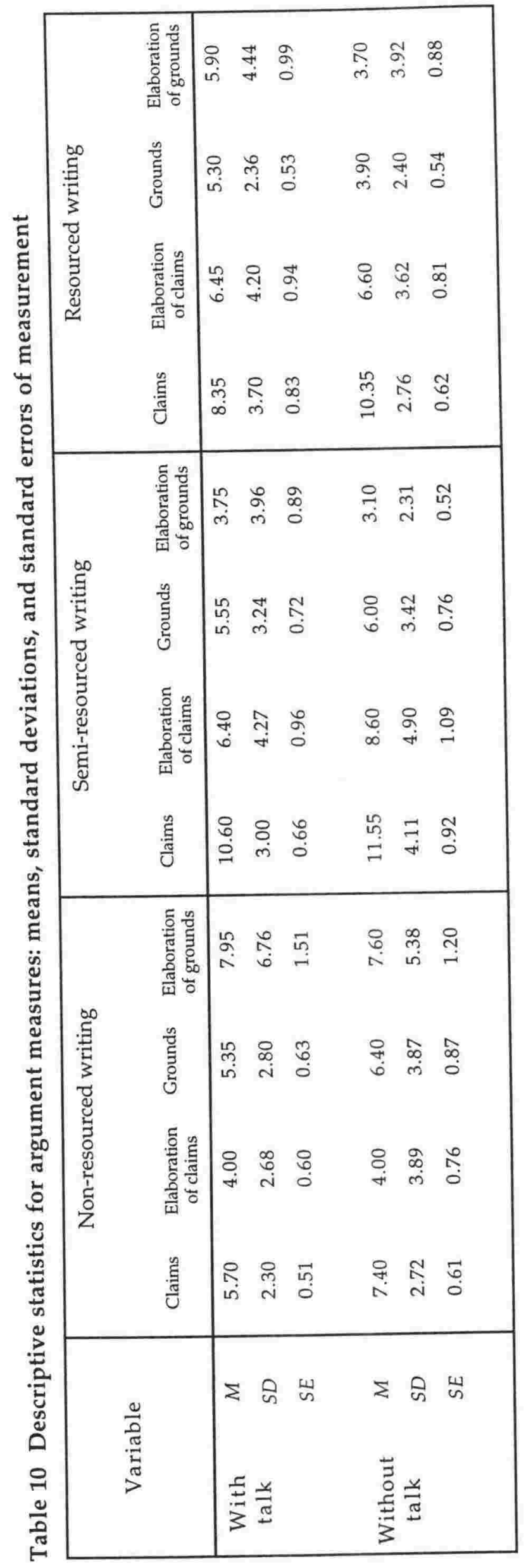


Visual inspection of the data in Table 10 indicates a more complex pattern of effects than was observed with the dependent variables relating to general text quality. The descriptive statistics indicate that the frequency of claims may have been most affected by the semi-resourced form of input and the opportunity to work alone, and that grounds and elaboration of grounds in particular may have been more sensitive to the effects of working with a partner using resourced forms of input. Whether these effects were statistically significant is explored through the multivariate and univariate analyses described in the following section.

\subsubsection{Claims}

A multivariate analysis was performed on the frequency data relating to number of claims. Wilks' Lambda indicated multivariate significance $(p=$ 0.0162) for a level of talk factor. Multivariate significance was also detected at the level of resourcing $(p=<0.0001)$. Results of the ANOVA procedures for both levels are described in Table 11.

Table 11 ANOVA of frequency of claims for level of talk and level of resourcing

\begin{tabular}{|c|c|c|c|c|}
\hline Source & $F$ & Num df & Den df & $p$ \\
\hline $\begin{array}{c}\text { Level of } \\
\text { talk }\end{array}$ & 7.22 & 1 & 16 & 0.0162 \\
\hline $\begin{array}{c}\text { Level of } \\
\text { resourcing }\end{array}$ & 31.86 & 2 & 15 & $<0.0001$ \\
\hline
\end{tabular}

The ANOVA, together with the means and standard errors associated with the level of talk, indicate that the without talk condition resulted in a greater number of claims being realised in students' texts irrespective of level of resourcing (see Table 12). 
Table 12 Descriptive statistics for frequency of claims: means, standard deviations, and standard errors of measurement for level of talk

\begin{tabular}{|c|c|c|}
\hline Statistic & Talk & Without talk \\
\hline$M$ & 8.22 & 9.77 \\
$S D$ & 3.61 & 3.65 \\
$S E$ & 0.47 & 0.47 \\
\hline
\end{tabular}

The level of resourcing found to be most associated with the number of claims produced was not full textual resourcing level as represented by the resourced writing condition, but rather the moderate level of resourcing as represented by the semi-resourced writing condition. Table 13 presents means, standard deviations and standard errors of measurement related to frequency of claims.

Table 13 Descriptive statistics for frequency of claims: means, standard deviations, and standard errors of measurement for level of resourcing

\begin{tabular}{|c|c|c|c|}
\hline Statistic & $\begin{array}{c}\text { Non-resourced } \\
\text { writing }\end{array}$ & $\begin{array}{c}\text { Semi-resourced } \\
\text { writing }\end{array}$ & $\begin{array}{c}\text { Resourced } \\
\text { writing }\end{array}$ \\
\hline$M$ & 6.55 & 11.08 & 9.35 \\
$S D$ & 2.63 & 3.57 & 3.38 \\
$S E$ & 0.42 & 0.56 & 0.53 \\
\hline
\end{tabular}

It appears that in the area of claims, students' texts were significantly affected by the semi-resourced form of input and the opportunity to work independently. 


\subsubsection{Elaboration of claims}

When a multivariate analysis was performed on the frequency data for elaboration of claims, significance was likewise found for the level of resourcing ( $p=0.005$ for Wilks' Lambda). The results of the ANOVA procedures are given in Table 14.

Table 14 ANOVA of frequency of elaboration of claims for level of resourcing

\begin{tabular}{|c|c|c|c|c|}
\hline Source & $F$ & Num df & Den $d f$ & $p$ \\
\hline $\begin{array}{c}\text { Level of } \\
\text { resourcing }\end{array}$ & 6.24 & 2 & 15 & 0.0052 \\
\hline
\end{tabular}

Table 15 below indicates that it was again the moderate level of resourcing that had the most significant effect on the frequency of elaboration of claims.

Table 15 Descriptive statistics for frequency of elaboration of claims: means, standard deviations, and standard errors of measurement for level of resourcing

\begin{tabular}{|c|c|c|c|}
\hline Statistic & $\begin{array}{c}\text { Non-resourced } \\
\text { writing }\end{array}$ & $\begin{array}{c}\text { Semi-resourced } \\
\text { writing }\end{array}$ & $\begin{array}{c}\text { Resourced } \\
\text { writing }\end{array}$ \\
\hline$M$ & 4.00 & 7.50 & 6.53 \\
$S D$ & 3.01 & 4.66 & 3.87 \\
$S E$ & 0.48 & 0.74 & 0.61 \\
\hline
\end{tabular}

As with the frequency of claims, the frequency of elaboration of claims was most affected by the semi-resourced level. It appears that input associated with claims was most accessible from fact sheets. 


\subsubsection{Grounds}

Interaction effects were found at two levels within the frequency of grounds analysis of variance. A level of talk by group interaction effect signified that the level of talk was producing a significant effect on the production of grounds for one of the groups. A second level of interaction was observed for level of resourcing, level of talk and group. This indicates that in addition to a specific effect of talk on one of the groups, a specific effect could also be located for one of the groups with one of the levels of resourcing. The test for significance showed $p=0.0357$ and $p$ $=0.0005$ respectively. Results of the ANOVA procedures for both of these interaction effects are reported below in Table 16.

Table 16 ANOVA of frequency of grounds scores for level of talk $x$ group interaction; level of resourcing $\times$ level of talk $\times$ group interaction

\begin{tabular}{|c|c|c|c|c|}
\hline & $F$ & Num df & Den $d f$ & $p$ \\
\hline $\begin{array}{c}\text { Level of talk } \times \\
\text { group } \\
\text { interaction }\end{array}$ & 5.26 & 1 & 16 & 0.0357 \\
\hline $\begin{array}{c}\text { Level of } \\
\text { resourcing } \times \\
\text { level of talk } \times \\
\text { group } \\
\text { interaction }\end{array}$ & 8.77 & 2 & 15 & 0.0009 \\
\hline
\end{tabular}

Means and standard deviations associated with the levels of resourcing, the levels of talk, and the two groups are presented for comparison in Table 17. 
Table 17 Descriptive statistics for frequency of grounds: means, standard deviations, and standard errors of measurement for level of resourcing, level of talk and group

\begin{tabular}{|c|c|c|c|c|c|c|c|}
\hline \multirow{2}{*}{ Group } & & \multicolumn{2}{|c|}{$\begin{array}{l}\text { Non-resourced } \\
\text { writing }\end{array}$} & \multicolumn{2}{|c|}{$\begin{array}{l}\text { Semi-resourced } \\
\text { writing }\end{array}$} & \multicolumn{2}{|c|}{ Resourced writing } \\
\hline & & Talk & No talk & Talk & No talk & Talk & No talk \\
\hline \multirow[t]{3}{*}{1} & $M$ & 4.20 & 8.10 & 4.10 & 7.00 & 5.50 & 1.90 \\
\hline & $S D$ & 1.55 & 4.41 & 1.97 & 3.43 & 2.68 & 1.37 \\
\hline & $S E$ & 0.49 & 1.39 & 0.62 & 1.09 & 0.85 & 0.43 \\
\hline \multirow[t]{3}{*}{2} & $M$ & 6.50 & 4.70 & 7.00 & 5.00 & 5.10 & 5.90 \\
\hline & $S D$ & 3.34 & 2.41 & 3.68 & 3.27 & 2.13 & 1.20 \\
\hline & $S E$ & 1.06 & 0.76 & 1.16 & 1.03 & 0.67 & 0.38 \\
\hline Total & $M$ & 5.35 & 6.40 & 5.55 & 6.00 & 5.30 & 3.90 \\
\hline
\end{tabular}

Table 17 indicates that in the non-resourced condition, group two had a higher mean score for frequency of grounds in the talk condition, while for group one, it was the without talk condition that resulted in higher mean scores. A similar pattern is seen in the semi-resourced condition. However, for the resourced condition for group one, the talk condition resulted in significantly higher scores than the without talk condition. Group two on the other hand had higher mean scores for the without talk condition.

In the study the group factor was confounded with a topics factor as the groups worked on different topics on each occasion. There were six occasions in all, each with a different topic. As explained in Chapter 5, students worked alternatively with talk and without talk. The first topic for instance, was carried out by group one with talk, while group two worked without talk. On the second occasion, the second topic was again 
done under two conditions, but group one experienced the without talk condition and group two the talk condition. Hence the effects of the group factor may be accounted for in terms of the topic differences.

The following graph, Figure 9, shows the frequency of grounds for each of the two groups in relation, not to the treatment or to level of resourcing but in terms of the topic.

Figure 9 Mean frequency of grounds for topics across levels of resourcing

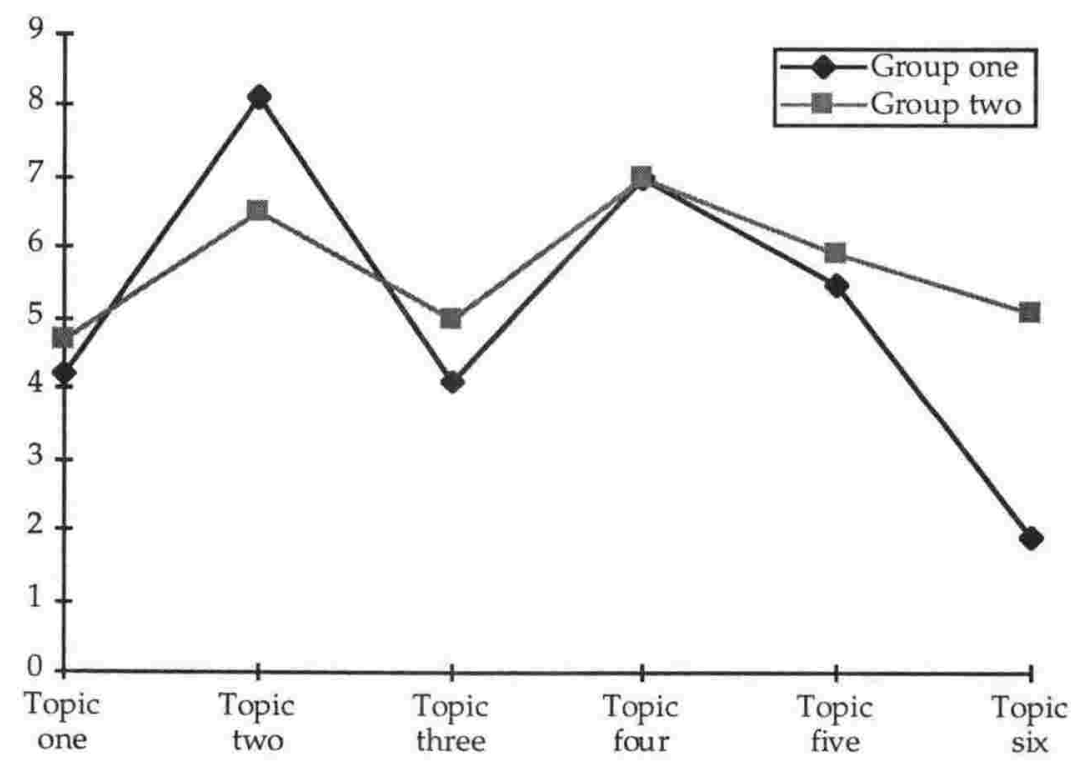

Group one and group two are seen to perform similarly on most of the topics. There are two important differences: topic two and topic six. The graph shows group one scoring much higher mean scores for frequency of grounds on topic two (which for them coincided with the without talk condition). The graph also shows group two scoring much higher on topic six than group one (this for them coincided with the talk condition). 
The latter finding suggests that group two benefited from talk when required to write on a topic on which few of the students would have had much content and domain-specific knowledge. In this context, grounds may have been more easy to derive from a partner and from the textual input by way of a partner. Working in a solitary way may have meant that the students had less opportunity to generate ideas and little access to the ideas in the source reading.

\subsubsection{Elaboration of grounds}

The frequency of elaboration of grounds is affected by the level of resourcing factor, the level of significance being $p=0.0104$. A significant effect was also observed for the interaction, level of resourcing, level of talk, and group $(\mathrm{p}=0.0462)$. Results of the ANOVA procedures are reported below in Table 18.

Table 18 ANOVA of frequency of elaboration of grounds for level of resourcing; level of resourcing $\times$ level of talk $\times$ group interaction

\begin{tabular}{|c|c|c|c|c|}
\hline & $F$ & Num df & Den df & $p$ \\
\hline $\begin{array}{c}\text { Level of } \\
\text { resourcing }\end{array}$ & 8.72 & 2 & 15 & 0.0009 \\
\hline $\begin{array}{c}\text { Level of } \\
\text { resourcing } \times \\
\text { level of talk } \times \\
\text { group } \\
\text { interaction }\end{array}$ & 0.66 & 2 & 15 & 0.1008 \\
\hline
\end{tabular}

It should be noted that the ANOVA procedures generated $\mathrm{F}$ values with lower levels of statistical significance in the case of the second result, the interaction between level of resourcing, level of talk and group. In cases such as these, it is suggested (SAS Manual: SAS/STAT users' guide, 1989: 
953-955) that the multivariate results be used rather than the univariate results as the former involves fewer assumptions. The SAS manual: SAS/STAT users' guide also makes the point that, if contrasts (suggested a priori) involving the 'last' time point in comparison with all others were tested, this test would result in greater significance than suggested above in Table 18.

Table 19 below explains the pattern of effects seen with the frequency data for elaboration of grounds. The descriptive statistics show that group two has consistently higher scores on frequency of elaboration of grounds in the talk condition for all three levels of resourcing. In contrast, group one shows the inverse for the first two levels of resourcing (nonresourced writing and semi-resourced writing). In these two contexts, their scores for the without talk condition exceed those for the talk condition.

Table 19 Descriptive statistics for frequency of elaboration of grounds: means, standard deviations, and standard errors of measurement for level of resourcing, level of talk and group

\begin{tabular}{|c|c|c|c|c|c|c|c|}
\hline \multirow[t]{2}{*}{ Group } & & \multicolumn{2}{|c|}{$\begin{array}{l}\text { Non-resourced } \\
\text { writing }\end{array}$} & \multicolumn{2}{|c|}{$\begin{array}{l}\text { Semi-resourced } \\
\text { writing }\end{array}$} & \multicolumn{2}{|c|}{ Resourced writing } \\
\hline & & Talk & No talk & Talk & No talk & Talk & No talk \\
\hline \multirow[t]{3}{*}{1} & $M$ & 6.10 & 7.50 & 1.80 & 3.40 & 4.70 & 2.20 \\
\hline & $S D$ & 5.07 & 6.74 & 1.69 & 2.76 & 2.91 & 4.13 \\
\hline & $S E$ & 1.60 & 2.13 & 0.53 & 0.87 & 0.92 & 1.31 \\
\hline \multirow[t]{3}{*}{2} & $M$ & 9.80 & 7.70 & 5.70 & 2.80 & 7.10 & 5.20 \\
\hline & $S D$ & 7.96 & 3.97 & 4.67 & 1.87 & 5.47 & 3.22 \\
\hline & $S E$ & 2.52 & 1.26 & 1.48 & 0.59 & 1.73 & 1.02 \\
\hline Total & $M$ & 7.95 & 7.60 & 3.75 & 3.10 & 5.90 & 3.70 \\
\hline
\end{tabular}


A topic factor alone appears to explain the results obtained for the first two levels of resourcing which cover topics one to four as the two groups irrespective of whether they are experiencing the talk or without talk condition have a similar pattern of achievement. It is also interesting to note that group two mean scores for these two levels of resourcing are consistently higher than those of group one. On topic five however, the difference in scores for frequency of elaboration of grounds becomes less. Although differences in frequencies can be observed, the general trends in the data for the first two levels are similar as Figure 10 below indicates.

Figure 10 Mean frequency of elaboration of grounds for topics across levels of resourcing

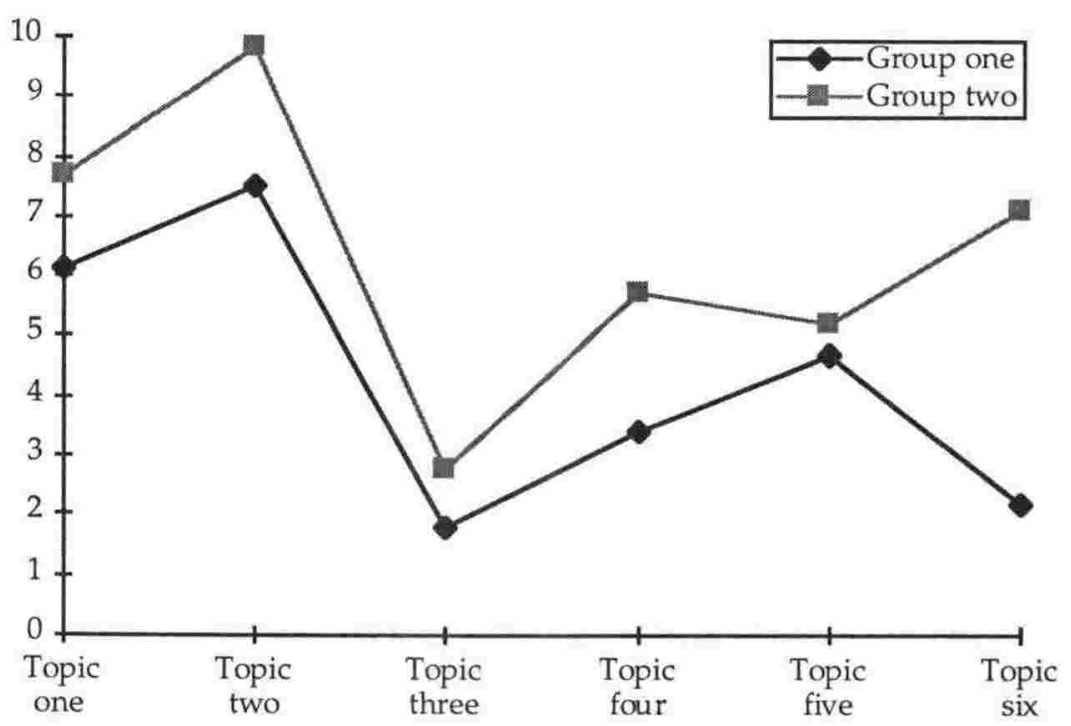

At topic six, which was also carried out with the support of the greatest level of resourcing, a different pattern emerges. Students working together with this level of resourcing and on this topic produced higher scores. Topic six was one in which few students would have had content and 
domain-specific knowledge. Group two working on this topic with talk enjoyed a significant advantage over group one who worked in a solitary way. This pattern is similar to that observed for the frequency of grounds (see Figure 9).

It appears that when faced with a topic on which students have little content and domain-specific knowledge, talk is critical for realising in text, grounds-related material for supporting the argument.

\subsection{Ratio scores}

The ratio scores captured relative, rather than absolute, frequency of constituents. As mentioned in section 5.7.2, ratio scores were seen as an alternative way of capturing the degree of elaboration in the argument texts the students wrote. This would be particularly true of the ratio score related to the relative frequency of grounds to elaboration of grounds. The ratio score expressing the relative frequency of claims to grounds aimed to capture the fact that 'good' argument texts need to be weighted in the area of grounds rather than claims. The results below indicate that there does appear some consistency with the latter and the frequency of grounds results.

\subsubsection{Claims/elaboration of claims}

No statistically significant effects were reported on this measure. The elaboration of claims in the students' texts appeared unrelated to the various conditions under which students were working during the study. 


\subsubsection{Grounds/elaboration of grounds}

The multivariate analysis performed on the ratio data for grounds/elaboration of grounds showed statistical significance ( $p=$ 0.0026 for the level of resourcing. The results of the ANOVA procedures are given in Table 20 .

Table 20 ANOVA of ratio scores for grounds/elaboration of grounds for level of resourcing

\begin{tabular}{|c|c|c|c|c|}
\hline Source & $F$ & Num df & Den $d f$ & $p$ \\
\hline $\begin{array}{c}\text { Level of } \\
\text { resourcing }\end{array}$ & 10.55 & 2 & 15 & 0.0003 \\
\hline
\end{tabular}

Table 21 below indicates that it was the non-resourced writing that had the greatest positive effect on the ratio scores for grounds/elaboration of grounds. The semi-resourced condition resulted in the least positive effect. The entries in Table 21 represent the relative frequency with which grounds were elaborated in the students' texts. For example, when using general prior knowledge as support for their texts (non-resourced writing), students on average tended to develop every ground with additional propositions while the semi-resourced writing resulted in approximately one in three grounds being elaborated. 
Table 21 Descriptive statistics for ratio scores for grounds/elaboration of grounds: means, standard deviations and standard errors of measurement for level of resourcing

\begin{tabular}{|c|c|c|c|}
\hline Statistic & $\begin{array}{c}\text { Non-resourced } \\
\text { writing }\end{array}$ & $\begin{array}{c}\text { Semi-resourced } \\
\text { writing }\end{array}$ & $\begin{array}{c}\text { Resourced } \\
\text { writing }\end{array}$ \\
\hline$M$ & 1.39 & 0.62 & 1.00 \\
$S D$ & 0.91 & 0.58 & 0.98 \\
$S E$ & 0.14 & 0.09 & 0.16 \\
\hline
\end{tabular}

\subsubsection{Claims/grounds}

The ratio scores for claims/grounds appears to be affected by the interaction of factors: task, treatment, and group. The level of significance reported is $\mathrm{p}=0.0010$. Results of the ANOVA procedures are reported below in Table 22.

Table 22 ANOVA of ratio scores for claims/grounds for level of resourcing; level of resourcing $\times$ level of talk $\times$ group interaction

\begin{tabular}{|c|c|c|c|c|}
\hline & $F$ & Num df & Den $d f$ & $p$ \\
\hline $\begin{array}{c}\text { Level of } \\
\text { resourcing }\end{array}$ & 10.54 & 2 & 15 & 0.0003 \\
\hline $\begin{array}{c}\text { Level of } \\
\text { resourcing } \times \\
\text { level of talk } \times \\
\text { group } \\
\text { interaction }\end{array}$ & 5.35 & 2 & 15 & 0.0099 \\
\hline
\end{tabular}

Means, standard deviations and standard errors of measurement are compared in Table 23. 
Table 23 Descriptive statistics for ratio scores for claims/grounds: means, standard deviations, and standard errors of measurement for level of resourcing, level of talk, and group

\begin{tabular}{|c|c|c|c|c|c|c|c|}
\hline \multirow[t]{2}{*}{ Group } & & \multicolumn{2}{|c|}{$\begin{array}{l}\text { Non-resourced } \\
\text { writing }\end{array}$} & \multicolumn{2}{|c|}{$\begin{array}{l}\text { Semi-resourced } \\
\text { writing }\end{array}$} & \multicolumn{2}{|c|}{ Resourced writing } \\
\hline & & Talk & No talk & Talk & No talk & Talk & No talk \\
\hline \multirow[t]{3}{*}{1} & $M$ & 0.95 & 1.58 & 0.45 & 0.80 & 0.84 & 0.20 \\
\hline & $S D$ & 0.56 & 1.48 & 0.30 & 0.31 & 0.48 & 0.15 \\
\hline & $S E$ & 0.18 & 0.47 & 0.10 & 0.10 & 0.15 & 0.47 \\
\hline \multirow[t]{3}{*}{2} & $M$ & 1.13 & 0.62 & 0.70 & 0.37 & 0.60 & 0.63 \\
\hline & $S D$ & 0.61 & 0.40 & 0.42 & 0.24 & 0.40 & 0.25 \\
\hline & $S E$ & 0.19 & 0.13 & 0.13 & 0.07 & 0.13 & 0.08 \\
\hline Total & $M$ & 1.04 & 1.10 & 0.58 & 0.59 & 0.72 & 0.42 \\
\hline
\end{tabular}

The relative frequency of claims to grounds showed a similar pattern to that observed for the frequency data related to grounds and elaboration of grounds when the ratio scores were plotted according to topic. The topic factor again appeared to explain the group effect (see Figure 11 below). 
Figure 11 Mean ratios of claims to grounds for topics across levels of resourcing

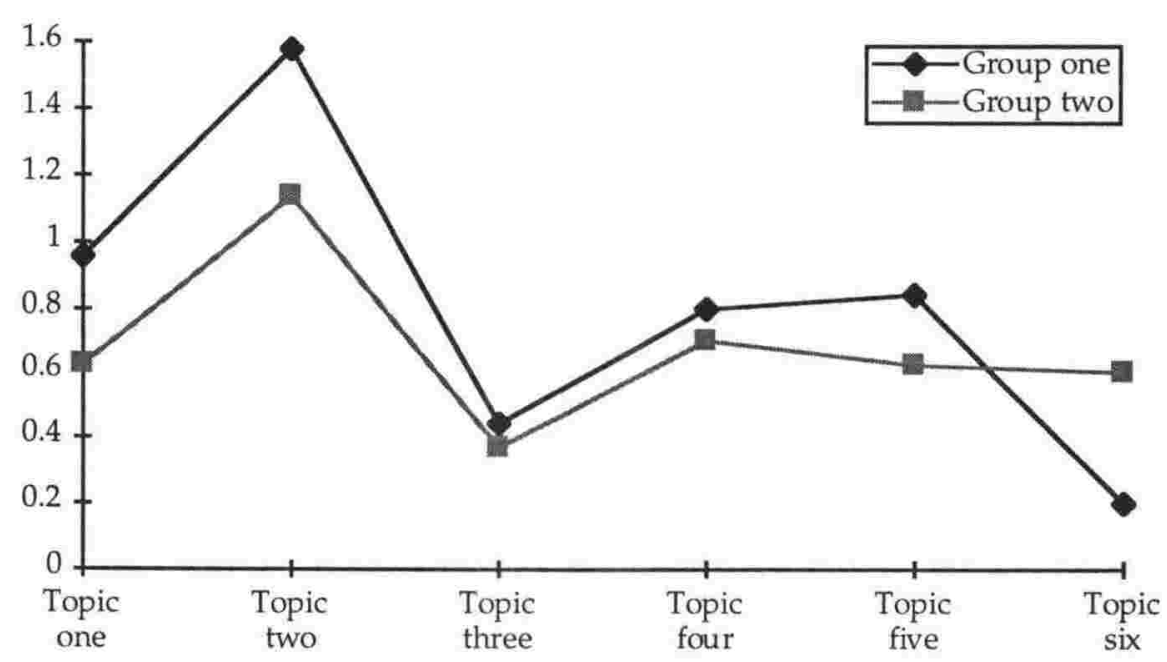

Figure 11 shows that in general, the groups responded similarly to each of the topics from one to four. However, on topics five and six, the group working with a partner before and during writing produced the greatest mean ratio scores.

\subsection{Summary}

The results of the quantitative analysis indicate that responses to the research question:

Does an instructional cycle that provides opportunities for talk of a particular kind lead to a better text than an instructional cycle that contains little or no opportunities for talk?

is not a straightforward one. Explaining the type of effects is a response to research question two:

What type of effect do opportunities for talk have on the quality of argument texts produced? 
In some instances, the opportunity to work in a solitary way appeared to result in gains that were greater than those when working with a partner. These gains were statistically significant in the area of linguistic accuracy and complexity, and frequency of claims. When talk was statistically significant, its effect appeared to be mediated by the type of topic students were writing on. Positive effects resulted from talk when students were working on topics 5 and 6 , both of which required content and domain-specific knowledge over and above that provided by textual input. Those effects however were restricted to the frequency of grounds (as expressed in the frequency scores for grounds and the ratio scores for claims to grounds), and the frequency of elaboration of grounds.

Level of resourcing was significant as a main effect and in its interaction with the treatment, with talk. However, it also proved significant as a main effect. Providing students with fully textual input brought statistically significant gains in all three general measures of text quality. However, input in the form of fact sheets resulted in gains for frequency of claims and elaboration of those claims.

An interpretation of the patterns of effects for talk, and for solitary activity are discussed in the following chapter, as are interpretations relating to resourcing effects. 


\section{DISCUSSION OF QUANTITATIVE RESULTS}

\subsection{Introduction}

Chapter three presented claims relating to the benefits of talk. It has been claimed that talk brings a number of different kinds of cognitive benefits as well as benefits relating to language acquisition. It also claimed to bring social and affective benefits. Some of these benefits cannot be seen to influence students' writing directly while some may in fact have a direct influence. In the former case, some influences may be able to be inferred from the transcript data described in the next chapter. In the latter case, the influences may be associated with the variables selected for analysis in the quantitative data. This chapter seeks to explain the complex set of effects present in the quantitative data. In particular, explanations have been sought in three areas: the specific effects of talk, the limited effects for talk with positive effects for solitary activity, and the effects for different types of resourcing. At times, reference will be made to the claims in chapter three. Where results are not interpretable with reference to these claims, other explanations have been sought.

\subsection{Explaining the specific effects of talk}

The research has pointed to very specific effects of talk. Positive effects were found in the resourced condition on some but not all of the variables. When faced with a topic on which students had little content knowledge, as was the case when they worked on topics supported by textual 
resources, talk appeared critical for realising, in text, grounds-related material for supporting a thesis.

A number of explanations need to be sought. Firstly, how could talk assist students when they have limited content knowledge? Secondly, how could talk assist when working with textual input? Thirdly, why were effects limited to grounds? The following discussion seeks to address these questions.

\subsubsection{Talk and content knowledge}

The content knowledge a writer brings to the writing task is clearly a factor in the successful production of text (see for instance Eigler et al, 1990). However, there is evidence that domain-specific topics vary considerably in terms of their requirement for knowledge, input, and information processing, prior to and during writing (see for instance the volume of articles edited by Carretero and Voss, 1994).

In the present study, the demands for domain-specific knowledge increased across the programme, with the last sessions requiring the most specific knowledge. Arguably the very last occasion, an Economics topic requiring students to reflect on the benefits of economic devolution would have placed the greatest demands on the students. The preceding topic was a historical/political topic, concerning Maori occupation of Moutua Gardens for the purposes of highlighting a land claim issue. The students would have been exposed to various perspectives on the topic through television and newspaper coverage of the event. In addition, all would have been exposed to land claim issues as part of the curriculum in the area of Social Studies. 
The reading of a writing topic and supporting resources by students would result, no doubt, in the activation of a schema albeit rather illformed. In addition, the students would have brought to the writing task, prior knowledge. It is the fact that talk appeared to bring closer the gap between what was known and what was specifically required for the writing task, that leads on to proposing the following functions of talk.

Under certain circumstances, talk can trigger memory searches of prior knowledge, it can facilitate the reorganisation of prior knowledge, and it can raise consciousness of knowledge gaps. Where relevant, talk enables thought to be monitored by the speaker and by others. De Bot (1996) makes similar claims with respect to language when he says that talk makes learners notice gaps in their linguistic knowledge and that noticing gaps may trigger cognitive processes which generate linguistic knowledge. In summary, talk provides a context for re-articulation, elaboration, transformation, and synthesis of other sources.

\subsubsection{Talk and grounds-related material}

In the present study, the processes mentioned above appeared to bring about effects in the area of grounds-related material. It appeared that talk could operate through these processes to help students generate concepts useful to support the claims made in their argument texts. How talk particularly helped to bridge the gap between what was known in terms of general and personally experienced and what was specifically required for the writing task is seen in the transcript data discussed in the following chapter. 


\subsubsection{Talk and textual resourcing}

In previous discussions of the variables related to the level of resourcing factor, it was mentioned that level of resourcing was, of necessity, confounded with topic. It would make little pedagogical sense to provide full textual support for topics that were well within the informational experience of students. However, for the moment, if we focus on the interaction effect between talk and level of resourcing, we can hypothesise that talk is useful in mediating textual resources. If we also wish to consider the effect of topic, we may hypothesise that when students were more reliant on textual resources to fill in gaps in background knowledge, talk may have helped to access ideas from those textual resources. However, as will be explained in the following chapter, the talk that successful pairs engaged in made no reference to the textual resources, rather it focused on students' own prior knowledge. The fact that they made no reference to the textual resources may actually be due to lack of content or domain-specific knowledge. As Moravcsik and Kintsch (1995:233) point out, domain-specific knowledge is not surprisingly a necessary condition for understanding texts.

\subsection{Explaining effects of solitary activity}

It was expected that there would have been better performance on the variable of linguistic accuracy and complexity in particular, and to a lesser extent on the variable of organisation and ideas, on the basis of two claims: one, that talk enhances fluency (Swain and Lapkin, 1995); and, two, that interaction can lead to improved grammatical performance (Pica, 1988; Pica et al, 1989). One may also have expected better performance on the variable of communicative quality on the basis of the 
claim related to fluency and that of Mangelsdorf (1989) that speaking activities combined with writing make writers more aware of audience requirements, thereby improving communicative quality. The results of this study did not confirm those predictions. Rather surprising however, were the positive effects on grammatical accuracy and complexity found for solitary activity at all stages of the programme. The effects were not associated with a particular occasion or level of resourcing. Explanations for the fact that solitary activity produced better linguistic accuracy and complexity scores are put forward below.

The explanations are grounded in the cognitive theory. The first major explanation lies in the notion of interference (or constraints on performance) and transfer (or facilitation), while the second makes reference to the attentional resources that a second language learner of English has at her/his disposal.

\subsubsection{Interference and transfer}

Chapter three included discussion of the output hypothesis, one of the major theoretical rationales for group work. Ellis's comment (1994: 283), "Evidence that learners improve the grammaticality of their utterances when pushed does not of course constitute evidence that acquisition takes place" is of relevance. We cannot assume that accuracy in the context of the speaking will transfer to the writing. The results of this study verify that caution.

A number of writers have predicted constraints on performance when students move from speaking to writing. Previously mentioned is Mangelsdorf's (1989) claim that there may be interference specifically 
where students apply speaking processes directly to writing processes. Bereiter and Scardamalia (1986) and Knudsen (1989) claim that there is interference specifically when moving from spoken argument to written argument.

How interference manifests itself is left unspecified by the writers mentioned above. Given Mangelsdorf's claim, one may have expected to find the effects of constraints evident in the communicative quality scores, but that did not occur. Given the claims made by Bereiter and Scardamalia, we may have expected to find constraining effects of talk evident in the way the rhetorical demands of the argument texts were met. Again this was not the case. The fact that no significant effect was found for the ideas and organisation suggests as may be expected, that constraining effects were limited largely to language concerns.

It may be that the claims of the negative relationship between spoken and written argument from a long term developmental perspective do not apply to the present study. The fact that speaking and writing were temporally aligned in the present study may have meant that the 'closedness' of the discourse requirements (Rumelhart, 1980) was facilitated as the result of the articulation of ideas and the laying out of a rhetorical plan. This may have had immediate effects on subsequent text production.

\subsubsection{Attentional resources}

The notion of attentional resources is fundamental to information processing and skill learning models of SLA (second language acquisition) (Anderson, 1983; McLaughlin, 1983). De Bot (1996:549) explains, 
"attention can be viewed as a limited set of mental resources that have to be shared by various processing activities". As mentioned in Chapter 3, de Bot (1996) says that the re-allocation of resources accounts for a shift from meaning to form-related aspects of language with speaking. Not specifically stated, but implied is that a demand on attentional resources occurs when students have less proficiency. There is considerable evidence in writing research to show that inexpert writers divest attentional resources in the same way as described above for speaking (see for instance Scardamalia, Bereiter and Goelman, 1982).

Speakers with greater proficiency would presumably be closer to the case of native speakers whom de Bot (1996:550) says experience the following: Most attention goes to higher processes such as the coordination of intentions; lower automatic processes on the morphosyntactic and phonological/articulatory level receive hardly any attention.

The output hypothesis which proposes that speaking pushes learners to consider lower level concerns does not account for the performance of students with greater proficiency. For the second language students in this study, the demand placed on them by communicating with a partner may have resulted in less, rather than more attention being paid to the surface features of their texts, as in the case with native speakers. Thus, the level of proficiency of the students in this study may have been a factor in determining how attentional resources were distributed.

As the measure for ideas and organisation was the least affected by opportunity to work in a solitary way, we may suppose that these students were in fact engaged in higher level concerns both in speaking 
and writing. A critical issue remains and was briefly alluded to in the beginning of section 7.3.1. We are assuming that language processing benefits gained from speaking, transfer to writing. Therefore if students were engaged in more high level concerns with writing, this would have facilitated these concerns in speaking. This seems logical but remains untested.

\subsection{Explaining the limited effects of talk}

The position that this discussion has assumed is that where solitary activity has no significant effect, there is potentially a positive effect from talk. However we know that the positive effects of talk are limited and specific. Are there in fact conditions that undermine potential positive effects from talk? These are discussed below.

Not only does the students' own information-processing ability affect how much input they can process (and presumably how much output they can process also), but also the nature of the task (Ellis, 1994: 390). A potential task factor that could contribute to the competition for attentional resources is 'task shifting', the moving from one type of task to another. In this study students were required to operate in two modes, one with speaking and one without. The speaking they were required to do was highly structured, and in terms of Doyle's $(1979,1983)$ analysis of tasks, students knew how and why they were to perform the speaking. The surveys reported in Chapter 2 suggest that the types of experience set up by the speaking tasks in the instructional sequence are not frequently encountered by students and would have been novel. The fact that the talk experienced in the instructional cycle was novel meant that it 
required a 'task shift' and that it had an associated 'cost' (Meiran, 1996). The cost was a decrement in performance. Specifically, the decrement was manifest in the linguistic accuracy and complexity of the texts the students wrote.

The fact that no positive effect for talk was found on the general measures of communicative quality, ideas and organisation and linguistic accuracy and complexity suggests that it may be necessary to design more specific dependent variables that are sensitive to the independent variable, opportunity to talk. For example, fluency may have been better investigated by protocol analysis or pausal analysis while students were writing (see for instance Matsuhashi, 1982).

The claim that talk encourages conceptual hypothesising and provides opportunities for the articulation of metalinguistic knowledge deserves exploration through transcript data. Indications of the latter, in particular, were observed in the transcript data from two of the three pairs selected for qualitative analysis in the following chapter.

The fact that positive effects for talk are not found in the initial stages of the programme may mean that we may need more time for an effect to take hold. As Meloth and Deering (1994) commented on their study, students appeared to need more time to adjust to new patterns of interaction in the two interactive conditions they set up. 


\subsection{Explaining the effects of resourcing}

As mentioned previously, level of resourcing proved to have statistically significant effects on the dependent variables irrespective of the talk condition. In section 7.2.3, the way in which level of resourcing could have interacted with content knowledge was discussed. In this section, the main effect associated with level of resourcing is related to the composing requirements of specific features of argument texts.

\subsubsection{The effects of non-textual resourcing}

The fact that the frequency of claims and elaboration of claims in students' texts were most affected by the semi-resourced form of input and the opportunity to work independently may be partly explained with reference again to the work of Mayer, Bove, Bryman, Mars and Tapangco (1985). Mayer et al (1995) claimed that the two features of source material, coherence and conciseness, affected the retention of content, and the ability to use content to solve problems in Science.

Textual input, used in the present study, can be characterised by coherence while fact sheets, representing the semi-resourced condition, can be characterised by conciseness. What does conciseness in resources facilitate? The cognitive rationale for conciseness is that a concise summary allows the learner to select the relevant words and images. By paying attention to the relevant material, the learner is able to build verbal and visual representations (Mayer et al, 1995: 65).

It may be that the frequency of claims and elaboration of claims reflected the fact that the students were, by and large, accessing material from the 
fact sheets and using that to represent their claims and elaboration of claims. Verbal and visual representations may be likely prerequisites for claims and elaboration of claims. The material in the fact sheets may have correlated more closely with that needed for claims and elaboration of claims and therefore also required little transformation. One possible interpretation of this is that the students merely copied the items from the fact sheet as these were indeed useful for claim-like material (see Appendix 1.2 for a sample fact sheet).

This in fact may have been the case for many of the students, although it was not the strategy reflected in all students' texts. Some students did in fact utilise the material in the fact sheets for grounds-related material. The following section of a student's text indicates how she has utilised the claim-like statements from the fact sheets (in normal type) as grounds for claims that she herself has produced (in italics).

The Department of Conservation should use the poison to kill the possums (claim) because it will be very harmful to animals and non living things (grounds). An example of these ideas here are the meat of infected animals cannot be eaten. If it is eaten the disease can be transferred to humans. Possums also destroy vegetation on farmland and the areas where vegetables are grown and also the trees in the orchards (elaboration of grounds).

(Student 6, group 1)

Clearly, an issue worthy of further exploration is how students make changes to and transform rhetorical plans from resources. This issue is again mentioned in the following section. The issue applies also of course 
to changes and transformations of rhetorical plans from prior knowledge, as mentioned above.

\subsubsection{The effects of textual resourcing}

The results of the research showed that students' texts were better on all three general analytical measures when they worked in the resourced condition. The finding that textual resourcing is the most valuable for the three general analytical measures, can be explained by the coherence of fully textual material. Mayer et al indicate how coherence may help in the construction of text. They state, "The cognitive rationale for coherence is that a coherent summary allows the learner to organise the relevant words and the relevant images into respective cause-and-effect chains" (Mayer et al, 1995:65). Mayer et al's statement gives support for the claim that textual input appeared to be a valuable linguistic and rhetorical resource for students when writing argument texts but it was less valuable for extracting content and propositions to support claims in argument texts. While fact sheets provided an accessible resource for claim-like material, textual resourcing may in fact have been relatively inaccessible. Propositions from the resource material required even greater transformation. As a linear text, the textual resource in itself represented a particular genre, and one which was different from argument. Both texts used in the resourced condition were largely recounts, giving historical information leading up to the present situation. Another way to describe the texts is with reference to Johns and Davies (1983) topic type analysis. The texts were state-situation texts. The rhetorical organisation of the resource material was not consistent with the planned writing outcome, which required the statement of a major claim or claims, and support through grounds and elaboration. 
The issue of the interaction effect when talk with textual resourcing was seen to benefit specific aspects of argumentation (namely grounds and grounds-related material) has previously been accounted for in section 7.2.3. However, the discussion above (section 7.5.2) has concerned itself with the main effects found for level of resourcing. A last point in association with the main effects of textual resourcing needs to be revisited. Although the interaction effects suggested that much of the improved performance may be attributed to textual resourcing per se, some part may also be attributed to the fact that this condition occurred at the end of the programme, when students may have been more used to speaking and gaining from speaking, when students may have been more tolerant of 'task shifting', and when students were becoming more familiar with the genre. These factors, associated with time on the programme may have contributed to improvement on the three general measures of text quality, and frequency of claim-related material where main effects were located.

\subsection{Additional factors}

The additional factor of time on the programme is discussed above. A last issue which arises when considering the relative value of talk is addressed below. The opportunity to talk with a partner in this research study made no essential contribution to argument text construction except in the context when content knowledge was lacking and grounds-related material was required. Said another way, the opportunity to talk could be replaced by solitary activity with similar results when students were writing from personal knowledge, on topics within their experience. Clark (1994), with reference to media intervention research has commented that 
in circumstances where a treatment can be replaced by another with similar results, the cause of the results is likely lie in some shared property or feature of both treatments. With respect to the present research, the features of the instructional sequence experienced in both the talk and without talk condition were described in Chapter 4. These include opportunities to articulate prior knowledge, opportunities to brainstorm and organise ideas, studying model texts and setting criteria, and the use of cue cards to develop specific procedural knowledge and generate domain-specific knowledge. Possibly the most likely candidate and the most potentially powerful of these is the use of the cue card as it develops and encourages knowledge consistent with views of writing expertise.

\subsection{Conclusion}

This chapter has sought explanations for the fact that talk had positive effects on the argument texts constructed by students but that these effects were limited. Talk appeared to play a role in generating content and domain-specific knowledge when students lacked it. The following chapter specifically explores how this could have been done by examining transcript data knowledge from one successful pair of students and two less successful pairs.

This chapter also sought to explain why solitary activity was found to have a beneficial effect on linguistic aspects of the students' texts by referring to research on constraints on performance, facilitation, and attentional resources. 
The effects of different types of resourcing also required explanation. The present study found that certain types of constituents for argument texts were more accessible from certain types of resources. One aspect that may have determined the accessibility of certain resources was the degree to which transformation of constituents from resource to students' own texts was required.

The results of the present study point to the fact that different forms of presentation of resource material for teaching writing across the curriculum requires further investigation as do the different processes that students may engage in as they write in a collaborative way and a solitary way. What exactly students do when they use talk effectively for bridging the gap between what is not known and what is required by the writing task is now dealt with in detail in the following chapter. 


\section{ANALYSING INTERACTION}

\subsection{Introduction}

The results of the quantitative data analysis pointed to the fact that effects from opportunity to talk were highly specific. The preceding discussion of the findings from the quantitative data analysis served to explain those effects to some extent. In so doing, it introduced consideration of some of the factors which may have contributed to the effects found in the study. The most important interpretation of the results appeared to be the fact that talk did contribute to the content resources available to students for subsequent writing.

This chapter considers the third research question, What is the nature of talk that best facilitates the production of argument texts? As a qualitative question it seeks to provide insight into the type of talk that took place between pairs of students and how different types of talk set up the conditions that facilitated better argument text construction. In other words, this is an analysis and discussion of the conditions under which talk produced positive effects. This line of investigation is consistent with recent work on cooperative learning. Cohen in her review article sums up the findings of recent research on cooperative learning. She states, "The advantages that can theoretically be obtained from cooperative learning can be obtained only under certain conditions" (1994:2). 
The data used to investigate conditions under which talk produces positive effects on the writing of argument texts were transcripts of peer interaction as students prepared for writing and while they wrote.

\subsection{Method}

\subsubsection{Selection of pairs for analysis}

The selection of peer interaction data for analysis was determined by the results of statistical analysis. Stables (1995) cautions researchers using transcript data. He maintains that the analysis of such data is open to individual interpretation and thus can be used to serve the researcher's own agenda. However in this study, the transcript data provided a means to interpret results already established by means of statistical analysis.

The quantitative statistical analysis showed positive significance for talk in the area of grounds-related material, only with a specific group, on a specific occasion. The specific effect was located for group two on topic six. When the standard deviation of the group on that occasion for the frequency of elaboration of grounds was examined, it was clear that there was considerable variation in terms of the positive effect gained from opportunity to speak. Cautioned by the fact that variation existed, the researcher selected three pairs that showed different patterns of effect for frequency of elaboration of grounds. The three pairs (with pseudonyms to ensure confidentiality) were: 
One of these students, Stan, scored highly on both measures while the other, Alan, had low scores. Both students had high initial rankings resulting from the pretest. Stan was ranked 1, while Alan was ranked 3, (rankings were from 1 to 10 ).

$2 \quad$ Will and Fred

Neither of these students scored highly on both measures. Will had an initial ranking of 6 while Fred had 8 .

3 Anne and Carl

Both of these students scored equally highly on both measures. Anne's initial ranking was 2, while that of Carl was 7.

It should be noted that the pseudonyms were chosen the basis of their closeness to the students' already anglicised names.

\subsubsection{Transcription}

The tapes of the interaction between the three pairs above were transcribed. The transcripts were minimally punctuated to facilitate reading. All phonological and paralinguistic information was omitted so that a focus on content could be maintained. This approach to transcription has previously been used by Fisher (1996). Full transcripts can be seen in Appendix 7.

The transcription yielded turns as the unit of analysis. Crookes (1988: 145) has this to say of the turn: 
A widely used discourse analysis unit is the turn, which is commonly defined as one or more streams of speech bounded by the speech of another, usually an interlocutor.

As Crookes states, the turn is usually a superordinate category and as such can be combined with another more finely grained unit if desired. As the purpose of the analysis was to capture the nature and function of peer talk, other linguistically defined units were rejected in favour of units of analysis similar to those used in Meloth and Deering's (1994) method of coding peer-group talk (see Appendix 9). Meloth and Deering's coding scheme has three aims: to describe the ways in which information was conveyed, to describe the quality of that information and to describe the level of cooperation between the peers. This seemed a valid approach to guide the analysis of the data of the current study. The adaptation of Meloth and Deering's coding scheme is described in the section below and presented in Figure 13.

\subsubsection{Framework for analysis}

Meloth and Deering (1994) propose three major types of talk in class tasks: academic, social/behavioural, and off task. These three types were adhered to in the model developed for the current study. The next level of analysis is a set of four major categories that specify the nature of the academic talk in particular. The four major categories from Meloth and Deering are: content talk, task question, task response, and oral reading. The categories content talk and task question were combined to form a category called task initiation which appears to be a more suitable functional match to the category task response and is consistent with other analyses of turn taking in the classroom (Sinclair and Coulthard, 
1975). An additional category was also added to this list. This category was labelled no response. It seemed important to record when the potential for a response existed or when a response could be expected but was not in fact made by the partner.

The most significant changes that were made to Meloth and Deering's coding scheme were made at the third level of analysis, the subcategories. Explanation/elaboration, an original subcategory, was replaced by two more general subcategories, substantive and procedural. It was discovered in the analysis of the data that there were initiations and responses that related specifically to the ideas or content of the topic and there were initiations and responses related specifically to getting the task done. Therefore these two subcategories were added to each of the two major categories. In addition to this, seeking clarification and providing clarification were added to the major categories, while counter-assertion (an original response subcategory) was removed and included in a subsequent analysis. The five subcategories within the social/behavioural type were retained from Meloth and Deering's original analysis. Off-task talk was not further analysed in any way by Meloth and Deering and neither is it here.

A discussion of observable features of the substantive and procedural talk replaced Meloth and Deering's last level of analysis. The purpose of this discussion was in general like that of Meloth and Deering, to describe the focus of the academic talk, but more specifically it was to focus on the nature of the substantive and procedural talk which would provide an insight into how the talk helped students to generate ideas, modify ideas, model processes and procedures all of which may have been available for 
the writing task. An analysis of the substantive and procedural talk is essentially an analysis of its quality. Figure 12 presents the coding scheme which was used in the study.

Figure 12 Coding scheme for peer talk (adapted from Meloth and Deering, 1994)

\begin{tabular}{|c|c|c|}
\hline Type of talk & Major categories & Subcategories \\
\hline \multirow[t]{4}{*}{ Academic } & Task initiation & $\begin{array}{l}1 \text { Substantive } \\
2 \text { Procedural } \\
3 \text { Seek clarification } \\
4 \text { Directive/direct attention } \\
5 \text { Offers of assistance } \\
6 \text { Other comment/ question }\end{array}$ \\
\hline & Task response & $\begin{array}{l}1 \text { Substantive } \\
2 \text { Procedural } \\
3 \text { Seek/provide clarification } \\
4 \text { Directive/direct attention } \\
5 \text { Repeat/acknowledge } \\
6 \text { Evaluation }\end{array}$ \\
\hline & Oral reading & \\
\hline & No response & \\
\hline $\begin{array}{l}\text { Social/ } \\
\text { behavioural }\end{array}$ & & $\begin{array}{l}1 \text { Positive appraisal } \\
2 \text { Cooperation } \\
3 \text { Negative appraisal } \\
4 \text { Pacing } \\
5 \text { Management }\end{array}$ \\
\hline Off task & & \\
\hline
\end{tabular}




\subsubsection{Procedure for analysis}

A description of the procedure for analysis will now serve to summarise the main points above as well as set out how the actual analysis took place. To analyse the types and categories of talk, the procedure for analysis involved the following. The transcript data was first coded according to Meloth and Deering's three types of talk, academic, social/behavioural, and off-task. Turns were then categorised according to one of the three major categories, task initiation, task response, or oral reading, and then further subcategorised. The talk (if it constituted task initiations or responses) was subcategorised. In the case of indecipherable turns, it was possible to categorise these as either task initiations, responses, oral reading or off-task. However it was not generally possible to further analyse the form of the turn. The number of times the potential for a response was not acted upon by a participant was also recorded in the major category, no response. Social/behavioural talk was also subcategorised. This coding procedure was followed by an analysis of frequency of types and categories of talk and an interpretation of that frequency data.

A number of questions guided the discussion of how the interaction of each of the three pairs operated. The questions and their theoretical rationale are given below.

$1 \quad$ What percentage of the talk was off task?

This is a general measure indicating whether or not students were engaged in the task. 
To what extent was positive social and behavioural talk used?

Meloth and Deering (1994:140) claim that this indicates the nature of the social climate and the general level of cooperation between participants.

3 How many initiations, either by statements or questions, were responded to?

As with question 2 above this may serve as an indicator of the level of cooperation between participants. This is also an indication of the way in which peers actually responded to the initiations of their partner. Conditions of effective talk are that questions are not only asked but responded to (Barnes, 1976); and that responses are matched to the requests of the partner (Webb, 1994).

4 How many repetitions and acknowledgments of each other's statements were made?

Repetitions and acknowledgments of another's talk (back-chanelling devices) have been used in previous analyses of interaction (Cazden, 1988). Cazden comments that they can indicate the level at which peers are contributing to the interaction (1988:144). For collaborative talk to occur, Wells (1989) maintains that participants must ensure that mutual understanding is maintained. Back-chanelling devices may also indicate the extent to which participants are working to maintain mutual understanding.

How many turns sought clarification or provided clarification?

Seeking clarification is an aspect of negotiation. Negotiation is a key feature of productive group work (Long, 1989) and, like back-chanelling devices discussed above, may indicate that students are aiming to maintain, if not mutual understanding, then at least their own individual 
The discussion looks at what the participants' substantive and procedural talk covers, how their talk relates to that of their partner and the respective roles that the participants play in the interaction.

\subsection{The interaction of three case study pairs}

\subsubsection{Stan and Alan}

The interaction between Alan and Stan is described below, based on the results of coding the turns (Table 24). The full transcript of the interaction is given in Appendix 7.1.

\subsubsection{Types and categories of talk}

The interaction of this pair of students is minimal, the least of all three pairs. In total, Alan and Stan engaged in 51 turns. Just under half of the talk $(49 \%)$ they engaged in, was off-task talk. Little social/behavioural talk was used with only one instance. Another noticeable feature of the interaction is the high number of times no responses occurred. On eight occasions, initiations were not responded to. Not surprisingly more of these initiations, particularly substantive questions came from Alan, the weaker of the two students (see section 8.3.1.2 for a further analysis and examples).

The total number of responses recorded in the transcript was 5 (one of which was not able to be subcategorised). Only two attempts were made to seek or provide clarification, a type of response. On two occasions, the participants repeated or acknowledged the other's talk by devices such as OK. On only one occasion did one of the participants, Alan respond 
beyond the level of mere acknowledgment. Alan made one evaluation of Stan's oral reading, when he stated:

Alan: You're writing in economics language. You're writing it actually in economics language.

The fact that so little of Stan and Alan's talk was on-task, suggests that they took little opportunity to interact with each other on matters relating to the completion of the instructional sequence. Little cooperation existed between the pair and neither did they work to maintain mutual understanding. One thing that should be said about Stan is that he did attempt to control the interaction by means of directives or attempts to direct attention. Three of the four examples below are his:

Stan: These are my points

Stan: Solet's see

Stan: Finished?

Alan: Read your three lines aloud

The turns that each student took that could be categorised as task-related talk (task initiations and task responses) numbered 17 and constituted $33.25 \%$ of all talk. However, as explained above, this category includes talk such as directives, and repetitions. When one tallies the number of turns that are either substantive or procedural, (subcategories 1 and 2 for task initiations and task responses) the result is an occurrence of only four turns (approximately $8 \%$ of all turns). 
Table 24 Frequency of types and categories of talk in the interaction between Stan and Alan

\begin{tabular}{|c|c|c|c|c|}
\hline $\begin{array}{l}\text { Major } \\
\text { categories }\end{array}$ & Subcategories & & Total & $\%$ \\
\hline Task initiation & $\begin{array}{l}1 \text { Substantive } \\
2 \text { Procedural } \\
3 \text { Seek clarification } \\
4 \text { Directive/direct attention } \\
5 \text { Offers of assistance } \\
6 \text { Other comment/ question } \\
\text { Unable to be subcategorised }\end{array}$ & $\begin{array}{l}3 \\
1 \\
1 \\
4 \\
0 \\
0 \\
3\end{array}$ & 12 & 23.50 \\
\hline Task response & $\begin{array}{l}1 \text { Substantive } \\
2 \text { Procedural } \\
3 \text { Seek/provide clarification } \\
4 \text { Directive/direct attention } \\
5 \text { Repeat/acknowledge } \\
6 \text { Evaluation } \\
\text { Unable to be subcategorised }\end{array}$ & $\begin{array}{l}0 \\
0 \\
1 \\
0 \\
2 \\
1 \\
1\end{array}$ & 5 & 9.75 \\
\hline Oral reading & & 7 & & 13.75 \\
\hline No response & & (8) & & NA \\
\hline $\begin{array}{l}\text { Socio/ } \\
\text { behavioural }\end{array}$ & $\begin{array}{l}1 \text { Positive appraisal } \\
2 \text { Cooperation } \\
3 \text { Negative appraisal } \\
4 \text { Pacing } \\
5 \text { Management }\end{array}$ & $\begin{array}{l}1 \\
0 \\
0 \\
0 \\
0\end{array}$ & 1 & 4.00 \\
\hline Off task & & 25 & & 49.00 \\
\hline Total & & 51 & & 100.00 \\
\hline
\end{tabular}

Further categorised utterances from the full transcript in the categories task initiations and task responses are given in Appendix 8.1. 


\subsubsection{The nature of the substantive and procedural talk}

In terms of forms of talk that directly relate to argument, little was carried out. As mentioned above, approximately $8 \%$ of all turns could be said to relate directly to either content or relevant procedures needed to complete the instructional sequence. On only one occasion was an explanation or elaboration offered which could serve usefully for either claims or grounds of the argument. No counter-assertions were made at any point in the interaction.

Two substantive questions were asked, neither of which were responded to. Stan asked the following:

Stan: What is the government for?

This question relates to the claims that could be made in the argument. One substantive question which focused on word meaning was asked:

Alan: I want to know this ... this word (...)?

As has been mentioned, the topic for this occasion was a difficult one and one which few had background knowledge of. One exception was Stan who was in fact studying Economics. It would appear that he had little need of peer interaction and made little effort to share his understanding of the topic with his partner, Alan. Therefore the peer interaction did little to help Alan. 


\subsubsection{Will and Fred}

The full transcript of the interaction between Fred and Will is contained in Appendix 7.2. Table 25 summarises the findings from the analysis of the transcript.

\subsubsection{Types and categories of talk}

Fred and Will talked more frequently than Alan and Stan. Ninety one turns were counted in this interaction compared with the previous figure of 57 for Alan and Stan. The talk between Fred and Will also featured much less off-task talk. In this interaction $21.75 \%$ of all turns could be classified as off-task talk, nearly half that seen with the previous pair.

Social/behavioural talk was relatively more frequent. However the most frequent type of social/behavioural talk was negative appraisal. The instances of negative appraisal numbered 4 out of a total of seven. All four instances of negative appraisal were uttered by Will and concerned the task itself, not Fred.

Will: Boring. I hate this (...) It's stupid

Will: This topic is so boring and we have to think

Will: It's stupid stupid stupid

Will: I hate those kinds of topics. The one I did before was better

Although the social/behavioural talk did little to facilitate positive interaction between the pair, the frequency of instances of no response were fewer, numbering six, than recorded in the previous interaction. The fact that participants in this interaction were more likely to respond can 
also be seen from the high frequency of actual responses. In total there were 27 responses, accounting for almost $30 \%$ of all turns. Eight of the 27 responses were acknowledgments, most of which were Will's. This suggests that, although Will appeared to have a negative attitude towards the task, he sometimes, but not always responded to his partner Fred, as in the interaction below.

Fred: I really don't know what to say

(Lengthy pause)

Fred: What do you say? What do you say for the first introduction?

Will: Boring. I hate this (...) It's stupid.

(Lengthy pause)

Fred: Tell me when you finish yours

Will: Yep. OK

\section{(Lengthy pause)}

Fred: Tell me yours

Other acknowledgments are of the form, Yeah, OK.

Acknowledgments may indicate a positive relationship between participants in interaction, however, they do not necessarily mean that much of substance is covered in the talk. Many of the acknowledgments were in response to Fred's directives or attempts to direct attention, not substantive initiations. There are eleven instances of these, ten of which were uttered by Fred. It appears then as if Fred controls and directs the interaction and Will is a less willing and less active participant. 
In this interaction, substantive talk accounts for nearly $19 \%$ of all talk, substantive/procedural talk accounts for just over 3\%, and procedural talk accounts for nearly $9 \%$. In total then, almost one third of the talk can be said to be substantive or procedural. There appears then to be a qualitative difference between this and the previous interaction between Stan and Alan. The next section discusses whether in fact this is so. 
Table 25 Frequency of types and categories of talk in the interaction between Will and Fred

\begin{tabular}{|c|c|c|c|c|}
\hline $\begin{array}{l}\text { Major } \\
\text { categories }\end{array}$ & Subcategories & & Total & $\%$ \\
\hline Task initiation & $\begin{array}{l}1 \text { Substantive } \\
2 \text { Procedural } \\
3 \text { Seek clarification } \\
4 \text { Directive/direct attention } \\
5 \text { Offers of assistance } \\
6 \text { Other comment/ question } \\
\text { Unable to be subcategorised }\end{array}$ & $\begin{array}{c}7,1 * \\
7 \\
1 \\
11 \\
0 \\
1 \\
0\end{array}$ & 28 & 30.75 \\
\hline Task response & $\begin{array}{l}1 \text { Substantive } \\
2 \text { Procedural } \\
3 \text { Seek/provide clarification } \\
4 \text { Directive/direct attention } \\
5 \text { Repeat/acknowledge } \\
6 \text { Evaluation } \\
\text { Unable to be subcategorised }\end{array}$ & $\begin{array}{c}10,2 * \\
1 \\
1 \\
0 \\
8 \\
2 \\
3\end{array}$ & 27 & 29.75 \\
\hline Oral reading & & 9 & & 10 \\
\hline No response & & 6 & & NA \\
\hline $\begin{array}{l}\text { Socio/ } \\
\text { behavioural }\end{array}$ & $\begin{array}{l}1 \text { Positive appraisal } \\
2 \text { Cooperation } \\
3 \text { Negative appraisal } \\
4 \text { Pacing } \\
5 \text { Management }\end{array}$ & $\begin{array}{l}2 \\
0 \\
4 \\
1 \\
0\end{array}$ & 7 & 7.75 \\
\hline Off task & & 20 & & 21.75 \\
\hline Total & & 91 & & 100.00 \\
\hline
\end{tabular}

* indicates substantive and procedural concerns are combined

Further categorised utterances from the full transcript in the categories task initiations and task responses are also given in for this interaction (see Appendix 8.2). 


\subsubsection{The nature of the substantive and procedural talk}

The instances of substantive talk are associated with several areas. The first of these is task number one in the sequence of instruction, setting criteria.

Will: For the introduction is actually is a excellent introduction It tells us what is the title talking about step by steps

Fred: I think that uh the introduction is very good too very easy to read

Fred: Uh (...) the second?

Will: Gives an example to show that Maoris people behaviour that is very good about that

Fred: Uhhuh Its good (...) a good example of the topic you know

Fred: Now the last one

Fred: I said that (...) examples suggesting for and against the topic which is (...)

Will: Um. OK

Will: Good ending um using good structure to finish the essay off

What is evident from the section of transcript above is that there is a sense in which the participants are moving through the task to get it completed, as the interaction follows a pattern in which responses are not further responded to. As Fisher (1996:242) states "If the participants see the task to be simply to 'get through' some aspect of work, it is quite likely that there will be little discussion and early 'closure'".

The interaction between Will and Fred very much follows through the stages of the instructional sequence. The section of transcript below relates to the second task, generating ideas.

Fred: I was thinking that that (...) some services but they should make some profit because if they don't do that they can't run (...) and uh They will have to increase the tax so that they can run that

(lengthy pause) 
Fred: Right we're starting. What do you say for uh (...)?

Will: This topic is so boring and we have to think

Fred: The Government does exist to provide service but it should charge a small amount for the service in order to be able to run an institution whether a school health or any other service My addition change was Any service provide by the Government it does not make a profit it might be closed To run this the Government may have to increase tax

Will: $O K$

(Lengthy pause)

Fred: What do you think there should be for first point?

(Lengthy pause)

Fred: I wrote this for the introduction should be a general comment about the topic about the history if possible (...) why Government should provide free services What is the advantage of doing this? Second paragraph why should should not the provide free services? and um advantages and um last (...) points in favour and against for the two paragraphs (...)

Fred: What'd you say? What'd you say?

Will: Um um What is the situation with (...) now. um Second part Is there any effects with the Government if the Government keep on provide a service without making a profit

Most of the substantive initiations in this section of transcript are put forward by Fred. In total there are only 7 substantive initiations. The fact that procedural initiations are as frequent, gives further support for the observation that Fred, in particular, and Will are concerned with getting the task done. The procedural initiations are below.

Fred: I really don't know what to say.

Fred: I don't know what to say but (...)

Fred: I can't think how to start this

Will: Can you think of anything that I should (...)

Will: Are you trying to expand your ideas?

Will: Are you trying to expand your ideas?

Fred: Do you think uh you need wh another reason that's good is about your (...) 
What the interaction between Fred and Will indicates is that the nature of the responses are critical. When either Fred or Will initiate, there is either no response, or the responses do not prompt elaboration or explanation. At best, the interaction between Fred and Will could be classified as 'cumulative talk' (Fisher, 1996:250). This type of talk occurs when speakers build on each others utterances and respond in a limited way, but not in an essentially non-reflective and uncritical way.

\subsubsection{Anne and Carl}

The full transcript of interaction between Anne and Carl is given in Appendix 7.3, while the list of categorised task initiations and responses is given in Appendix 8.3.

\subsubsection{Types and categories of talk}

The amount of talk engaged in by Anne and Carl was close to that of the previous pair, Fred and Will as in total there were 94 turns (see Table 25). However the talk was qualitatively different. The frequency of turns of different types and categories differed substantially. In the first instance, the amount of off-task talk for this pairing was extremely low with only $8.5 \%$ of all talk being off the topic. Secondly there was only one occasion on which no response was made but could have been made or could have been expected. The third important difference lies in the area of task initiations and responses. Task responses outnumber task initiations suggesting that sequences of turns are sustained for a length of time and that responses themselves are being responded to. In the previous pair, task responses almost equalled task initiations suggesting that talk was not sustained on a particular topic or issue for a period of time. In this 
interaction between Anne and Carl, not only is the ratio of responses to initiations high but the amount of substantive and procedural talk about the task (subcategories 1 and 2) is also great (just over $50 \%$ of the total number of turns).

Another frequent category of talk is directives and attempts to direct attention. These are equally shared between Anne and Carl, unlike Fred and Will. Repetitions and acknowledgments are also frequent. These two observations suggest that there is a cooperative and positive interaction between Carl and Anne.

Carl is the most frequent user of turns to seek clarification. His attempts focus largely on substantive issues, for example:

Carl: You said (...) takes (... ) when you going to hospital new country you didn't pay?

Carl: Just I am asking do we have the government hospital in Korea

Carl: What you write is the government should care about people more (...)

As mentioned above, the interaction between Anne and Carl featured a great deal of substantive talk. In total, 17 task initiations and 22 task responses could be classified as substantive. The nature of the substantive and procedural talk is discussed in the following section. 
Table 26 Frequency of types and categories of talk in the interaction between Anne and Carl

\begin{tabular}{|c|c|c|c|c|}
\hline $\begin{array}{l}\text { Major } \\
\text { categories }\end{array}$ & Subcategories & & Total & $\%$ \\
\hline Task initiation & $\begin{array}{l}1 \text { Substantive } \\
2 \text { Procedural } \\
3 \text { Seek clarification } \\
4 \text { Directive/direct attention } \\
5 \text { Offers of assistance } \\
6 \text { Other comment/ question } \\
\text { Unable to be subcategorised }\end{array}$ & $\begin{array}{l}17 \\
2 \\
4 \\
7 \\
0 \\
3 \\
1\end{array}$ & 34 & 35.5 \\
\hline Task response & $\begin{array}{l}1 \text { Substantive } \\
2 \text { Procedural } \\
3 \text { Seek/provide clarification } \\
4 \text { Directive/direct attention } \\
5 \text { Repeat/acknowledge } \\
6 \text { Evaluation } \\
\text { Unable to be subcategorised }\end{array}$ & $\begin{array}{c}22,3 * \\
3 \\
4 \\
2 \\
10 \\
1 \\
7\end{array}$ & 52 & 54 \\
\hline Oral reading & & 1 & & 1 \\
\hline No response & & 1 & & $\mathrm{NA}$ \\
\hline $\begin{array}{l}\text { Social/ } \\
\text { behavioural }\end{array}$ & $\begin{array}{l}1 \text { Positive appraisal } \\
2 \text { Cooperation } \\
3 \text { Negative appraisal } \\
4 \text { Pacing } \\
5 \text { Management }\end{array}$ & $\begin{array}{l}0 \\
0 \\
0 \\
0 \\
1\end{array}$ & 1 & 1 \\
\hline Off task & & 8 & & 8.50 \\
\hline Total & & 94 & & 100.00 \\
\hline
\end{tabular}

* indicates that substantive and procedural concerns are combined

\subsubsection{The nature of the substantive and procedural talk}

Apart from two claim-like statements, the rest of the turns centred around discussion of how two issues (the health system and taxation) 
were handled in the students' respective countries. The following sequence of turns illustrates this.

Carl: You said (...) takes (... ) when you going to hospital new country you didn't pay?

Anne: Um in government hospital no

Carl: Government

Anne: You pay little bit only so if just like I'm very poor now my (...) just like um I my just like uh I only have ten cents. Ok I only have ten cents and I have to go the hospital. So if I go to the hospital and then I tell I only have ten cents and I dress badly just like you can tell ...

Carl: (laughs)

Anne: You can tell that you poor. You don't have to pay you don't have to pay. Usually usually in Malaysia people go to private hospitals private clinics because just like the government hospital mostly mainly the doctors will just like uh you know. Because all those good doctors they open their own private hospitals just like um so then the bad ones stay in the Government hospital and then uh the nurses they will tr. just like under training so they will not train and then you know people just worry about going to going to government hospital

Carl: Just I am asking do we have the government hospital in Korea (Both laugh)

Carl: You know so tax

Anne You pay taxes?

Carl: No not me my parents

Anne: Yeah. Yeah

Anne: Is it high? High taxes? Or low?

Carl: Maybe normal because someone gave us (...) benefit (...)

Anne: Does does all those the money you pay go to the welfare just like

Carl: No. Some parts is going to army. Because North Korea South Korea

Anne: Oh yeah

Anne: So mean just like some of the money you pay have to go to just like the Government services like um Army or (...)

Anne: Army the same?

Carl: Yeah army the same. Some other things

Anne: Don't you feel don't you feel that is not fair? Just that you pay money to to to other people just like you giving money to other people

Carl: We have to pro protect by ourselves because North Korea and South Korea both (...) but about $17 \%$ is going to army

Anne: Wow!

Carl: Because depending depending on (...) the country 
The section of transcript above shows Anne initially making two turns in response to Carl's first attempt to seek clarification. The responses Anne gives are long and offer a great deal of substantive information. Then the roles change with Anne asking questions specifically about taxation in Korea. Her questions are factual and she seeks clarification to ensure she has understood Carl's intention. Then she asks Carl an evaluative question, "Don't you feel ...".

The ensuing discussion is about being a soldier in Korea and the conditions experienced by soldiers. The talk then continues on the topic of taxation. Taxation in Korea is a proposition that Carl used to support the claims made in his subsequent written text (see Appendix 10.1).

Again, in the section of transcript below, we see Anne in the role of initiator and facilitator in building on Carl's responses to previous questions.

Anne: So then just like if you if you work you work and then you pay taxes and then you get all Do you get pension?

Carl: No

Anne: You don't get pension! Oh goodness gracious

Carl: (...) some problem

Anne: So what do all Koreas do if they retire?

Carl: They what?

Anne: Retire

Carl: Um Few people like soldiers ...

Anne: No I mean just like like more if you just

Anne: Ssh (tells off another student)

(Both laugh

Carl: Just for few people like when someone (...) he hasn't got a one leg or something like this

(Both laugh)

Carl: When you return you get some money from the Government 
The sections of transcript above illustrate the fact that Anne and Carl adopt complementary roles in the interaction. Anne initiates most of the turns in the interaction, and Carl responds to her questions and prompts. Anne pushes Carl to provide further explanation and elaboration, which he does.

What characterises the talk of the participants in this productive interaction is its reflective and exploratory nature. Wegerif and Mercer in Fisher (1996:250) redefine exploratory talk as talk "in which participants engage critically but constructively with each other's ideas. It is characterised by the explicit use of reasons, a hypothetical mode and constructive exchanges".

Talk that appears particularly useful is when substantive and procedural concerns are combined. Not only does this appear to provide potentially useful content, it also appears to provide a model for how to proceed in the writing of an argument text. Anne does this on three occasions in response to Carl's initiations or requests for clarification. Two of these can be seen in the sequence below.

Carl: So .... So what do you think?

Anne: Well. There are there are benefits on both sides just like ....So I'm I'm going to write some just like some just like I'm going to write about the benefits if the Government just only um just like the more important uh just like they care more about profit so I'm going to write about the benefits and then on the other side

Carl: What you write is the government should care about people more (...)

Anne: That's right I'm I'm writing about on both sides what if the Government cares about people just like the benefits and then what if the Government does not care about the people the benefits I'm writing about both sides and then the conclusion 
It is difficult to account for Anne's expertise in this regard. However it is possible that the repeated use of the cue card and repeated experience with the task of setting criteria and evaluating argument texts became internalised by Anne and expressed in her interaction with a questioning partner.

Carl, the weaker student clearly benefited from the interaction with Anne. This is evident from the fact that he scored almost identically to Anne on the variables relating to frequency of grounds. Carl does not normally score so highly and was ranked fairly low in the initial rankings. His text produced on this occasion, picked up many of the concepts from the interaction. Carl's text and that of Anne is contained in Appendix 10. This supports the claim that talk can operate to generate useful content knowledge for writing, if it is indeed exploratory.

\subsection{Discussion of observations}

The transcript data from the case study pairs provides a number of insights both in the area of previous claims with respect to speaking and for the quantitative results of the present study. The interaction of the three pairs differed markedly in quantity and quality, a factor obscured to some extent by group data. Previous research in collaborative learning arrangements (see for instance Foreman in Cazden, 1988), has likewise found very different patterns of interaction in pairs.

The nature of the interaction varied in terms of quantity but most importantly it also differed qualitatively. The pair of students that exhibited the most productive talk engaged in more on-task talk, a greater 
amount of procedural and substantive talk, and a greater degree of sustained interaction on a topic. The less proficient partner in this interaction, Carl, appeared to have access to relevant prior knowledge and appeared able to transform this knowledge for use in supporting the claims made in the argument text under construction. The less productive pairs showed a variety of other features. Their interaction contained a greater amount of off-task talk, a smaller amount of substantive talk, and a greater number of responses not responded to. The interaction of Fred and Will, although seemingly more productive than that of Stan and Alan, was still characterised by a task completion orientation and lack of engagement. A number of different conditions distinguished the productive interaction from the non-productive. These are discussed below.

\subsubsection{Affective factors}

Affective factors with respect to both writing and speaking were raised previously. In writing, the perspective is that students may well experience negative academic affect and that this can influence writing performance. Bereiter and Scardamalia (1983), for instance, identify a 'low-road' approach where students avoid rhetorical problems that would lead to major changes of content, a 'take-it-or-leave-it' attitude towards the audience particularly and a willingness to put up with recognised weaknesses in structure of content and other deficiencies. In speaking, the perspective is that students may be positively affected by opportunities to interact with peers. However, given the potential for negative academic affect associated with writing tasks, and individual learning style preferences, the degree to which the participants engaged in and therefore benefited from interaction may have been limited and 
various. One of the students, Will, indicated on several occasions that he was not merely lacking in engagement but that he had negative views of the topic and task. Fred his partner, although not obviously negative, appeared to have a fairly procedurally-dominated attitude, an attitude of merely getting the task done.

\subsubsection{Engagement in knowledge sharing}

Bruffee (1984) proposed that if engagement in knowledge sharing was to occur, the discourse would have to be 'abnormal', in that the respective beliefs of the participants would be different. The distinction between abnormal and normal discourse does not seem directly to apply in terms of determining in the conditions that facilitated talk for argument text production in the present study. Bruffee focuses on beliefs being different. However, it appears from the study of the interaction of the case study pairs that benefits are likely when it is not beliefs as such, but rather background and content knowledge, that is different.

In the most successful pairing not only did both participants share different knowledge but they were engaged in that respective knowledge. There appears to be limited benefits both for language and content, from mere articulation. The condition that appears essential is engagement in the other partner's position. In the least successful pairing, one had the necessary content knowledge but chose not to share it with his partner.

The conditions that Wells (1989:260) specified for talk to result in critical thinking seem to be closer to what was observed in the transcript data. The speakers in the successful pairing did know each other's understanding and intentions, did take the appropriate steps to ensure 
that mutual understanding was maintained, did offer opinions and alternative suggestions each from his/her own perspective and did justify and support opinions and suggestions by relevant arguments.

\subsubsection{Gender}

Fisher (1996) in her two different groups observed very different interaction patterns. The three males that constituted one group:

exhibited a style of non-collaborative interaction.... Their talk showed few examples of listening to and building on one another's ideas but exemplified three individuals who were unclear how to develop ideas jointly. (p. 248)

The two least successful pairings in this study comprised males. The interaction that exhibited reflective and exploratory talk was made up of one female and one male. This is a small sample but nonetheless an interesting observation worthy of further investigation.

\subsubsection{Proficiency and expertise of participants}

Cohen (1994:10) reports "There is considerable support in the research for the beneficial effects of heterogeneous groups because of the hypothesised benefits to low-achieving students of receiving instruction from high-achieving students". In work investigating effects of low achieving children with high achieving children there is some evidence to suggest that low achievers will perform better, at a higher level of cognitive achievement (Tudge, in Cohen, 1994). It is also possible that high achievers will regress. The transcript data indicates that one weak 
student did in fact appear to benefit from interaction with his more expert peer.

The expertise of the peer related not only to her greater level of language proficiency and her higher level of writing proficiency, but also to her ability as a conversational facilitator. She initiated most of the interaction and was an active listener who provided support through the use of backchanelling devices and by means of questions and responses that required her partner to explain and elaborate.

\subsubsection{Clarifying the status of the variable, talk}

The sections above have discussed factors that may have played a part in determing the conditions for effective talk. This brings us to a consideration of talk itself. When investigating the effect of an independent instructional variable, in this case talk, it is important to examine the underlying constructs of the variable with respect to its status. Is the variable an actual cause of subsequent effects or does it enable conditions under which other effects can take place?

Talk can have causal features in the sense that a student through talk with a partner can initiate, direct, sustain and limit activity directed at achieving an eventual writing goal using the inputs available to her/him. Alternatively talk can also act as a constraint (boundary condition) placed on the degrees of freedom and latitude of behaviour that students have in particular task situations. In this view, the relationship between talk and writing proficiency is normative and not causal. Talk is judged according to its power to be appreciated by the learner as an aid to the construction of better texts. 
Talk may serve to articulate the parameters of the solution to the problem of constructing text. Indeed when the case study subject, Carl, constructed his argument texts subsequent to, and simultaneously with his interaction with Anne, he chose to remain within the limits of the discourse covered in the interaction. However the transcript between these two successful participants in interaction also demonstrated the causal potential of talk. The talk did prompt Carl to articulate prior knowledge relevant to the rhetorical and content demands of the writing task.

\subsection{Conclusion}

Talk, interaction, and discussion are very general terms. Any research that investigates their effects must look at the different conditions under which they take place. The analysis of a small number of the transcripts in this study indicates a huge variability in the way talk between participants was managed.

Talk that pushes a partner to respond, elaborate and explain appears to be successful in affecting subsequent text construction. This type of talk, variously referred to as constructive (Wells, 1989), collaborative (Cohen, 1994), and educational (Fisher, 1996), appeared to operate specifically to mediate between what the participants already knew (domain-related but not domain-specific) and what was required in their texts to relevantly support the claims made in their argument texts.

The evidence of this successful talk however is limited in this study to the interaction of one pair. Clearly much more investigative research needs to 
be carried out to explore how talk can operate to recall and facilitate the development of different types of knowledge required for expert writing performance. 


\section{CONCLUSION}

\subsection{Introduction}

The present study aimed to investigate the effects of talk on argument text construction. A number of premises underpinned the hypothesis that talk would bring positive effects both to the general and specific aspects of the argument texts students wrote. Talk and writing are not autonomous modes of communication. They share grammatical features and discourse features, and they share functions. Given their shared characteristics, one can assume that to some extent, the transfer of benefits from speaking to writing would be evident in the construction of argument texts in cooperative working arrangements.

It is claimed that speaking brings cognitive, language-related, and socioaffective benefits. The present study has pointed to specific effects of talk on argument text construction. The effects were seen in the area of grounds-related material. Students wrote a greater number of grounds per se, and a greater number of grounds relative to claims when their writing was preceded and accompanied by talk. However, this specific effect was restricted to the occasion when the topic required domain-specific knowledge which students may have lacked. Therefore the 'productivity' of talk (Cohen, 1994) appeared to be activated when there were knowledge demands.

The standard deviations recorded for the effects on the frequency of grounds-related material indicated that there was considerable variation 
in effect sizes between different students. The selection of three case study pairs representing different degrees of effect illustrated aspects or conditions of talk that may have contributed to positive effects. The obvious factors that differentiated the more 'productive' participants in interaction were the amount of on-task talk, the amount of procedural and substantive talk, and the way in which interaction was sustained. The most productive pair of students engaged in a relatively large amount of on-task and substantive talk. Their interaction was sustained by means of content-related initiations and responses. The substantive responses themselves were responded to. Such interaction, typical of the productive pair, resulted in the weaker of the two students, being able to access and transform prior knowledge for use in supporting the claims made in the argument text under construction.

A number of issues arose from the findings of the present study. These issues are threefold: pedagogical, theoretical and methodological. As the issues are discussed, implications for future research are raised.

\subsection{Pedagogical issues}

Peer and group interaction in which students have opportunities to talk is believed by many teachers to bring benefits. Lesson planning and classroom arrangements reflect this belief. However the results of this study suggest that in some circumstances, the benefits of talk may have been overestimated. Furthermore, when peer talk is built into an instructional sequence, the talk may need monitoring and support. 
The quantitative data analysis carried out in the present study pointed to specific and limited positive effects of talk. Talk helped when students appeared to lack content and domain-specific knowledge. In this context, talk appeared to help students to generate material which was useful for elaborating the grounds for an argument. The qualitative data analysis pointed to the fact that the students who used talk effectively appeared to use it to generate prior knowledge that was useful for elaborating the grounds on which a claim or claims were made. In this way prior knowledge, specifically personal knowledge related to the content and domain, was incorporated into the schema for the writing task. The effect of talk in this study could be related to its function as a catalyst for thinking. In a sense also, talk was used as a scaffold. It appeared to mediate between, or narrow the distance between domain-specific knowledge and prior knowledge. And indeed this was done through interaction with a more expert peer.

One of the major uses for talk may then be to mediate between prior knowledge and the specific knowledge required in academic tasks. One student in the transcript data, was able to do this for her peer. She however made little or no use of the insights gained in the interaction in her own text. She may have gained in ways that were not observable from the transcript data. Nonetheless the issue remains, that she herself would benefit from interaction with a relatively more expert peer. Teachers need to be sure that pairings and groupings are varied and that each student, at some point benefits from an expert. Research (Cazden, 1988; Webb, 1989, 1991; Webb et al, 1995; Cohen, 1994) suggests that much more needs to be done to analyse the interaction of successful partners in interaction in a classroom context. In this way, successful strategies for 
managing interaction and getting 'the most out of your peer' may be modelled and taught to students.

The quantitative data analysis pointed to the fact that there was a greater benefit when working alone as compared with having the opportunity to work with a peer. The benefit was manifested in the area of grammatical accuracy and complexity. Although this benefit was restricted to one area, it undermines an unequivocal acceptance of peer and group work. Stables (1995) contends that in today's classrooms there is insufficient time given to students for reflection and purposeful activity. We know from the transcript data, that the opportunity of working with a partner does not necessarily ensure focused, purposeful activity. The transcripts of interaction in the case studies showed great variability in the amount and quality of talk. What appears to be at issue is the provision for reflection and purposeful activity within the context of collaboration.

There are a number of considerations with respect to the provision for reflective and purposeful activity. Techniques such as setting criteria for the genre and the use of cue cards aim to encourage reflective thinking. However they do not ensure it, and nor do they ensure purposeful activity. Group or two-way tasks demand purposeful activity but do not necessarily encourage reflective thinking. The challenge is, in fact, to combine these two elements by requiring students to exchange resources and to be reflective and critical about those resources. For instance, in the task of setting criteria for the genre, one partner's identified features could be evaluated by both partners and could then serve as the criteria for the other partner's text. Another possibility is that students themselves be encouraged to evaluate what they have gained from interaction with a 
peer so that there is an element of reflection on both procedural and substantive material generated in the interaction. In this way, a time for reflection is added to the collaborative task. Stables (1995) claims that this is essential for group work to have benefits. He says:

For groupwork to result in learning, there must be time for reflection. It is this time which is not made available in many of today's more overtly 'collaborative' classrooms, where talk is valued at the expense of silence. (p. 64)

Another important issue related to productivity of peer work versus solitary work is that some students may prefer and work better on their own. Although the recognition of different learning styles amongst learners has meant that teachers have attempted to consider alternative ways in which input is presented in a classroom, pair and group work is still the dominant paradigm for processing and reviewing that input. Preference for working in a solitary way may be as much an individual as well as cultural and social phenomenon and we must guard against making presumptions about preferences on the basis of culture and ethnicity.

Like all other classroom practices, the application of pair and group work requires careful support and monitoring if its benefits are to be realised. This is particularly important with respect to pair and group work as they are fundamental precepts of a social constructivist theory. As such their benefits are widely accepted at face value by teachers. Stables (1995) makes a useful comment to conclude this section:

Theories of collaborative learning, or 'social constructivism', have often been inappropriately applied in terms of classroom methodology, resulting in a recommended overemphasis on 
groupwork and peerwork talk while insufficient attention has been paid to reflection and inner dialogue. (p. 61)

\subsection{Theoretical issues}

Social constructivism is a powerful theoretical position that has affected thinking in education for some considerable time. The seemingly logical extension of this theory has been that meaning must be constructed by the individual to have validity, but there are additional benefits when this is done in collaboration with others. However this may not be a logical corollary. Meaning may be constructed by the individual but from a variety of experiences including pair and group work, and solitary work. As Stables (1995:65) points out, opportunity for solitary work and reflection are not incompatible with a constructivist approach.

Theories of talk themselves would benefit from redefinition and extension. Cohen (1994) identified a number of parameters along which the outcomes or the 'productivity' of talk can be assessed. These include: standardised measures of academic achievement, conceptual learning and higher order thinking, equity, and desirable prosocial behaviours. We can add to this list, achievement in language learning and achievement in specific areas of language learning, as well as achievement in specific genres and in specific aspects of those genres. In the introduction, it was mentioned that much second language acquisition research looks at separate skills rather than the interaction of those skills and the effects of one on the other. The present study concludes that much more research can profitably be carried out with respect to speaking and writing. Such research would help redefine and extend theories of talk. It would 
continue to tell us more about the features that may be shared by both, and about underlying conditions and processes associated with talk which brings positive effects.

Lastly, in terms of theory, views concerning the interaction of written discourse and speaking and the constraints operating between spoken language and written argument require further investigation. The present research represents an exploration of this interaction and of the constraints of that speaking may induce. Research needs to further investigate how speaking operates to affect the writing of other genres. This would in a sense bring concerns of the output hypothesis and collaborative learning together.

\subsection{Methodological issues}

One of the features of the present study is that is has proceeded by way of two forms of data analysis, quantitative and qualitative. The quantitative has, in fact, guided the selection of transcript data for qualitative analysis. In this way the status of the qualitative transcript data is enhanced. The researcher knows that there are statistically significant effects and that aspects of the qualitative data can be taken more seriously in terms of its explanatory potential. Experimental research also allows a comparison to be made. Stables (1995:62) discusses the fact that often, when research is limited to the examination of classroom transcript data where students appear to be learning and gaining valuable insights from their peers, the possibility that "these insights could not have been gained in other ways or, indeed, that the learning which no doubt came about could not have come about faster by different means" is not explored. 
A number of issues remain however. One of these is the status of the independent variables, talk and without talk. As discussed in the methodology section, a renaming of variables was carried out because the variable labels did not capture the nature of the working conditions. The variables were renamed, opportunity to talk, and little or no opportunity to talk. The amount of talk all pairs engaged in was calculated. However this data was not used as a covariate measure because case study data indicated that quality of interaction, not quantity, appeared to be significant in bringing about changes in text. A further analysis of all transcript data to generate a quality of talk measure would serve as a better covariate measure.

Another important issue arises in relation not to the independent variables, but to the dependent variables as indicators of effects. The literature makes a number of claims with respect to gains from speaking. These claims are very general as they refer to learning, and slightly more specific, as they relate to writing. The present study, extrapolating from this literature, has set out to investigate specifically the effects of opportunities to talk on argument text construction. The results gained from the quantitative analysis do not necessarily negate the more general claims made with respect to what talk can achieve. It may be that talk can achieve certain aspects of 'productivity' (Cohen, 1994), but that these aspects are not necessarily transferred to the written texts produced by students. The qualitative data analysis did indicate that one of the students in the most successful pair utilised knowledge generated in the interaction in the text he subsequently wrote. More of this type of investigation in which sources are traced through different tasks is needed. Other methodology, for instance protocol analysis, may help to 
more directly identify the source of ideas when content and domainspecific knowledge is lacking. It may also identify if students in fact do gain from interaction but decide for some reason not to make use of the gains from speaking for their texts.

This line of reasoning indicates that the present study has important links with studies of intertextuality (for instance Spivey and King, 1989; Spivey, 1990; McGinley, 1992). The contribution it makes to these studies is to provide some insight into how and when use of textual sources may be mediated by talk, and more importantly how talk itself can act as a source of information by accessing prior knowledge. Thus it opens up the consideration of sources other than only the textual.

The methodology and research design implemented in the present study are compromised by requirements of external validity. Measures of prior knowledge (as in the work of Langer, 1984 for instance) for reasons of time and interference in the students' course of study, could not be carried out. Only the researcher and the class teacher taught on the programme so that as little disruption to the class occurred. A time-restricted research programme means that the need for scaffolded instruction and teacher modelling, that for instance Brown and Palincsar (1989) maintain is so important, is often overlooked. The students in the present study would have benefited from opportunities to become more familiar with the task types used in the instructional sequence. If, as some have claimed (Cohen, 1994) talk, and procedural knowledge (Alexander and Judy, 1988) interact with different types of knowledge and different levels of expertise, it may be that the present study has restricted the possible effects of talk. 
The measures chosen for the study were also informed by concerns for construct validity. They were both conventional (general quality measures) and new (argument structure measures). The former have been used previously (see for instance, Hamp-Lyons, 1986; Hamp-Lyons and Henning, 1991). In terms of the latter, the feature of elaboration, in particular, is clearly an important focus for analysis of argument texts. It has proved to be significantly affected by the intervention. However the text analysis procedure used to capture the extent of elaboration in students' texts needs to be trialled with other examples of argument text construction to test its generality.

The level of resourcing was not initially predicted to be a significant source of variation. It was a factor built into the design mainly for purposes of ensuring a pedagogically sound progression of work in the programme. However, it proved to a more general source of group difference in the texts produced than talk itself. Therefore much more work needs to be carried out exploring how levels of resourcing are used by students during text construction. The work of Mayer et al (1996) for instance on learning in Science from different types of summaries, incorporating both texts and visuals, is an interesting model which could provide some inspiration for researchers in writing.

\subsection{Summary}

Many pedagogical, theoretical and methodological issues have arisen from this research. Clearly for teachers and students the important outcome to emerge from the study is the idea that interactional proficiency, like any other type of language-related proficiency, is a complex notion. Thus 
teachers need to provide support and guidance if proficiency and expertise are to develop in the context of writing. For writers and researchers the theoretical and methodological issues are also important. Researching the role of talk is not an easy task. This research has looked at its effect in the context of one genre, on certain aspects of writing, and produced under certain conditions. Many other contexts and genres are worthy of exploration using analytical techniques. This study has tested effects on a specific set of variables. The variables related to capturing the nature of a quality argument deserve further attention. In addition, there may well be other variables that better capture the productivity of talk.

This research has not negated the claims inherent in a social constructivist theory and interactive theory of writing. Rather it has highlighted the need for further empirical research in the area. 


\section{BIBLIOGRAPHY}

Abedi, J. (1996). Interrater/test reliability system (ITRS). Multivariate Behavioural Research, 31, 409-417.

Adegbija, E. (1991). A survey of students' prewriting activities and their implications for teaching. English for Specific Purposes, 10, 227-235.

Alexander, P.A. and Judy, J.E. (1988). The interaction of domain-specific and strategic knowledge in academic performance. Review of Educational Research, 58, 375-404.

Alexander, P.A., Schallert, D.L. and Hare, V.C. (1991). Coming to terms: How researchers in learning and literacy talk about knowledge. Review of Educational Research, 61, 315-343.

Anderson, R.C. (1972). How to construct achievement tests to assess comprehension. Review of Educational Research, 42, 145-170.

Anderson, J. (1983). The architecture of cognition. Cambridge, Mass: Harvard University Press.

Applebee, A.N. (1981). Writing in the secondary school. Research Monograph No. 21. Urbana, IL: National Council of Teachers of English.

Applebee, A.N. (1984). Contexts for learning to write: Studies of secondary school writing instruction. Norwood, New Jersey: Ablex. 
Arevart, S. and Nation, I.S.P. (1991). Fluency improvement in a second language. RELC Journal, 22, 84-94.

Arndt, V. (1987). Six writers in search of texts: A protocol based study of L1 and L2 writing. ELT Journal, 41, 257-267.

Barnes, D. (1976). From communication to curriculum. Harmondsworth, Middlesex: Penguin.

Barnes, D. and Todd, F. (1977). Communication and learning in small groups. London: Routledge and Kegan Paul.

Beck, E. and Bachmann, T. (1990). "Composition book"- learning to write by dialogue. In H. Mandl, E. de Corte, N. Bennett and H.F. Friedrich (Eds.), Learning and instruction: European research in an international context (Vol. 2.2, pp. 329-340). Oxford: Pergamon Press.

Bereiter, C. (1985). Toward a solution of the learning paradox. Review of Educational Research, 55, 201-226.

Bereiter, C. (1990). Aspects of an educational learning theory. Review of Educational Research, 60, 603-624.

Bereiter, C., Burtis, P.J. and Scardamalia, M. (1988). Cognitive operations in constructing main points in written composition. Journal of Memory and Language, 27, 261-278. 
Bereiter, C. and Scardamalia, M. (1982). From conversation to composition: The role of instruction in a developmental process. In R. Glaser (Ed.), Advances in instructional psychology (Vol. 2, pp. 1-64). Hillsdale, NJ: Lawrence Erlbaum Associates.

Bereiter, C. and Scardamalia, M. (1987a). The psychology of written composition. Hillsdale, NJ: Lawrence Erlbaum Associates.

Bereiter, C. and Scardamalia, M. (1987b). An attainable version of high literacy: Approaches to teaching higher-order skills in reading and writing. Curriculum Inquiry, 17, 9-30.

Berkenkotter, C. (1981). Understanding a writer's awareness of audience. College Composition and Communication, 32, 388-399.

Berlin, J.A. (1987). Rhetoric and reality: Writing instruction in American colleges, 1900-1985. Carbondale: Southern Illinois University Press.

Bernstein, B. (1971). Classes, codes and control (Vol. 1). London: Routledge and Kegan Paul.

Biber, D. (1988). Variation across speech and writing. Cambridge: Cambridge University Press.

Biber, D. (1989). A typology of English texts. Linguistics, 27, 3-43.

Bizzell, P. (1987). Language and literacy. In T. Enos (Ed.), A sourcebook for basic writing teachers (pp. 125-137). New York: Random House. 
de Bot, K. (1996). Review article: The psycholinguistics of the output hypothesis. Language Learning, 46, 529-555.

Bowden, D. (1989). Spoken and written voices in the composition classroom. The Writing Instructor, 8, 100-104.

Britton, J. (1966). Talking and writing. London: Methuen and Co.

Britton, J. (1970). Language and learning. London: Penguin.

Britton, J. (1983). Writing and the story world. In B.M. Kroll, and G. Wells (Eds.), Explorations in the development of writing (pp. 3-30). Chichester: John Wiley and Sons.

Britton, J., Burgess, T., Martin, N., McLeod, A., and Rosen, H. (1975). The development of writing abilities (11-18). London: Macmillan.

Brown, A, and Palincsar, A. (1989). Guided, cooperative learning and individual knowledge acquisition. In L. Resnick (Ed.), Learning, knowing, and instruction: Essays in honour of Robert Glaser (pp. 393-451). Hillsdale, NJ: Lawrence Erlbaum.

Bruffee, K. (1984). Collaborative learning and the "conversation of mankind". College English, 46, 635-652.

Bryson, M. and Scardamalia, M. (1991). Teaching writing to students at risk for academic failure. In B. Means, C. Chelemer, and M.S. Knapp (Eds.), Teaching advanced skills to at risk students: Views from research and practice (pp. 141-167). San Francisco: Jossey-Bass Publishers. 
Burry-Stock, J.A., Shaw, D.G., Laurie, C. and Chissom, B.S. (1996). Rater agreement indexes for performance assessment. Educational and Psychological Measurement, 56, 251-262.

Carlsen, W.S. (1991). Questioning in classrooms: A sociolinguistic perspective. Review of Educational Research, 61, 157-178.

Carrell, P.L. (1983). Some issues in studying the role of schemata, or background knowledge in second language comprehension. Reading in a Foreign Language, 1, 81-92.

Carrell, P.L. (1984). Evidence of formal schema in second language comprehension. Language Learning, 34, 87-112.

Carrell, P.L. and Connor, U. (1990). Reading and writing persuasive and expository texts. In H. Burmeister (Ed.), Proceedings of the tenth second language research forum (pp. 251-272). Eugene, OR: University of Oregon.

Carretero, M. and Voss, J.F. (Eds.) (1994). Cognitive and instructional processes in History and the social sciences. Hillsdale, NJ: Lawrence Erlbaum.

Carter, M. (1990). The idea of expertise: An exploration of the cognitive and social dimensions of writing. College Composition and Communication, $41,265-286$.

Cazden, C.B. (1985). Relationships between talking and learning in classroom interaction. In B.K. Das (Ed.), Patterns of classroom interaction in Southeast Asia (pp. 1-16). Singapore: SEAMEO Regional Language Centre. 
Cazden, C.B. (1988). Classroom discourse: The language of teaching and learning. Portsmouth, NH: Heinemann.

Chan, C.K.K., Burtis, P.J., Scardamalia, M. and Bereiter, C. (1992). Constructive activity in learning from text. American Educational Research Journal, 29, 97-118.

Christie, F. (1989). Language education. Oxford: Oxford University Press.

Clark, R.E. (1994). Media will never influence learning. Educational Technology Research and Development, 42, 21-29.

Cleary, L.M. (1991). Affect and cognition in the processes of eleventh graders. Written Communication, 8, 473-507.

Coe, R.M. (1988). Toward a grammar of passages. Carbondale and Edwardsville: Southern Illinois University Press.

Cohen, E.G. (1994). Restructuring the classroom: Conditions for productive small groups. Review of Educational Research, 64, 1-35.

Connor, U.M. (1987). Research frontiers in writing analysis. TESOL Quarterly, 21, 677-696.

Connor, U.M. (1990). Discourse analysis and writing/reading instruction. Annual Review of Applied Linguistics, 11, 164-180.

Connor, U. and Johns, A. (Eds.). (1990). Coherence in writing: Research and pedagogical perspectives. Washington DC: TESOL Publications. 
Connor, U. and Lauer, J. (1985). Understanding persuasive essay writing: Linguistic/rhetorical approach. Text, 5, 309-326.

Cope, B. and Kalantzis, M. (Eds.). (1993). The powers of literacy: A genre approach to teaching writing. London: Falmer Press.

Corbeil, G. (1992). Fostering high levels of constructive responses in second language learners. The Canadian Modern Language Review, 48, 760779.

Corson, D. (1988). Oral language across the curriculum. Clevedon, Philadelphia: Multilingual Matters.

Corson, D. (1990). Language policy across the curriculum. Clevedon, Philadelphia: Multilingual Matters.

Corson, D. (1993). Language, minority education and gender: Linking social justice and power. Clevedon, Philadelphia: Multilingual Matters.

Costello, P.J.M. and Mitchell, S. (Eds.). (1995). Competing and consensual voices: The theory and practice of argument. Clevedon, Philadelphia: Multilingual Matters.

Crombie, W. (1985). Discourse and language learning: A relational approach to syllabus design. Oxford: Oxford University Press.

Cumming, A. (1989). Writing expertise and second language proficiency. Language Learning, 39, 81-141. 
Cumming, A. (1990). Metalinguistic and ideational thinking in second language composing. Written Communication, 7, 482-511.

Cumming, A. (1992). Instructional routines in ESL composition teaching: A case study of three teachers. Journal of Second Language Writing, 1, 1735.

Daly, J.A. (1985). Writing apprehension. In M. Rose (Ed.), When a writer can't write (pp. 43-82). New York: Guilford.

Daly, J.A. and Miller, M.D. (1975). The empirical development of an instrument of measure of writing apprehension. Research in the Teaching of English, 9, 242-249.

Davies, F. (1989). Designing a writing syllabus in English for academic purposes: Process and product. ELT Documents, 129, 130-142.

Derewianka, B. (1990). Exploring how texts work. Sydney: Primary Teaching Association.

Devine, J., Carrell, P.L. and Eskey, D.E. (Eds.). (1987). Research in reading in English as a second language. Washington, DC: TESOL.

van Dijk, T.A. (1980). Macrostructures: An interdisciplinary study of global structures in discourse, interaction and cognition. Hillsdale, NJ: Lawrence Erlbaum. 
Doyle, W. (1979). Classroom tasks and students' abilities. In P.L. Peterson and H.J. Walberg (Eds.), Research on teaching: Concepts, findings and implications (pp. 183-209). Berkeley, California: McCutchan Publishing Corporation.

Doyle, W. (1983). Academic work. Review of Educational Research, 53, 159200.

Doyle, W. (1986). Content representation in teachers' definitions of academic work. Journal of Curriculum Studies, 18, 365-379.

Dyson, A.H. (1992). The case of the singing scientist: A performance perspective on the 'stages' of school literacy. Written Communication, 9, 347.

Eccles, J., Wigfield, A., Harold, R.D. and Blumenfeld, P. (1993). Age and gender differences in children's self and task perception during elementary school. Child Development, 64, 830-847.

Eggins, S. (1994). An introduction to systemic functional linguistics. London: Pinter Publishers.

Eigler, G., Jechle, T., Merziger, G. and Winter, A. (1990). Knowledge and text production. In H. Mandl, E. de Corte, N. Bennett and H.F. Friedrich (Eds.), Learning and instruction: European research in an international context (Vol. 2.2, pp. 341-356). Oxford: Pergamon Press. 
Eisterhold, J.C. (1990). Reading-writing connections: Toward a description for second language learners. In B. Kroll (Ed.), Second language writing (pp. 88-101). Cambridge: Cambridge University Press.

Elbow, P. (1973). Writing without teachers. New York: Oxford University Press.

Elley, W.B. (1991). The Elley report: How well do New Zealand students achieve by international standards? Christchurch: NZ Post-Primary Teachers' Association.

Elley, W.B. (1992). How in the world do students read? New York: IEA.

Elley, W.B. (Ed.). (1994). The IEA study of reading literacy: Achievement and instruction in thirty two school systems. Oxford: Pergamon Press.

Ellis, R. (1994). The study of second language acquisition. Oxford: Oxford University Press.

Fisher, E. (1996). Identifying effective educational talk. Language and Education, 10, 237-253.

Fitzgerald, J. (1987). Research on revision in writing. Review of Educational Research, 57, 481-506.

Fletcher, B. (1985). Group and individual learning of junior high school children on a micro-computer-based task. Educational Review, 37, 252261. 
Flower, L. (1984). Writer-based prose: A cognitive basis for problems in writing. In S.L. McKay (Ed.), Composing in a second language (pp. 16-42). Rowley, MA: Newbury House.

Flower, L.S. and Hayes, J.R. (1980a). The cognition of discovery: Defining a rhetorical problem. College Composition and Communication, 31, 21-32.

Flower, L.S. and Hayes, J.R. (1980b). The dynamics of composing: Making plans and juggling constraints. In L.W. Gregg and E.R. Steinberg (Eds.), Cognitive processes in writing: An interdisciplinary approach (pp. 31-50). Hillsdale, NJ: Lawrence Erlbaum Associates.

Flower, L. and Hayes, J.R. (1981). A cognitive process theory of writing. College Composition and Communication, 32, 365-387.

Fox, B. (1987). Discourse structure and anaphora in written and conversational English. Cambridge: Cambridge University Press.

Franken, M. (1988). Topic type as input for an academic writing task: The use of self-questioning scales by students for whom English is a second language. Unpublished M.A. thesis. Wellington: Victoria University of Wellington.

Franken, M. (1991). Collaborative mapping as rehearsal for writing. Paper presented at TESOL 25th Annual Convention and Exposition, New York, USA. 
Franken, M. (1995). Using talk to become an expert in writing argument texts. In B. Cavallari (Ed.), Language and literacy: Finding the balance. The proceedings of the ACTA-ATESOL NSW National Conference and 9th Summer School (pp. 81-86). Sydney: ACTA-ATESOL.

Franken, M. and Watson, F. (1996). Working with the new English curriculum. English in Aotearoa, 30, 52-57.

Fulkerson, R. (1990). Composition theory in the eighties: Axiological consensus and paradigmatic diversity. College Composition and Communication, 41, 409-428.

Gagne, R.M. and White, R.T. (1978). Memory structures and learning outcomes. Review of Educational Research, 48, 187-222.

Gaies, S.J. (1980). T-unit analysis in second language research: Applications, problems and limitations. TESOL Quarterly, 14, 53-60.

Gaies, S.J. (1983). Learner feedback: An exploratory study of its role in the second language classroom. In H. Seliger and R. Long (Eds.), Classroom oriented research in second language acquisition (pp. 190-212). Rowley, MA: Newbury House.

Garton, A. and Pratt, C. (1989). Learning to be literate: The development of spoken and written language. Oxford: Basil Blackwell.

Givon, T. (1979). On understanding grammar. New York: Academic Press. 
Goody, J. (Ed.). (1968). Literacy in traditional societies. Cambridge: Cambridge University Press.

Goody, J. (1986). The logic of writing and the organisation of society. Cambridge: Cambridge University Press.

Goody, J. (1987). The interface between the written and the oral. Cambridge: Cambridge University Press.

Grabe, W. (1991). Current developments in second language reading research. TESOL Quarterly, 25, 375-406.

Graves, D, (1983). Writing: Teachers and children at work. Portsmouth, New Hampshire: Hiennemann Educational Books.

Gredler, M.E. (1997). Learning and instruction: Theory into practice (3rd Ed.). Upper Saddle River, NJ: Prentice Hall.

Halliday, M.A.K. (1985). An introduction to functional grammar. London, Baltimore and Melbourne: Edward Arnold.

Halliday, M.A.K. (1989). Spoken and written language (2nd Ed.). Oxford: Oxford University Press.

Halliday, M.A.K. and Hasan, R. (1976). Cohesion in English. London: Longman. 
Halliday, M.A.K. and Hasan, R. (1989). Language, context and text: Aspects of language in a social-semiotic perspective. Oxford: Oxford University Press.

Hamp-Lyons, L. (1986). Testing writing across the curriculum. Papers in Applied Linguistics, 2, 16-29.

Hamp-Lyons, L. and Henning, G. (1991). Communicative writing profiles: An investigation of the transferability of a multiple-trait scoring instrument across ESL writing assessment contexts. Language Learning, $41,337-373$.

Hartfiel, V.F., Hughey, J.B., Wormuth, D.R. and Jacobs, H.L. (1985). Learning ESL composition. Rowley, Mass: Newbury House.

Hasan, R. (1989). The structure of a text. In M.A.K. Halliday and R. Hasan (Eds.), Language, context and text: Aspects of language in a socialsemiotic perspective (pp. 52-69). Oxford: Oxford University Press.

Hays, J.N., Durham, R.L., Brandt, K.S. and Raitz, A.E. (1990). Argumentative writing of students: Adult socio-cognitive development. In G. Kirsch, and D.H. Roen (Eds.), A sense of audience in written communication (pp. 248-266). California: Sage.

Heap, J.L. (1986). Cultural logic and schema theory: A reply to Bereiter. Curriculum Inquiry, 16, 73-86.

Heap, J.L. (1991). Ethnomethodology, cultural phenomenology, and literacy activities. Curriculum Inquiry, 21, 109-117. 
Heath, S.B. (1982). Protean shapes in literacy events: Ever-shifting oral and literate traditions. In D. Tannen (Ed.), Spoken and written language: Exploring orality and literacy. Advances in Discourse Processes 9 (pp. 91117). Norwood, NJ: Ablex.

Heath, S.B. (1983). Ways with words: Language, life and work in communities and classrooms. Cambridge: Cambridge University Press.

Herber, H.L. (1970). Teaching reading in the content areas. Englewood Cliffs, NJ: Prentice Hall.

Hidi, S. and McLaren, J. (1990). The effect of topic and theme interestingness on the production of school expositions. In H. Mandl, E. de Corte, N. Bennett and H.F. Friedrich (Eds.), Learning and instruction: European research in an international context (Vol. 2.2, pp. 295-308). Oxford: Pergamon Press.

Hillocks, G. Jr. (1984). What works in teaching composition: A metaanalysis of experimental treatment studies. American Journal of Education, 93, 133-169.

Hillocks, G. Jr. (1986). Research on written composition: New directions for teaching. Urbana, Illinois: NCRE, ERIC.

Hinds, J. (1987). Reader vs. responsibility: A new typology. In U. Connor and R.B. Kaplan (Eds.), Writing across languages: Analysis of L2 text (pp. 141-152). Reading, MA: Addison Wesley. 
Hitchcock, G. and Hughes, D. (1995). Research and the teacher: A qualitative introduction to school-based research (2nd Ed.). London: Routledge.

Hoey, M. (1983). On the surface of discourse. London: George, Allen and Unwin.

Hoge, R.D. (1985). The validity of direct observation measures of classroom behaviour. Review of Educational Research, 55, 469-484.

Hunt, K.W. (1965). Grammatical structures written at three grade levels. Research Report No.3, Urbana, Illinois: NCTE.

Hunter, S. (1989). Oral negotiations in a textual community: A case for pedagogy and theory. The Writing Instructor, 8, 105-110.

Hyland, K. (1990). A genre description of the argumentative essay. RELC Journal, 21, 66-78.

Johns, A.M. (1990). L1 composition theories: Implications for developing theories of L2 composition. In B. Kroll (Ed.), Second language writing (pp. 24-36). Cambridge: Cambridge University Press.

Johns, A.M. (1993). Written argumentation for real audiences: Suggestions for teacher research and classroom practice. TESOL Quarterly, 27, 75-90.

Johns, T. and Davies, F. (1983). Text as a vehicle for information. Reading in a Foreign Language, 1, 1-19. 
Johnson, D. (1992). Perceiving writing quality through gender lenses. paper presented at TESOL 26th Annual Convention and Exposition, Vancouver, Canada

Jones, A. (1991). At school I've got a chance. Palmerston North: Dunmore Press.

Joyce, H. (1992). Workplace texts in the language classroom. Sydney: NSW Adult Migrant English Service.

Kamler, B. (1980). One child, one teacher, one classroom: The story of one piece of writing. Language Arts, 57, 680-693.

Killingsworth. M.J. (1993). Product and process, literacy and orality: An essay on composition and culture. College Composition and Communication, 44, 26-39.

Kinney, J. (1979). Classifying heuristics. College Composition and Communication, 30, 351-355.

Kintsch, W. and van Dijk, T.A. (1978). Toward a model of text comprehension and production. Psychological Review, 85, 363-394.

Kirsch. G. and Roen, D. (Eds.). (1990). A sense of audience in written communication. Newbury Park: Sage.

Kirsch, I.S. and Mosenthal, P.B. (1990). Exploring document literacy: Variables underlying the performance of young adults. Reading Research Quarterly, 25, 5-30. 
Knudsen, R.E. (1989). Effects of instructional strategies on children's informational writing. Journal of Educational Research, 83, 91-96.

Knudsen, R.E. (1992a). Analysis of argumentative writing at two grade levels. Journal of Educational Research, 85, 169-179.

Knudsen, R.E. (1992b). The development of written argumentation: An analysis and comparison of argumentative writing at four grade levels. Child Study Journal, 22, 167-184.

Kopperschmidt, J. (1985). An analysis of argumentation. In T.A. van Dijk (Ed.), Handbook of discourse analysis (Vol. 2, pp. 159-168). London: Academic Press.

Krapels, A.R. (1990). An overview of second language writing process research. In B. Kroll (Ed.), Second language writing (pp. 37-56). Cambridge: Cambridge University Press.

Krashen, S.D. (1984). Writing: Research, theory, and applications. Oxford: Pergamon Institute of English.

Krashen, S.D. (1989). We acquire vocabulary and spelling by reading: additional evidence for the input hypothesis. Modern Language Journal, 73, 440-464.

Kress, G. (1989). Linguistic processes in sociocultural practice. Oxford: Oxford University Press. 
Kress, G. (1993). Genre as social process. In B. Cope, and M. Kalantzis (Eds.), The powers of literacy: A genre approach to teaching writing (pp. 2237). London: Falmer Press.

Kroll, B. (Ed.). (1990). Second language writing. Cambridge: Cambridge University Press.

Lakoff, R.T. (1982). Some of my favourite writers are literate: The mingling of oral and literate strategies in written communication. In D. Tannen (Ed.), Spoken and written language: Exploring orality and literacy. Advances in Discourse Processes 9 (pp. 239-260). Norwood, New Jersey: Ablex

Langer, J.A. (1984). The effects of available information on responses to school writing tasks. Research in the Teaching of English, 18, 27-44.

Larson, R. (1985). Emotional scenarios in the writing process: An examination of young writers' affective experience. In M. Rose (Ed.), When a writer can't write (pp. 19-42). New York: Guilford.

Liebman-Kleine, J. (1987). Teaching and researching invention: Using ethnography in ESL writing classes. ELT Journal, 41, 104-111.

Lim, H. P. (1983). Using T-unit measures to assess writing proficiency of university ESL students. RELC Journal, 14, 35-44.

Littel, R.C., Freund, R.J. and Spector, P.C. (1991). SAS system for linear models (3rd Ed.). Cary, NC: SAS Institute. 
Lohnes, P.R. (1988). Factorial modelling. In J.P. Keeves (Ed.), Educational research methodology and measurement: An international handbook. Oxford: Pergamon Press.

Long, M.H. (1989). Task, group, and task-group interactions. University of Hawai'i Working Papers in English as a Second Language, 8, 1-26.

Long, M. and Porter, P. (1985). Group work, interlanguage talk and second language acquisition. TESOL Quarterly, 19, 207-228.

Lumbelli, L. and Cavazzini, G. (1991). Planning comprehensible discourse and cooperative interaction. In M. Carretero, M. Pope, R.J. Simons and J.I. Pozo (Eds.), Learning and instruction: European research in an international context (Vol. 3, pp. 141-154). Oxford: Pergamon.

MacIntyre, P. and Gardner, R. (1991). Methods and results in the study of foreign language anxiety: A review of the literature. Language Learning, 41, 25-57.

Macken, M. (Project officer). (1989). An approach to writing K-12: Introduction. Sydney: Literacy and Education Research Network, Directorate of Studies, NSW Department of Education.

Macken, M. (Project officer). (1990). A genre-based approach to teaching writing in years 3-6. Book 1: An introduction to genre-based writing. Sydney: Literacy and Education Research Network, Directorate of Studies, NSW Department of Education. 
Mahala, D. (1991). Writing utopias: Writing across the curriculum and the promise of reform. College English, 53, 773-789.

Manglesdorf, K. (1989). Parallels between speaking and writing in second language acquisition. In D. Johnson, and D. Roen (Eds.), Richness in writing: Empowering ESL students (pp. 134-145). London: Longman.

Mann W.C. and Thompson, S.A. (1988). Rhetorical structure theory: Toward a functional theory of text organization. Text, 8, 243-281.

Mann, W.C., Matthiessen, C.M.I.M., and Thompson, S.A. (1992). Rhetorical structure theory and text analysis. In W.C. Mann and S.A. Thompson (Eds.), Discourse description: Diverse linguistic analyses of a fundraising text (pp. 39-78). Amsterdam/Philadelphia: John Benjamins.

Marsh, H.W. and Yeung, A.S. (1996). The distinctiveness of affects in specific school subjects: An application of confirmatory factor analysis with the National Educational Longitudinal Study of 1988. American Educational Research Journal, 33, 665-689.

Martin, J.R. (1989). Factual writing: Exploring and challenging social reality (2nd Ed.). Oxford: Oxford University Press.

Martin, J.R. (1991). Critical literacy: The role of a functional model of literacy. Australian Journal of Reading, 14, 117-131.

Martin, J.R. (1992). English text: System and structure. Amsterdam: John Benjamins. 
Martin, N., D'Arcy, P., Newton, B., and Parker, R. (1976). Writing and learning across the curriculum, 11-16. London: Ward Lock.

Matsuhashi, A. (1982). Explorations in the real-time production of written discourse. In M. Nystrand (Ed.), What writers know (pp. 269-290). New York: Academic Press.

Marttunen, M. (1994). Assessing argumentation skills among Finnish university students. Learning and Instruction, 4, 175-191.

Mayer, R.E., Bove, W., Bryman, A., Mars, R., and Tapangco, L. (1996). When less is more: Meaningful learning from visual and verbal summaries of science textbook lessons. Journal of Educational Psychology, 88, 64-73.

McCann, T.M. (1989). Student argumentative writing: Knowledge and ability at three grade levels. Research in the Teaching of English, 23, 62-76.

McGinley, W. (1992). The role of reading and writing while composing from sources. Reading Research Quarterly, 27, 227-248.

McGroarty, M. (1989). The benefits of cooperative learning arrangements in second language instruction. NABE Journal, 13, 127-143.

McKay, S.L. (1993). Examining L2 composition ideology: A look at literacy education. Journal of Second Language Writing, 2, 65-81.

McLaughlin, B. (1987). Theories of second language learning. London: Edward Arnold. 
Means, B., Chelemer, C. and Knapp, M.S. (Eds.). (1991). Teaching advanced skills to at risk students: Views from research and practice. San Francisco: Jossey Bass Publishers.

Meek, M. (1991). On being literate. London: The Bodley Head.

Meloth, M.S. and Deering, P.D. (1994). Task talk and task awareness under different cooperative learning conditions. American Educational Research Journal, 31, 138-165.

Meyer, B. (1975). The organisation of prose and its effects on memory. Amsterdam: North-Holland.

Meyer, B., Brandt, D.M. and Bluth, G.J. (1980). Use of top level structure in text: Key for reading comprehension of ninth-grade students. Reading Research Quarterly, 16, 72-103.

Michaels, S. and Collins, J. (1984). Oral discourse styles: Classroom interaction and the acquisition of literacy. In D. Tannen (Ed.), Coherence in spoken and written discourse (pp. 219-24). Norwood, New Jersey: Ablex.

Ministry of Education, (1993). The New Zealand Curriculum Framework. Wellington: Learning Media.

Ministry of Education, (1994a). English in the New Zealand curriculum. Wellington: Learning Media.

Ministry of Education, (1994b). Education for the 21st century. Wellington: Learning Media. 
Mohan, B.A. (1986). Language and content. Reading, Massachusetts: Addison-Wesley.

Moravcsik, J. and Kintsch, W. (1995). Writing quality, reading skills, and domain knowledge as factors in text comprehension. In J. M. Henderson, M. Singer and F. Ferreira (Eds.), Reading and language processing (pp. 232246). NJ: Lawrence Erlbaum.

Morris, A. and Stewart-Dore, N. (1984). Learning to learn from text. NSW: Addison-Wesley.

Mosenthal, P.B. (1983). Defining classroom writing competence: A paradigmatic perspective. Review of Educational Research, 53, 157-171.

Mosenthal, P.B. (1985). Tetrahedral and pyramid models in educational research: A rejoinder to Fagley and Millar. Review of Educational Research, $55,5-8$.

Nation, I.S.P. (1989a). Improving speaking fluency. System, 17, 377-384.

Nation, I.S.P. (1989b). Speaking activities: Five features. ELT Journal, 43, 24-29.

Nespor, J. (1987). Analysing academic tasks in a high school English class. Curriculum Inquiry. 17, 203-222.

Newell, A. and Simon, H. (1972). Human problem solving. Englewood Cliffs, New Jersey: Prentice-Hall. 
Newman, D., Griffin, P. and Cole, M. (1984). Social constraints in laboratory and classroom tasks. In B. Rogoff, and J. Lave (Eds.), Everyday cognition: Its development in social context (pp. 172-193). Cambridge: Harvard University Press.

Newton, J. (1993). The negotiation of meaning among non-native adult learners of English. Unpublished $\mathrm{PhD}$ thesis. Wellington: Victoria University of Wellington.

Nobuyoshi, J. and Ellis, R. (1993). Focused communication tasks. English Language Teaching Journal, 47, 203-210.

Nystrand, M. (1982). Rhetoric's "audience" and Linguistics' "speech community": Implications for understanding writing, reading, and text. In M. Nystrand (Ed.), What writers know: The language, process, and structure of written discourse (pp. 1-28). New York: Academic Press.

Nystrand, M. (1986). The structure of written communication: Studies in reciprocity between writers and readers. Orlando and London: Academic Press.

Nystrand, M. (1990). Sharing words: The effects of readers on developing writers. Written Communication, 7, 3-24.

Nystrand, M., and Gamoran, A. (1991). Instructional discourse, student engagement, and literature achievement. Research in the Teaching of English, $25,261-287$. 
O'Brien, T. (1995). Rhetorical structure analysis and the case of the inaccurate, incoherent source hopper. Applied Linguistics, 16, 442-482.

Olson, D. (1977). From utterance to text: The bias of language in speech and writing. Harvard Educational Review, 47, 257-281.

Olson, D.R. and Torrance, N. (Eds.). (1991). Literacy and orality. Cambridge: Cambridge University Press.

Ong, W.J. (1978). Literacy and orality in our times. In T. Enos (Ed.), A sourcebook for basic writing teachers (pp. 45-55). New York: Random House.

Ong, W.J. (1982). Orality and literacy: The technologizing of the word. London: Methuen.

Pajares, M.F. (1992). Teachers' beliefs and educational research: Clearing up a messy construct. Review of Educational Research, 62, 307-332.

Paltridge, B. (1995). Analyzing genre: A relational perspective. System, $23,503-511$.

Perkins, D.N. and Salomon, G. (1989). Are cognitive skills contextbound? Educational Researcher, 18, 16-25.

Perl, S. (1978). The composing process of unskilled college writers. Research in the Teaching of English, 13, 317-336.

Philips, D. (1985). A month's writing in four classrooms. Writing Research Report No. 1, Wellington: NZCER. 
Piaget, J. (1950). The psychology of intelligence. London: Routledge and Kegan Paul.

Pica, T. (1988). Interlanguage adjustments as an outcome of NS-NNS negotiated interaction. Language Learning, 38, 45-73.

Pica, T. and Doughty, C. (1985). The role of group work in classroom second language acquisition: A comparison of teacher-fronted and group activities. In S. Gass and C. Madden (Eds.), Input in second language acquisition (pp. 115-132). Rowley, Mass: Newbury House.

Pica, T., Holliday, L., Lewis, N. and Morgenthaler, L. (1989). Comprehensible output as an outcome of linguistic demands on the learner. Studies in Second Language Acquisition, 13, 343-376.

Pradl, G.M. (Ed.). (1982). Prospect and retrospect: Selected essays of James Britton. Montclair, NJ: Boynton/Cook.

Prior, P. (1991). Conceptualising writing and response in a graduate seminar. Written Communication, 8, 267-310.

Raimes, A. (1985). What unskilled ESL students do as they write: A classroom study of composing. TESOL Quarterly, 19, 229-258.

Raimes, A. (1991). Out of the woods: Emerging traditions in the teaching of writing. TESOL Quarterly, 25, 407-430. 
Reed, M., Burton, J. and Kelly, P. (1985). The effects of writing ability and mode of discourse on cognitive capacity engagement. Research in the Teaching of English, 19, 283-297.

Reese, W.H. (1997). Counterbalancing and other uses of repeatedmeasures in latin square designs: Analyses and interpretations. Journal of Experimental Child Psychology, 64, 137-158.

Resnick, L.B. (1987). Education and learning to think. Washington, DC: National Academy Press.

Robertson, I. (1980). Language across the curriculum: Four case studies. London: Methuen Educational.

Robinson, D.H. and Kiewra, K.A. (1995). Visual argument: Graphic organizers are superior to outlines in improving learning from text. Journal of Educational Psychology, 87, 455-467.

Rowan, K.E. (1990). Cognitive correlates of explanatory writing skill. Written Communication, 7, 316-341.

Rubin, D.L., Goodrum, R. and Hall, B. (1990). Orality, oral-based culture, and the academic writing of ESL learners. Issues in Applied Linguistics, 11, 56-76.

Rumelhart, D.E. (1980). Schemata: The building blocks of cognition. In R. Spiro, B. Bruce and W. Brewer (Eds.), Theoretical issues in reading comprehension (pp. 33-58). Hillsdale, NJ: Lawrence Erlbaum Associates. 
Sadoski, M., Paivio, A. and Goetz, E.T. (1991). A critique of schema theory in reading and a dual coding alternative. Reading Research Quarterly, 26, 463-484.

Saljo, R. (Ed.). (1988). The written word: Studies in literate thought and action. Berlin: Springer-Verlag.

SAS Institute, (1989). SAS manual: SAS/STAT users' guide. Version 6 (4th Ed.). Cary, North Carolina: SAS Institute Inc.

Scardamalia, M. and Bereiter, C. (1985). Development of dialectal processes in composition. In D. Olsen, N. Torrence and A. Hildyard (Eds.), Literacy, language and learning: The nature and consequences of reading and writing (pp. 307-329). Cambridge: Cambridge University Press.

Scardamalia, M. and Bereiter, C. (1987). Knowledge telling and knowledge transforming in written composition. In S. Rosenberg (Ed.), Advances in applied psycholinguistics: Reading, and language learning (Vol. 2, pp. 142-175). Cambridge: Cambridge University Press.

Scardamalia, M., Bereiter, C. and Goelman, H. (1982). The role of production factors in writing ability. In M. Nystrand (Ed.), What writers know: The language, process, and structure of written discourse (pp. 173-210). New York: Academic Press.

Schmitt, M.C. (1990). A questionnaire to measure children's awareness of strategic reading processes. The Reading Teacher, March, 454-461. 
Schneider, M. and Connor, U. (1990). Analysing topical structure in ESL essays: Not all topics are equal. Studies in Second Language Acquisition, 12, 411-427.

Schumacher, G.M., Klare, G.R., Cronin, F.C. and Moses, J.D. (1984). Cognitive activities of beginning and advanced college writers: A pausal analysis. Research in the Teaching of English, 18, 169-187.

Schumacher, G.M. and Nash, J.G. (1991). Conceptualising and measuring knowledge change due to writing. Research in the Teaching of English, 25, 67-96.

Scolfield, P. (1995). Quantifying language: A researcher's and teacher's guide to gathering language data and reducing it to figures. Clevedon: Multilingual Matters.

Sillince, J.A.A. (1995). Shifts in focus and scope during argumentation. Journal of Pragmatics, 25, 413-341.

Sinclair, J. McH., and Coulthard, R.M. (1975). Towards an analysis of discourse: The language used by teachers and pupils. London: Oxford University Press.

Silva, T. (1990). Second language composition instruction: Developments, issues, and directions. In B. Kroll (Ed.), Second language writing (pp. 1123). Cambridge: Cambridge University Press.

Slimani, A. (1989). The role of topicalization in classroom language learning. System, 17, 223-234. 
Smagorinsky, P. and Smith, M.W. (1992). The nature of knowledge in composition and literacy understanding: The question of specificity. Review of Educational Research, 62, 279-305.

Snow, C. (1983). Literacy and language: Relationships during the preschool years. Harvard Educational Review, 53, 165-189.

Snyder, I. (1995). Multiple perspectives in literacy research: Integrating the quantitative and qualitative. Language and Education, 9, 45-59.

Soltis, J.M. and Walberg, H.J. (1989). Thirteen-year-olds' writing achievements: A secondary analysis of the fourth national assessment of writing. Journal of Educational Research, 83, 22-29.

Spack, R. (1984). Invention strategies and the ESL composition student. TESOL Quarterly, 18, 649-670.

Spivey, N.N. (1990). Transforming texts: Constructive processes in reading and writing. Written Communication, 7, 256-287.

Spivey, N.N. and King, J.R. (1989). Readers as writers composing from sources. Reading Research Quarterly, 24, 7-26.

Stables, A. (1995). Learning through talk and learning through talking: Sound and silence in the classroom. Language and Education, 9, 61-68.

Stahl, S.A., Chou Hare, V., Sinatra, R. and Gregory, J.F. (1991). Defining the role of prior knowledge and vocabulary in reading comprehension: The retiring of number 41. Journal of Reading Behaviour, 23, 487-508. 
Stenstrom, A. (1994). An introduction to spoken interaction. London: Longman.

Street, B. (1984). Literacy in theory and practice. Cambridge: Cambridge University Press.

Street, B. (Ed.). (1993). Cross cultural approaches to literacy. Cambridge: Cambridge University Press.

Sullivan, P.N. (1996). Sociocultural influences on classroom interactional styles. TESOL Journal, 6, 32-34.

Swain, M. (1985). Communicative competence: Some roles of comprehensible input and comprehensible output in its development. In S. M. Gass and C.G. Madden (Eds.), Input in second language acquisition (pp. 235-253). Rowley, MA: Newbury House.

Swain, M. (1995). Three functions of output in second language learning. In G. Cook and B. Seidlhofer (Eds.), Principle and practice in applied linguistics: Studies in honour of H.G. Widdowson (pp. 125-144). Oxford: Oxford University Press.

Swain, M. and Lapkin, S. (1995). The development of fluency in advanced learners of French. Applied Linguistics, 17, 84-119.

Swales, J. (1990). Genre analysis: English in academic and research settings. Cambridge: Cambridge University Press. 
Sweigert, W. (1991). Classroom talk, knowledge development, and writing. Research in the Teaching of English, 25, 469-496.

Sweller, J. (1994). Cognitive load theory, learning difficulty, and instructional design. Learning and Instruction, 4, 295-312.

Swing, S.R. and Peterson, P.L. (1982). The relationship of student ability and small group interaction to student achievement. American Educational Research Journal, 19, 259-274.

Tannen, D. (Ed.). (1982). Spoken and written language: Exploring orality and literacy. Advances in Discourse Processes 9. Norwood, New Jersey: Ablex.

Tannen, D. (Ed.). (1984). Coherence in spoken and written discourse. Norwood, New Jersey: Ablex.

Tannen, D. (Ed.). (1989). Talking voices: Repetition, dialogue and imagery in conversational discourse. Cambridge: Cambridge University Press.

Toulmin, S.E. (1958). The uses of argument. Cambridge: Cambridge University Press.

Toulmin, S.E., Rieke, R. and Janki, A. (1984). An introduction to reasoning (2nd Ed.). New York: Macmillan.

Vygotsky, L.S. (1978). Mind in society: The development of higher psychological processes. Cambridge: Harvard University Press. 
Vygotsky, L.S. (1986). Thought and language. Cambridge: MIT Press.

Walberg, H.J. and Ethington, C.A. (1991). Correlates of writing performance and interest: A U.S. national assessment study. Journal of Educational Research, 84, 198-203.

Watkins, D. and Hattie, J. (1990). Individual and contextual differences in the approaches to learning in Australian secondary schools. Educational Psychology, 10, 333-342.

Webb, N.M. (1989). Peer interaction and learning in small groups. International Journal of Educational Research, 13, 21-40.

Webb, N.M. (1991). Task-related verbal interaction and mathematics learning in small groups. Journal of Research in Mathematics Education, 22, 366-389.

Webb, N.M., Troper, J. D. and Fall, R. (1995). Constructive activity and learning in collaborative small groups. Journal of Educational Psychology, $87,406-423$.

Weissberg, B. (1994). Speaking and writing: Some functions of talk in the ESL composition class. Journal of Second Language Writing, 3, 121-139.

Wells, G. (1981). Learning through interaction. Cambridge: Cambridge University Press.

Wells, G. (1987). Apprenticeship in literacy. Interchange, 18, 109-123. 
Wells, G. (1989). Language in the classroom: Literacy and collaborative talk. Language and Education, 3, 251-274.

Wells, G. (1990). Talk about text: Where literacy is learned and taught. Curriculum Inquiry, 20, 369-405.

Wenden, A. and Rubin, J. (1987). Learner strategies in language learning. London: Prentice Hall.

Wong-Fillmore, L. (1982). Instructional language as linguistic input: second language learning in classrooms. In L. Wilkinson (Ed.), Communicating in the classroom (pp. 283-296). New York: Academic Press.

Young, R.E., Becker, A.L. and Pike, K.L. (1970). Rhetoric: Discovery and change. New York: Harcourt Brace Jovanovich.

Zamel, V. (1983). The composing process of advanced ESL students: Six case studies. TESOL Quarterly, 17, 165-187.

Zammuner, V.L. (1990). Constructing and highlighting main points in production. In H. Mandl, E. de Corte, N. Bennett and H.F. Friedrich (Eds.), Learning and instruction: European research in an international context (Vol. 2.2, pp. 309-328). Oxford: Pergamon Press. 
APPENDIX 1 SAMPLE INSTRUCTIONAL MATERIALS AND RESOURCE MATERIALS 


\subsection{Instructional materials for unresourced condition, week 2}

(Brackets indicate additional instructions for talk condition.)

This is a set of tasks to help you write an argument text. The topic is:

FOR OVERSEAS STUDENTS STUDYING IN NEW ZEALAND THERE ARE BENEFITS AND DISADVANTAGES. THE BENEFITS OUTWEIGH THE DISADVANTAGES.

Task one

What do you know/think about the topic? Write your ideas in the table below (as you tell your partner).

Add new ideas and change your old ones (as you hear your partner talking). Put these in the bottom of the table.

What you know/think about the topic.

Additions/Changes 


\section{Task two}

Look at the argument text below. This is a good example of an argument text. What makes the text a goodtext? Circle the things that are good.

Say why they are good. Write your reasons on the side of the page (as you tell your partner).

Add new ideas and change your old ones (as you hear your partner talking).

Circle the things that make this a good argument text.

STUDENTS SHOULD ALL HAVE AT LEAST ONE YEAR'S WORK EXPERIENCE BEFORE THEY CAN ENTER UNIVERSITY

Education is very important for people. If people have not had the experience of a good education, it is unlikely that they will have a satisfying job and earn a good salary. But how do people choose a course of study at university that will ensure a good job when they leave? Having work experience before they go to university may solve this problem.

Students should have work experience before they go to university because after they have worked in a job they will know what knowledge they need so that they can choose the course of study which best fits the requirements of their ideal job. Secondly, students can earn money for their living expenses and more importantly, their university fees. Lastly, they can learn other useful skills that they cannot learn in school like for instance how to cope with workmates.

Students could choose a job which has some relation to the subject they want to study. For example if you want to be a doctor or a nurse, you can go to a hospital to work. Doing this job would be good experience before you study the course. You will feel more interested and motivated, so you will do better in that course of study.

There are a large number of students who have worked for one year or more before they go to university. Their marks are often better that those who have come directly from school. They can easily understand the issues in the topic area because they have experienced the job before. They know the importance of the issues and can concentrate an the main points to address the issues.

In my opinion, having experience is very important. It helps students to know what subject they are really interested in. If they know what they are going to do they will not choose a wrong subject.
List the reasons for each of the circled features.

These become the criteria for your own essay 


\section{Task three}

Map important information that will be useful for writing your text.

When you have finished, explain your map to your partner.

Add new ideas and change old ones as you hear your partner talking.

\section{Task four}

Begin writing your text.

When you have written three sentences, read them carefully. Use the cue card to help you improve your text. Make changes to your text if you need to. Tick any cues you have used from the cue card.

(Work with your partner as you are writing your text. After you have written three sentences, read them to your partner. Your partner will cue you to improve your text. Make changes to your text with the help of your partner.)

Please cross out when you make changes so that I can see where they are. Don't rub out or use white out. 


\section{Cue sheet to help review an argument text}

Tick the cues you have chosen (for your partner)

If the ideas in the text could be improved, choose one of these cues

An even better idea is ...

An important idea you haven't thought about is ...

A whole new way to think of this topic is ...

No one will have thought of ...

If the ideas in the text need expanding and further explanation, choose one of these cues An example of this idea here is ...

You could add your own opinion to support this reason ...

Another reason that's good is...

You could develop this idea by adding ...

A good point on the other side of the argument is ...

You could make your point clearer by ...

If the ideas in the text need editing and refining, choose one of these cues

This isn't necessary because ...

You're getting off the topic here so ...

But many readers won't agree that ...

If the text doesn't hang together in a convincing way, choose one of these cues

The purpose of your text is to ...

Your main point or thesis is ...

If you want to start off with your strongest reason you need to choose ...

You can tie things together at the end by ... 


\section{Task five}

Use the criteria you have listed on task sheet two.

Prove (to your partner) that you have met the criteria. Put a tick beside the criteria on task sheet two each time your writing shows that good thing. See how many ticks you can get.

\section{Task six}

Spend some time now making any changes to your text that you feel are necessary.

\section{Task seven}

Without using your text, explain your argument to the teacher (or to your partner). 


\subsection{Resource material for semi- resourced condition, week 4.}

\section{Topic: THE ADVANTAGES OF USING FOOD ADDITIVES OUTWEIGH THE DISADVANTAGES}

Resource:

\section{Fact Sheet}

- Food additives are substances which have been added to food.

- There are different kinds of food additives. The main kinds are: preservatives, colourings, flavourings, sweeteners, nitrates, monosodium glutamate (MSG) and antioxidants.

- Manufacturers must list all the additives they put in their food.

- Many additives are copies of substances found naturally in food, for example tomatoes contain a small amount of MSG.

- Preservatives, nitrates and antioxidants make food last longer.

- Nitrates are added to meat.

- Colourings and flavourings have no food value e.g soft drink is just water with

- flavouring and colouring added.

- Most food additives are tested on animals over a short time. Only one additive is tested at a time.

- Many cancer specialists say smoking and too much sun are more important causes of cancer.

- Preservatives, colourings and antioxidants may cause allergies and hyperactivity in a small number of people.

- Sweeteners such as saccharin and nitrates may cause cancer.

- MSG causes cancer in young animals.

- Antioxidants which are used to stop oil going bad, cause abnormal growth and behaviour in mice.

- Natural food that has no additives often takes longer to prepare.

- If food does not go bad so quickly there is less chance we will get food poisoning.

- Manufacturers could use natural colourings and flavourings but they are more expensive.

- Manufacturers make money by processing food e.g a bag of potato chips may have only $5 \mathrm{c}$ worth of potatoes but costs $\$ 1.00$.

- Food additives mean that manufacturers can make a lot of different food products. 


\subsection{Resource material for resourced condition, week 6}

\section{Topic: THE GOVERNMENT DOES NOT EXIST ONLY TO PROVIDE A SERVICE FOR THE PEOPLE. ALL GOVERNMENT SERVICES SHOULD MAKE A PROFIT.}

\section{Resource:}

In 1995, New Zealand has a deregulated economy. This means that the Government has less control over the way in which the financial sector of the country is managed. To do this, it has sold many of the assets that the state and the people of New Zealand owned. The assets have become privatised, and are now not only in the hands of New Zealand companies but also overseas companies. These assets include such things as the post offices, the organisations controlling electricity and gas power, telecommunications, the health service, the national airline and some forests.

This process began in 1984 when a Labour Government came to power. For a long time before this, a National government had been in power led by Mr Muldoon. He had a tight control over prices and the economy in general.

Roger Douglas the Minister of Finance in the Labour Government at the time began the process. He maintained that if the State's assets were sold and run in a more businesslike manner they would be more efficient, fewer people would be needed and the people that were managing the companies would be more responsible. This is referred to as a process of deregulation.

Eleven years ago, the Labour Government set in motion a process which has not stopped today. Roger Douglas now has a political party called ACT (The association of consumers and taxpayers which he says will finish the job he started in 1984.

The sacking of the CHE chief executive in the news the other day for criticising the government shows how touchy this issue is. 
APPENDIX 2 INFORMATION ON SUBJECTS 


\subsection{Background information}

\section{Group one}

\begin{tabular}{|c|c|c|c|c|c|c|}
\hline $\begin{array}{l}\text { Rank } \\
\text { no. }\end{array}$ & Sex & Ethnicity & $\begin{array}{l}\text { Country of } \\
\text { origin }\end{array}$ & $\begin{array}{l}\text { Other } \\
\text { languages } \\
\text { spoken }\end{array}$ & $\begin{array}{l}\text { Length of } \\
\text { time in } \\
\mathrm{NZ}\end{array}$ & Subjects studied \\
\hline 1 & M & Macedonian & Macedonia & $\begin{array}{l}\text { Macedonian, } \\
\text { Serbian, } \\
\text { Croatian }\end{array}$ & 4 months & $\begin{array}{l}\text { English, Maths, Biology, } \\
\text { Chemistry, Physics, } \\
\text { Health and Recreation }\end{array}$ \\
\hline 2 & $\mathrm{~F}$ & Indian & Malaysia & Malay & 2 months & $\begin{array}{l}\text { English, Maths, Biology, } \\
\text { Chemistry, Economics, } \\
\text { Accounting, Health and } \\
\text { Recreation }\end{array}$ \\
\hline 3 & M & Chinese & Hong Kong & Cantonese & 8 months & $\begin{array}{l}\text { English, Maths, Science, } \\
\text { Geography, Health and } \\
\text { Recreation }\end{array}$ \\
\hline 4 & $\mathrm{~F}$ & Macedonian & Macedonia & $\begin{array}{l}\text { Macedonian, } \\
\text { Serbian, } \\
\text { Croatian }\end{array}$ & 4 months & $\begin{array}{l}\text { English, Maths, Biology, } \\
\text { Chemistry, Health and } \\
\text { Recreation }\end{array}$ \\
\hline 5 & M & Chinese & Malaysia & Chinese & 4 months & $\begin{array}{l}\text { English, Maths, } \\
\text { Chemistry, Physics, } \\
\text { Design }\end{array}$ \\
\hline 6 & $\mathrm{~F}$ & Chinese & Malaysia & $\begin{array}{l}\text { Chinese, } \\
\text { Cantonese, } \\
\text { Malay, Hakka }\end{array}$ & 1 year & $\begin{array}{l}\text { English, Maths, } \\
\text { Economics, Accounting, } \\
\text { Computer Studies, } \\
\text { Health and Recreation }\end{array}$ \\
\hline 7 & M & Korean & Korea & Korean & 2 years & $\begin{array}{l}\text { English, Maths, Physics, } \\
\text { Japanese, }\end{array}$ \\
\hline 8 & M & Chinese & Taiwan & Mandarin & 4 years & $\begin{array}{l}\text { English, Maths, Physics, } \\
\text { Design }\end{array}$ \\
\hline 9 & M & Chinese & Hong Kong & Cantonese & 1 year & $\begin{array}{l}\text { English, Maths, Biology, } \\
\text { Chemistry, Physics, } \\
\text { Health and Recreation }\end{array}$ \\
\hline 10 & M & Chinese & Hong Kong & Cantonese & $\begin{array}{l}1 \text { year, } 2 \\
\text { months }\end{array}$ & $\begin{array}{l}\text { English, Maths, Physics, } \\
\text { Accounting }\end{array}$ \\
\hline
\end{tabular}




\section{Group 2}

\begin{tabular}{|c|c|c|c|c|c|c|}
\hline $\begin{array}{l}\text { Rank } \\
\text { no. }\end{array}$ & Sex & Ethnicity & $\begin{array}{l}\text { Country of } \\
\text { origin }\end{array}$ & $\begin{array}{l}\text { Other } \\
\text { languages } \\
\text { spoken }\end{array}$ & $\begin{array}{l}\text { Length of } \\
\text { time in } \\
\mathrm{NZ}\end{array}$ & Subjects \\
\hline 1 & $\mathrm{M}$ & Chinese & Malaysia & Hakka & 2 months & $\begin{array}{l}\text { English, Maths, } \\
\text { Economics, Accounting }\end{array}$ \\
\hline 2 & $\mathrm{~F}$ & Chinese & Malaysia & Chinese & 2 months & $\begin{array}{l}\text { English, Maths, Biology, } \\
\text { Chemistry, Physics, } \\
\text { Health and Recreation }\end{array}$ \\
\hline 3 & M & Indian & India & Hindi & 1 month & $\begin{array}{l}\text { English, Maths, Biology, } \\
\text { Chemistry, Physics }\end{array}$ \\
\hline 4 & M & Chinese & Hong Kong & Cantonese & $\begin{array}{l}1 \text { year, } 3 \\
\text { months }\end{array}$ & $\begin{array}{l}\text { English, Maths, Biology } \\
\text { Chemistry, Physics, } \\
\text { Health and Recreation }\end{array}$ \\
\hline 5 & $\mathrm{~F}$ & Chinese & Hong Kong & Cantonese & 3 months & $\begin{array}{l}\text { English, Maths, } \\
\text { Geography, Economics, } \\
\text { Accountancy }\end{array}$ \\
\hline 6 & $\mathrm{M}$ & Chinese & Taiwan & Chinese & 4 months & $\begin{array}{l}\text { English, Maths, Bilogy, } \\
\text { Chemistry, Health and } \\
\text { Recreation }\end{array}$ \\
\hline 7 & M & Korean & Korea & Korean & $\begin{array}{l}1 \text { year, } 7 \\
\text { months }\end{array}$ & $\begin{array}{l}\text { English, Maths, Biology, } \\
\text { Chemistry, Health and } \\
\text { Recreation }\end{array}$ \\
\hline 8 & M & Mexican & Mexico & $\begin{array}{l}\text { Chinautec, } \\
\text { Spanish }\end{array}$ & 2 years & $\begin{array}{l}\text { English, Maths Biology, } \\
\text { Chemistry, Spanish, }\end{array}$ \\
\hline 9 & M & Korea & Korean & Korean & 1 year & $\begin{array}{l}\text { English, Maths, } \\
\text { Chemistry, Health and } \\
\text { Recreation }\end{array}$ \\
\hline 10 & M & Korea & Korean & Korean & 2 years & $\begin{array}{l}\text { English, Maths, Physics, } \\
\text { Accounting, Graphics }\end{array}$ \\
\hline
\end{tabular}




\subsection{Proficiency data including summed pretest scores}

\section{Group one}

\begin{tabular}{|c|c|c|c|c|}
\hline Rank no. & $\begin{array}{c}\text { Summed pretest } \\
\text { scores }\end{array}$ & zscore & $\begin{array}{c}\text { Delta reading } \\
\text { comprehension score }\end{array}$ & $\begin{array}{c}3000 \text { word } \\
\text { vocabulary score }\end{array}$ \\
\hline $\mathbf{1}$ & 54 & 4.09 & 84 & 72 \\
$\mathbf{2}$ & 50 & 3.17 & 79 & 100 \\
\hline $\mathbf{3}$ & 50 & 3.17 & 86 & 78 \\
$\mathbf{4}$ & 47 & 2.49 & 86 & 72 \\
\hline $\mathbf{5}$ & 40 & 0.88 & 70 & 72 \\
$\mathbf{6}$ & 31 & -1.18 & 60 & 72 \\
$\mathbf{7}$ & 28 & -1.87 & - & 94 \\
$\mathbf{8}$ & 25 & -2.56 & 60 & 61 \\
\hline 9 & 13 & -3.70 & 53 & 67 \\
$\mathbf{1 0}$ & 20 & -5.30 & - & 55 \\
$\mathbf{M}$ & 35.8 & -0.81 & & \\
\hline
\end{tabular}

\section{Group two}

\begin{tabular}{|c|c|c|c|c|}
\hline Rank no. & $\begin{array}{c}\text { Summed pretest } \\
\text { scores }\end{array}$ & z score & $\begin{array}{c}\text { Delta reading } \\
\text { comprehension score }\end{array}$ & $\begin{array}{c}3000 \text { word } \\
\text { vocabulary score }\end{array}$ \\
\hline $\mathbf{1}$ & 57 & 4.78 & 84 & 100 \\
$\mathbf{2}$ & 50 & 3.17 & 95 & 94 \\
\hline $\mathbf{3}$ & 50 & 3.17 & 74 & 100 \\
$\mathbf{4}$ & 45 & 2.03 & 79 & 89 \\
$\mathbf{5}$ & 44 & 1.8 & 79 & 83 \\
$\mathbf{6}$ & 35 & -0.26 & 63 & 77 \\
\hline $\mathbf{7}$ & 27 & -2.09 & 65 & 50 \\
$\mathbf{8}$ & 24 & -2.78 & 77 & 83 \\
$\mathbf{9}$ & 18 & -4.16 & 70 & 61 \\
$\mathbf{1 0}$ & 15 & -4.85 & 60 & 61 \\
$\mathbf{M}$ & 36.5 & 0.81 & & \\
\hline
\end{tabular}




\section{APPENDIX 3 MATERIALS FOR SCORING TEXTS}




\subsection{Scale for general text quality measures (adapted from Hamp- Lyons, 1986)}

\begin{tabular}{|c|c|c|c|}
\hline \multirow{5}{*}{$\begin{array}{l}\text { Communicative } \\
\text { quality }\end{array}$} & 14 & Excellent & a pleasure to read \\
\hline & 10 & Very good & causes the reader few difficulties \\
\hline & 7 & Adequate & communicates although with some strain \\
\hline & 4 & Fair & conveys its message with difficulty \\
\hline & 1 & Weak & does not adequately convey its message \\
\hline \multirow[t]{5}{*}{$\begin{array}{l}\text { Ideas and } \\
\text { organisation }\end{array}$} & 14 & Excellent & $\begin{array}{l}\text { completely logical organisational structure; effective } \\
\text { arguments and supporting material }\end{array}$ \\
\hline & 10 & Very good & $\begin{array}{l}\text { good organisational structure; well-presented and } \\
\text { relevant arguments and supporting material }\end{array}$ \\
\hline & 7 & Adequate & $\begin{array}{l}\text { clear but limited organisational structure; some } \\
\text { arguments unsupported or material irrelevant }\end{array}$ \\
\hline & 4 & Fair & $\begin{array}{l}\text { logical breakdowns apparent; ideas inadequate } \\
\text { and/or poorly organised }\end{array}$ \\
\hline & 1 & Weak & logical organisation absent; no suitable material \\
\hline \multirow[t]{5}{*}{$\begin{array}{l}\text { Linguistic } \\
\text { accuracy and } \\
\text { complexity }\end{array}$} & 14 & Excellent & $\begin{array}{l}\text { wide range and fluent control of grammatical } \\
\text { structures }\end{array}$ \\
\hline & 10 & Very good & $\begin{array}{l}\text { effective use of an adequate range of grammatical } \\
\text { structures }\end{array}$ \\
\hline & 7 & Adequate & $\begin{array}{l}\text { adequate range of grammatical structures but could be } \\
\text { used more effectively }\end{array}$ \\
\hline & 4 & Fair & $\begin{array}{l}\text { restricted range and uncertain control of grammatical } \\
\text { structures }\end{array}$ \\
\hline & 1 & Weak & grammatical structures not mastered \\
\hline
\end{tabular}




\subsection{Holistic scoring scale (Knudsen, 1992a, 1992b)}

6

Papers that address the topic, state and elaborate arguments, and exhibit logical thought. These papers are outstanding.

Responses are well organised and fluent. The word choice is effective. The organisation is excellent. Punctuation is very good. Either mechanical errors do not interfere with reading the paper or there are few mechanical errors. Responses may develop an argument to support the point of view and may list, develop, or elaborate multiple points of view.

5

Papers which respond to the task with developed and substantiated reasons/appeals. These papers are well organised, fluent, and function as a unified piece of persuasion. They are characterised by some of the following:

Responses that are organised such that they operate as a unified piece of persuasion. They tend to have openings, to state and develop a thesis and to have a closing. Responses that are highly persuasive by developing and substantiating an appeal. Responses that are fluent, contain moderate/few mechanical errors, and show evidence of effective word choice.

4

These papers represent very good attempts at developing a persuasive argument. The reader has no difficulty understanding the student's viewopoint. These papers are better organised than Score Point 3 papers. These papers are characterised by some of the following:

Arguments are moderately well developed. The development of the argument is frequently accomplished by stating a reason to convince the audience of a point of view, developing that reason and stating several reasons that are not elaborated upon to support the point of view

Responses are well organised Responses state a point of view, support reason(s) for that point of view, and may state or develop the opposite point of view.

These papers represent good attempts at developing a persuasive argument. The reader has no difficulty understanding the student's viewpoint. These papers are characterised by some of the following:

Arguments that are moderately well developed. The development of the argument may be accomplished in several ways: By stating a reason to convince 
the audience of a point of view and then developing that reason. By stating several reasons that are not elaborated to support a point of view. Responses that contain several reasons to convince the audience of a point of view but have no apparent organisational strategy. The reasons presented, however are not contradictory. Responses that are not only elaborated but are organised. These responses represent an overall argument. Responses that exhibit a control of written language characterised by clarity of expression, some effectiveness in word choice, and correctness of punctuation so that the reader does not have to insert or delete punctuation to understand the point(s) made.

2

Papers which respond to the task with some argument(s). These papers are more fluent than the Score Point 1 paper and exhibit some development of logical reasoning. These papers are characterised by some of the following:

Responses that contain somewhat elaborated arguments. Responses characterised by limited control of written language. The word choice may be limited; errors in usage may occur; sentence structure may be simplistic; and responses may be awkward.

1

Papers that attempt to address the topic but are general and vague. In general, they are not fluent, do not list or discuss reasons for an argument, and contain many errors in form. They are characterised by some of the following:

Responses that are persuasive but are unsuccessful in their presentation. These papers include: Papers that contain sparse responses so that the reader is able to obtain only a vague impression of responding to the task. Papers that contain no more than a brief unelaborated argument. Papers that contain lists of words or phrases. Responses that attend very briefly to the task but do not remain on the topic. Responses that exhibit a lack of control of written discourse so that communication is impaired. 


\subsection{Scoring guide based on Toulmin's criteria for argumentation (McCann, 1989).}

\section{Proposition}

3 The writer clearly links the proposition to the issues.

2 The writer offers a proposition that is relevant to the issues, but it is not complete or clear

1 The proposition does not clearly address the issues and no specific policy or action is proposed.

0 The writer does not offer a relevant proposition.

\section{Claims}

6 Clear, complete generalisations related to the proposition are stated.

4 The reader must infer the writer's intent from information given by the writer, but enough information is given so that generalisations are related to the proposition or topic.

2 The writer's assertions are unclear and lack specificity although the generalisations are related to the proposition or topic.

0 There is no claim related to the proposition or topic.

\section{Data}

6 The writer gives supporting data that is complete, accurate and related to the proposition.

4 The writer gives supporting data that is related to the proposition, but not complete. The reader must infer much from the data.

2 The writer offers weak, inaccurate, or incomplete data

0 The writer either offers no data or offers data having no relevance to the claim. 


\section{Warrant}

6 The data is presented in such a way that it is clear how they support the claim.

4 The explanation linking the data to the claim is not specific.

2 The writer fails to make a connection between data and the claim even though there is some elaboration about the data.

0 The writer does not give a warrant.

\section{Opposition}

3 There is a systematic identification of the opposition and the opposing arguments.

2 There is an identification of opposing arguments but these arguments are not specific.

1 There is some offering of opposition but it is not specific.

0 There is no recognition of opposition offered.

\section{Response to opposition}

3 There is systematic identification of the opposition and the opposing arguments.

2 Counterarguments are present, but the reader must provide the link between the counterarguments and the specific opposition.

1 There is a vague reference to implied opposition or a weak denial of opposition claims.

0 There is no offering of response to counterarguments. 


\section{APPENDIX 4 TEXT RELATIONS (ADAPTED FROM O'BRIEN, 1995) USED TO GUIDE TEXT ANALYSIS}

The following text relations and associated linguistic realisations were used to identify constituents and to separate claims and grounds from elaboration of claims and elaboration of grounds.

\section{Claims (CL) and grounds (G)}

Claims or grounds serve as the nucleus to the list of satellite elements explained below. Restatements of claims or grounds are also considered to be nucleus constituents.

\section{Elaboration of claims and elaboration of grounds}

Elaboration of claims or elaboration of grounds serve as satellite constituents, and can be represented by any of the following:

\section{Elaboration (EL)}

Elaboration elements present additional detail about the situation or some element of the subject matter which is presented in the claims or grounds or inferentially accessible in the claims or grounds, in one or more of the ways listed below:

set: member

abstract : instance

whole: part

process: step

object: attribute

generalisation: specific

eg Many overseas students are come to New Zealand to study. Most of them come from Hong Kong, Taiwan, Korea, Malaysia, Japan and some from Europe.

\section{Result (R)}

Result elements present a situation that could have arisen from the claim or grounds eg Some of the families can't afford the money for their children to university so they need to support by themselves. 


\section{Evidence (EV)}

Evidence is intended to increase the reader's belief in the claim

eg Nowadays the education system is getting better. More and more young people had become a beachlor.

\section{Purpose (P)}

The activity in the nucleus is initiated in order to realise the satellite

eg I think they went to university to get higher qualification to work.

\section{Condition (CN)}

The satellite imposes a condition on the nucleus

eg Although a majority of people today start working only after completing their tertiary level in universities or unitechs, there are still a small percentage that choose to start working after finishing their secondary education.

\section{Other relations}

Sequence

\section{Linguistic realisations}

Claims are realised by main clauses, with or without subordinate elements.

Grounds can be a separate noun phrases

eg The benefits can be as I mentioned several times before. NZ's lovely environment/ not too much pressure on study/good chance to learn English/learn relationships between people/ learn to control yourself and your money.

The first noun clause is not separated from the main clause eg I think the solution may be to use 1080 poison.

If there is more than one noun clause, the second or subsequent noun clauses are counted as separate constituents eg So its up to each student to decide/if they really want this/and are able to do it. 
Relative clauses are not considered separate elements.

Adverbials of purpose, reason, conditional, and concessive adverbials are separated from main clause

eg They went to university/to get higher qualification.

The second item of a conjoined adverbial of purpose is counted as an additional constituent on the same level of analysis

eg The students who haven't made up their mind can use this year /to improve/and consider about their future.

Adverbial clauses of time, location, simultaneity and manner are not separated eg If it add one or two years' work experience before you enter university.

It/there clauses + to - infinitive are not separated

eg But there is also some advantage to have some work experience. 


\section{APPENDIX 5 SAMPLE TEXT, TEXT ANALYSIS AND SCORE SHEET}

\section{STUDENTS SHOULD ALL HAVE AT LEAST ONE YEAR'S WORK EXPERIENCE BEFORE THEY CAN ENTER UNIVERSITY}

An average child in a family spends at least one quarter of his or her life in school and goes through three different levels of learning. These levels are the primary, secondary and tertiary levels. Although a majority of people today start working only after completing their tertiary level in universities or unitechs, there are still a small percentage that choose to start working after finishing their secondary education.

Education today costs a lot and not everyone could afford it. A low income or even a middle income family with an average of three children may not be able to afford the high prices of tertiary education for all of their children. This may result to these students having to work to support themselves through university. Thus, this doesn't mean that every student should or must start working before they can enter university.

In my opinion, I think that not everyone would agree or support the idea of all students working for one year before they can enter university. I think it should be up to the individual to decide whether or not he or she would like to do so or not. For example, a student going to university would maybe be more responsible because he or she knows that they have to spend a lot on school fees therefore be more carefull with money. On the other hand, a student who works first before entering university, wouldn't be so carefull with their money when they are university because they would most probably have gotten used to the working life and would have much more money to spend. This means they may have a problem with budgeting money when their in university. This of course wouldn't be of any problem to the elite class of people but may be a big problem for those in the low or middle income families.

Text written by student 2 , group 1 , occasion 1 

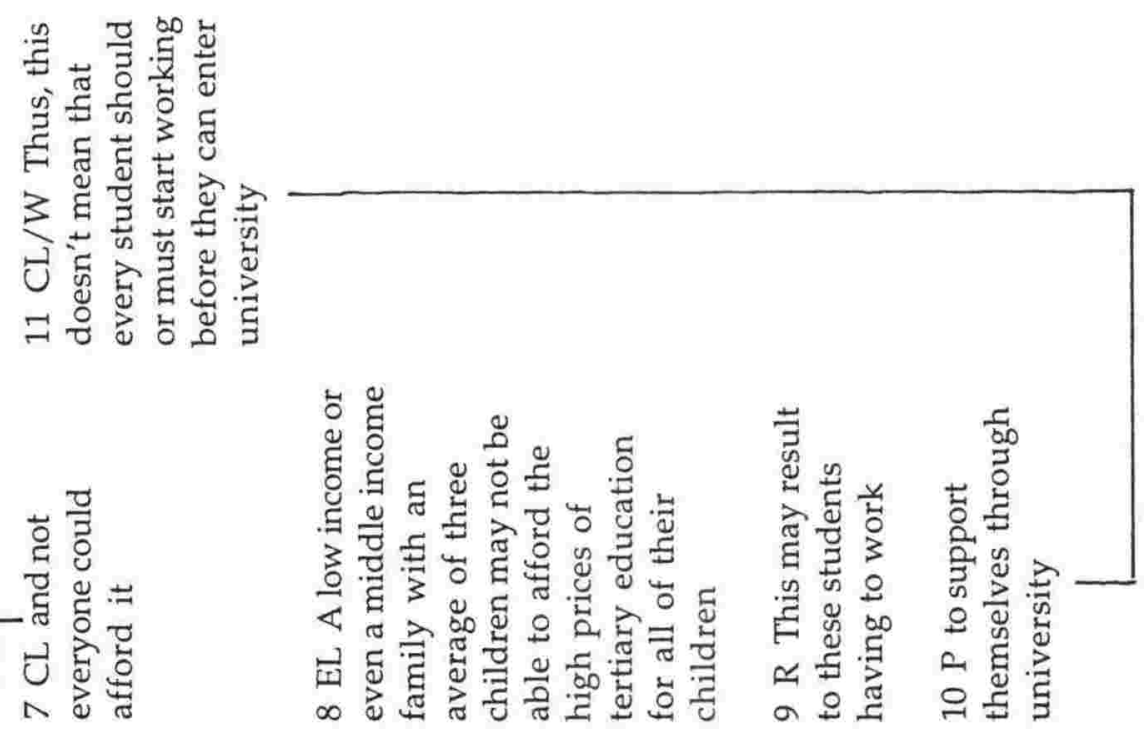

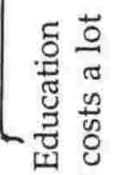

$0 \frac{\pi}{0}$
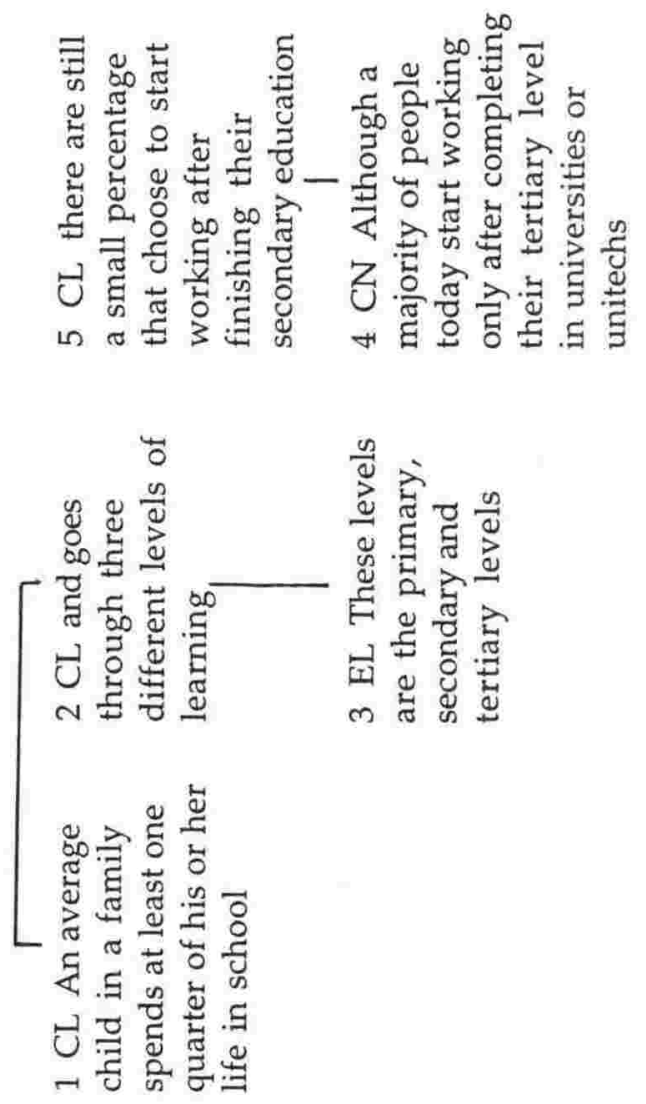


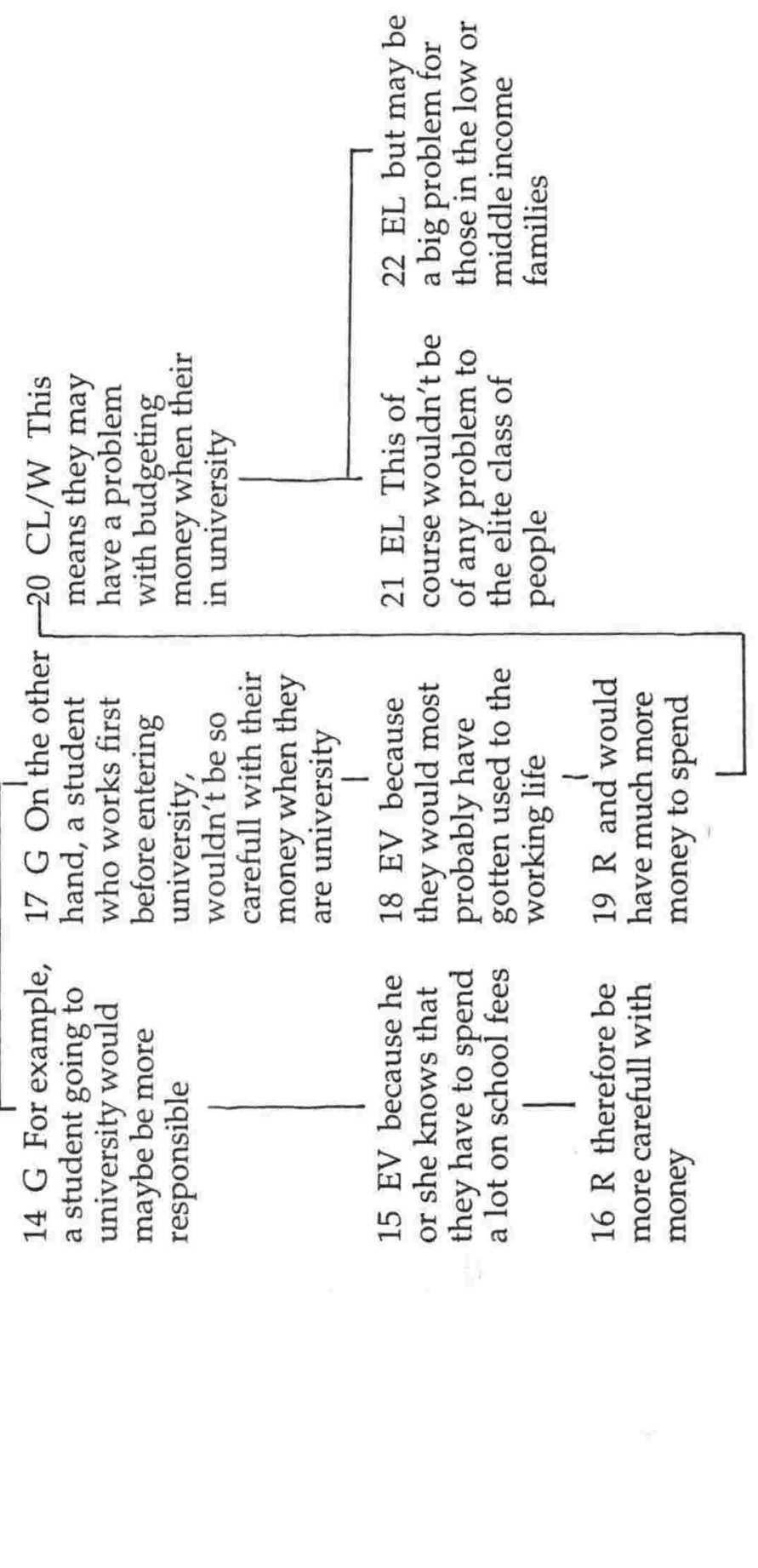




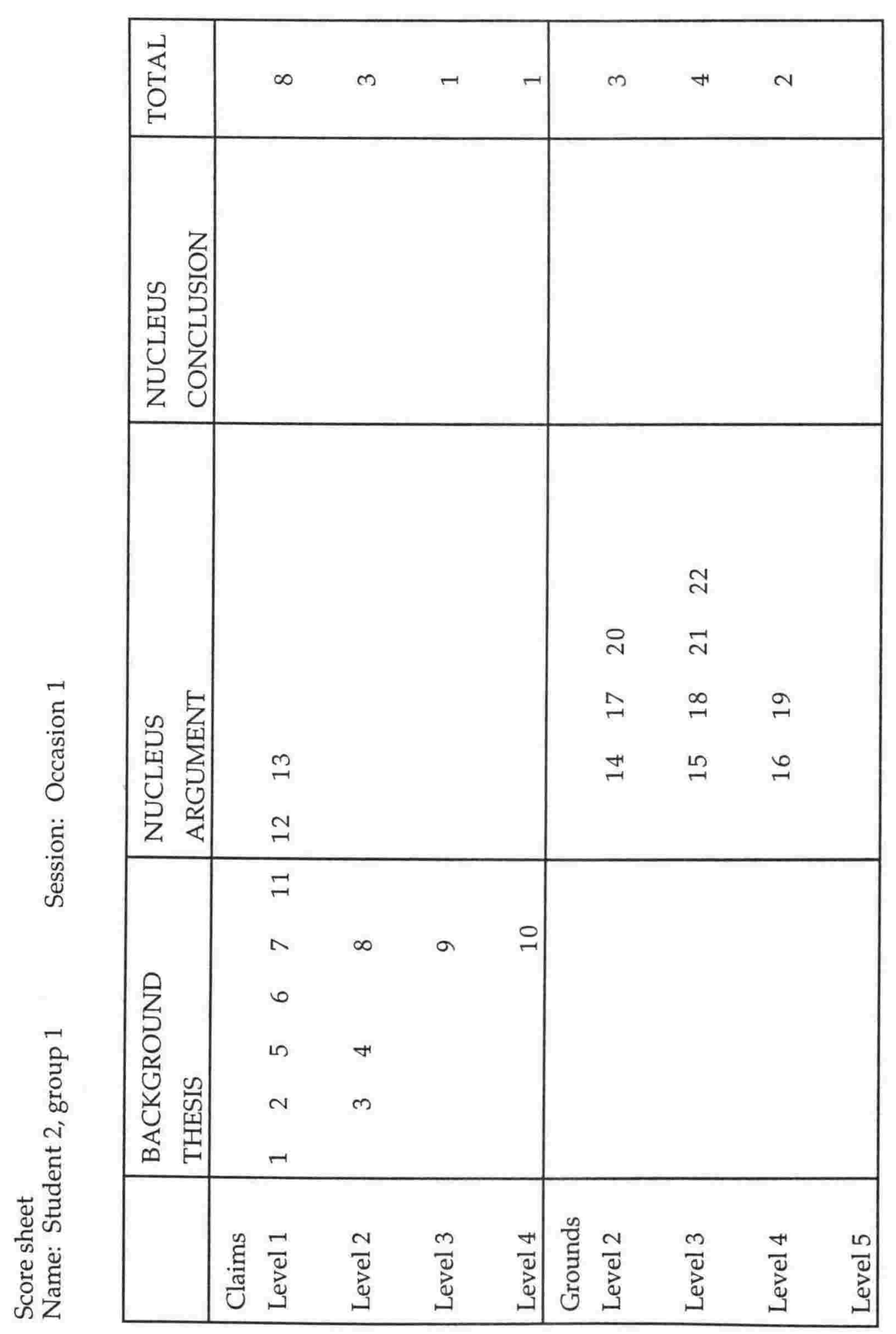


APPENDIX 6 MATERIALS FOR STATISTICAL ANALYSIS 


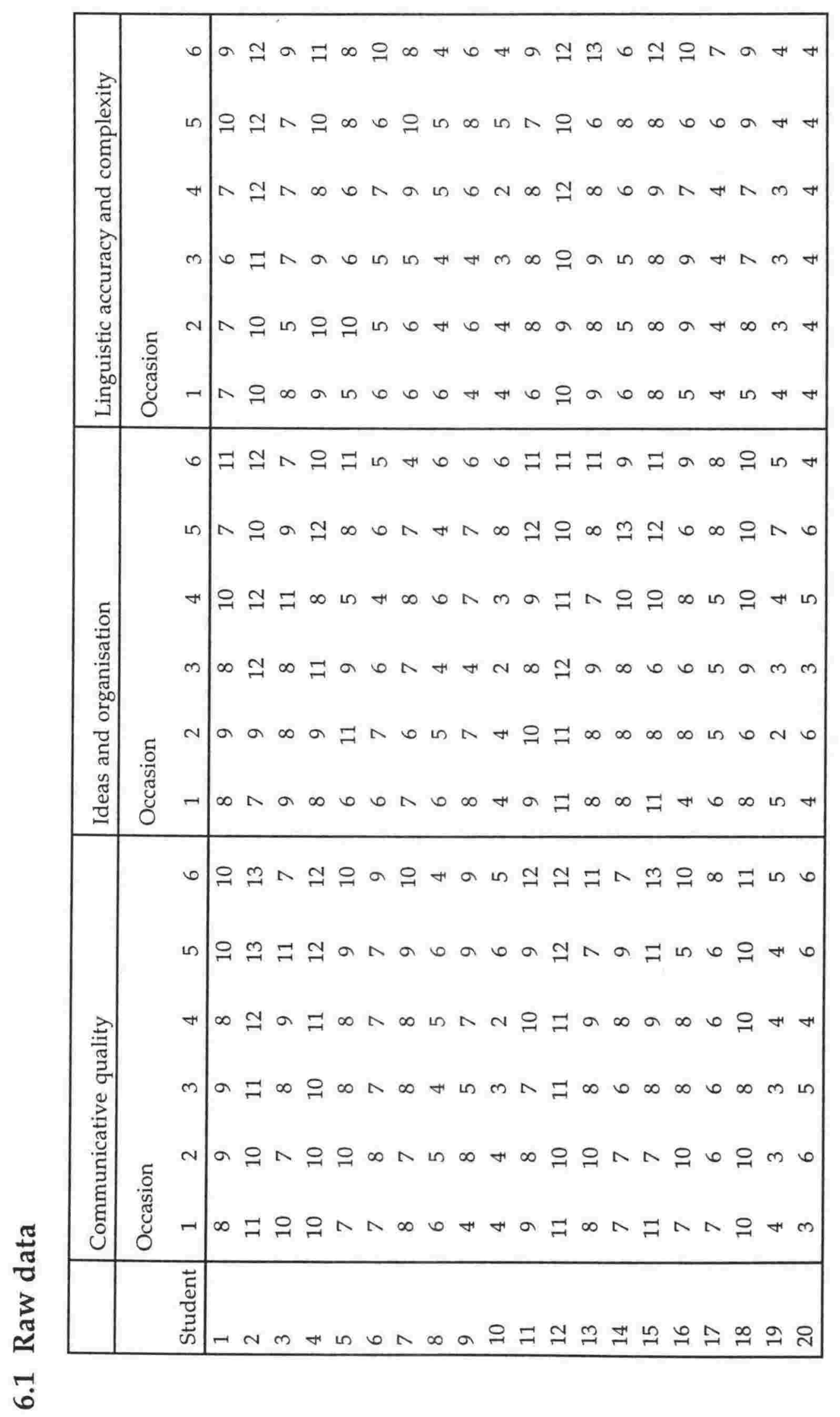




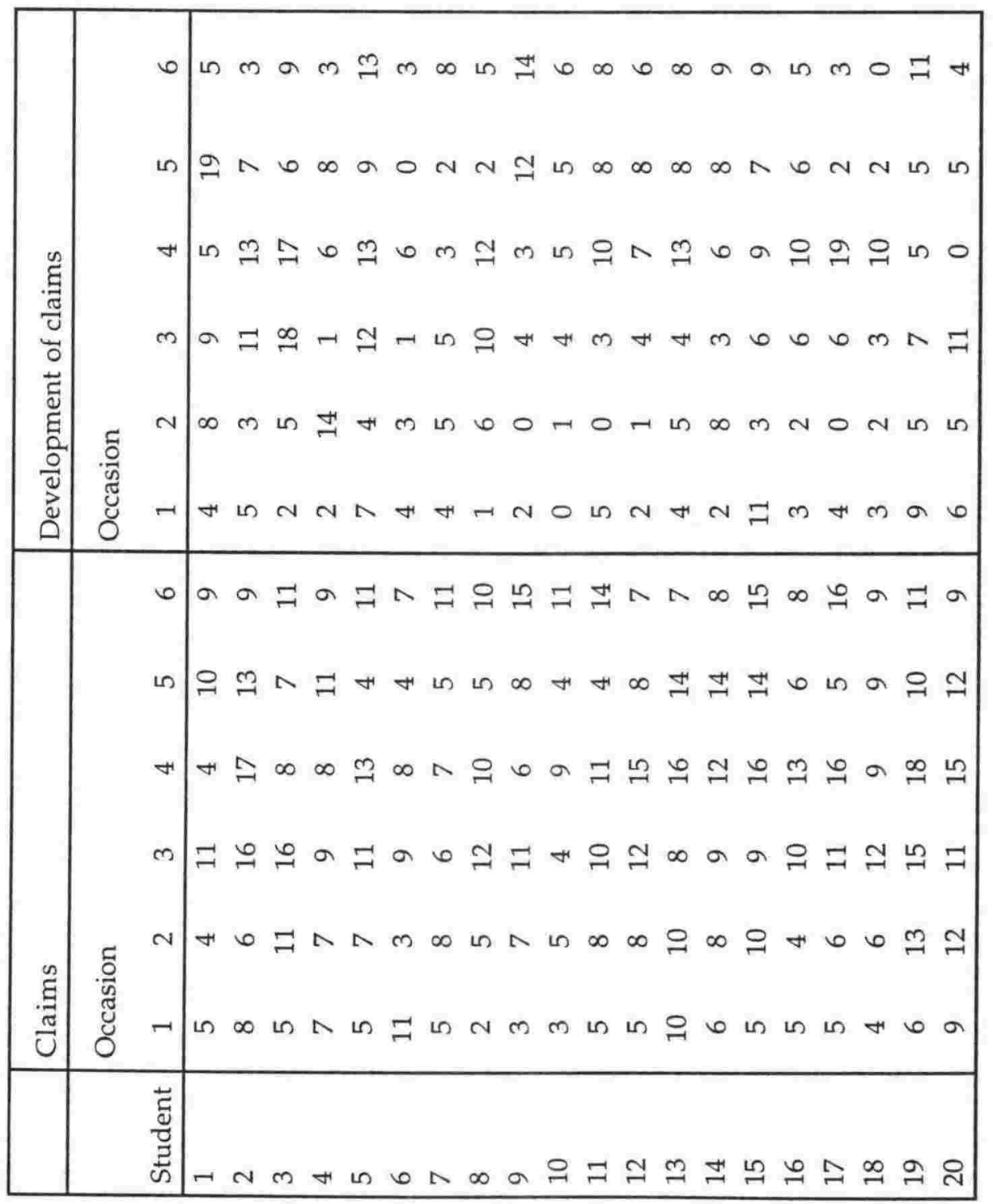




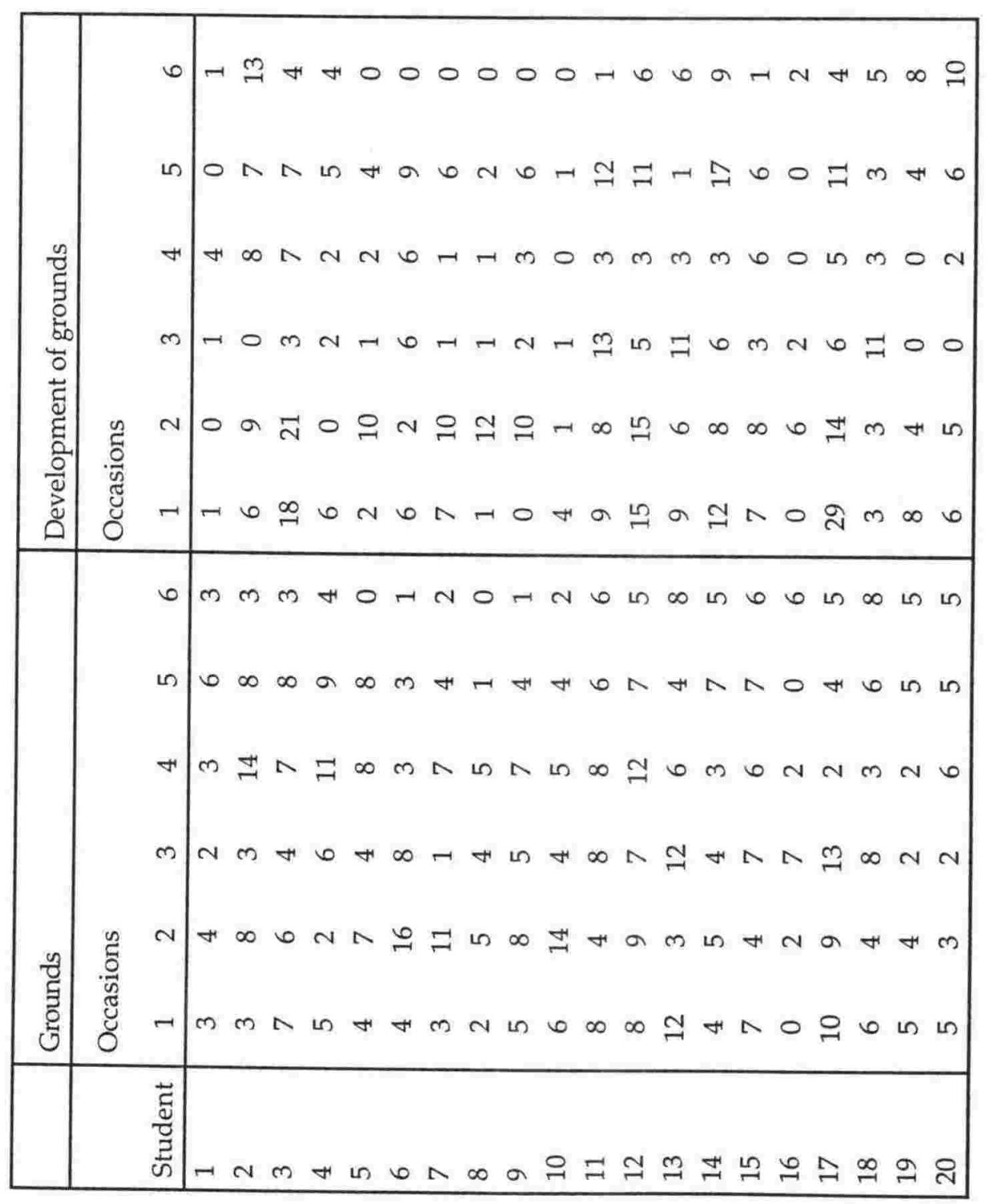




\subsection{Statistical program}

The following codes have been used for variables:

ga1 $=$ communicative quality

ga2 = ideas and organisation

ga3 = linguistic accuracy and complexity

$\mathrm{cl}=$ claims

$\mathrm{dc}=$ elaboration of claims

$\mathrm{g}=$ grounds

$\mathrm{dg}=$ elaboration of grounds

$\mathrm{gcl}=$ grounds to claims ratio

$\mathrm{dcl}=$ elaboration of claims to claims ratio

$\mathrm{dgg}=$ elaboration of grounds to grounds ratio

\section{General Linear Measures Procedure}

data first;

infile ' $\mathrm{h}: \backslash \mathrm{mf} \backslash \mathrm{mfdata}$.dat' lrecl=554 missover;

input

person group pret1ga1 pret2ga1 EngTga1 EngCga1 SciTga1SciCga1 HisTga1 HisCga1

pret1ga2 pret2ga2 EngTga2 EngCga2 SciTga2 SciCga2 HisTga2 HisCga2 pret1ga3 pret2ga3 EngTga3 EngCga3 SciTga3 SciCga3 HisTga3 HisCga3 pret1cl pret2cl EngTcl EngCcl SciTcl SciCcl HisTcl HisCcl pret1dc pret2dc EngTdc EngCdc SciTdc SciCdc HisTdc HisCdc pret1g pret2g EngTg EngCg SciTg $\mathrm{SciCg}$ HisTg $\mathrm{HisCg}$ pret1dg pret2dg EngTdg EngCdg SciTdg SciCdg HisTdg HisCdg; array cl pret1cl--HisCcl;

array dc pret1dc--HisCdc;

array g pret1g-- $\mathrm{His} \mathrm{Cg}$;

array dg pret1dg--HisCdg;

array dcl pret1dcl pret2dcl EngTdcl EngCdcl SciTdcl SciCdcl HisTdcl HisCdcl; array gcl pret1gcl pret2gcl EngTgcl EngCgcl SciTgcl SciCgcl HisTgcl HisCgcl; array dgg pret1dgg pret2dgg EngTdgg EngCdgg SciTdgg SciCdgg HisTdgg HisCdgg; do over cl; if $\mathrm{cl}=0$ then do; $\mathrm{dcl}=\mathrm{dc} / \mathrm{cl}$; 
$\mathrm{gcl}=\mathrm{g} / \mathrm{cl}$;

end;

if $\mathrm{g} \sim=0$ then

$\mathrm{dgg}=\mathrm{dg} / \mathrm{g}$;

if $\mathrm{dcl}=$, then $\mathrm{dcl}=0$;

if $\mathrm{gcl}=$, then $\mathrm{gcl}=0$;

if $\mathrm{dgg}=$. then $\mathrm{dgg}=0$;

end;

proc glm data=first;

class group;

model EngTga1--HisCga1=group pret1ga1 pret2ga1/ss2;

repeated task 3 , treat 2 ;

output out=f1 r=EngTga1r EngCga1r SciTga1r SciCga1r HisTga1r HisCga1r; proc univariate normal plot data $=\mathrm{f} 1$;

var EngTga1r--HisCga1r;

proc glm data=first;

class group;

model EngTga2--HisCga2=group pret1ga2 pret2ga2/ss2;

repeated task 3 , treat 2 ;

output out=f1 r=EngTga2r EngCga2r SciTga2r SciCga2r HisTga2r HisCga2r;

proc univariate normal plot data $=\mathrm{f} 1$;

var EngTga2r--HisCga2r;

proc glm data=first;

class group;

model EngTga3--HisCga3=group pret1ga3 pret2ga3/ss2;

repeated task 3 , treat 2 ;

output out=f1 r=EngTga3r EngCga3r SciTga3r SciCga3r HisTga3r HisCga3r; proc univariate normal plot data $=\mathrm{f} 1$;

var EngTga3r--HisCga3r;

proc glm data=first;

class group;

model EngTdcl--HisCdcl=group pret1dcl pret2dcl/ss2;

repeated task 3 , treat 2 ;

output out=f1 r=EngTdclr EngCdclr SciTdclr SciCdclr HisTdclr HisCdclr;

proc univariate normal plot data $=\mathrm{f} 1$;

var EngTdclr--HisCdclr;

proc $\mathrm{glm}$ data=first;

class group; 
model EngTgcl--HisCgcl=group pret1gcl pret2gcl/ss2;

repeated task 3 , treat 2 ;

output out=f1 r=EngTgclr EngCgclr SciTgclr SciCgclr HisTgclr HisCgclr;

proc univariate normal plot data $=\mathrm{f} 1$;

var EngTgclr--HisCgclr;

proc glm data=first;

class group;

model EngTdgg--HisCdgg=group pret1dgg pret2dgg/ss2;

repeated task 3 , treat 2 ;

output out=f1 r=EngTgclr EngCgclr SciTgclr SciCgclr HisTgclr HisCgclr;

proc univariate normal plot data $=\mathrm{f} 1$;

var EngTgclr--HisCgclr;

run;

proc print;

run;

proc glm data=first;

class group;

model EngTcl--HisCcl=group pret1cl $\mathrm{pret} 2 \mathrm{cl} / \mathrm{ss} 2$;

repeated task 3 , treat 2 ;

output out=f1 r=EngTclr EngCclr SciTclr SciCclr HisTclr HisCclr;

proc univariate normal plot data $=\mathrm{f} 1$;

var EngTclr--HisCclr;

proc glm data=first;

class group;

model EngTdc--HisCdc=group pret1dc pret2dc/ss2;

repeated task 3 , treat 2 ;

output out=f1 r=EngTder EngCder SciTdcr SciCdcr HisTder HisCdcr;

proc univariate normal plot data $=\mathrm{f} 1$;

var EngTdcr--HisCdcr;

proc glm data=first;

class group;

model EngTg--His $\mathrm{Cg}=$ group pret1 $\mathrm{g}$ pret2g/ss2;

repeated task 3 , treat 2;

output out=f1 r=EngTgr EngCgr SciTgr SciCgr HisTgr HisCgr;

proc univariate normal plot data $=\mathrm{f} 1$;

var EngTgr--HisCgr;

proc glm data=first;

class group; 
model EngTdg--HisCdg=group pret1dg pret2dg/ss2;

repeated task 3 , treat 2 ;

output out=f1 r=EngTdgr EngCdgr SciTdgr SciCdgr HisTdgr HisCdgr;

proc univariate normal plot data $=\mathrm{f} 1$;

var EngTdgr--HisCdgr;

run;

data second; set first;

score $=$ EngTga1; resource $=$ 'Eng '; treat $=$ 'T'; measure = 'ga1'; 'measure = 'ga1'; output;

score $=$ EngCga1; resource $=$ 'Eng ';treat $=$ 'C'; measure = 'ga1'; measure = 'ga1'; output;

score $=$ SciTga1; resource $=$ 'Sci '; treat $=$ ' $\mathrm{T}$ '; measure = 'ga1'; output;

score $=$ SciCga1; resource $=$ 'Sci '; treat $=$ 'C';measure = 'ga1'; output;

score $=$ HisTga1; resource $=$ 'His'; treat $=$ 'T';measure = 'ga1'; output;

score $=$ HisCga1; resource $=$ 'His'; treat $=$ 'C';measure = 'ga1'; output;

score $=$ EngTga2; resource $=$ 'Eng '; treat $=$ 'T'; measure $=$ 'ga2'; output;

score = EngCga2; resource $=$ 'Eng '; treat $=$ 'C';measure = 'ga2'; output;

score $=$ SciTga2; resource $=$ 'Sci '; treat $=$ 'T';measure = 'ga2'; output;

score $=$ SciCga2; resource $=$ 'Sci '; treat $=$ 'C'; measure = 'ga2'; output;

score $=$ HisTga2; resource $=$ 'His'; treat $=$ 'T'; 'measure = 'ga2'; output;

score $=$ HisCga2; resource $=$ 'His'; treat $=$ 'C'; measure = 'ga2'; output;

score = EngTga3; resource = 'Eng '; treat = 'T'; 'measure = 'ga3'; output;

score = EngCga3; resource = 'Eng '; treat = 'C'; measure = 'ga3'; output;

score $=$ SciTga3; resource = 'Sci '; treat = 'T';measure = 'ga3'; output;

score $=$ SciCga3; resource $=$ 'Sci '; treat = 'C'; 'measure = 'ga3'; output;

score $=$ HisTga3; resource $=$ 'His'; treat $=$ 'T'; 'measure = 'ga3'; output;

score $=$ HisCga3; resource $=$ 'His'; treat = 'C'; 'measure = 'ga3'; output;

score $=$ EngTcl; resource $=$ 'Eng '; treat $=$ 'T'; 'measure = 'cl'; output;

score $=$ EngCcl; resource $=$ 'Eng '; treat = 'C'; measure = 'cl'; output;

score $=$ SciTcl; resource $=$ 'Sci '; treat $=$ 'T'; measure = 'cl'; output;

score $=\mathrm{SciCcl}$; resource $=$ 'Sci '; treat = 'C'; measure = ' $\mathrm{cl}^{\prime}$; output;

score $=$ HisTcl; resource $=$ 'His'; treat $=$ 'T'; ;measure $=$ 'cl'; output;

score $=\mathrm{HisCl}$; resource $=$ 'His'; treat $=$ ' $\mathrm{C}$ '; measure = 'cl'; output;

score = EngTdc; resource = 'Eng '; treat $=$ 'T'; 'measure = 'dc'; output;

score = EngCdc; resource = 'Eng '; treat = 'C'; measure = 'dc'; output;

score $=$ SciTdc; resource $=$ 'Sci '; treat $=$ 'T'; ;measure $=$ 'dc'; output;

score $=$ SciCdc; resource = 'Sci '; treat = 'C'; measure = 'dc'; output;

score $=$ HisTdc; resource $=$ 'His'; treat = 'T'; 'measure = 'dc'; output;

score = HisCdc; resource = 'His'; treat = 'C';measure = 'dc'; output;

score $=$ EngTg; resource $=$ 'Eng '; treat $=$ 'T'; 'measure = ' $\mathrm{g}$ '; ;utput; 


$$
\begin{aligned}
& \text { score }=\text { EngCg; resource }=\text { 'Eng '; treat }={ }^{\prime} C^{\prime} \text {; } \text { measure }=\text { 'g '; output; } \\
& \text { score }=\text { SciTg; resource }=\text { 'Sci '; treat }=\text { 'T'; measure }=\text { 'g '; output; } \\
& \text { score }=\mathrm{SciCg} \text {; resource }=\text { 'Sci '; treat }=\text { ' }^{\prime} \text {; } \text {;measure }={ }^{\prime} \mathrm{g} \text { '; output; } \\
& \text { score = HisTg; resource = 'His'; treat = 'T';measure = 'g ';output; } \\
& \text { score }=\text { HisCg; resource }=\text { 'His'; treat }=\text { ' } \mathrm{C}^{\prime} \text {; measure }=\text { 'g '; output; } \\
& \text { score }=\text { EngTdg; resource }=\text { 'Eng '; treat }=\text { 'T'; } \text { measure = ' } \mathrm{dg}^{\prime} \text {; output; } \\
& \text { score = EngCdg; resource = 'Eng '; treat = 'C'; } \\
& \text { score }=\text { SciTdg; resource }=\text { 'Sci '; treat }=\text { 'T'; } \text { 'measure = 'dg'; } \text { output; } \\
& \text { score }=\text { SciCdg; resource = 'Sci '; treat = 'C'; measure = 'dg'; output; } \\
& \text { score }=\text { HisTdg; resource }=\text { 'His'; treat }=\text { 'T'; measure = 'dg'; output; } \\
& \text { score }=\text { HisCdg; resource }=\text { 'His'; treat = 'C'; measure = 'dg'; output; } \\
& \text { score }=\text { EngTgcl; resource }=\text { 'Eng '; treat = 'T'; measure = 'gcl'; output; } \\
& \text { score }=\text { EngCgcl; resource }=\text { 'Eng '; treat }=\text { 'C'; } \text { 'measure = 'gcl'; } \text {;output; } \\
& \text { score }=\text { SciTgcl; resource }=\text { 'Sci '; treat }=\text { 'T';measure = 'gcl'; output; } \\
& \text { score }=\mathrm{SciCgcl} \text {; resource }=\text { 'Sci '; treat }=\text { 'C'; } \text { 'measure = 'gcl';output; } \\
& \text { score }=\text { HisTgcl; resource }=\text { 'His'; treat }=\text { 'T';measure = 'gcl'; output; } \\
& \text { score }=\mathrm{HisCgcl} \text {; resource }=\text { 'His'; treat }=\text { 'C';measure = 'gcl'; } \text { 'output; } \\
& \text { score = EngTdgg; resource = 'Eng '; treat = 'T'; } \text { 'measure = 'dgg'; output; } \\
& \text { score = EngCdgg; resource = 'Eng '; treat = 'C';measure = 'dgg'; output; } \\
& \text { score = SciTdgg; resource }=\text { 'Sci '; treat = 'T'; measure = 'dgg'; output; } \\
& \text { score }=\text { SciCdgg; resource = 'Sci '; treat = 'C';measure = 'dgg'; output; } \\
& \text { score = HisTdgg; resource = 'His'; treat = 'T'; } \text { 'measure = 'dgg'; output; } \\
& \text { score = HisCdgg; resource = 'His'; treat = 'C';measure = 'dgg'; } \text {; } \\
& \text { drop }
\end{aligned}
$$$$
\text { EngTga1 EngCga1 SciTga1 SciCga1 HisTga1 HisCga1 }
$$$$
\text { EngTga2 EngCga2 SciTga2 SciCga2 HisTga2 HisCga2 }
$$$$
\text { EngTga3 EngCga3 SciTga3 SciCga3 HisTga3 HisCga3 }
$$$$
\text { EngTcl EngCcl SciTcl SciCcl HisTcl HisCcl }
$$$$
\text { EngTdc EngCdc SciTdc SciCdc HisTdc HisCdc }
$$$$
\text { EngTg EngCg SciTg SciCg HisTg HisCg }
$$$$
\text { EngTdg EngCdg SciTdg SciCdg HisTdg HisCdg; }
$$$$
\text { EngTgcl EngCgcl SciTgcl SciCgcl HisTgcl HisCgcl }
$$$$
\text { EngTgcl EngCgcl SciTgcl SciCgcl HisTgcl HisCgcl }
$$$$
\text { EngTdgg EngCdgg SciTdgg SciCdgg HisTdgg HisCdgg; }
$$$$
\text { proc sort; by measure resource treat group; }
$$$$
\text { run; }
$$$$
\text { proc means n mean std stderr; }
$$$$
\text { var score; by measure; }
$$ 
proc means n mean std stderr;

var score; by measure resource;

proc means n mean std stderr;

var score; by measure resource treat;

proc means $n$ mean std stderr;

var score; by measure treat resource;

proc sort; by measure treat resource;

proc means n mean std stderr;

var score; by measure treat;

run;

proc freq;

run; 
APPENDIX 7 INTERACTION FULL TRANSCRIPTS OF STUDENT 


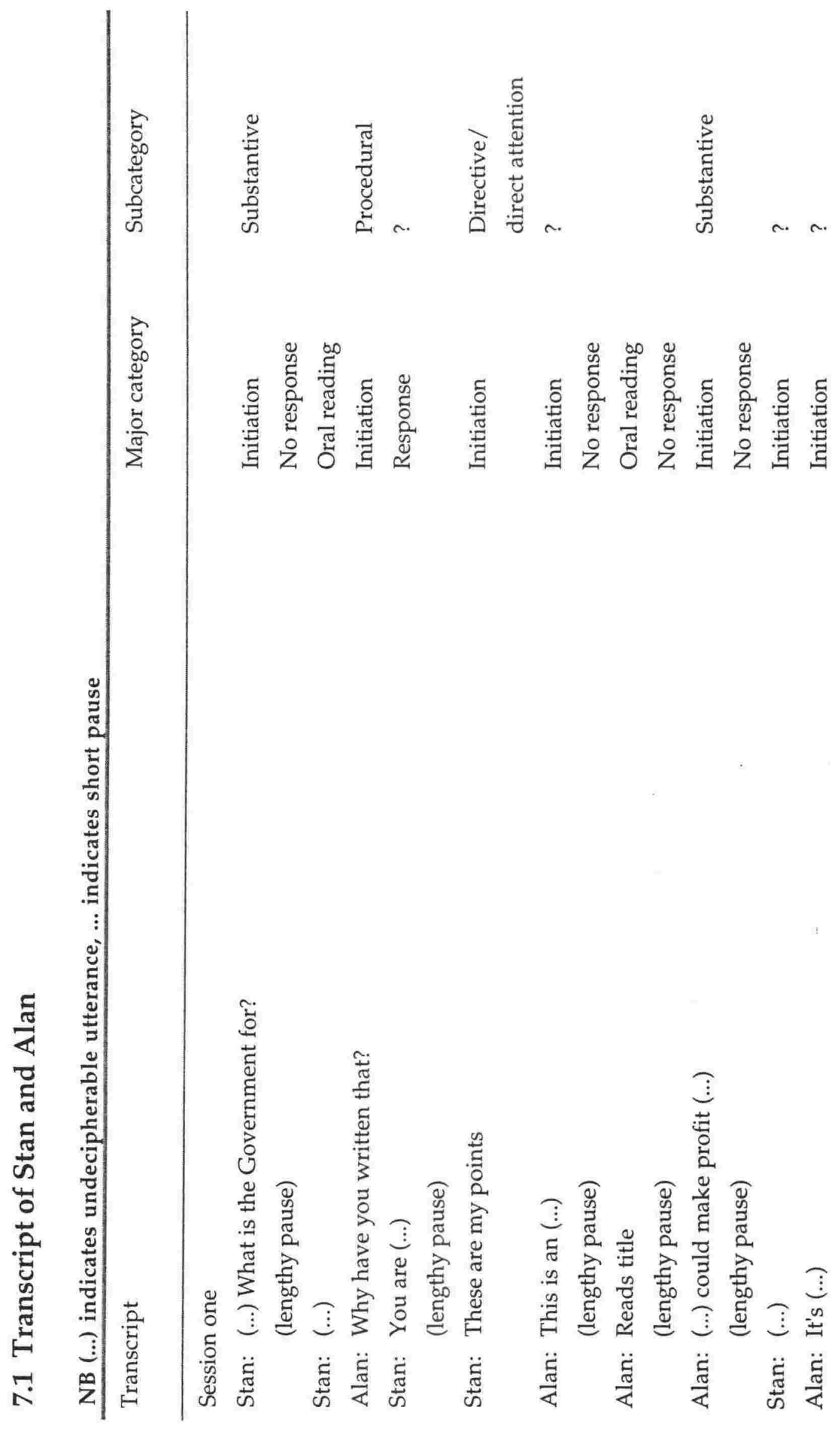




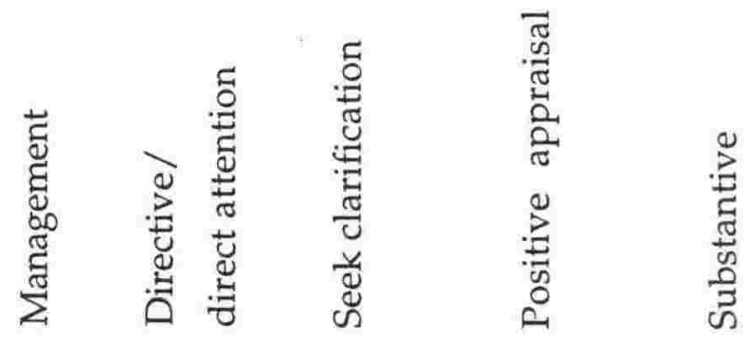

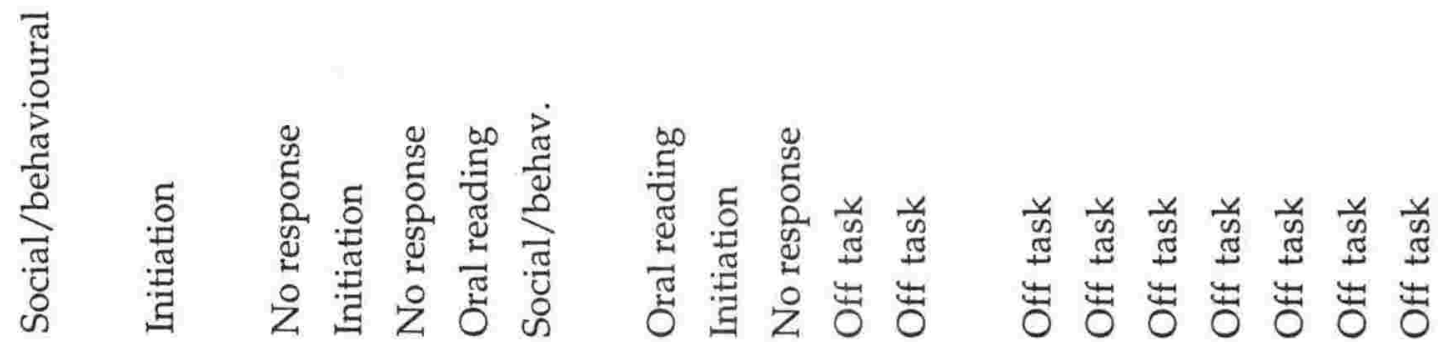

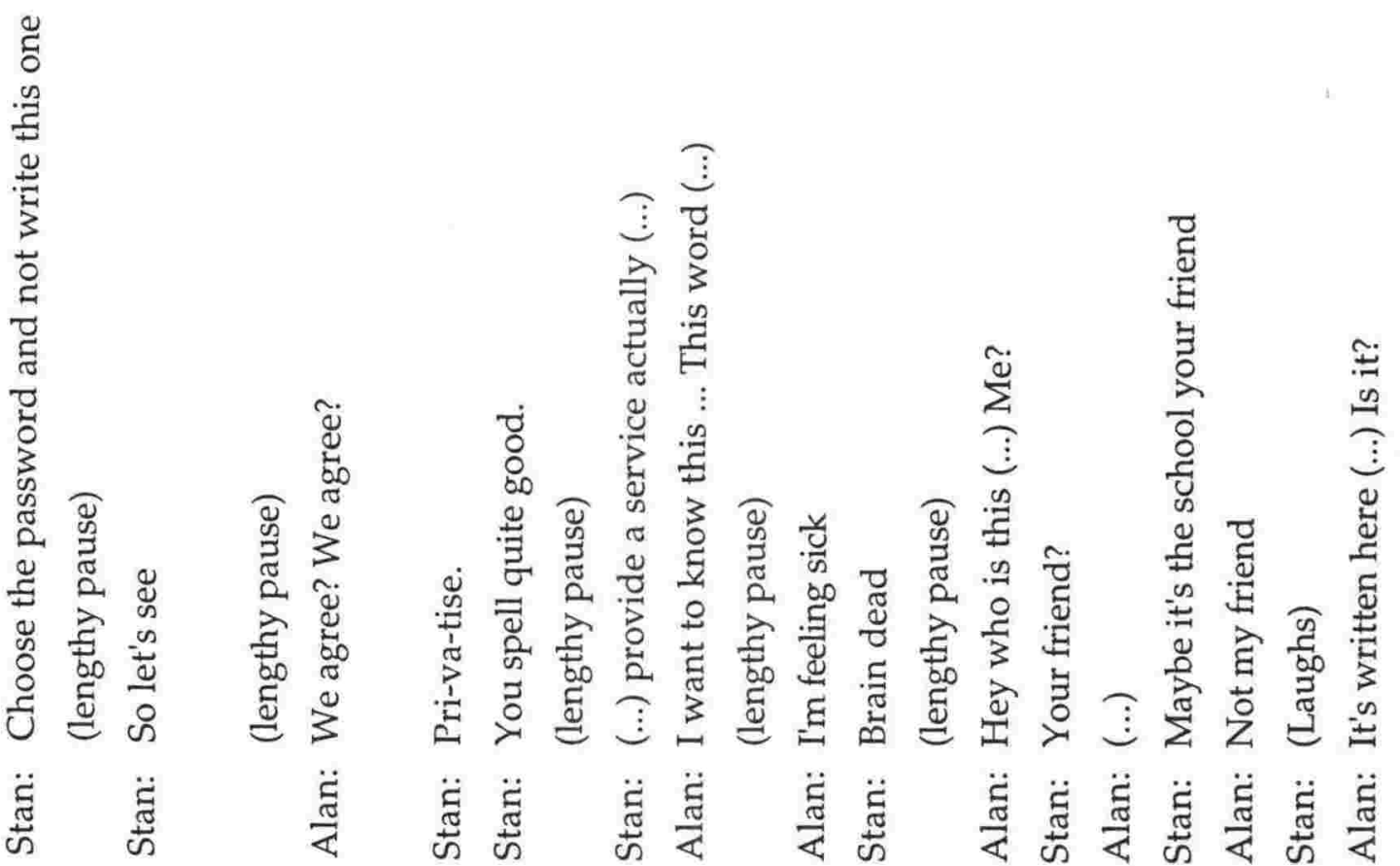




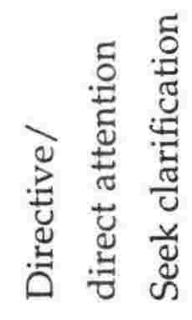

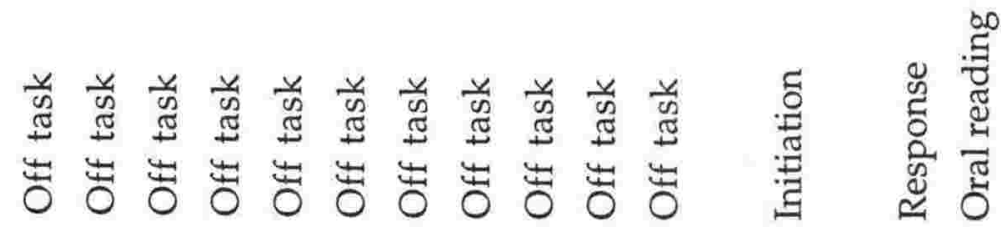

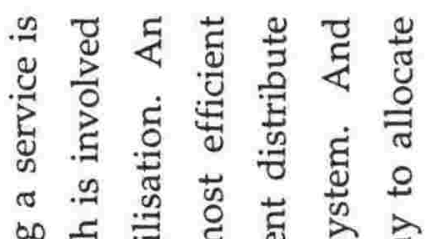

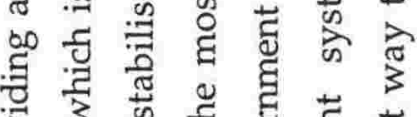

空苛

¿ है छ

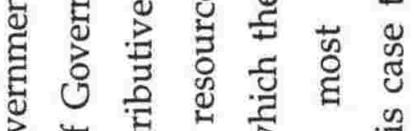

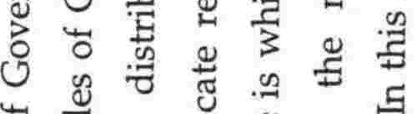

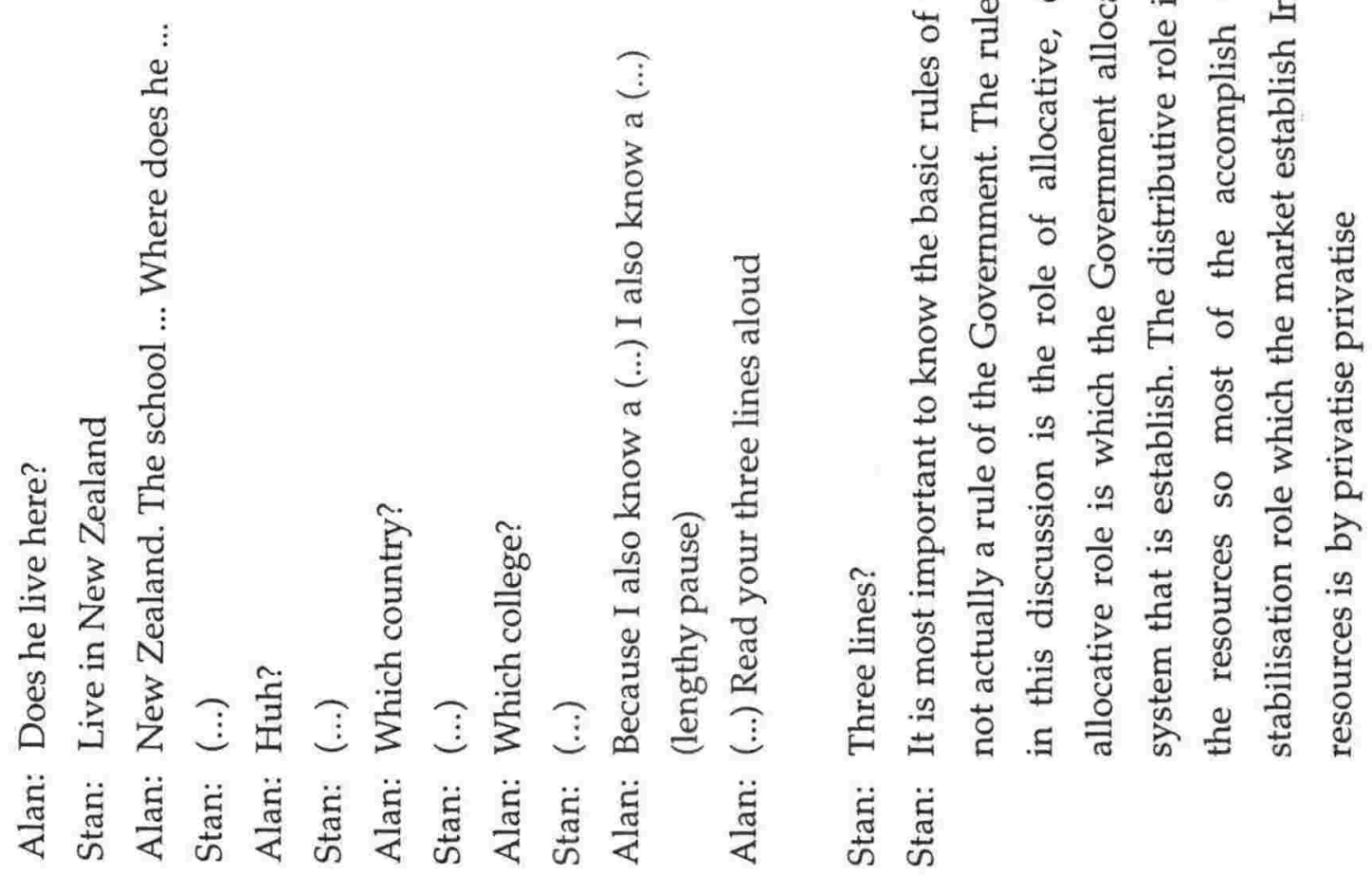



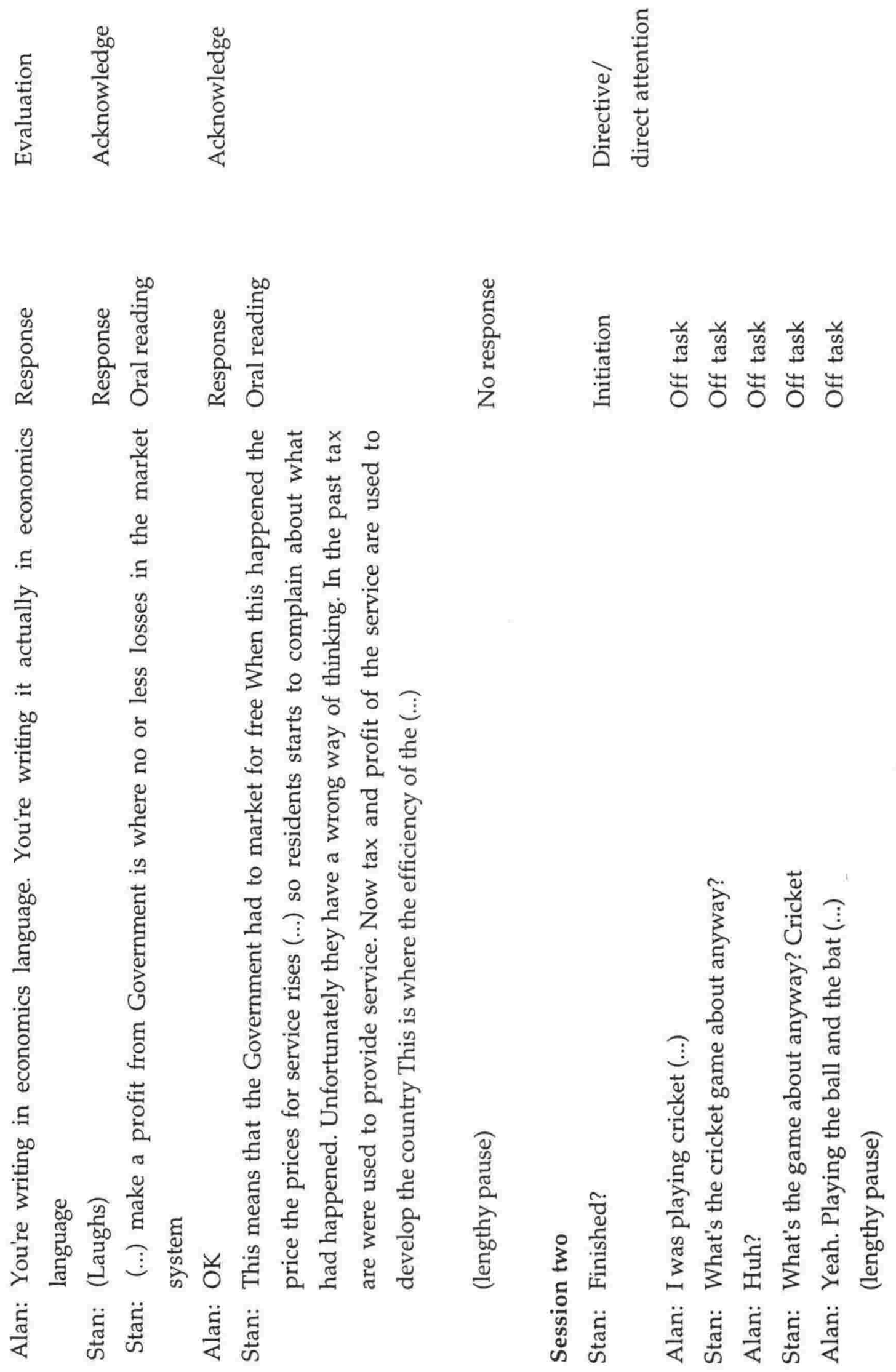

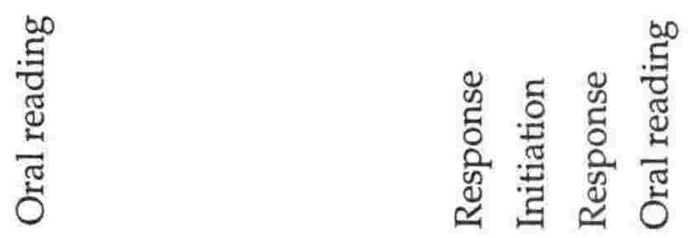

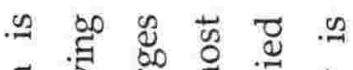

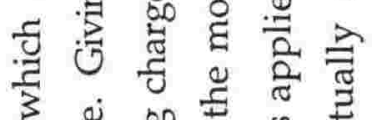

उ

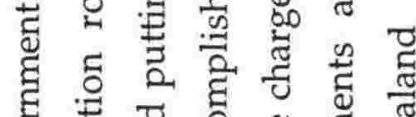

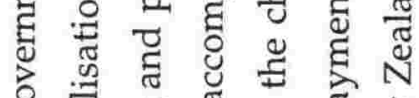

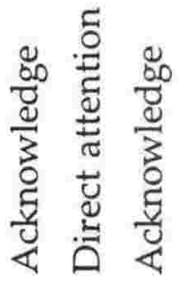

ن స

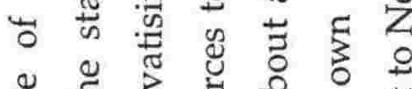

๘

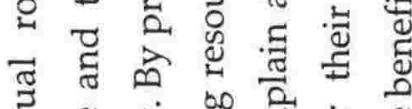

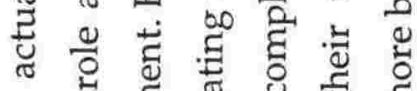

¿ $\doteq$ छ

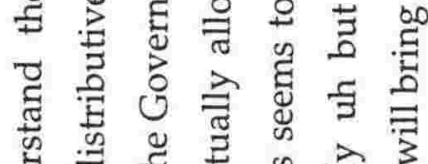

Ð 当 $\frac{0}{\pi}$

芯范坖

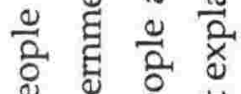

ฉ. ¿

ப० छ

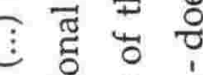

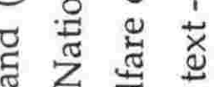

$0 \pi$

䒕范

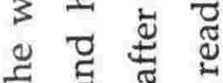

क त क

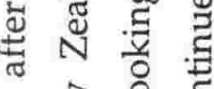

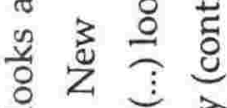

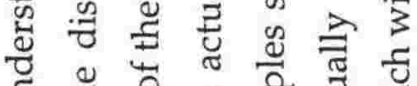

모

I

水

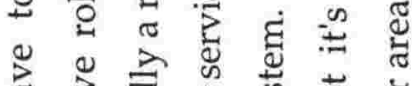

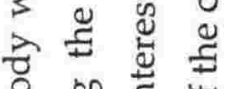

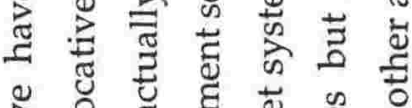

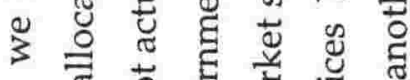

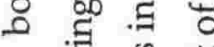

० 坣 䒕

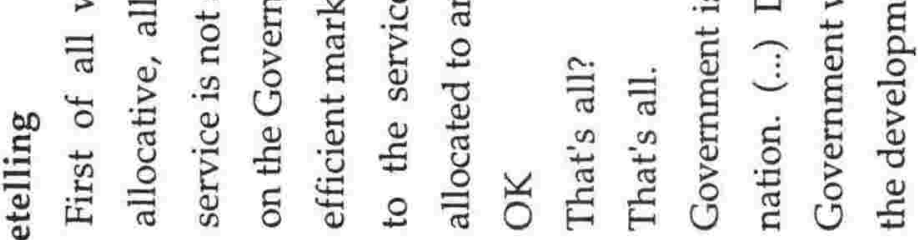

$\leadsto 53$ है

吾

茂离芯芯 


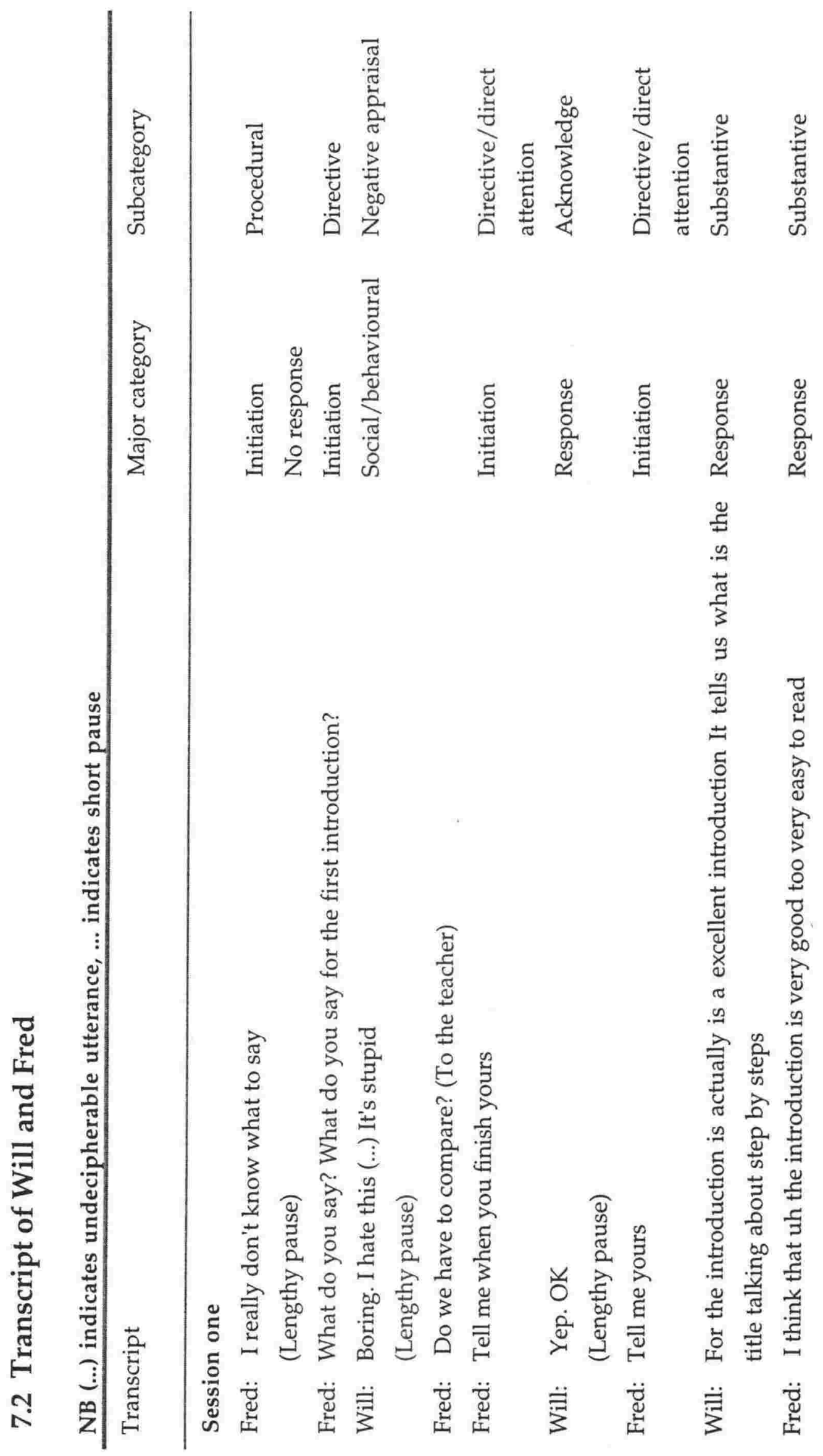



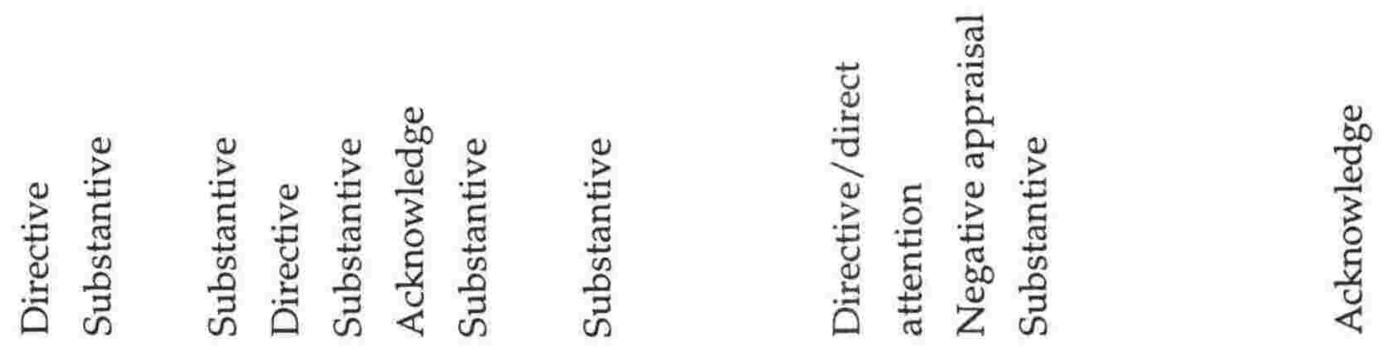

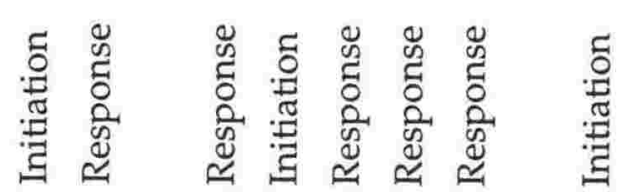

言

ד.

家

.

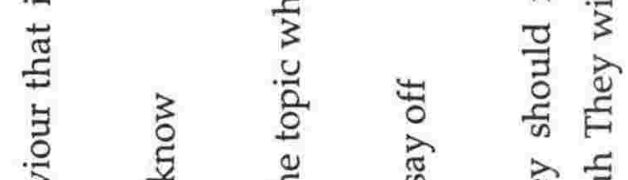

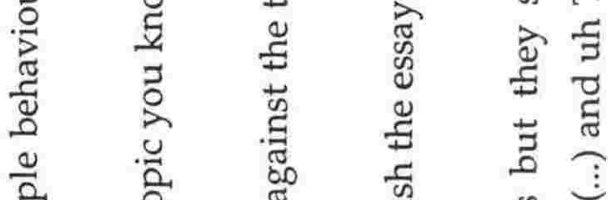

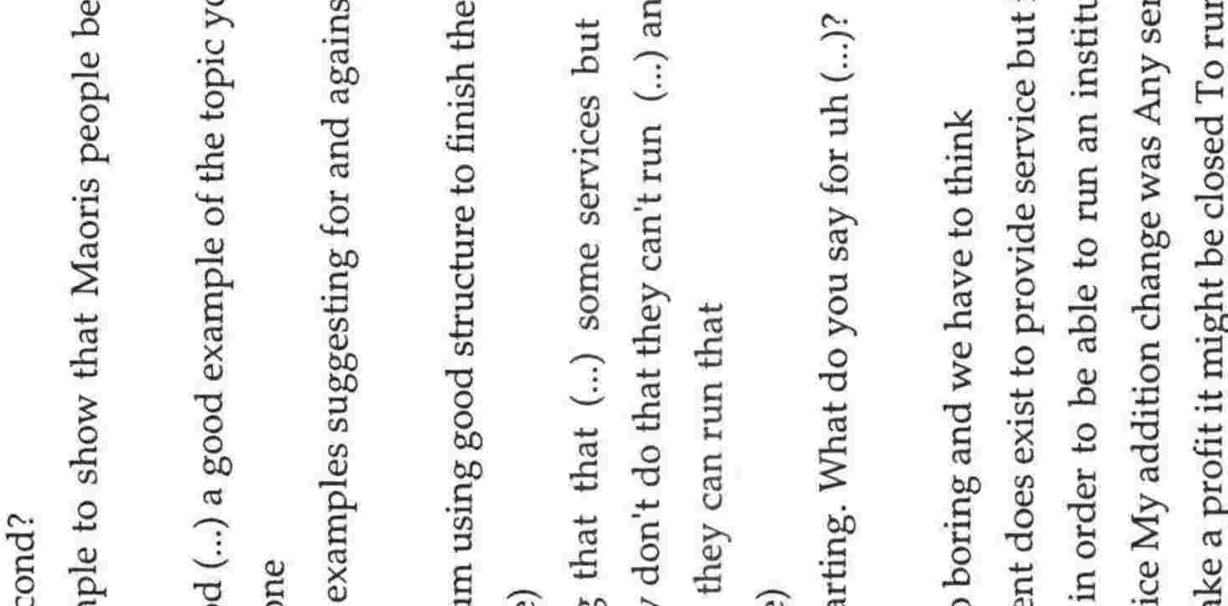

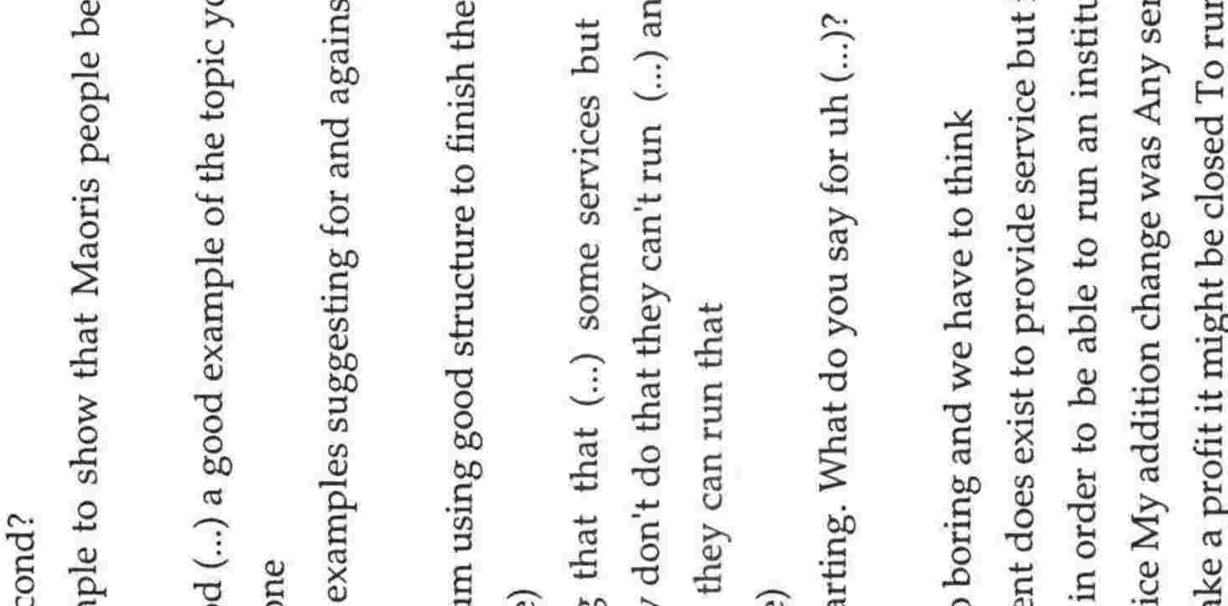

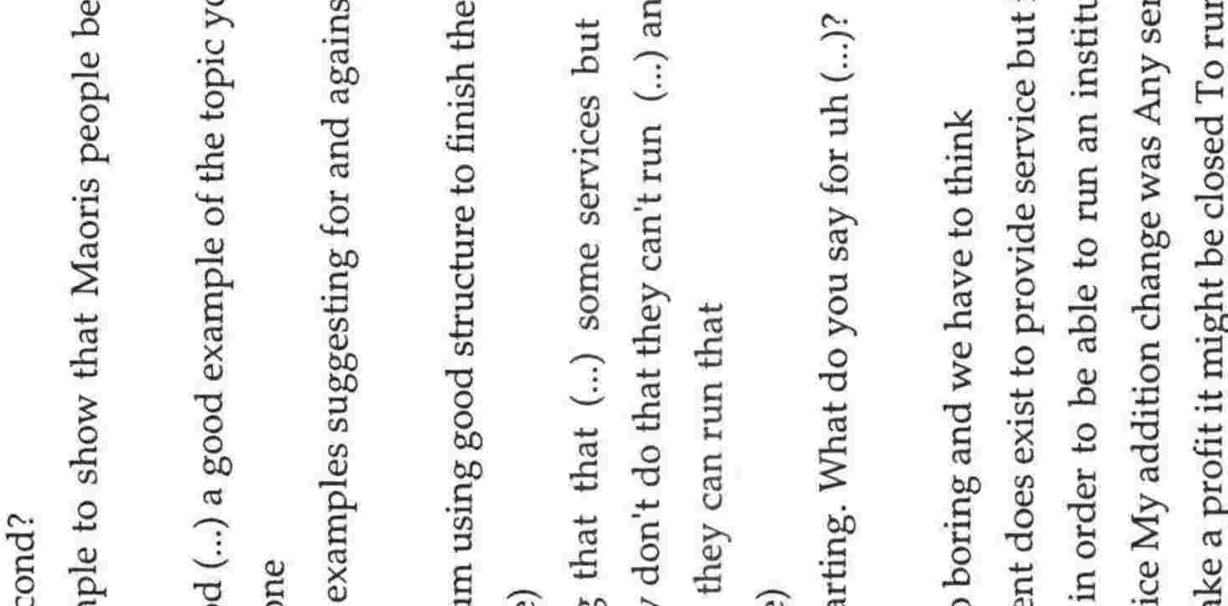

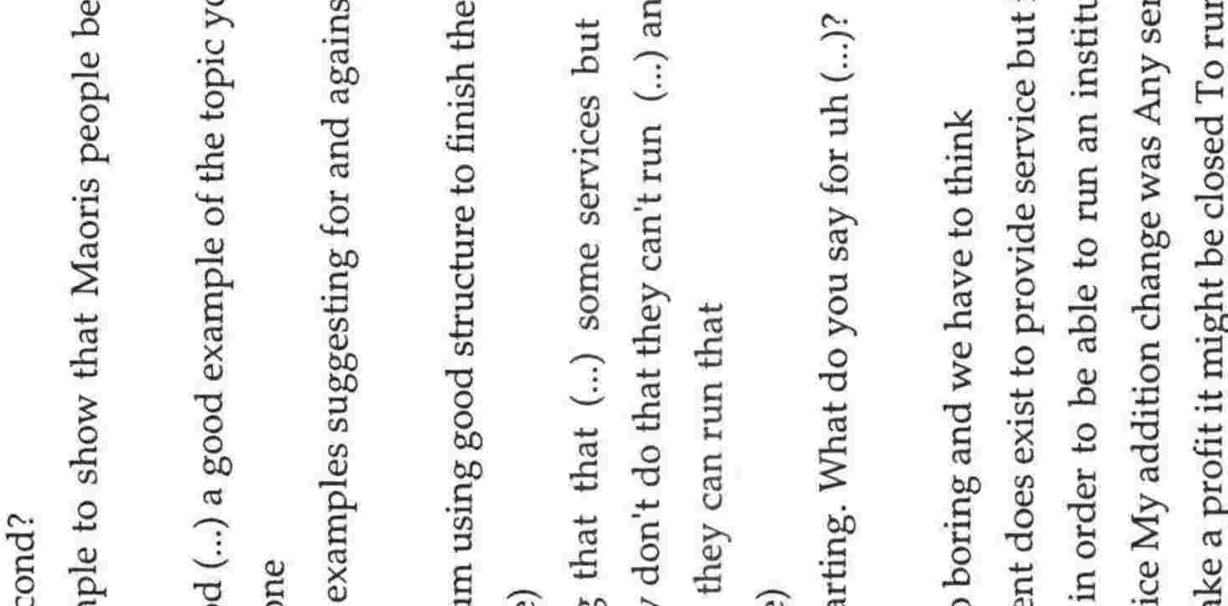

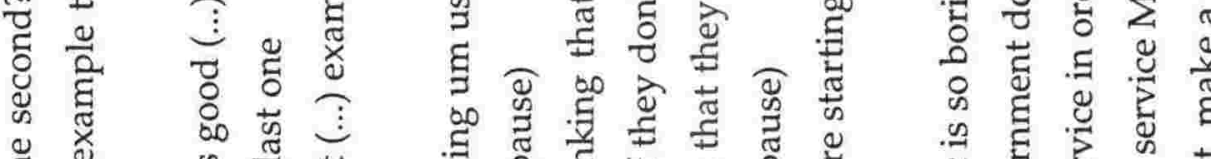

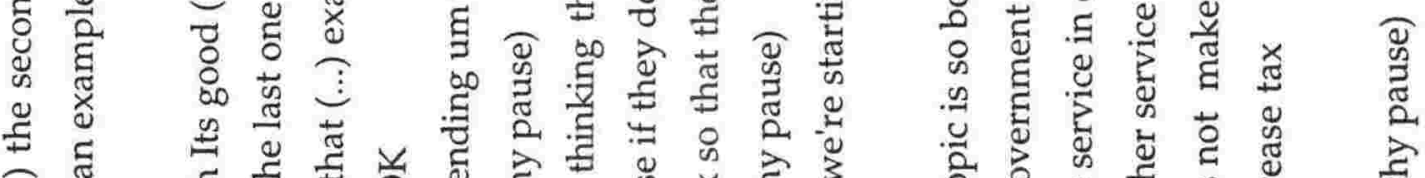

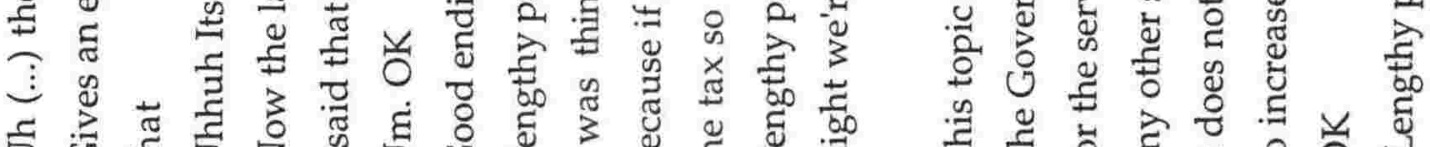

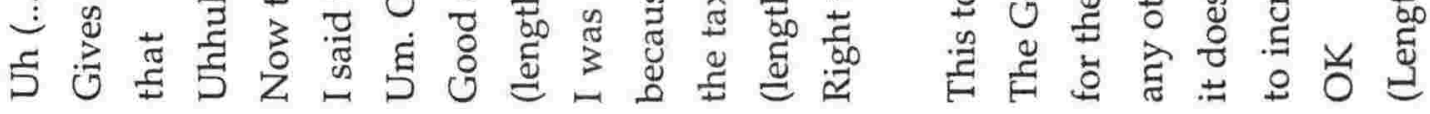

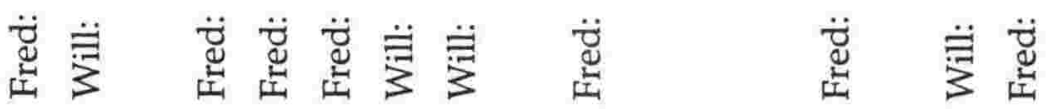

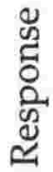

藞 

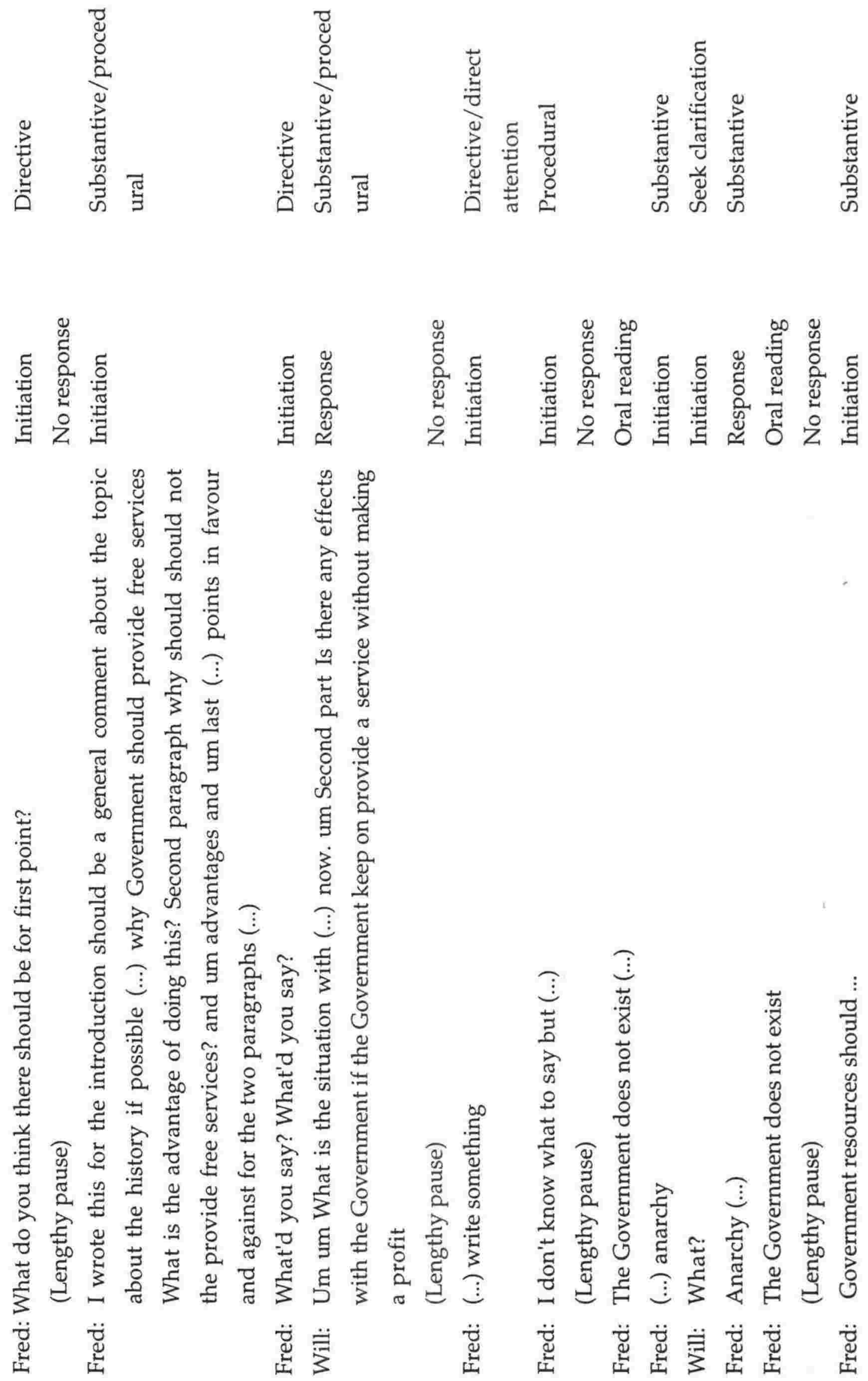

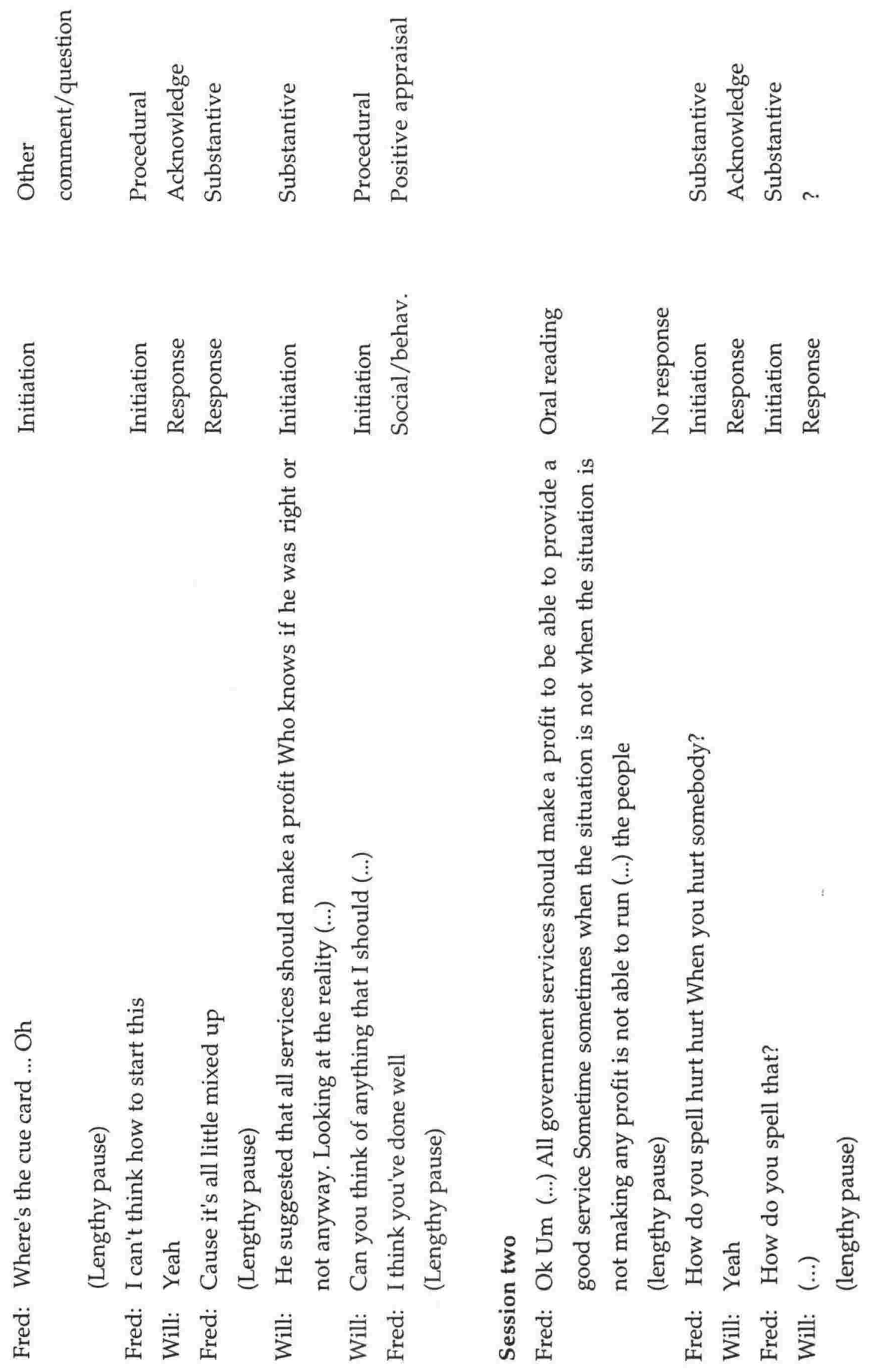
$\pi$
0
0
0
0
0
0
0
0
0
0
2
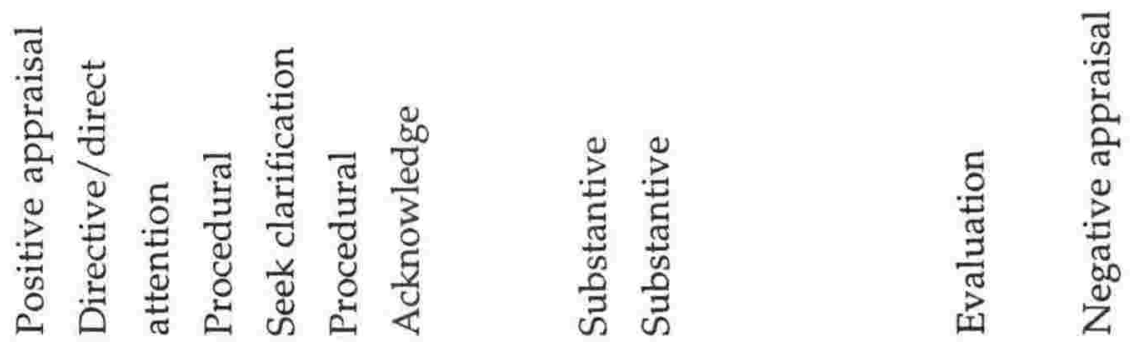

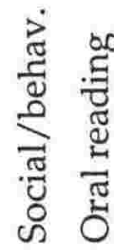

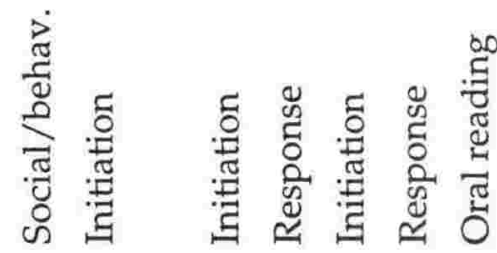

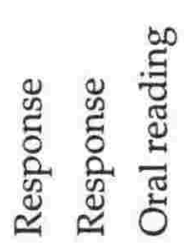

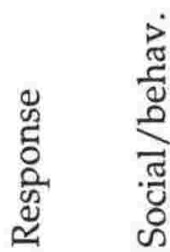

च

\&

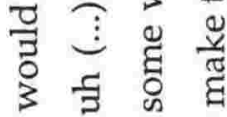

$=$ 월 용

드 훙

䒕

हु 3

ป స

ठ ¿ ए

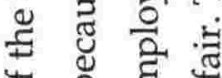

च \& छ छ

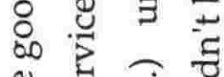

\&

苛芷

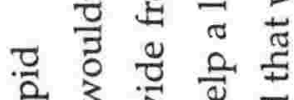

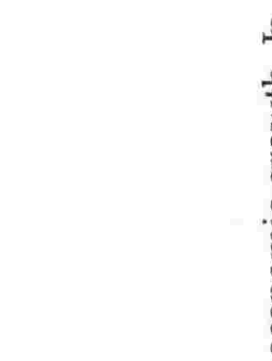

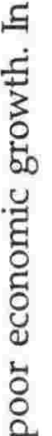

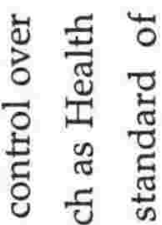

?

$\pi$

"ृ

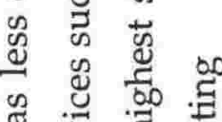

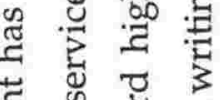

茟焉豆

至

茎

壳 芯

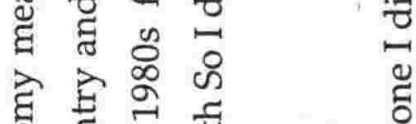

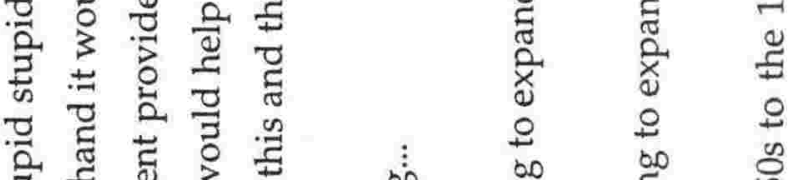

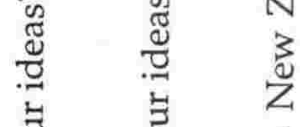

도욣

蓠

के छ

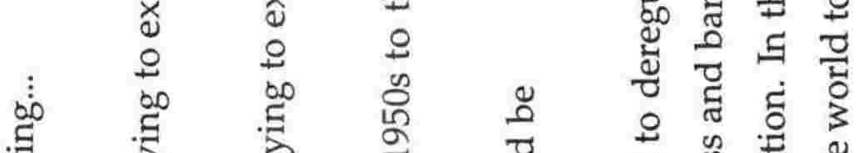

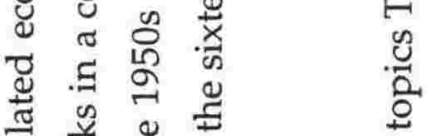

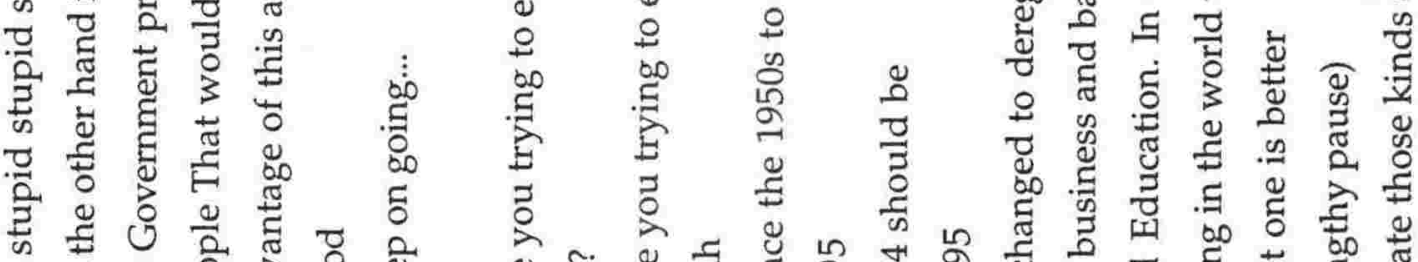

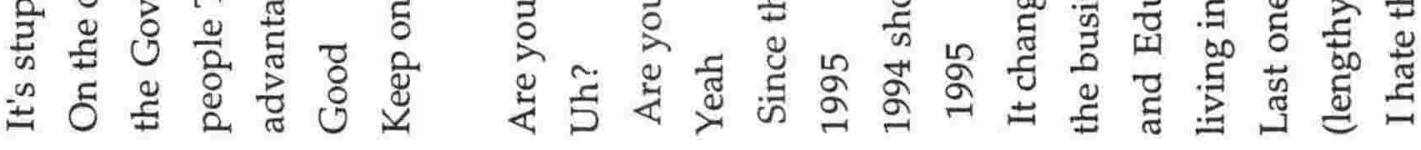

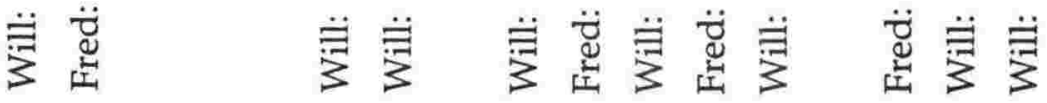

离 $\quad$ 竞 

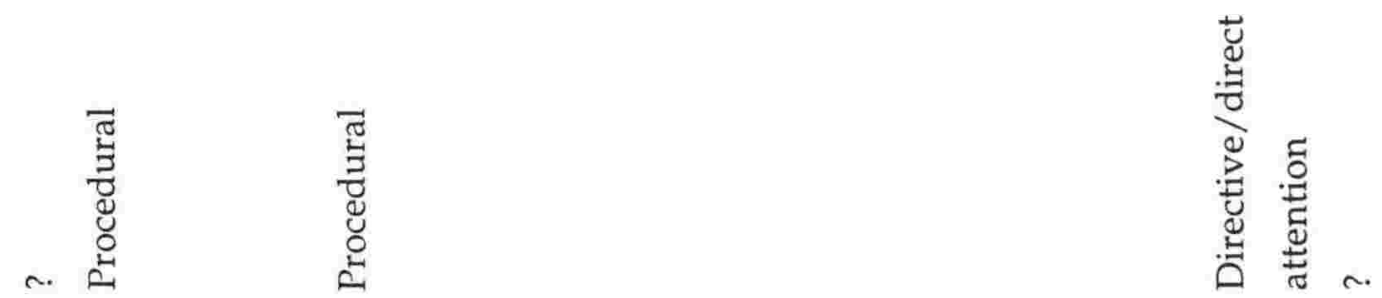

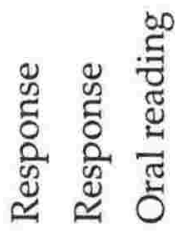
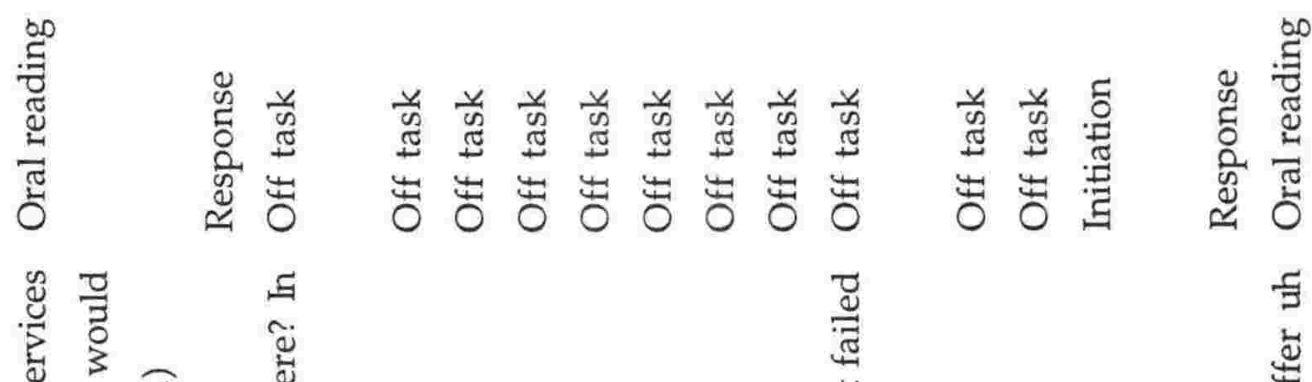

$$
\text { ક્ઞ }
$$

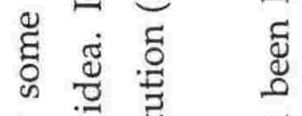

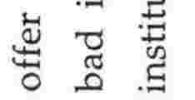

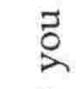

ఫัँ

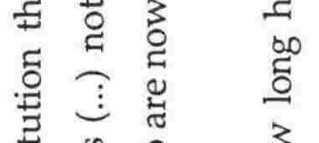

营

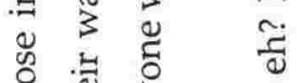

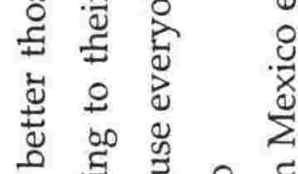

寻

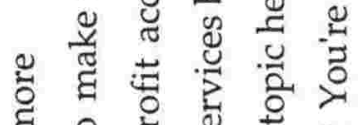

몷

э

घ)

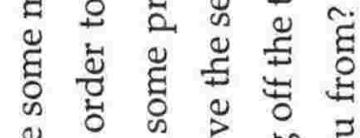

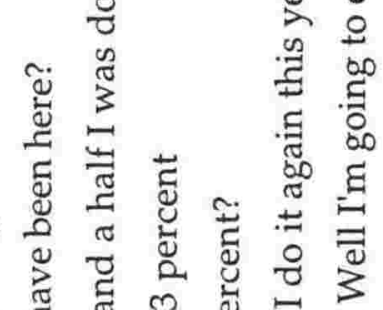

$\cong$

ธิ

훈 요

एँّ

き ઘ

宩

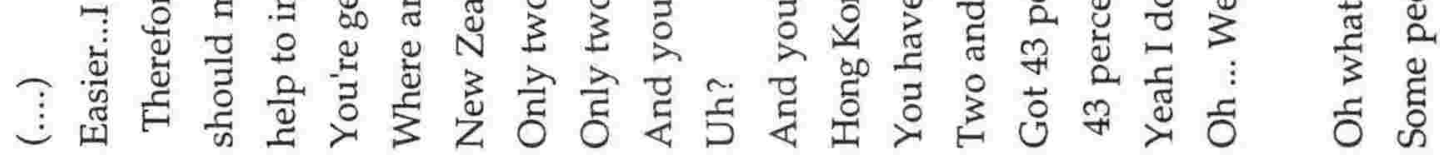

咅息

볼

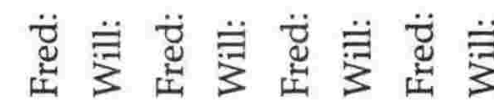

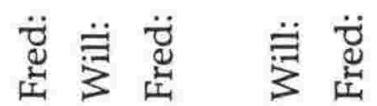


\begin{tabular}{l}
0 \\
0 \\
0 \\
3 \\
0 \\
0 \\
0 \\
\hline
\end{tabular}

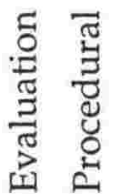

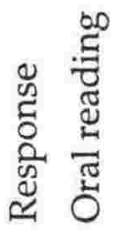

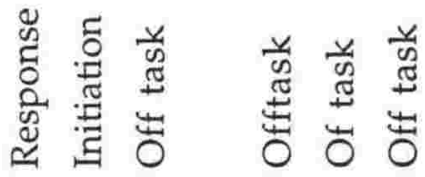

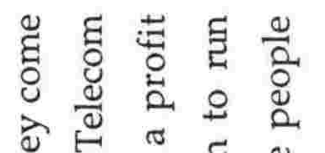

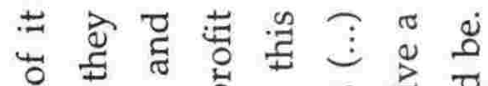

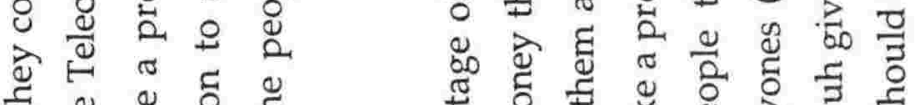

离

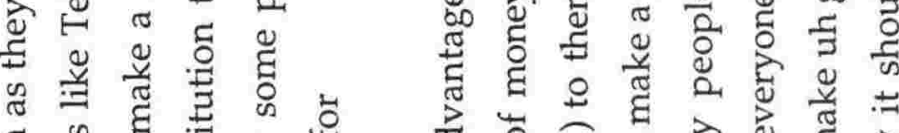

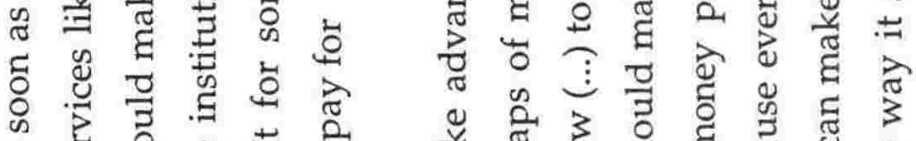

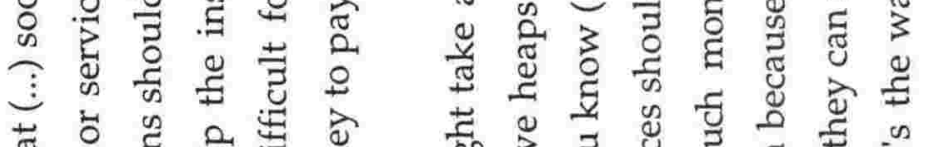

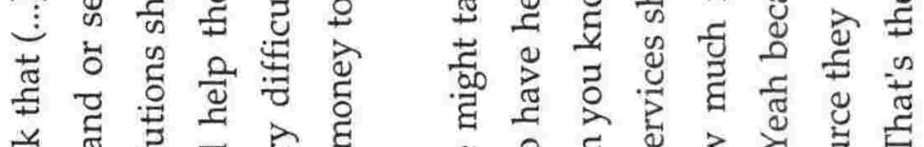

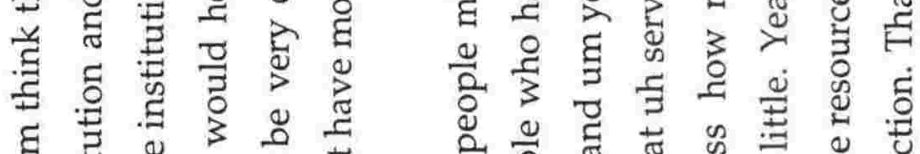

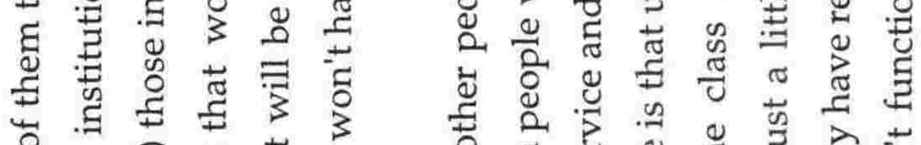

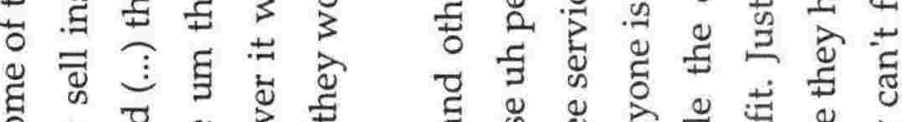

总

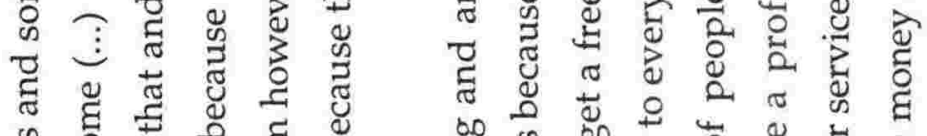

嵌

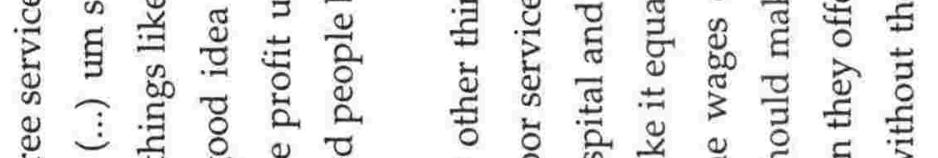

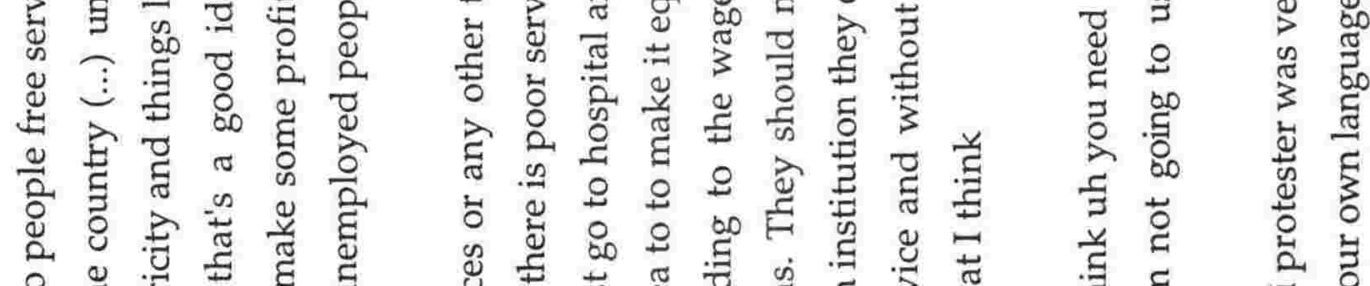

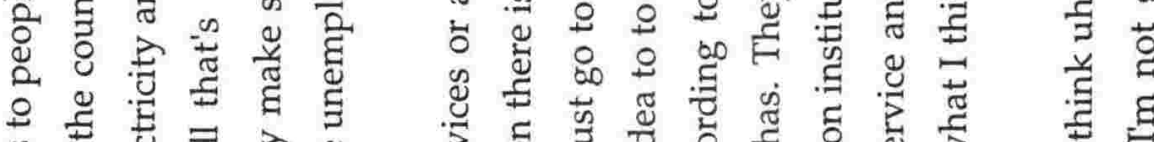

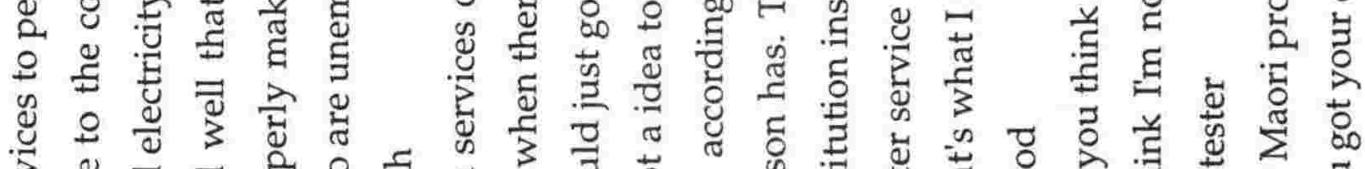

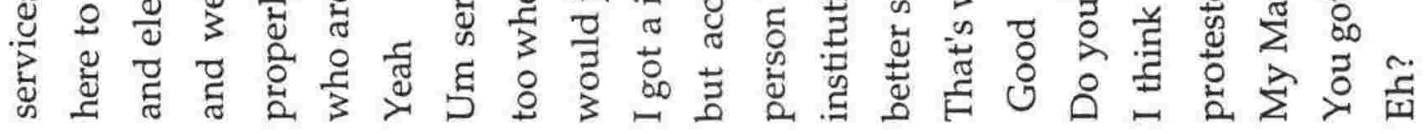

率蓠

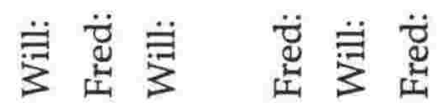




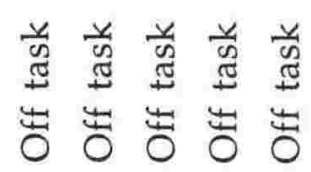

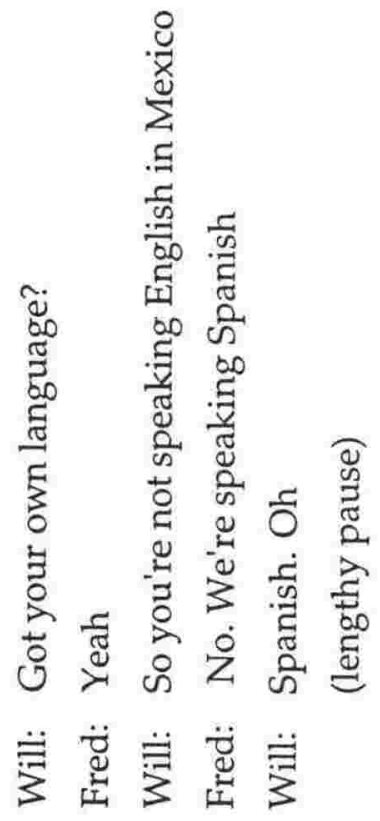

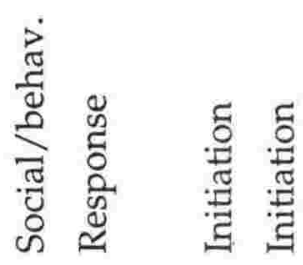

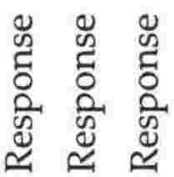

ट्व है

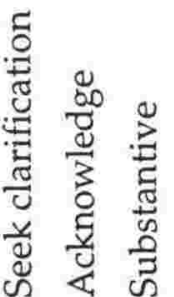

宅

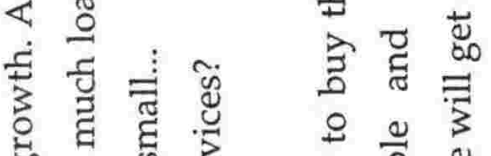

ฯ $₫$

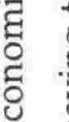

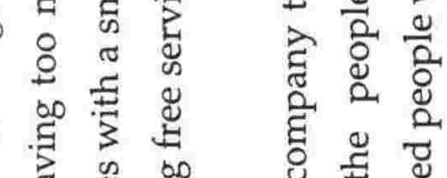

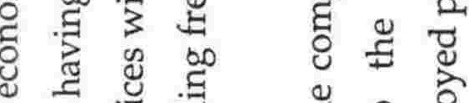

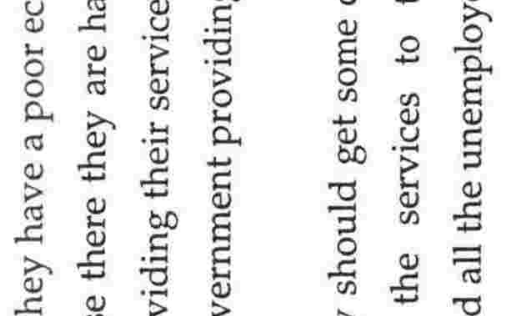

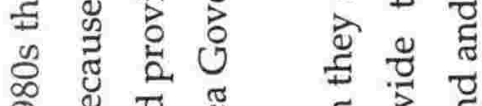

๙

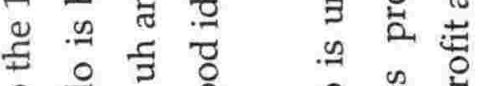

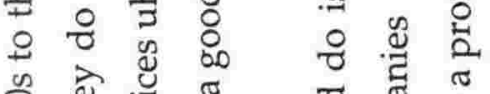
के के

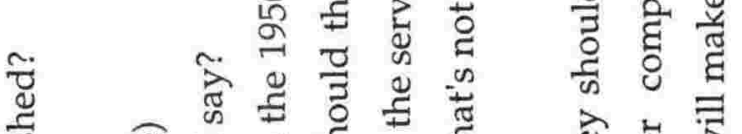

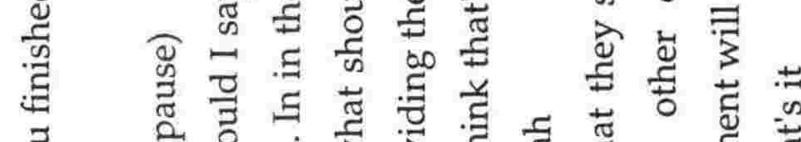

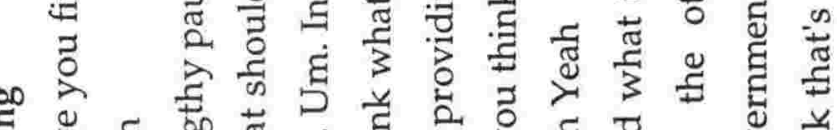

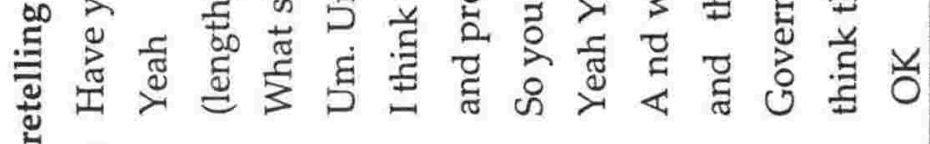

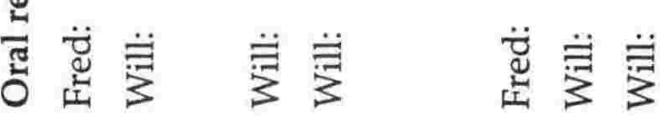




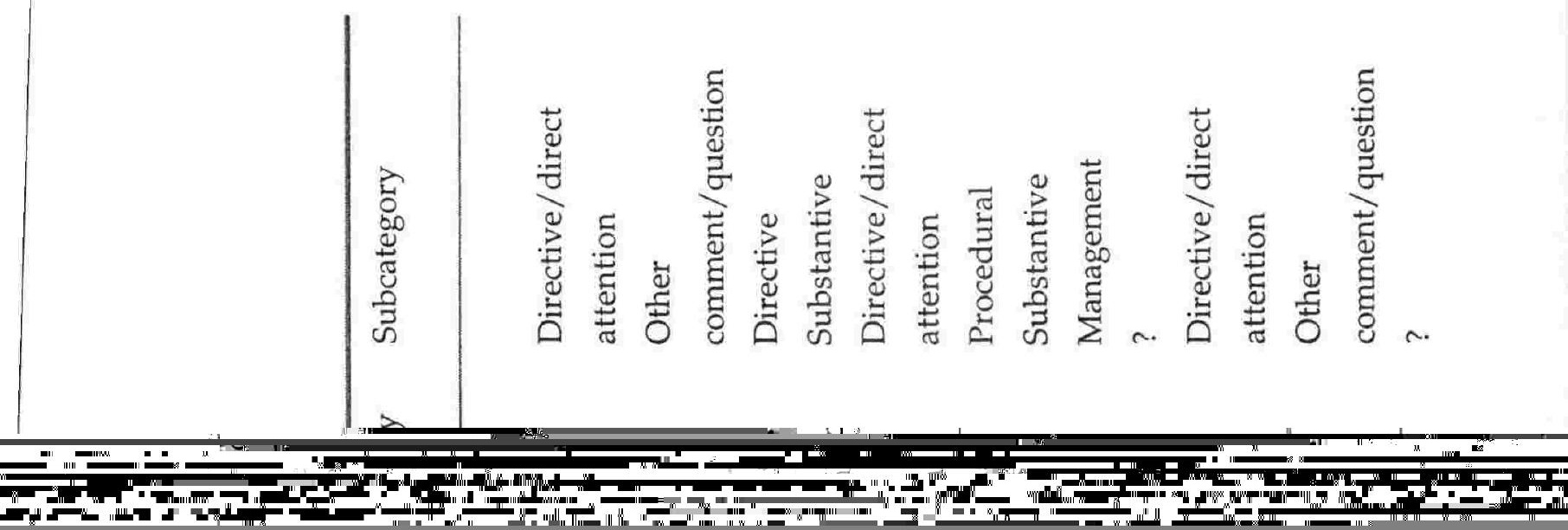




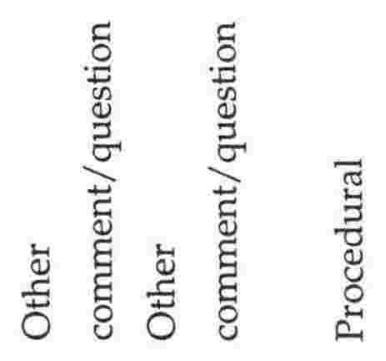

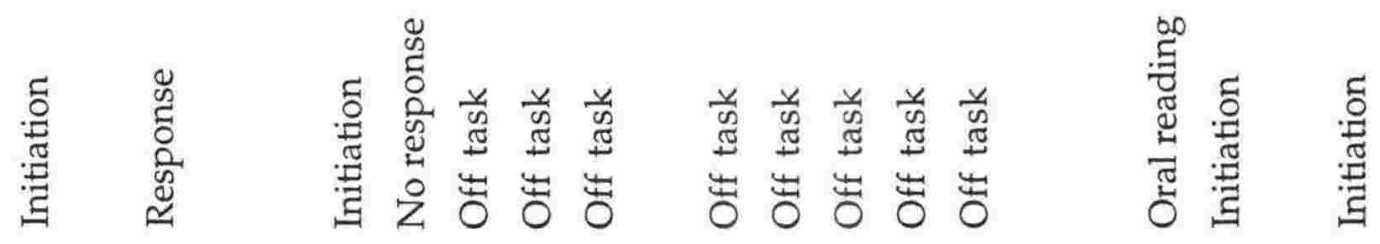

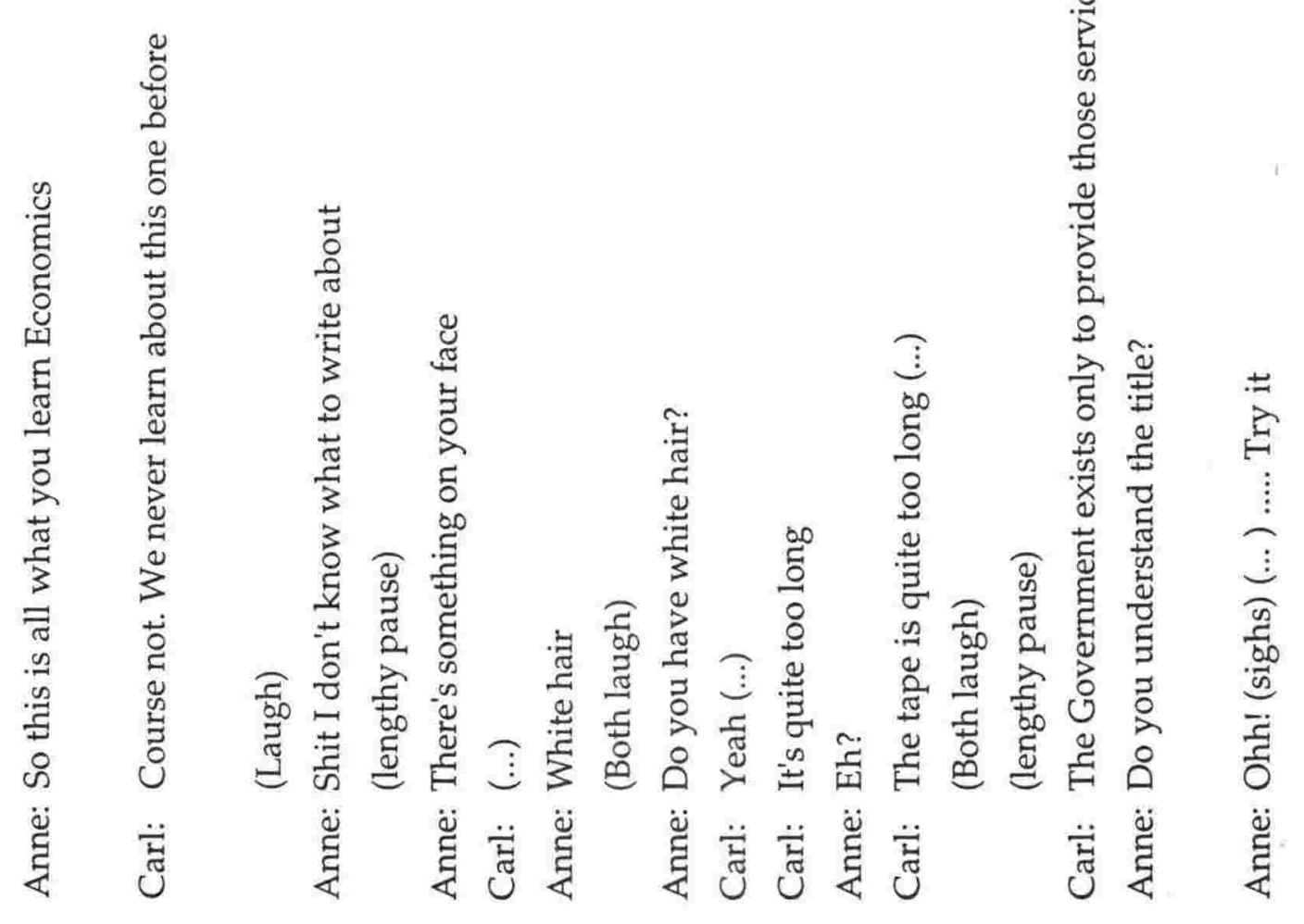



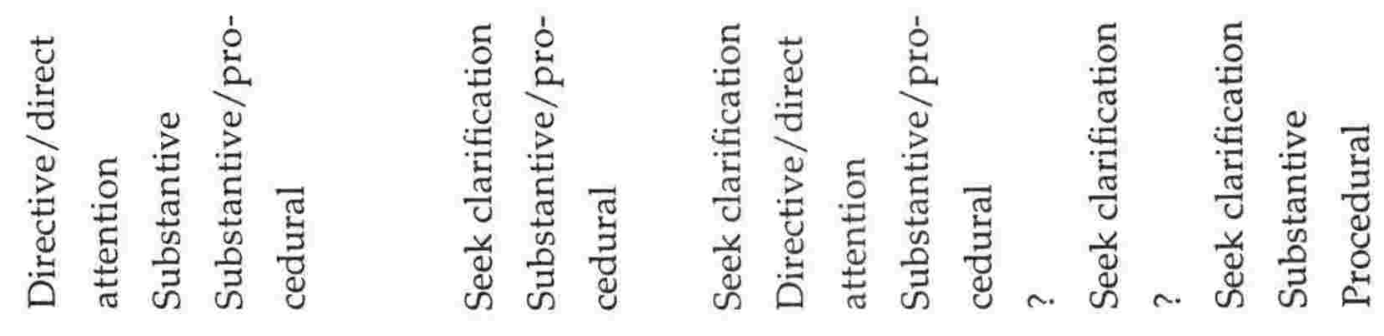

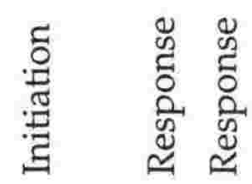
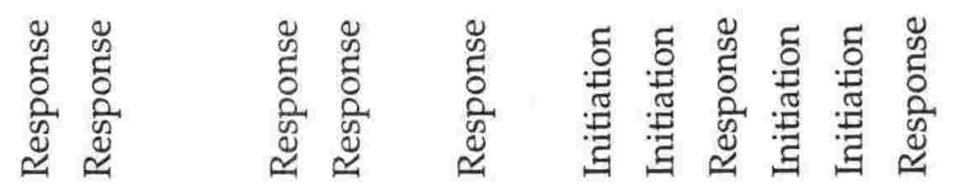

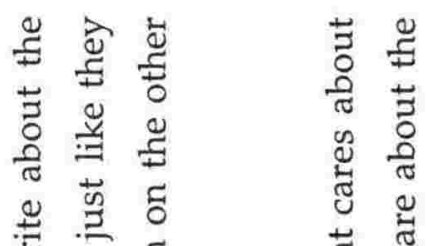

3 步

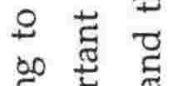

동 ڤ.

$\vdots$ ¿

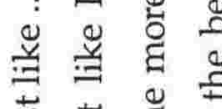

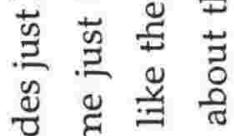

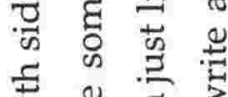

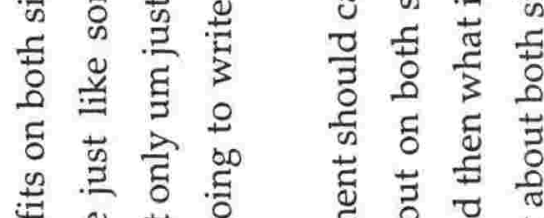

交

है 0 ป

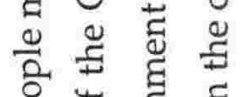

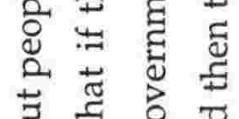

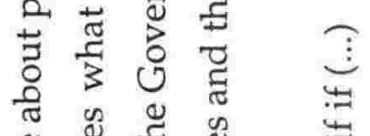

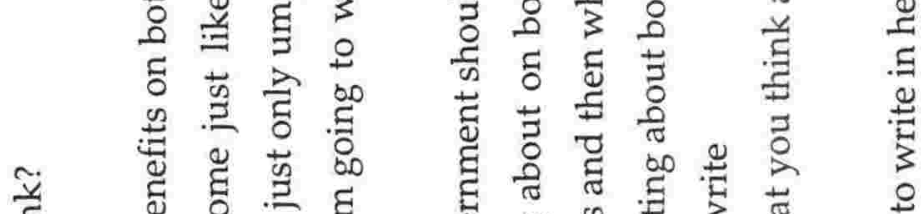

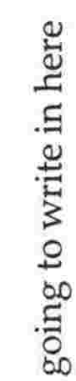

؛ัّ

光 D

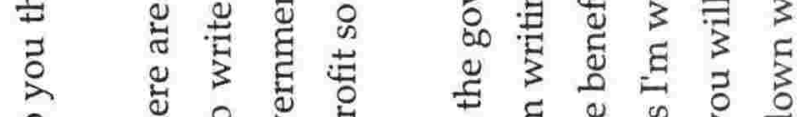

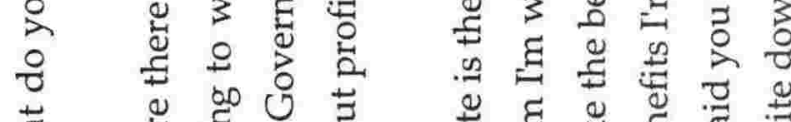

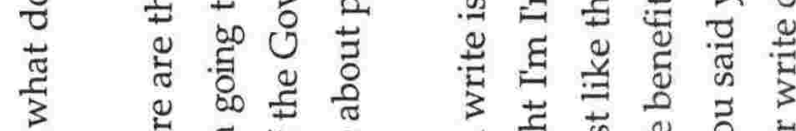

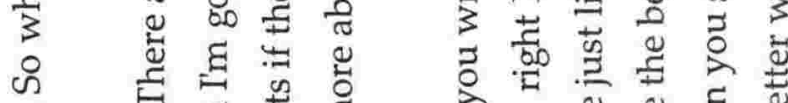

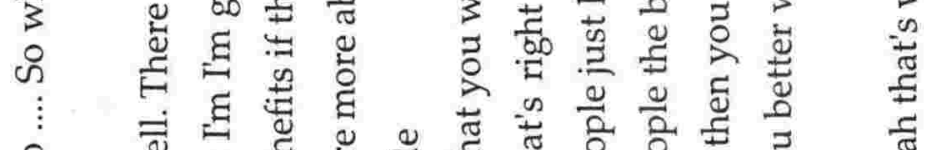

E

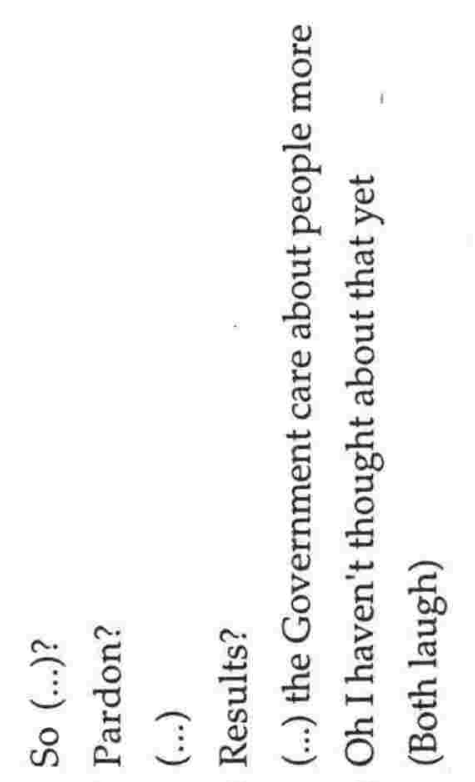

蒫 㝕完

范茞

音亲等

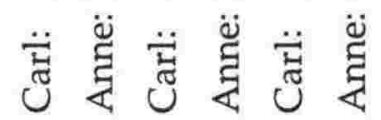



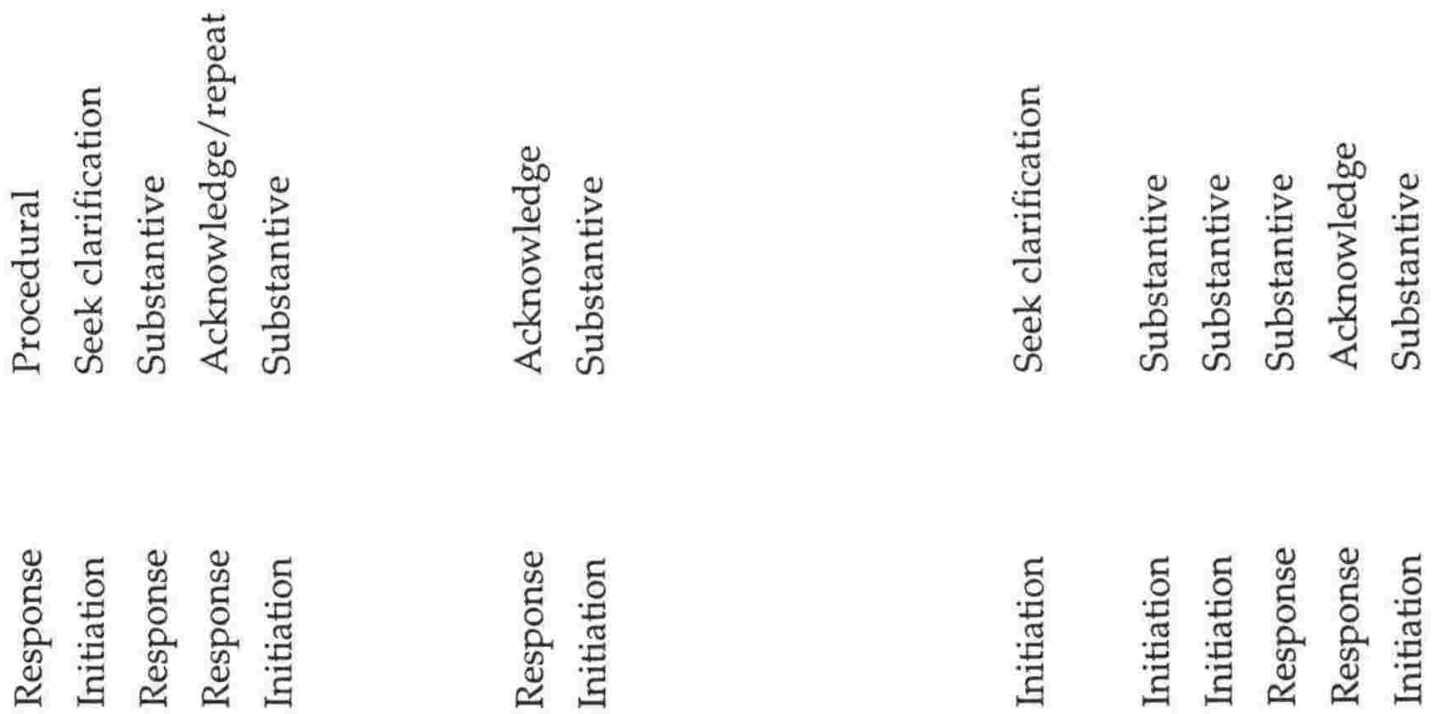

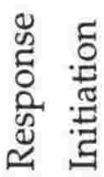

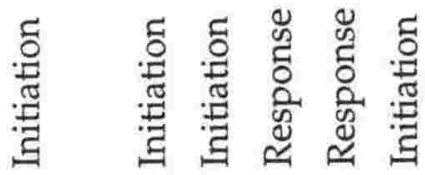

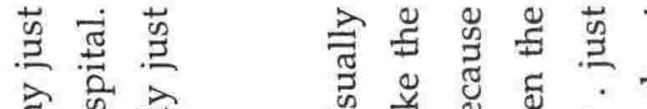

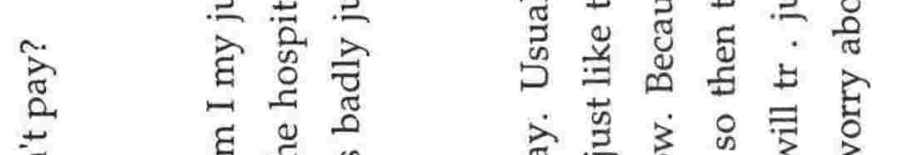

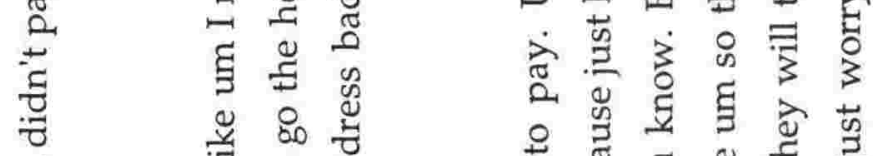

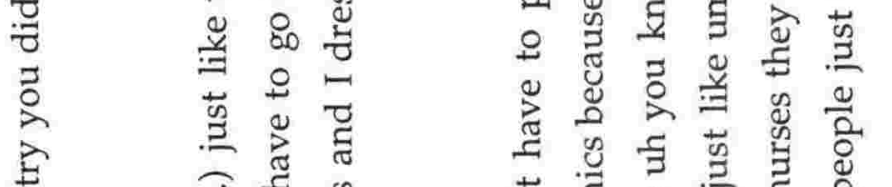

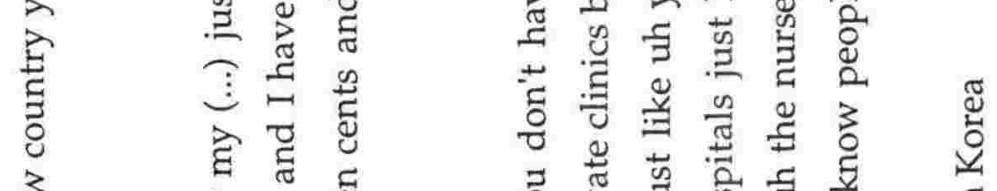

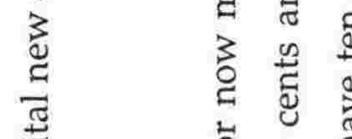

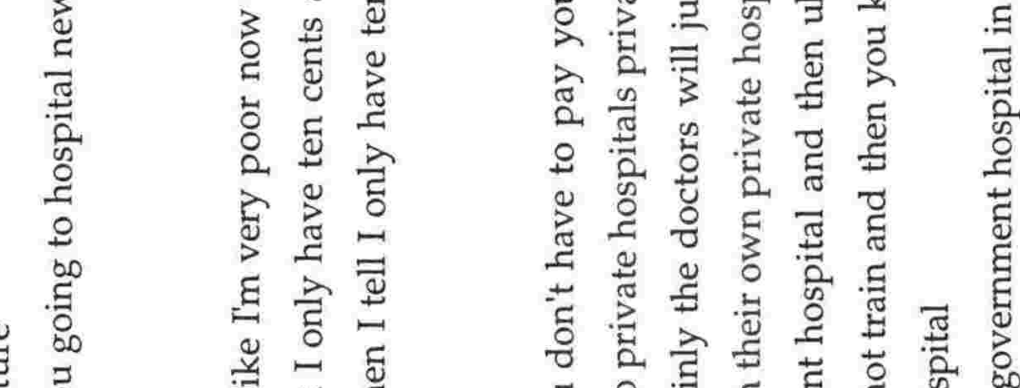

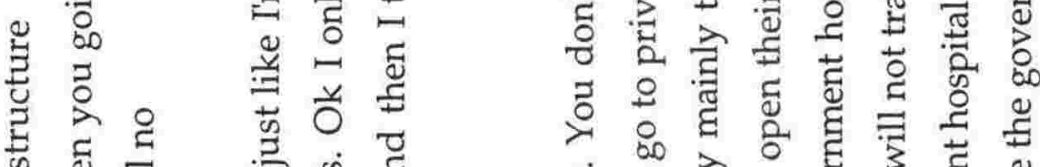

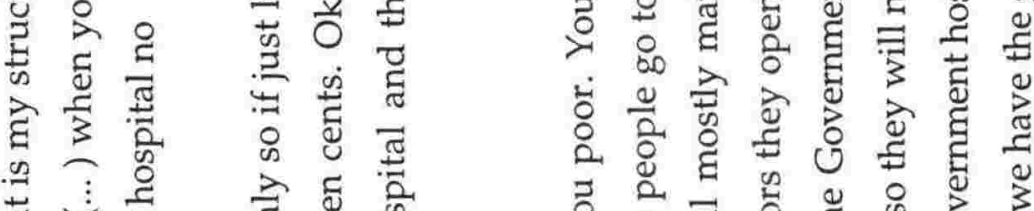

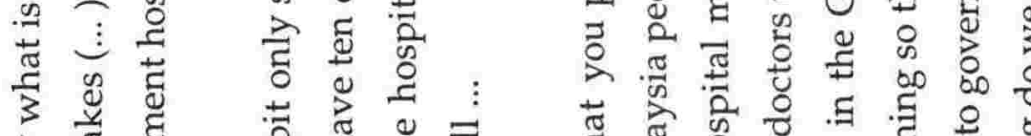

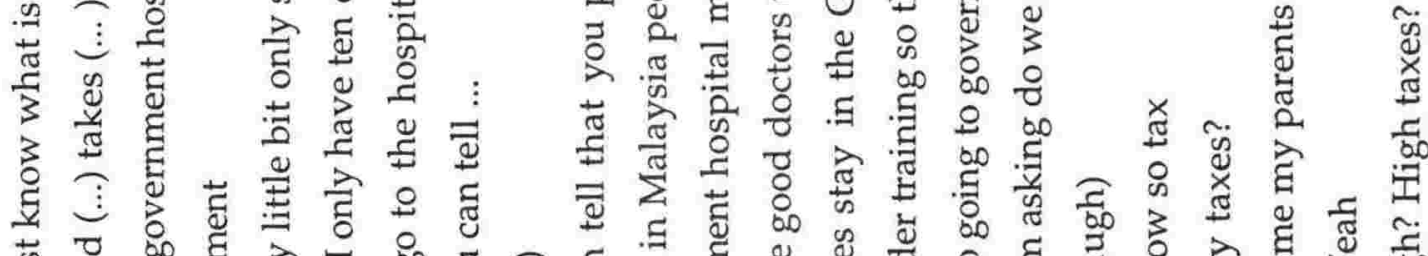

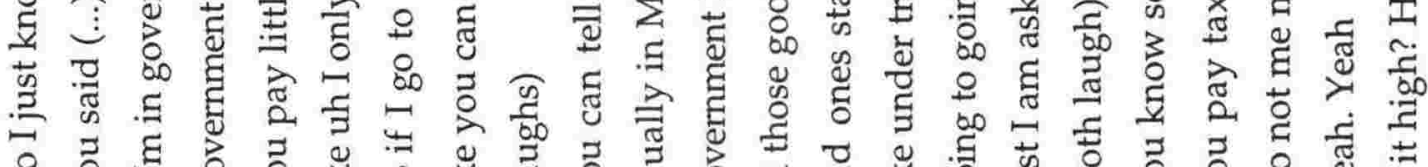

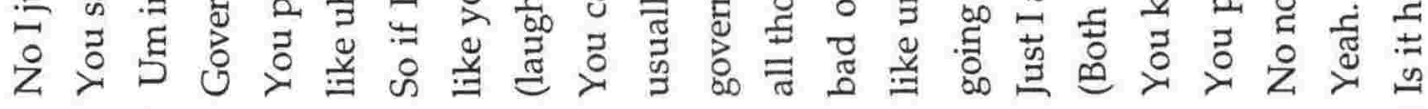

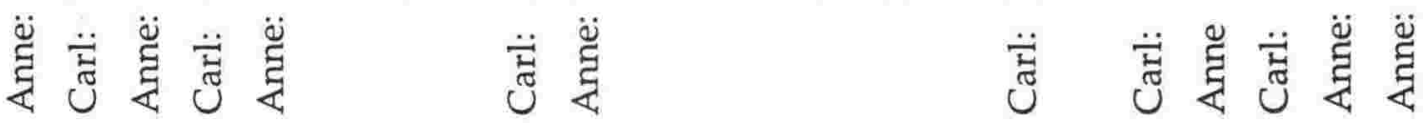




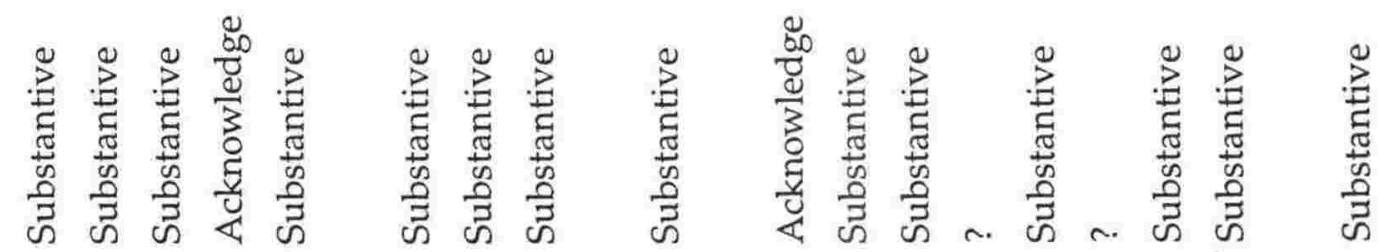

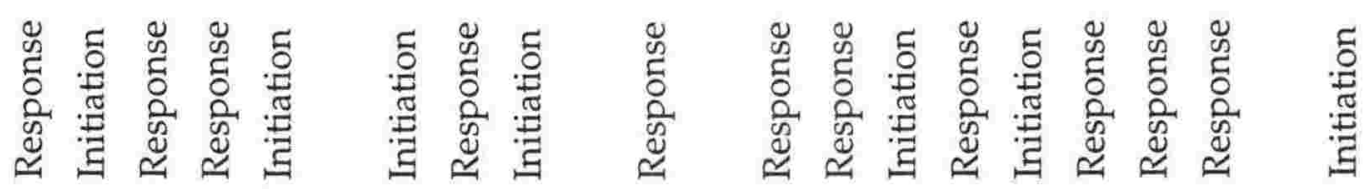

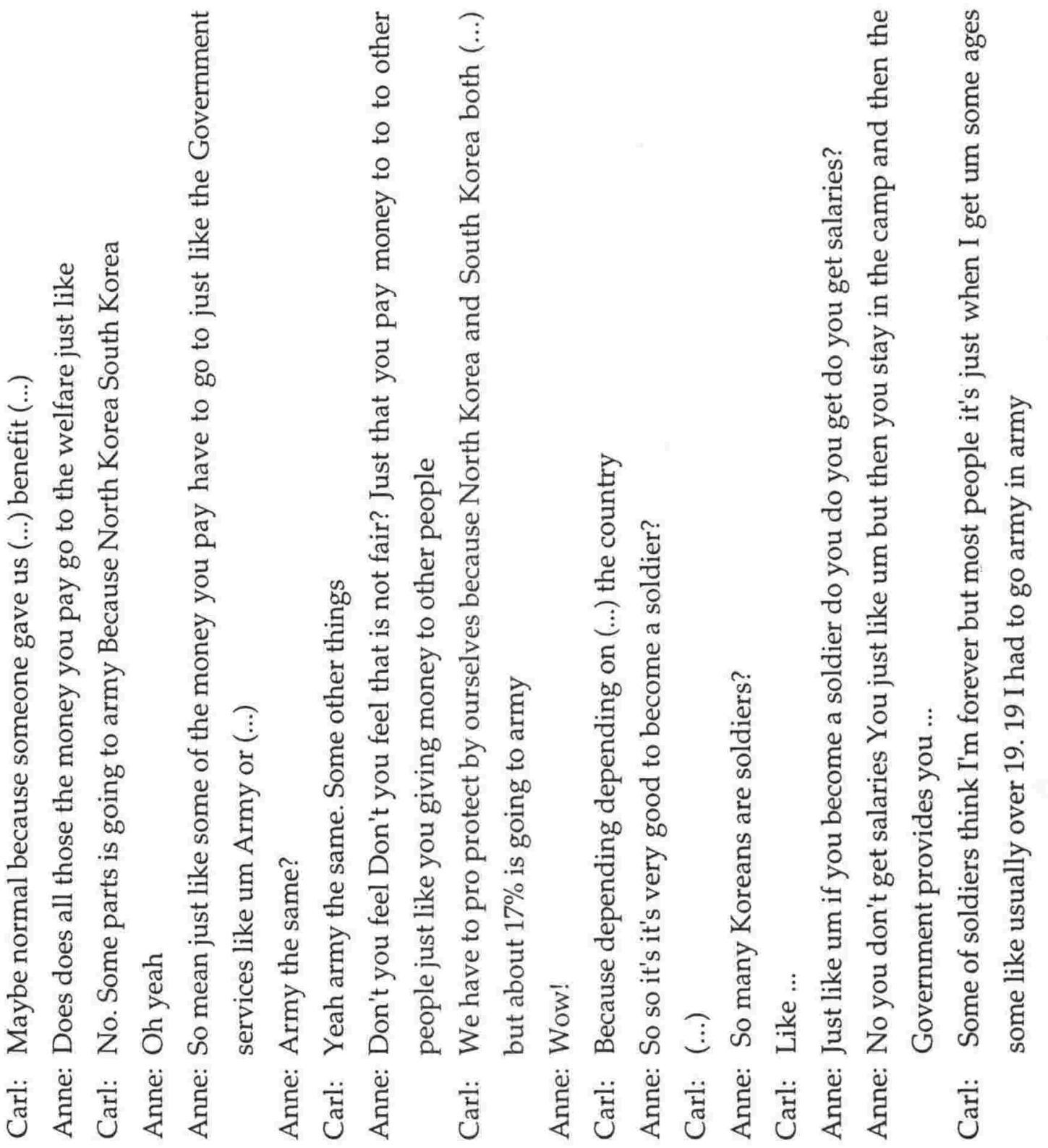



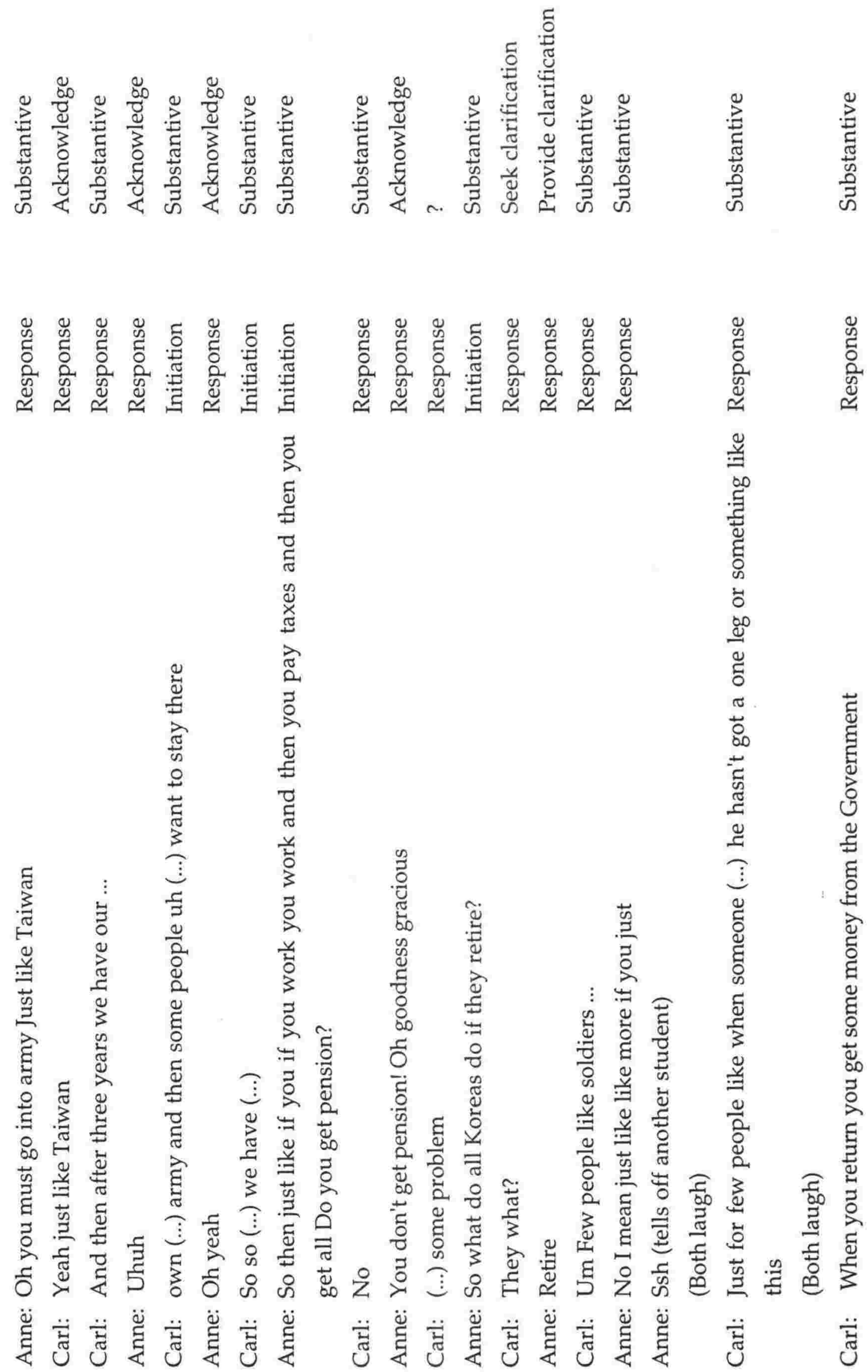
D

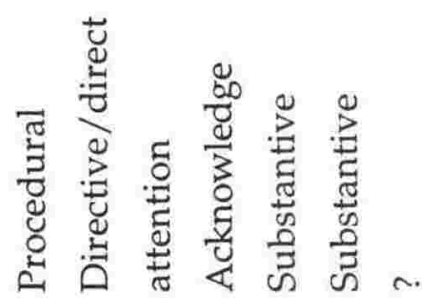

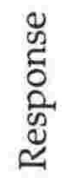

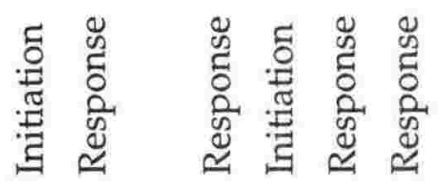

密

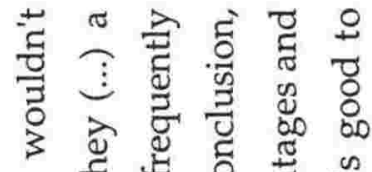

છ

凹

ॐँ

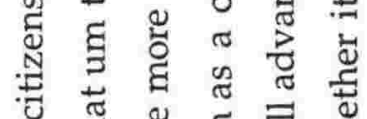

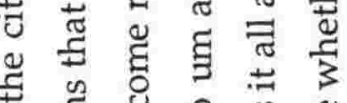

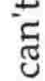

$\mp$ ¿ 0 के

్ㅜㄱ

ஒ

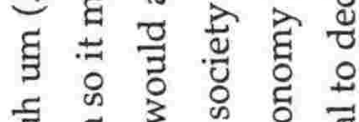

है.

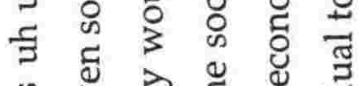

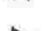

तै

की पै

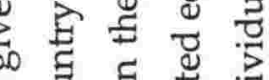

范

O

‡

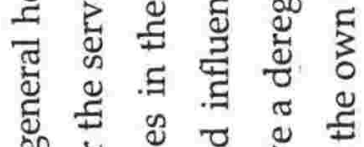

㫋

3
3
0
0
3
3

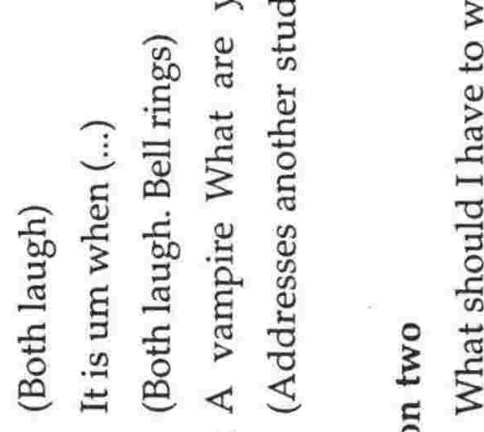

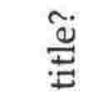

홍

荧

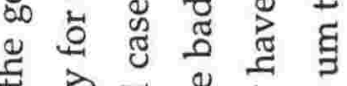

远西要

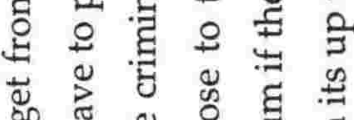

ชั.

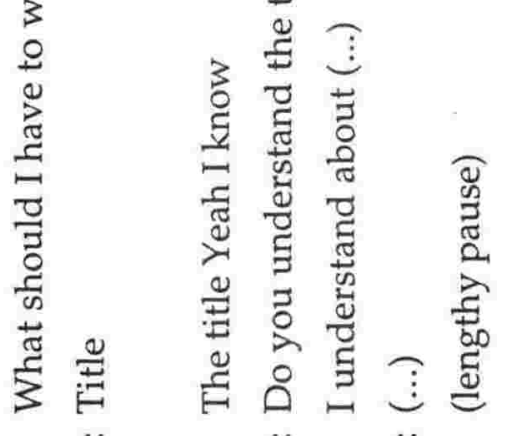

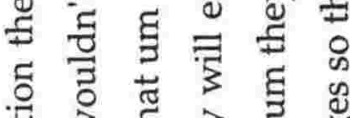

ن̈ 这

5

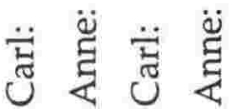




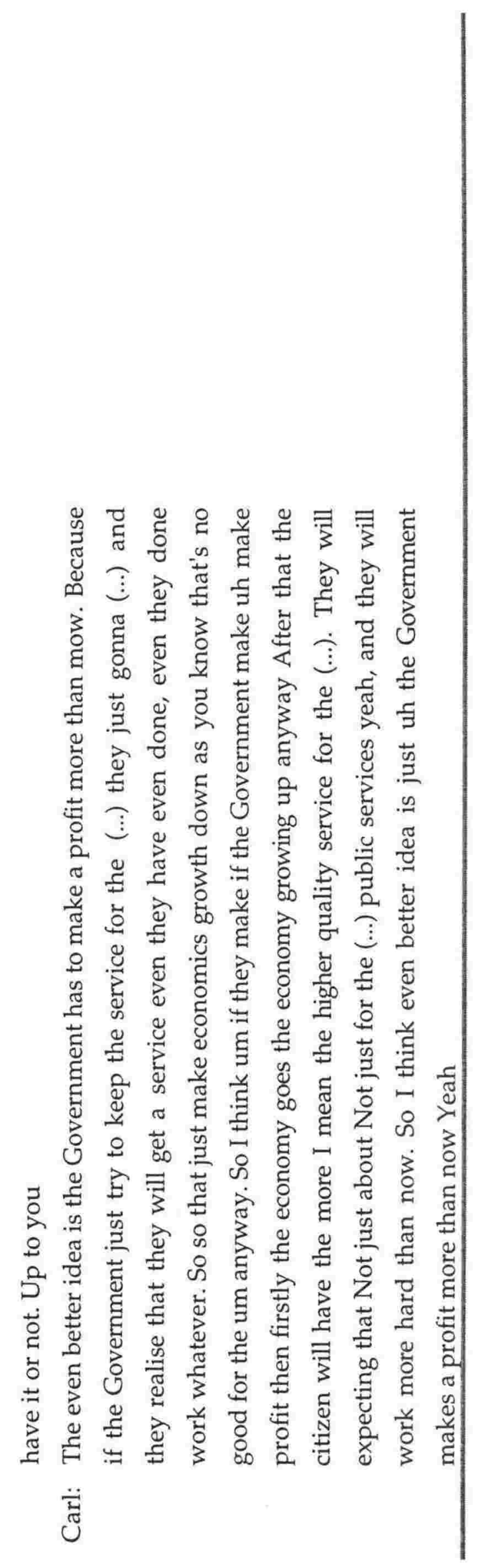


APPENDIX 8 CATEGORISED TRANSCRIPTS 


\subsection{Categorised transcript of Stan and Alan}

Task initiation: substantive

Stan: (...) What is the Government for?

Alan: (...) could make profit (...)

Alan: I want to know this ... This word (...)

Task initiation: procedural

Alan: Why have you written that?

Task initiation: seek clarification

Alan: We agree? We agree?

Task initiation: directive/direct attention

Stan: These are my points

Stan: So let's see

Alan: (...) Read your three lines aloud

Stan: Finished?

Task response: seek clarification

Stan: Three lines?

Task response: acknowledge

Stan: (Laughs)

Alan: $O K$

Alan: OK

Stan: That's all

Task response: evaluation

Alan: You're writing in economics language. You're writing it actually in economics language 


\subsection{Categorised transcript of Fred and Will}

\section{Task initiation: substantive}

Fred: I was thinking that that (...) some services but they should make some profit because if they don't do that they can't run (...) and uh They will have to increase the tax so that they can run that

Fred: The Government does exist to provide service but it should charge a small amount for the service in order to be able to run an institution whether a school health or any other service My addition change was Any service provide by the Government it does not make a profit it might be closed To run this the Government may have to increase tax

Fred: (...) anarchy

Fred: Government resources should ...

Will: He suggested that all services should make a profit Who knows if he was right or not anyway. Looking at the reality (...)

Fred: How do you spell hurt hurt When you hurt somebody?

Fred: How do you spell that?

\section{Task initiation: substantive/procedural}

Fred: I wrote this for the introduction should be a general comment about the topic about the Hisory if possible (...) why Government should provide free services What is the advantage of doing this? Second paragraph why should should not the provide free services? and um advantages and um last (...) points in favour and against for the two paragraphs (...)

\section{Task initiation: procedural}

Fred: I really don't know what to say

Fred: I don't know what to say but (...)

Fred: I can't think how to start this

Will: Can you think of anything that I should (...)

Will: Are you trying to expand your ideas?

Will: Are you trying to expand your ideas?

Fred: Do you think uh you need uh another reason that's good is about your (...) 
Task initiation: seek clarification

Will: What?

Task initiation: directive

Fred: What do you say? What do you say for the first introduction?

Fred: Tell me when you finish yours

Fred: Tell me yours

Fred: Uh (...) the second?

Fred: Now the last one

Fred: Right we're starting. What do you say for uh (...)?

Fred: What do you think there should be for first point?

Fred: What'd you say? What'd you say?

Fred: (...) write something

Will: Keep on going...

Fred: Oh ... Well I'm going to explain to you (...)

Task initiation: other

Fred: Where's the cue card ... Oh

\section{Task response: substantive}

Will: For the introduction is actually is a excellent introduction It tells us what is the title talking about step by steps

Fred: I think that uh the introduction is very good too very easy to read

Will: Gives an example to show that Maoris people behaviour that is very good about that

Fred: Uhhuh Its good (...) a good example of the topic you know

Fred: I said that (...) examples suggesting for and against the topic which is (...)

Will: Good ending um using good structure to finish the essay off

Fred: Anarchy (...)

Fred: Cause it's all little mixed up

Fred: 1994 should be

Will: 1995 
Task response: substantive/procedural

Will: Um um What is the situation with (...) now. um Second part Is there any effects with the Government if the Government keep on provide a service without making a profit

Will: You're getting off the topic here so

Task response: procedural

Will: Easier...I write some more

Task response: seek/provide clarification

Fred: Uh?

Fred: So you think that's not a good idea Government providing free services?

Task response: acknowledge

Will: Yep. OK

Will: Um. OK

Will: OK

Will: Yeah

Will: Yeah

Fred: Yeah

Will: Yeah

Will: Yeah

\section{Response: evaluation}

Fred: Last one is better

Will: Good 


\subsection{Categorised transcript of Anne and Carl}

Task initiation: substantive

Carl: Do you think they should (...)

Carl: (...) the Government care about people more

Carl: You know so tax

Anne You pay taxes?

Anne: Is it high? High taxes? Or low?

Anne: Does does all those the money you pay go to the welfare just like

Anne: So mean just like some of the money you pay have to go to just like the Government services like um Army or (...)

Anne: Army the same?

Anne: Don't you feel Don't you feel that is not fair? Just that you pay money to to to other people just like you giving money to other people

Anne: So so it's it's very good to become a soldier?

Anne: So many Koreans are soldiers?

Carl: Some of soldiers think I'm forever but most people it's just when I get um some ages some like usually over 19. 19 I hAnne to go army in army

Carl: own (...) army and then some people uh (...) want to stay there

Carl: So so (...) we have (...)

Anne: So then just like if you if you work you work and then you pay taxes and then you get all Do you get pension?

Anne: So what do all Koreas do if they retire?

Anne: Do you understand the title?

\section{Task initiation: procedural}

Anne: Shit I don't know what to write about

Carl: What should I have to write now?

\section{Task initiation: seek clarification}

Anne: Pardon?

Anne: Results?

Carl: You said (...) takes (...) when you going to hospital new country you didn't pay?

Carl: Just I am asking do we have the government hospital in Korea 
Task initiation: directive/direct attention

Carl: See your point Your point.

Carl: What do you think? (...)

Carl: So what are you up to?

Anne: Think

Anne: Do you understand the title?

Anne: Ohh! (sighs) (... ) ..... Try it.

Carl: So .... So what do you think

\section{Task initiation: other comment/question}

Carl: They allowed to ask to talk so we can talk eh (...)

Anne: Why are Economics for?

Anne: So this is all what you learn Economics

\section{Task response: substantive}

Carl: The Governnment should (...) some money for them

Anne: Well. There are there are benefits on both sides just like ....

Anne: Um in government hospital no

Anne: You pay little bit only so if just like I'm very poor now my (...) just like um I my just like uh I only have ten cents. Ok I only have ten cents and I have to go the hospital. So if I go to the hospital and then I tell I only have ten cents and I dress badly just like you can tell ...

Anne: You can tell that you poor. You don't have to pay you don't have to pay. Usually usually in Malaysia people go to private hospitals private clinics because just like the government hospital mostly mainly the doctors will just like uh you know. Because all those good doctors they open their own private hospitals just like um so then the bad ones stay in the Government hospital and then uh the nurses they will tr . just like under training so they will not train and then you know people just worry about going to going to government hospital

Carl: No not me my parents

Carl: Maybe normal because someone gave us (...) benefit (...)

Carl: No. Some parts is going to army Because North Korea South Korea

Carl: Yeah army the same. Some other things

Carl: We have to pro protect by ourselves because North Korea and South Korea both (...) but about $17 \%$ is going to army

Carl: Because depending depending on (...) the country 
Anne: Just like um if you become a soldier do you do you get do you get salaries?

Anne: No you don't get salaries You just like um but then you stay in the camp and then the Government provides you ...

Anne: Oh you must go into army Just like Taiwan

Carl: And then after three years we have our ...

Carl: No

Carl: Um Few people like soldiers ...

Anne: No I mean just like like more if you just

Carl: Just for few people like when someone (...) he hasn't got a one leg or something like this

Carl: When you return you get some money from the Government

Carl: It is um when (...)

Carl: I understand about (...)

\section{Task response: procedural/substantive}

Anne: So I'm I'm going to write some just like some just like I'm going to write about the benefits if the Government just only um just like the more important uh just like they care more about profit so I'm going to write about the benefits and then on the other side

Anne: That's right I'm I'm writing about on both sides what if the Government cares about people just like the benefits and then what if the Government does not care about the people the benefits I'm writing about both sides and then the conclusion

Anne: Yeah that's what I'm going to write in here

\section{Task response: procedural}

Anne: I'm going to do this first

Anne: Oh I haven't thought about that yet

Anne: No I just know what is my structure

\section{Task response: seek/provide clarifcation}

Carl: What you write is the government should care about people more (...)

Carl: So then you said you will write

Carl: They what?

Anne: Retire 
Task response: directive/direct attention

Carl: You better write down what you think about if if (...)

Anne: Title

Task response: acknowledge

Carl: Government

Carl: (laughs)

Anne: Yeah. Yeah

Anne: Oh yeah.

Anne: Wow!

Carl: Yeah just like Taiwan

Anne: Uhuh

Anne: Oh yeah

Anne: You don't get pension! Oh goodness gracious

Carl: The title Yeah I know

Task response: other comment/question

Carl: Course not. We never learn about this one before 


\section{APPENDIX 9 MELOTH AND DEERING'S (1994) ORIGINAL CODING SCHEME FOR TASK TALK}

\begin{tabular}{|c|c|c|}
\hline Coding & $\begin{array}{c}\text { Nature of } \\
\text { Communication }\end{array}$ & Description/example \\
\hline $\begin{array}{l}\text { Major } \\
\text { categories }\end{array}$ & $\begin{array}{l}\text { (CT) Content Talk } \\
\text { (Q) Question } \\
\text { (R) Response } \\
\text { (OR) Oral Reading } \\
\text { (PR) Praise } \\
\text { (C) Cooperation } \\
\text { (CR) Praise } \\
\text { (P) Pacing } \\
\text { (M) Management } \\
\text { (OT) Off-task }\end{array}$ & $\begin{array}{l}\text { Unprompted statement about the task } \\
\text { Unprompted question/request on the task } \\
\text { Response to content talk or question } \\
\text { Reading aloud } \\
\text { Positive appraisal of another or the task } \\
\text { Helping the group work together } \\
\text { Negative appraisal of another or the task } \\
\text { Concern about task completion or progress } \\
\text { Controlling behavior of others } \\
\text { Off-task talk }\end{array}$ \\
\hline $\begin{array}{l}\text { Content-talk } \\
\text { subcategories }\end{array}$ & $\begin{array}{l}\text { 1. Explanation/ } \\
\text { elaboration } \\
\text { 2. Directive } \\
\text { 3. Direct attention } \\
\text { 4. Offers of assistance } \\
\text { 5. Relevant comment }\end{array}$ & $\begin{array}{l}\text { "One way to think about it is ...," } \\
\text { "I think there are three ideas here ..." } \\
\text { "Write down the butterfly's name." } \\
\text { "Let's talk about ..." } \\
\text { "Want help figuring that out?" } \\
\text { "Statements not coded under 1-4 }\end{array}$ \\
\hline $\begin{array}{l}\text { Question } \\
\text { subcategories }\end{array}$ & $\begin{array}{l}\text { 1. Request for task- } \\
\text { related information } \\
\text { 2. Direct attention } \\
\text { 3. Other request }\end{array}$ & $\begin{array}{l}\text { "Can you help me figure out } \\
\text { "What should we do about number 5?" } \\
\text { "What should we do first?" } \\
\text { Nonspecific, eg, "Can you help me?", } \\
\text { "What is this?", or requests for teacher } \\
\text { assistance }\end{array}$ \\
\hline $\begin{array}{l}\text { Response } \\
\text { subcategories }\end{array}$ & $\begin{array}{l}\text { 1. Explanation/ } \\
\text { elaboration } \\
\text { 2. Directive/request } \\
\text { 3. Counterassertion } \\
\text { 4. Repeat/acknowledge } \\
\text { another's comment } \\
\text { 5. Uninformative/ } \\
\text { incomplete response }\end{array}$ & $\begin{array}{l}\text { Within a content-talk-response or question- } \\
\text { response exchange } \\
\text { Within a content-talk-response or question- } \\
\text { response exchange } \\
\text { Argument, corrective, alternative } \\
\text { Verbatim repetition or responses such as } \\
\text { "Yeah," "OK," "Good." } \\
\text { Nonspecific or incomplete sentence }\end{array}$ \\
\hline $\begin{array}{l}\text { Focus of } \\
\text { academic talk }\end{array}$ & $\begin{array}{l}\text { (A) Resources } \\
\text { (B) Answers } \\
\text { (C) Facts } \\
\text { (D) } \\
\text { Concepts/strategies } \\
\text { (E) Task organization }\end{array}$ & $\begin{array}{l}\text { Materials used for activity } \\
\text { Statements about recording information } \\
\text { that is correct and accurate } \\
\text { Factual content (eg, "What's a pupae?") } \\
\text { Compare, contrast, target strategies } \\
\text { Task sequence, steps, procedures }\end{array}$ \\
\hline
\end{tabular}


APPENDIX 10 TEXTS WRITTEN BY CASE STUDY SUBJECTS, CARL AND ANNE, OCCASION 6 


\section{THE GOVERNMENT DOES NOT EXIST ONLY TO PROVIDE A SERVICE FOR THE PEOPLE OF THE COUNTRY. ALL GOVERNMENT SERVICE SHOULD MAKE A PROFIT.}

I can't agree with this topic, because we are paying the tax, so the governement should do something for us. This topic say, all Governemnt service should make a profit. This means we have to pay more tax for them. I don't know much about this but the system is not good. Example is Korea. In Korea we also pay lots of taxes but the services can also get lots of profits like phone call. When we make phone call we must pay money for one call. Also the Post office. When we want to send something have to pay. When we old and retired they Government didn't care about people. So they just stay home and wait for their children's help. The Governement say almost all tax for defend to North Korea. When New Zealand was strong country people paid small tax but now NZ is not that much strong but people's tax must cover it so will be same position.

I think NZ should find other way for nationality. Government help some part of service and service have to make profit for people not for government.

Text written by case study subject, Carl, occasion 6 . 


\section{THE GOVERNMENT DOES NOT EXIST ONLY TO PROVIDE A SERVICE FOR THE PEOPLE OF THE COUNTRY. ALL GOVERNMENT SERVICE SHOULD MAKE A PROFIT.}

New Zealand now has a deregulated economy. Eleven years ago, New Zealand don't charge for the services given. Now the corporations like the Post Office, general hospitals and many others charge for the service. Many people would either disagree with the deregulated economy or agree with it. What do you know about having it of not having it?

First of all, what would happen if the Government make a profit out of it? One thing for sure is that the citizens would have to work harder in order to pay for the services. To pay of the service means extra burden financially. For example, one would have to pay an extra money for the services given at the hospital and the post office. That means that he would have to prepare a certain amount of money that has to be paid monthly. Secondly, if the government makes a profit, the quality of the services given would be better. It means that if a person pay for the medication, he would receive a better service by the doctor and by the nurses. Generally, by having this deregulated economy, the citizens would become more hardworking, clever and independent.

From the other point of view, citizens would not have to pay for the services given to them. That would include the medication, post offices, education, electricity and telecommunications. All the citizens would have to pay is only for their food, accommodation and transportation. The citizens would lead a very normal life without any challenge. Other than that, the citizens would build up a lazy habit of not working. They will get lazier and lazier each day because they will get money from the government even though they were employed. The government just simply subsidise their living. Above all that, they would be an increase in the criminal cases in the country too. It is because the unemployed were so free that it leads them to bad influence in the society.

As a conclusion, one cannot decide whether it is good to have a deregulated economy or not. The deregulated economy personally have it's own benefits and disadvantages. Actually the government should try to have a half-deregulated economy. That means that the citizens would have to pay for the service but the price is very low. By doing this, the unemployed problem would be solved and the criminal cases that happens in the country would be lessened.

Text written by case study subject, Anne, occasion 6 . 